\title{
Gold-Catalyzed Asymmetric Thioallylation of Propiolates via Charge-Induced Thio-Claisen Rearrangement
}

\author{
Hanbyul Kim, ${ }^{\dagger}$ Jiwon Jang, ${ }^{\dagger}$ and Seunghoon Shin* \\ Department of Chemistry, Research Institute of Natural Sciences and Center for New \\ Directions in Organic Synthesis (CNOS), Hanyang University, 222 Wangsimni-ro, \\ Seongdong-gu, Seoul 04763, Korea. \\ sshin@hanyang.ac.kr
}

\section{Table of Contents}

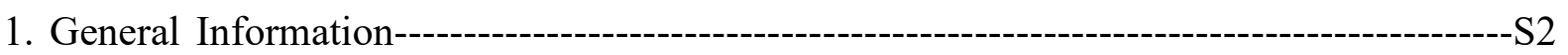

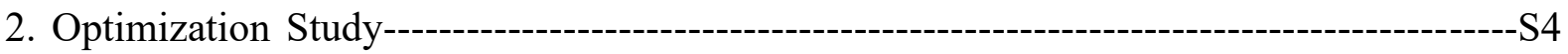

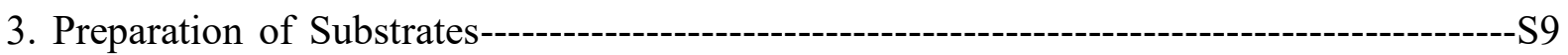

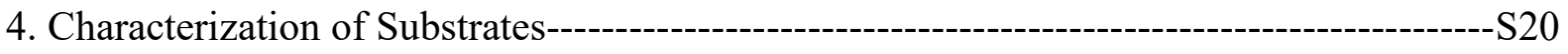

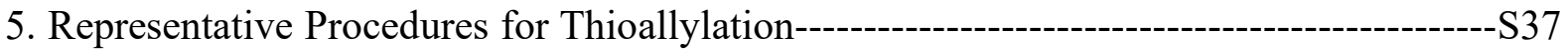

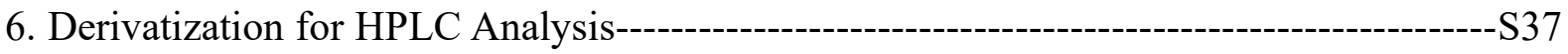

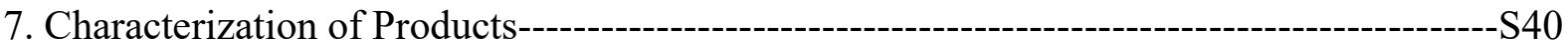

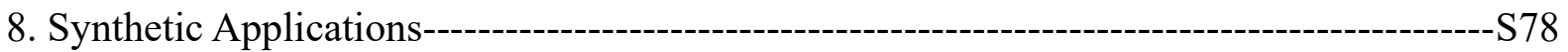

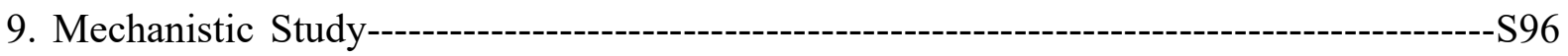

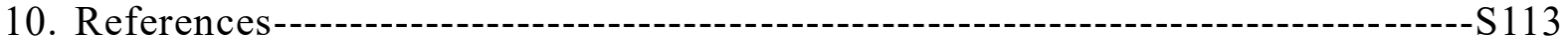

Appendix: Copy of ${ }^{1} \mathrm{H}$ and ${ }^{13} \mathrm{C}$ spectra 


\section{General Information}

All solvents were dried and distilled according to standard methods before use. ${ }^{1}$ All the proiolates 1 (Table S1) and counter-anions were commercially available from Tokyo Chemical Industry, Sigma Aldrich and Alfa Aesar and were used as received. DM-Segphos, DTBMSegphos and DM-Binap ligands were purchased from Tokyo Chemical Industry. MeO-Biphep and a series of Josiphos and Walphos ligands were purchased from Strem. ${ }^{t} \mathrm{Bu} / 2-\mathrm{Me}-\mathrm{C}_{6} \mathrm{H}_{4}-$ Josiphos (L-S7) was purchased from Sigma Aldrich. The dinuclear gold complexes (P$\mathrm{P})(\mathrm{AuCl})_{2}$ were prepared from the corresponding bisphosphine ligands and $\left(\mathrm{Me}_{2} \mathrm{~S}\right) \mathrm{AuCl}(2$ equiv) according to the literature. ${ }^{2}$ The following compounds were prepared according to the literature: ethyl (E)-3-iodoacrylate, ${ }^{3}(E)$-tert-butyl(3-iodoallyloxy)dimethylsilane, ${ }^{4}$ ethyl but3-enoate, ${ }^{5}(E)$-(3-bromobut-2-en-1-yloxy)(tert-butyl)dimethylsilane, ${ }^{6}(E)$-3-bromobut-2-en-1ol, ${ }^{7}$ (E)-4-(tert-butyldimethylsilyloxy)-3-methylbut-2-en-1-ol, ${ }^{8}$ (E)-2-methylbut-2-en-1-ol, ${ }^{9}$ (Z)-2-bromobut-2-en-1-ol, ${ }^{10} \quad(E)$-(3-bromo-2-methylallyloxy)(tert-butyl)dimethyl-silane. ${ }^{11}$ TLC (this-layer chromatography) analyses were carried out on Merck silica gel 60 F254 TLC plates and was visualized with UV lamp, phosphomolybdic acid and $\mathrm{KMnO}_{4}$ solution. Flash chromatography was performed on Kieselgel 60 (230-400 mesh). ${ }^{1} \mathrm{H}$ and ${ }^{13} \mathrm{C}$ NMR spectra were recorded on a Bruker (400 MHz) spectrometer with TMS as an internal standard. High resolution mass spectra (HRMS) were obtained from Korea Basic Science Institute (KBSI, Daegu) and from Organic Chemistry Research Center in Sogang University. Optical purity assay was conducted on Shimadzu HPLC (LC-20A Prominence Series) using Chiralpak ${ }^{\circledR}$ IA, IC, IG, AD-H, OJ-H and OD-H column (5 $\mu \mathrm{m}$ particle size, $4.6 \mathrm{~mm}$ x $250 \mathrm{~mm}$ ) with IPA and $n$-hexane as mobile phases. 


\section{Optimization Study}

Table S1. Screening of propiolate moieties.
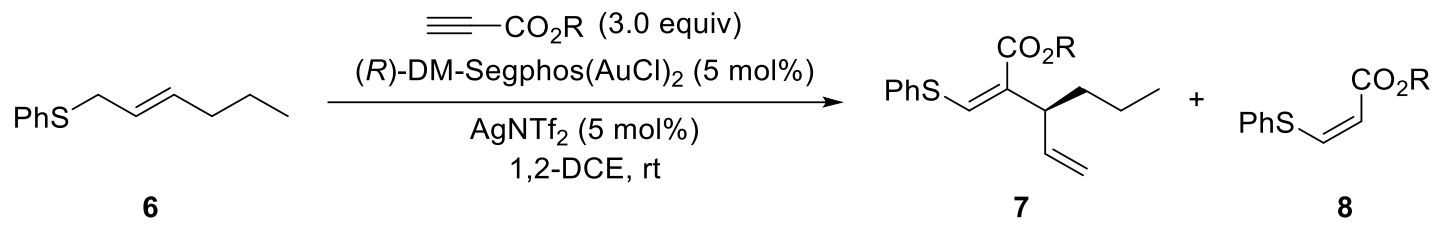

\begin{tabular}{ccccc}
\hline Entry & $\mathrm{R}$ & Time & $\begin{array}{c}\text { Yield }(\%)^{\mathrm{a}} \\
(\mathbf{7 / 8})\end{array}$ & $\%$ ee \\
\hline 1 & $\mathrm{Me}$ & $3 \mathrm{~d}$ & $82 / 5$ & $34^{b}$ \\
2 & $\mathrm{Et}$ & $3 \mathrm{~d}$ & $83 / 13$ & $37^{c}$ \\
3 & ${ }^{i} \mathrm{Pr}$ & $3 \mathrm{~d}$ & $74 / 19$ & $43^{d}$ \\
4 & ${ }^{t} \mathrm{Bu}$ & $3 \mathrm{~d}$ & $80 / 13$ & $58^{e}$ \\
\hline
\end{tabular}

${ }^{a}$ Isolated yield. ${ }^{b}$ Chiral assay was conducted on Chiralpak ${ }^{\circledR}$ IC column using IPA: $n$ Hex (1:99) as an eluent (1.0 $\mathrm{mL} / \mathrm{min}) .{ }^{c}$ Chiral assay was conducted on Chiralpak ${ }^{\circledR}$ IC column using IPA: $n$ Hex $(0.5: 99.5)$ as an eluent (1.0 $\mathrm{mL} / \mathrm{min}) .{ }^{d}$ The product was derivatized into the corresponding sulfone according to Method A, before chiral assay on Chiralpak ${ }^{\circledR}$ IA column using IPA: $n$ Hex (1:99) as an eluent $(1.0 \mathrm{~mL} / \mathrm{min}) .{ }^{e}$ The product was derivatized into the corresponding lactone according to Method B, before chiral assay on Chiralpak ${ }^{\circledR}$ IA column using IPA: $n$ Hex $(0.5: 99.5)$ as an eluent $(1.0 \mathrm{~mL} / \mathrm{min})$. 
Table S2. Screening of ligands.

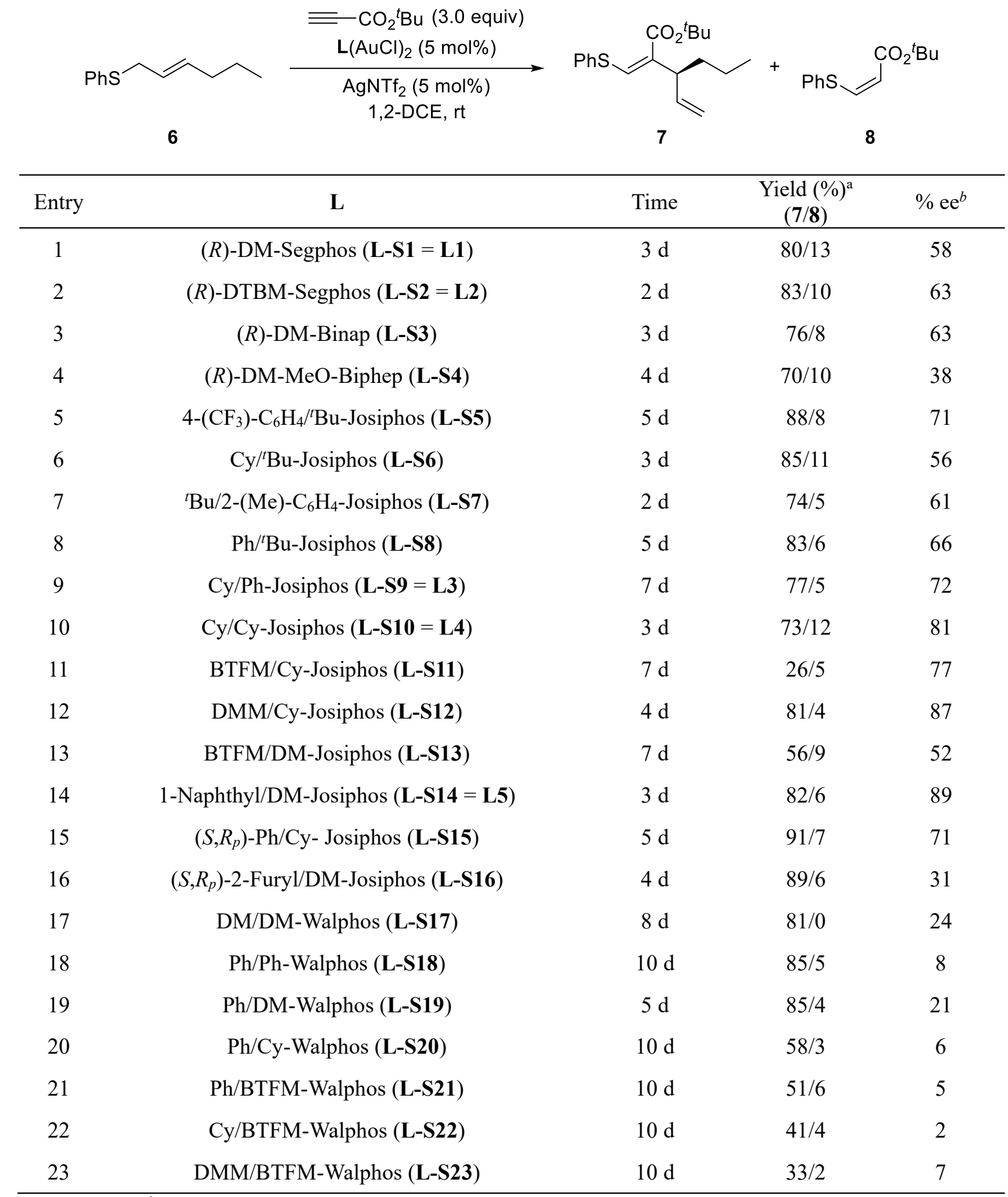

${ }^{a}$ Isolated yield. ${ }^{b}$ The product was derivatized into the corresponding lactone according to Method B, and chiral assay of the lactone was conducted on Chiralpak ${ }^{\circledR}$ IA column using IPA: $n$ Hex $(0.5: 99.5)$ as an eluent $(1.0 \mathrm{~mL} / \mathrm{min})$. 
<smiles>CCCCCc1ccc2c(c1-c1c(P)ccc3c1OCO3)OCO2</smiles>

L-S1: $\mathrm{Ar}=3,5-(\mathrm{Me})_{2}-\mathrm{C}_{6} \mathrm{H}_{3}$

L-S2: $\mathrm{Ar}=3,5-\left({ }^{\mathrm{B}} \mathrm{Bu}\right)_{2}-4-(\mathrm{MeO})-\mathrm{C}_{6} \mathrm{H}_{2}$

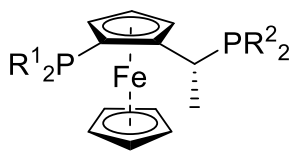

$\left(R, S_{p}\right)$-josiphos

L-S5: $\mathrm{R}^{1}=4-\left(\mathrm{CF}_{3}\right)-\mathrm{C}_{6} \mathrm{H}_{4}, \mathrm{R}^{2}={ }^{t_{B}} \mathrm{Bu}$

L-S6: $\mathrm{R}^{1}=\mathrm{Cy}, \mathrm{R}^{2}={ }^{t} \mathrm{Bu}$

L-S7: $\mathrm{R}^{1}={ }^{t} \mathrm{Bu}, \mathrm{R}^{2}=2-(\mathrm{Me})-\mathrm{C}_{6} \mathrm{H}_{4}$

L-S8: $\mathrm{R}^{1}=\mathrm{Ph}, \mathrm{R}^{2}={ }^{t} \mathrm{Bu}$

L-S9: $\mathrm{R}^{1}=\mathrm{Cy}, \mathrm{R}^{2}=\mathrm{Ph}$

L-S10: $\mathrm{R}^{1}=\mathrm{Cy}, \mathrm{R}^{2}=\mathrm{Cy}$

L-S11: $\mathrm{R}^{1}=3,5-\left(\mathrm{CF}_{3}\right)_{2}-\mathrm{C}_{6} \mathrm{H}_{3}, \mathrm{R}^{2}={ }^{{ }^{C} \mathrm{Hex}}$

L-S12: $\mathrm{R}^{1}=3,5-(\mathrm{Me})_{2}-4-(\mathrm{MeO})-\mathrm{C}_{6} \mathrm{H}_{2}, \mathrm{R}^{2}={ }^{\mathrm{C}} \mathrm{Hex}$

L-S13: $\mathrm{R}^{1}=3,5-\left(\mathrm{CF}_{3}\right)_{2}-\mathrm{C}_{6} \mathrm{H}_{3}, \mathrm{R}^{2}=3,5-(\mathrm{Me})_{2}-\mathrm{C}_{6} \mathrm{H}_{3}$

L-S14: $\mathrm{R}^{1}=1$-Naphthyl, $\mathrm{R}^{2}=3,5-(\mathrm{Me})_{2}-\mathrm{C}_{6} \mathrm{H}_{3}$<smiles>CCCCc1ccc2ccccc2c1C(c1ccccc1)c1cccc2ccccc12</smiles>

L-S3: $\mathrm{Ar}=3,5-(\mathrm{Me})_{2}-\mathrm{C}_{6} \mathrm{H}_{3}$

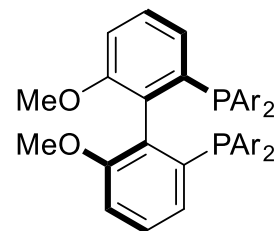

L-S4: $\mathrm{Ar}=3,5-(\mathrm{Me})_{2}-\mathrm{C}_{6} \mathrm{H}_{3}$

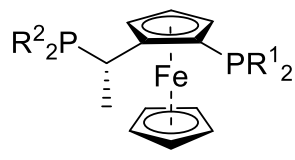

$\left(S, R_{p}\right)$-josiphos

L-S15: $\mathrm{R}^{1}=\mathrm{Ph}, \mathrm{R}^{2}={ }^{\mathrm{C}} \mathrm{Hex}$

L-S16: $\mathrm{R}^{1}=2$-Furyl, $\mathrm{R}^{2}=3,5-(\mathrm{Me})_{2}-\mathrm{C}_{6} \mathrm{H}_{3}$

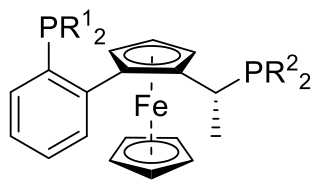

$\left(R, R_{p}\right)$-Walphos

L-S17: $\mathrm{R}^{1}=3,5-(\mathrm{Me})_{2}-\mathrm{C}_{6} \mathrm{H}_{3}, \mathrm{R}^{2}=3,5-(\mathrm{Me})_{2}-\mathrm{C}_{6} \mathrm{H}_{3}$

L-S18: $R^{1}=P h, R^{2}=P h$

L-S19: $\mathrm{R}^{1}=\mathrm{Ph}, \mathrm{R}^{2}=3,5-(\mathrm{Me})_{2}-\mathrm{C}_{6} \mathrm{H}_{3}$

L-S20: $R^{1}=P h, R^{2}=C y$

L-S21: $\mathrm{R}^{1}=\mathrm{Ph}, \mathrm{R}^{2}=3,5-\left(\mathrm{CF}_{3}\right)_{2}-\mathrm{C}_{6} \mathrm{H}_{3}$

L-S22: $R^{1}=\mathrm{Cy}, \mathrm{R}^{2}=3,5-\left(\mathrm{CF}_{3}\right)_{2}-\mathrm{C}_{6} \mathrm{H}_{3}$

L-S23: $\mathrm{R}^{1}=3,5-(\mathrm{Me})_{2}-4-(\mathrm{MeO})-\mathrm{C}_{6} \mathrm{H}_{2}, \mathrm{R}^{2}=3,5-\left(\mathrm{CF}_{3}\right)_{2}-\mathrm{C}_{6} \mathrm{H}_{3}$ 
Table S3. Screening of equivalent.

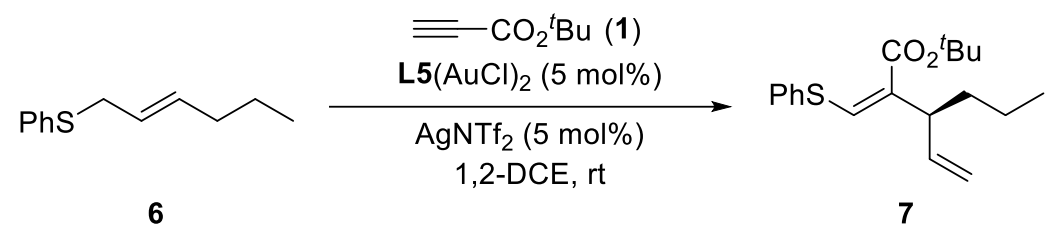

\begin{tabular}{cccccc}
\hline Entry & Equiv of $\mathbf{6}$ & Equiv of $\mathbf{1}$ & Time & ${\text { Yield }(\%)^{\mathrm{a}}}^{\mathrm{a}}$ & $\% \mathrm{ee}^{b}$ \\
\hline 1 & 1 & 1 & $7 \mathrm{~d}$ & 68 & 88 \\
2 & 1 & 3 & $3 \mathrm{~d}$ & 82 & 89 \\
3 & 1 & 5 & $2 \mathrm{~d}$ & 79 & 87 \\
4 & 3 & 1 & $7 \mathrm{~d}$ & 58 & 87 \\
\hline
\end{tabular}

${ }^{a}$ Isolated yield. ${ }^{b}$ The product was derivatized into the corresponding lactone according to Method $\mathbf{B}$, and chiral assay of the lactone was conducted on Chiralpak ${ }^{\circledR}$ IA column using IPA: $n \mathrm{Hex}(0.5: 99.5)$ as an eluent $(1.0 \mathrm{~mL} / \mathrm{min})$.

Table S4. Screening of counteranion.

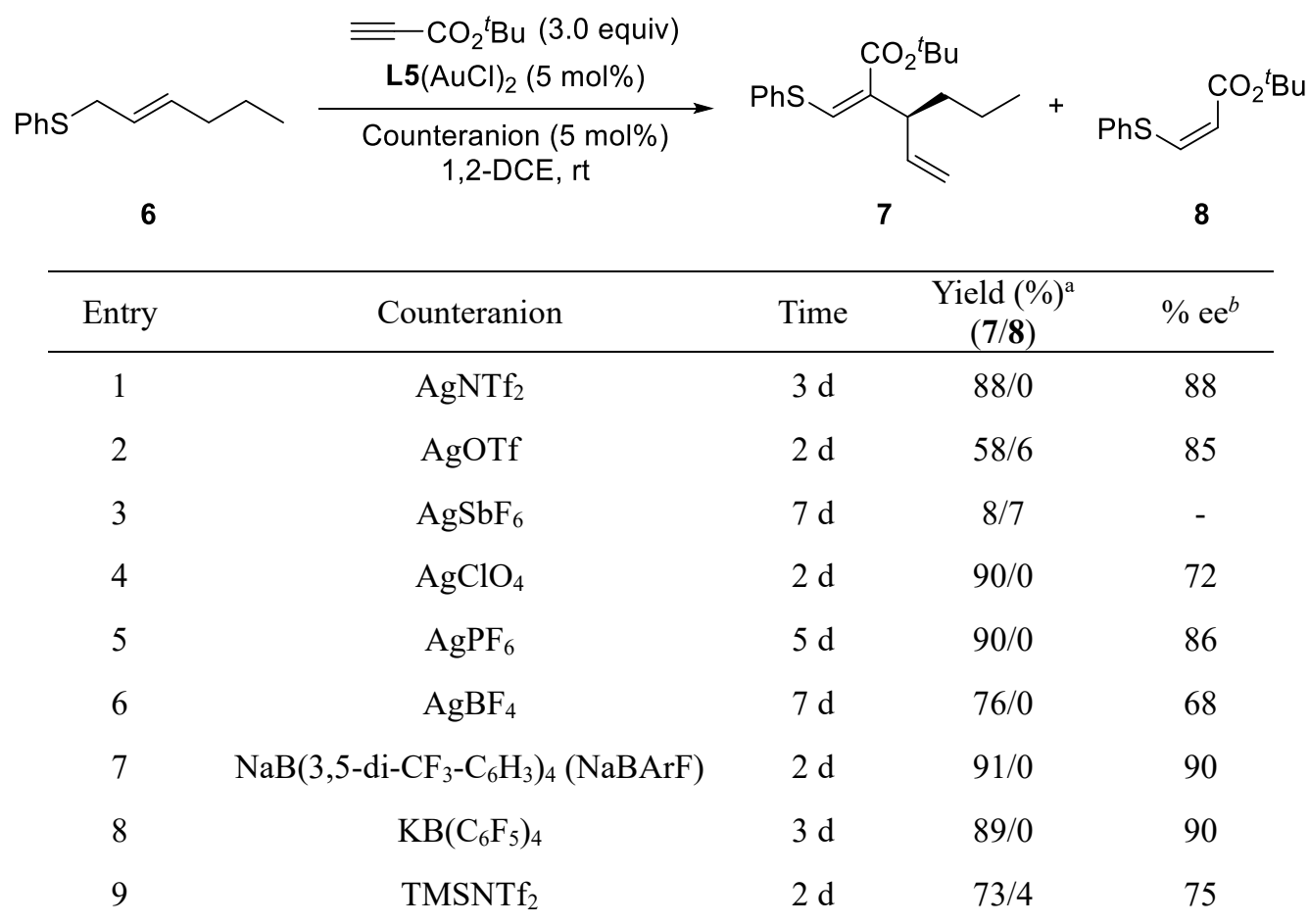

${ }^{a}$ Isolated yield. ${ }^{b}$ The product was derivatized into the corresponding lactone according to Method $\mathbf{B}$, and chiral assay of the lactone was conducted on Chiralpak ${ }^{\circledR}$ IA column using IPA: $n \mathrm{Hex}(0.5: 99.5)$ as an eluent $(1.0 \mathrm{~mL} / \mathrm{min})$. 
Table S5. Screening of solvents.

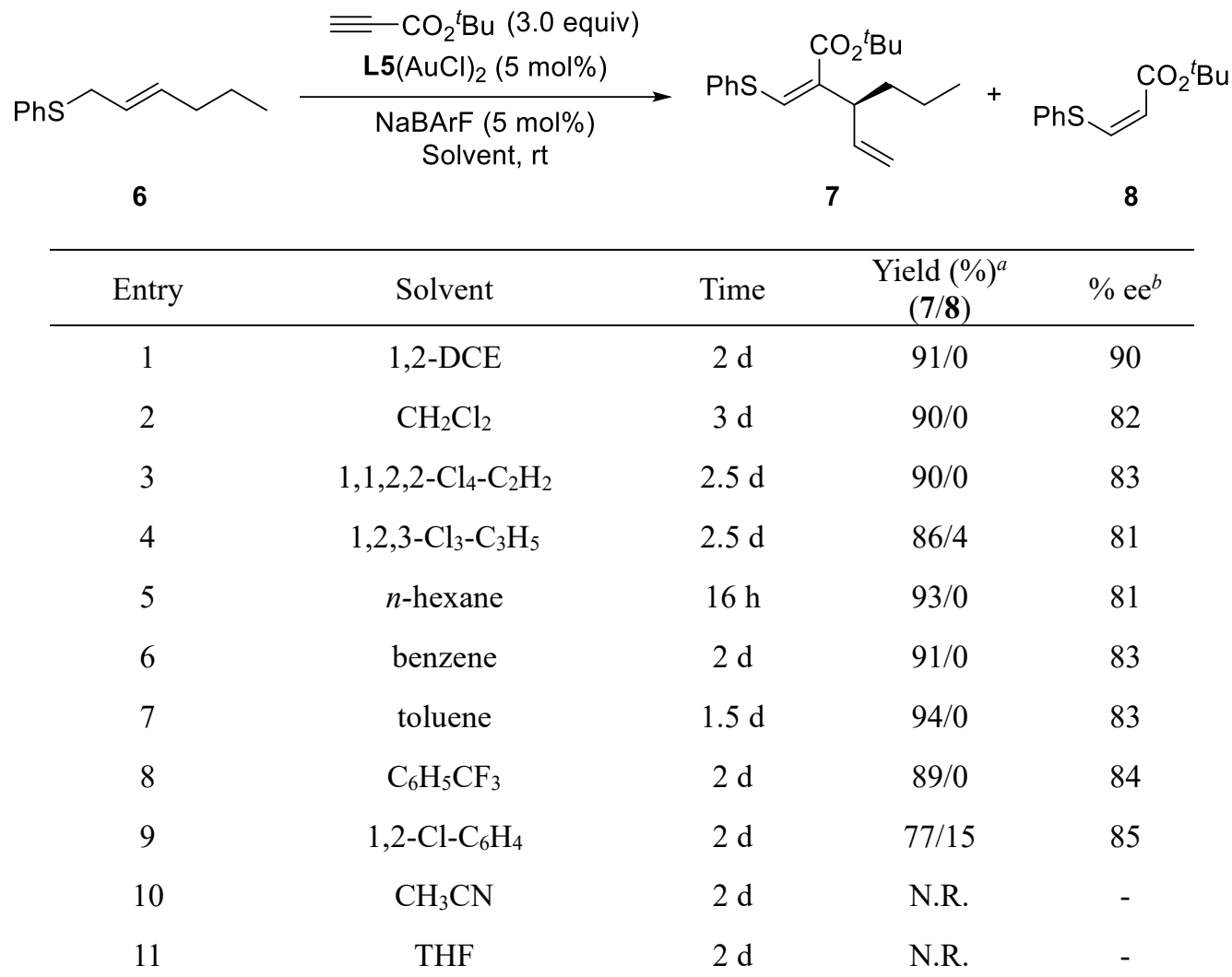

${ }^{a}$ Isolated yield. ${ }^{b}$ The product was derivatized into the corresponding lactone according to Method $\mathbf{B}$, and chiral assay of the lactone was conducted on Chiralpak ${ }^{\circledR}$ IA column using IPA: $n \mathrm{Hex}(0.5: 99.5)$ as an eluent $(1.0 \mathrm{~mL} / \mathrm{min})$. 
Table S6. Screening of sulfide moieties.

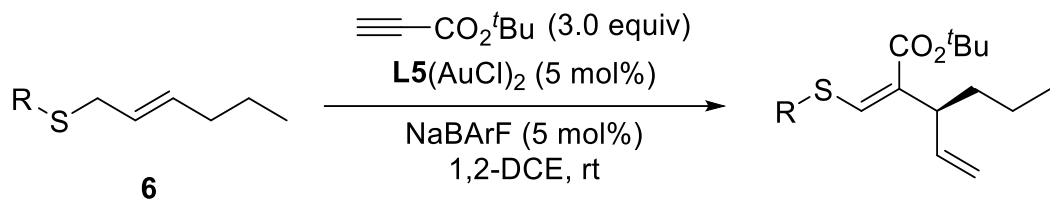

7

\begin{tabular}{ccccc}
\hline Entry & $\mathrm{R}$ & Time & ${\text { Yield }(\%)^{\mathrm{a}}}^{\mathrm{a}}$ & $\%$ ee \\
\hline 1 & $n$-propyl & $7 \mathrm{~d}$ & 50 & $75^{b}$ \\
2 & benzyl & $7 \mathrm{~d}$ & 45 & $83^{c}$ \\
3 & $\mathrm{C}_{6} \mathrm{H}_{5}$ & $2 \mathrm{~d}$ & 88 & $90^{d}$ \\
4 & $4-\mathrm{MeO}-\mathrm{C}_{6} \mathrm{H}_{4}$ & $3.5 \mathrm{~d}$ & 76 & $82^{e}$ \\
5 & $4-\mathrm{F}_{6} \mathrm{C}_{6} \mathrm{H}_{4}$ & $1 \mathrm{~d}$ & 92 & $93^{e}$ \\
6 & $4-\mathrm{CF}_{3}-\mathrm{C}_{6} \mathrm{H}_{4}$ & $1 \mathrm{~d}$ & 82 & $91^{e}$ \\
7 & $4-\mathrm{Cl}_{6} \mathrm{C}_{6} \mathrm{H}_{4}$ & $1.5 \mathrm{~d}$ & 95 & $90^{e}$ \\
8 & $4-\mathrm{Br}_{6} \mathrm{C}_{6} \mathrm{H}_{4}$ & $1 \mathrm{~d}$ & 82 & $89^{e}$ \\
9 & $2-\mathrm{Cl}_{-} \mathrm{C}_{6} \mathrm{H}_{4}$ & $1 \mathrm{~d}$ & 79 & $91^{f}$ \\
10 & $3-\mathrm{Br}_{-}-\mathrm{C}_{6} \mathrm{H}_{4}$ & $1 \mathrm{~d}$ & 89 & $87^{g}$ \\
11 & $3,5-\left(\mathrm{CF}_{3}\right)_{2}-\mathrm{C}_{6} \mathrm{H}_{3}$ & $1.5 \mathrm{~d}$ & 58 & $94^{h}$ \\
\hline
\end{tabular}

${ }^{a}$ Isolated yield. ${ }^{b}$ The product was derivatized into the corresponding lactone according to Method $\mathbf{B}$, and chiral assay of the lactone was conducted on Chiralpak ${ }^{\circledR}$ IA column using IPA: $n$ Hex $(5: 95)$ as an eluent $(1.0 \mathrm{~mL} / \mathrm{min})$. ${ }^{c}$ Chiral assay was conducted on Chiralpak ${ }^{\circledR}$ IC column using IPA: $n$ Hex $(0.5: 99.5)$ as an eluent $(1.0 \mathrm{~mL} / \mathrm{min}) .{ }^{d}$ The product was derivatized into the corresponding lactone according to Method B, and chiral assay of the lactone was conducted on Chiralpak ${ }^{\circledR}$ IA column using IPA: $n \mathrm{Hex}(0.5: 99.5)$ as an eluent $(1.0 \mathrm{~mL} / \mathrm{min}) .{ }^{e} \mathrm{Chiral}$ assay was conducted on Chiralpak ${ }^{\circledR}$ IA column using IPA: $n$ Hex $(0.5: 99.5)$ as an eluent $(1.0 \mathrm{~mL} / \mathrm{min}) .{ }^{f}$ The product was derivatized into the corresponding sulfone according to Method A, and chiral assay of the sulfone was conducted on Chiralpak ${ }^{\circledR}$ IG column using IPA: $n$ Hex (3:97) as an eluent $(1.0 \mathrm{~mL} / \mathrm{min}) .{ }^{8}$ The product was derivatized into the corresponding sulfone according to Method A, and chiral assay of the sulfone was conducted on Chiralpak ${ }^{\circledR}$ IC column using IPA: $n$ Hex (2:98) as an eluent $(1.0 \mathrm{~mL} / \mathrm{min}) .{ }^{h}$ The product was derivatized into the corresponding sulfone according to Method A, and chiral assay of the sulfone was conducted on Chiralpak ${ }^{\circledR}$ IC column using IPA: $n$ Hex $(0.5: 99.5)$ as an eluent $(1.0 \mathrm{~mL} / \mathrm{min})$. 


\section{Preparation of Substrates}

General Procedure 1 (6a)

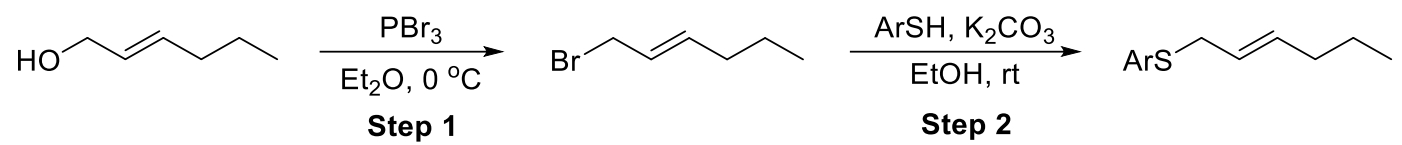

Step 1. To a solution of $(E)$-hex-2-en-1-ol $(300.5 \mathrm{mg}, 3.0 \mathrm{mmol})$ in $\mathrm{Et}_{2} \mathrm{O}(8 \mathrm{~mL})$ in a flamedried flask at $0{ }^{\circ} \mathrm{C}$, was added phosphorous tribromide $\left(1.0 \mathrm{M}\right.$ in $\left.\mathrm{CH}_{2} \mathrm{Cl}_{2}, 3.0 \mathrm{~mL}, 3.0 \mathrm{mmol}\right)$ and the mixture was stirred $2 \mathrm{~h}$ at $0{ }^{\circ} \mathrm{C}$. The mixture was quenched with saturated aq. $\mathrm{NaHCO}_{3}$ $(10 \mathrm{~mL})$ and the aqueous phase was extracted with $\mathrm{Et}_{2} \mathrm{O}(10 \mathrm{~mL} \times 2)$. The combined organic layers were dried $\left(\mathrm{MgSO}_{4}\right)$, filtered and concentrated in vacuo. The crude (E)-1-bromohex-2ene was used in the next step without further purification.

Step 2. To a solution of 4-fluorobenzenethiol $(461.4 \mathrm{mg}, 3.6 \mathrm{mmol})$ in EtOH $(15 \mathrm{~mL})$ was added $\mathrm{K}_{2} \mathrm{CO}_{3}(497.5 \mathrm{mg}, 3.6 \mathrm{mmol})$ and the crude $(E)$-1-bromohex-2-ene prepared above (neat) at RT and the mixture was stirred $3 \mathrm{~h}$ at RT. When the reaction was complete ( ${ }^{1} \mathrm{H} \mathrm{NMR}$ ), solvent was removed in vacuo and the residue was purified by flash column chromatography $\left(\mathrm{SiO}_{2}\right.$, hexanes) to provide (E)-(4-fluorophenyl)(hex-2-en-1-yl)sulfane as a colorless oil (497.5 mg, $79 \%)$.

General Procedure 2 (6b-d, 6h-k, 9a-e, 9i-j, 11c-f and 11h)

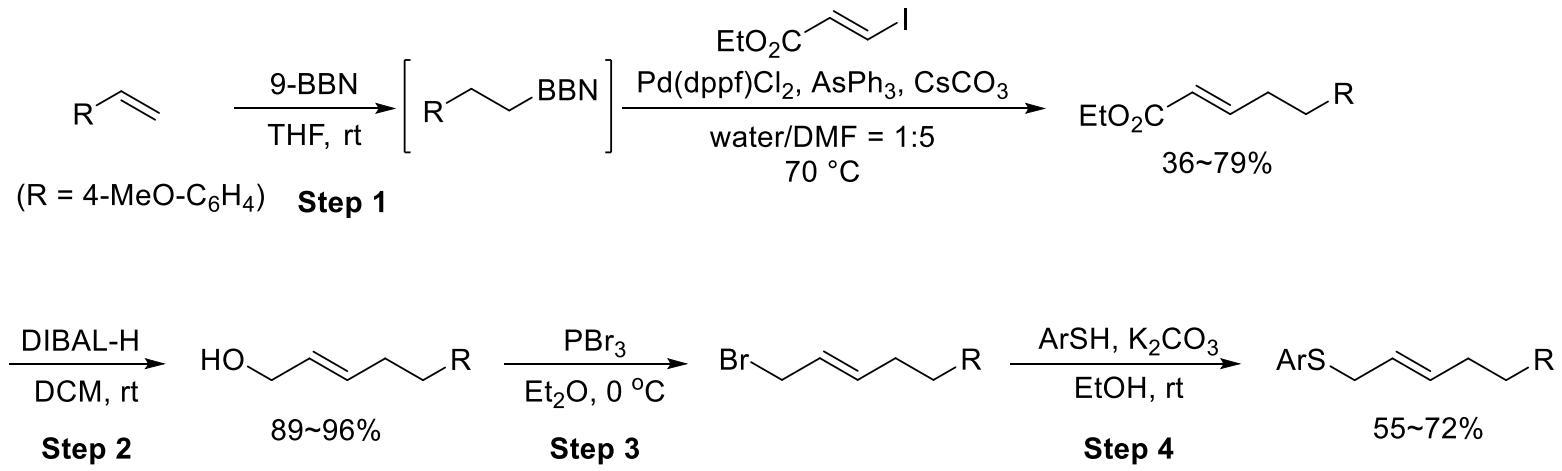

Step 1. ${ }^{12}$ 1-Methoxy-4-vinylbenzene $(286.4 \mathrm{mg}, 2.2 \mathrm{mmol})$ was placed in a flame-dried vial and was capped with a septum. A solution of 9-borabicyclo[3.3.1]nonane (0.5 M in THF, 4.4 $\mathrm{mL}, 2.2 \mathrm{mmol}$ ) was added dropwise over $5 \mathrm{~min}$ at $0{ }^{\circ} \mathrm{C}$ through the septum and the mixture 
was allow to warm to RT over $5 \mathrm{~h}$. To this was added $\mathrm{Pd}(\mathrm{dppf}) \mathrm{Cl}_{2}(73.2 \mathrm{mg}, 0.10 \mathrm{mmol}), \mathrm{AsPh}_{3}$ (61.2 mg, $0.20 \mathrm{mmol}), \mathrm{Cs}_{2} \mathrm{CO}_{3}(1.30 \mathrm{~g}, 4.0 \mathrm{mmol}$ ), ethyl (E)-3-iodoacrylate (452.0 mg, 2.0 $\mathrm{mmol})$, water $(2 \mathrm{~mL})$ and $\mathrm{DMF}(10 \mathrm{~mL})$ and the mixture was stirred overnight at $70{ }^{\circ} \mathrm{C}$. Then the mixture was cooled to RT, diluted with water $(10 \mathrm{~mL})$ and extracted with $\mathrm{Et}_{2} \mathrm{O}(10 \mathrm{~mL} x$ 2). The combined organic layers were dried $\left(\mathrm{MgSO}_{4}\right)$, filtered and concentrated in vacuo. The residue was purified by flash column chromatography $\left(\mathrm{SiO}_{2}\right.$, hexanes) to provide ethyl $(E)-5$ (4-methoxyphenyl)pent-2-enoate as a colorless oil (370.2 mg, 79\%).

Step 2. To a solution of the ethyl (E)-5-(4-methoxyphenyl)pent-2-enoate (370.2 mg, $1.6 \mathrm{mmol})$ in $\mathrm{CH}_{2} \mathrm{Cl}_{2}(4 \mathrm{~mL})$ in a flame-dried flask at $0{ }^{\circ} \mathrm{C}$, was added diisobutylaluminum hydride (1.0 $\mathrm{M}$ in $\mathrm{CH}_{2} \mathrm{Cl}_{2}, 4.0 \mathrm{~mL}, 4.0 \mathrm{mmol}$ ) and the mixture was stirred $2 \mathrm{~h}$ at $0{ }^{\circ} \mathrm{C}$. The mixture was quenched with $\mathrm{MeOH}(1 \mathrm{~mL})$ and saturated solution of Rochelle's salt $(20 \mathrm{~mL})$ and extracted with $\mathrm{CH}_{2} \mathrm{Cl}_{2}(10 \mathrm{~mL} \times 2)$. The combined organic phases were washed with brine, dried $\left(\mathrm{MgSO}_{4}\right)$, filtered, and concentrated in vacuo. The residue was purified by flash column chromatography $\left(\mathrm{SiO}_{2}, \mathrm{EtOAc}: \mathrm{Hex}=1: 4\right)$ to furnish $(E)-5$-(4-methoxyphenyl)pent-2-en-1-ol as a colorless oil (295.3 $\mathrm{mg}, 96 \%)$.

Step 3. To a solution of the (E)-5-(4-methoxyphenyl)pent-2-en-1-ol (295.3 mg, $1.5 \mathrm{mmol})$ in $\mathrm{Et}_{2} \mathrm{O}(4 \mathrm{~mL})$ in a flame-dried flask at $0{ }^{\circ} \mathrm{C}$, was added phosphorous tribromide $\left(1.0 \mathrm{M}^{\text {in }} \mathrm{CH}_{2} \mathrm{Cl}_{2}\right.$, $1.5 \mathrm{~mL}, 1.5 \mathrm{mmol}$ ) and the mixture was stirred $2 \mathrm{~h}$ at $0{ }^{\circ} \mathrm{C}$. The mixture was quenched with saturated aq. $\mathrm{NaHCO}_{3}(5 \mathrm{~mL})$ and the aqueous layer was extracted with $\mathrm{Et}_{2} \mathrm{O}(3 \mathrm{~mL} x 2)$. The combined organic layers were dried $\left(\mathrm{MgSO}_{4}\right)$, filtered and concentrated in vacuo. The crude (E)-1-(5-bromopent-3-en-1-yl)-4-methoxybenzene was used in the next step without further purification.

Step 4. Alkylation with the crude (E)-1-(5-bromopent-3-en-1-yl)-4-methoxybenzene prepared above was conducted similarly to Step 2 in GP1 (white solid, $326.6 \mathrm{mg}, 72 \%$ ). 


\section{General Procedure 3 (6e 6g and 6n)}
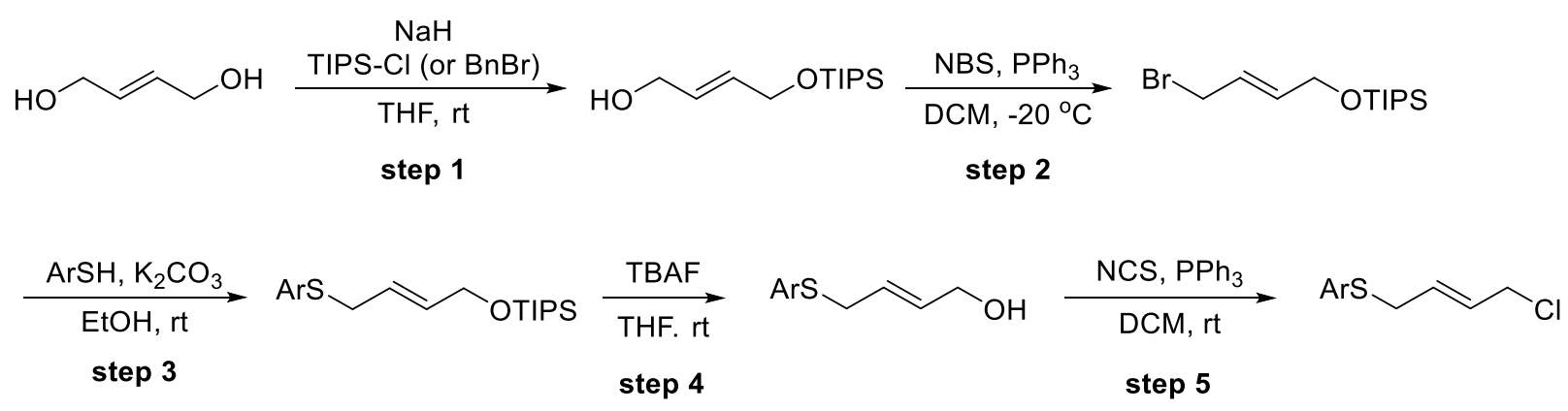

Step 1. To a suspension of sodium hydride (60\% in mineral oil, $879.6 \mathrm{mg}, 22 \mathrm{mmol})$ in THF $(70 \mathrm{~mL})$ in a flame-dried flask at $0{ }^{\circ} \mathrm{C}$, was added $(E)$-but-2-ene-1,4-diol $(1.76 \mathrm{~g}, 20 \mathrm{mmol})$ and the mixture was stirred $30 \mathrm{~min}$ at $0{ }^{\circ} \mathrm{C}$. To this was added triisopropylsilyl chloride $(4.24 \mathrm{~g}, 22$ $\mathrm{mmol}$ ), the mixture was allowed to warm to RT over $3 \mathrm{~h}$. The mixture was quenched with saturated aq. $\mathrm{NH}_{4} \mathrm{Cl}(30 \mathrm{~mL})$, extracted with $\mathrm{Et}_{2} \mathrm{O}(70 \mathrm{~mL} \times 3)$ and the combined organic phases were washed with brine, dried $\left(\mathrm{MgSO}_{4}\right)$, filtered and concentrated in vacuo. The residue was purified by flash column chromatography $\left(\mathrm{SiO}_{2}\right.$, EtOAc:Hex $\left.=1: 4\right)$ to afford $(E)-4-$ (triisopropylsilyloxy)but-2-en-1-ol as a colorless oil (3.51 g, 72\%).

Step 2. To a solution of triphenylphosphine $(4.20 \mathrm{~g}, 16 \mathrm{mmol})$ and the $(E)-4$-(triisopropylsilyloxy)but-2-en-1-ol (3.51 g, $14 \mathrm{mmol})$ in $\mathrm{CH}_{2} \mathrm{Cl}_{2}(20 \mathrm{~mL})$ in a flame-dried flask, at $-20{ }^{\circ} \mathrm{C}$, was added a solution of $\mathrm{N}$-bromosuccinimide $(2.67 \mathrm{~g}, 15 \mathrm{mmol})$ in $\mathrm{CH}_{2} \mathrm{Cl}_{2}(20 \mathrm{~mL})$. The mixture was stirred $1 \mathrm{~h}$ at $-20{ }^{\circ} \mathrm{C}$ and solvent was removed in vacuo. The residue was purified by flash column chromatography $\left(\mathrm{SiO}_{2}\right.$, EtOAc:Hex $\left.=1: 50\right)$ to provide $(E)$-(4-bromo-but-2-en-1yloxy)triisopropylsilane as a pale yellow oil (4.00 g, 90\%).

Step 3. Alkylation with the (E)-(4-bromobut-2-en-1-yloxy)triisopropylsilane (4.0 g, $13 \mathrm{mmol}$ ) was conducted similarly to Step 2 in GP1 (colorless oil, 4.40g, 89\%).

Step 4. To a solution of the (E)-(4-(4-fluorophenylthio)but-2-en-1-yloxy)triisopropylsilane $(4.40 \mathrm{~g}, 12 \mathrm{mmol})$ in THF $(60 \mathrm{~mL})$ in a flame-dried flask at $0{ }^{\circ} \mathrm{C}$, was added tetrabutylammonium fluoride (1.0 M in THF, $19 \mathrm{~mL}, 19 \mathrm{mmol})$ and the mixture was allowed to warm to RT over $2 \mathrm{~h}$. The mixture was diluted with water $(100 \mathrm{~mL})$, extracted with $\mathrm{Et}_{2} \mathrm{O}(100 \mathrm{~mL} \times 3)$ and the combined organic phases were washed with brine, dried $\left(\mathrm{MgSO}_{4}\right)$, filtered and concentrated in vacuo. The residue was purified by flash column chromatography $\left(\mathrm{SiO}_{2}\right.$, EtOAc:Hex = 1:4) to provide $(E)-4$-(4-fluorophenylthio)-but-2-en-1-ol as a colorless oil (2.19 
g, 92\%).

Step 5. To a solution of triphenylphosphine $(2.52 \mathrm{~g}, 9.6 \mathrm{mmol})$ and the $(E)$-4-(4-fluorophenylthio)but-2-en-1-ol $(1.59 \mathrm{~g}, 8.0 \mathrm{mmol})$ in $\mathrm{CH}_{2} \mathrm{Cl}_{2}(10 \mathrm{~mL})$ in a flame-dried flask at $-20{ }^{\circ} \mathrm{C}$, was added $N$-chlorosuccinimide $(1.17 \mathrm{~g}, 8.8 \mathrm{mmol})$ in $\mathrm{CH}_{2} \mathrm{Cl}_{2}(10 \mathrm{~mL})$. The cooling bath was removed and the mixture was allowed to warm to RT over $1 \mathrm{~h}$. Solvent was removed in vacuo and the residue was purified by flash column chromatography $\left(\mathrm{SiO}_{2}, \mathrm{EtOAc:Hex}=1: 50\right)$ to provide (E)-(4-chlorobut-2-en-1-yl)(4-fluoro-phenyl)sulfane as a colorless oil (1.42 g, 82\%).

\section{General Procedure 4 (6l and 6m)}
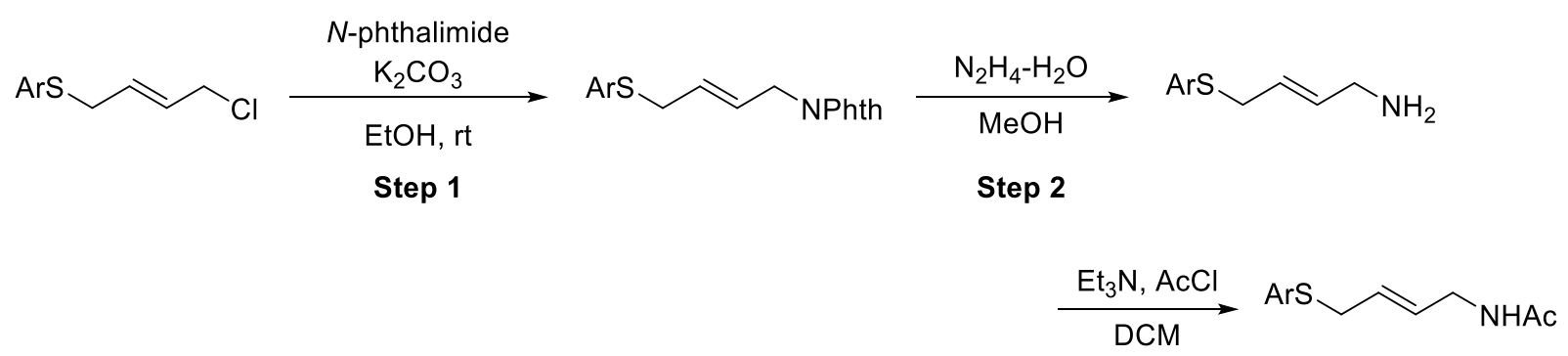

Step 3

Step 1. Alkylation with (E)-(4-chlorobut-2-en-1-yl)(4-fluorophenyl)sulfane (1.4 g, $6.5 \mathrm{mmol})$ was conducted similarly to Step 2 in GP1 (pale yellow solid, $1.10 \mathrm{~g}, 53 \%$ ).

Step 2. To solution of the (E)-2-(4-(4-fluorophenylthio)but-2-en-1-yl)isoindoline-1,3-dione (327.4 mg, $1.0 \mathrm{mmol}$ ) in $\mathrm{MeOH}(3 \mathrm{~mL})$ was added hydrazine (50 \% aq., $150.2 \mu \mathrm{L}, 3.0 \mathrm{mmol}$ ) and the reaction mixture was stirred overnight at RT. The mixture was dried $\left(\mathrm{Na}_{2} \mathrm{SO}_{4}\right)$, filtered and concentrated in vacuo. The crude (E)-4-(4-fluorophenylthio)but-2-en-1-amine was used in the next step without further purification.

Step 3. The crude $(E)$-4-(4-fluorophenylthio)but-2-en-1-amine prepared above was dissolved in $\mathrm{CH}_{2} \mathrm{Cl}_{2}(4 \mathrm{~mL})$. To this was added triethylamine $(202.4 \mathrm{mg}, 2.0 \mathrm{mmol})$ and acetyl chloride (102.0 $\mathrm{mg}, 1.3 \mathrm{mmol})$ at $0{ }^{\circ} \mathrm{C}$. The mixture was allowed to warm to RT over $1 \mathrm{~h}$. The mixture was quenched with saturated aq. $\mathrm{NH}_{4} \mathrm{Cl}(3 \mathrm{~mL})$, extracted with ethyl acetate $(3 \mathrm{~mL} \times 3)$ and the combined organic phases were washed with brine, dried $\left(\mathrm{Na}_{2} \mathrm{SO}_{4}\right)$, filtered and concentrated in vacuo. The residue was purified by flash column chromatography $\left(\mathrm{SiO}_{2}, \mathrm{EtOAc}: \mathrm{Hex}=2: 1\right)$ to provide $(E)-N$-(4-(4-fluorophenyl-thio)but-2-en-1-yl)acetamide as a pale yellow oil (161.1 
$\mathrm{mg}, 67 \%)$.

\section{General Procedure 5 (6o)}<smiles>O=C(O)CCCCCCC=CCCBr</smiles>

To a solution of 4-fluorobenzenethiol (302.8 mg, $2.4 \mathrm{mmol})$ in EtOH $(5 \mathrm{~mL})$ was added $\mathrm{K}_{2} \mathrm{CO}_{3}$ (331.7 g, $2.4 \mathrm{mmol})$ and (E)-1,4-dibromo-2-butene (213.9 $\mathrm{mg}, 1.0 \mathrm{mmol})$ and the mixture was stirred overnight at RT. When the reaction was complete ( ${ }^{1} \mathrm{H}$ NMR), solvent was removed in vacuo and the residue was purified by flash column chromatography $\left(\mathrm{SiO}_{2}\right.$, hexanes) to provide (E)-1,4-bis(4-fluorophenylthio)but-2-ene as a white solid (308.4 mg, 88\%).

\section{General Procedure 6 (6p and 6q)}

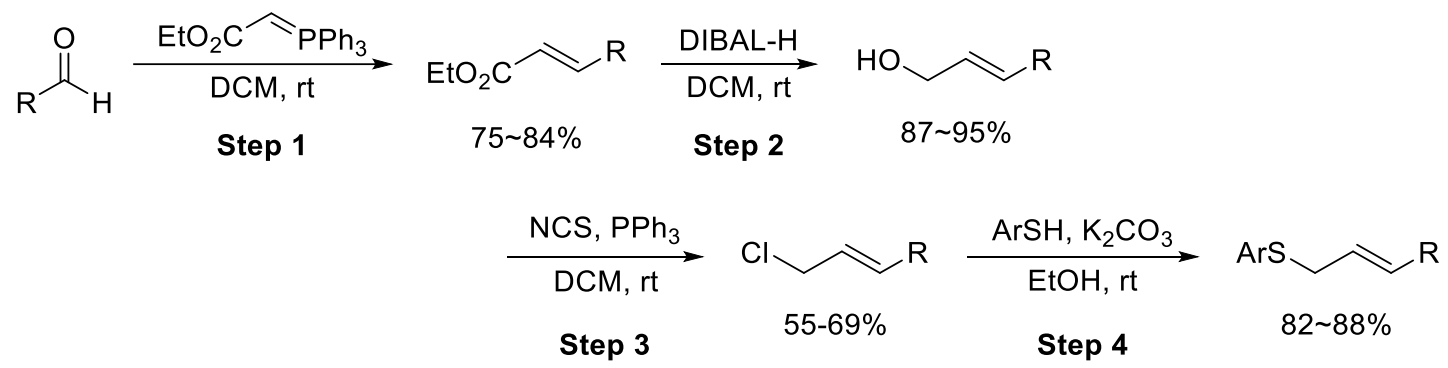

Step 1. To a solution of (ethoxycarbonylmethylene)triphenylphosphorane (2.09 g, $6.0 \mathrm{mmol}$ ) in $\mathrm{CH}_{2} \mathrm{Cl}_{2}(20 \mathrm{~mL})$ was added cyclohexanecarbaldehyde $(448.7 \mathrm{mg}, 4.0 \mathrm{mmol})$ and the mixture was stirred $2 \mathrm{~h}$ at RT. Solvent was removed in vacuo and the residue was purified by flash column chromatography $\left(\mathrm{SiO}_{2}\right.$, EtOAc:Hex $\left.=1: 10\right)$ to provide ethyl $(E)$-3-cyclohexylacrylate as a colorless oil (612.4 $\mathrm{mg}, 84 \%)$.

Step 2. To a solution of the (E)-3-cyclohexylacrylate (612.4 $\mathrm{mg}, 3.4 \mathrm{mmol})$ in $\mathrm{CH}_{2} \mathrm{Cl}_{2}(8.5 \mathrm{~mL})$ in a flame-dried flask at $0{ }^{\circ} \mathrm{C}$, was added diisobutylaluminum hydride $\left(1.0 \mathrm{M}\right.$ in $\mathrm{CH}_{2} \mathrm{Cl}_{2}, 8.4$ $\mathrm{mL}, 8.4 \mathrm{mmol}$ ) and the mixture was stirred $2 \mathrm{~h}$ at $0{ }^{\circ} \mathrm{C}$. The mixture was quenched with $\mathrm{MeOH}$ $(2 \mathrm{~mL})$ and a saturated solution of Rochelle's salt $(20 \mathrm{~mL})$, extracted with $\mathrm{CH}_{2} \mathrm{Cl}_{2}(15 \mathrm{~mL} \times 2)$ and the combined organic phases were washed with brine, dried $\left(\mathrm{MgSO}_{4}\right)$, filtered and concentrated in vacuo. The residue was purified by flash column chromatography $\left(\mathrm{SiO}_{2}\right.$, 
EtOAc:Hex $=1: 4)$ to provide $(E)-3$-cyclo-hexylprop-2-en-1-ol as a colorless oil $(452.9 \mathrm{mg}$, $95 \%)$.

Step 3. To a solution of triphenylphosphine $(472.1 \mathrm{mg}, 1.8 \mathrm{mmol})$ and the $(E)-3-$ cyclohexylprop-2-en-1-ol $(210.3 \mathrm{mg}, 1.5 \mathrm{mmol})$ in $\mathrm{CH}_{2} \mathrm{Cl}_{2}(3 \mathrm{~mL})$ at $-20{ }^{\circ} \mathrm{C}$, was added a solution of $N$-chlorosuccinimide $(227.0 \mathrm{mg}, 1.7 \mathrm{mmol})$ in $\mathrm{CH}_{2} \mathrm{Cl}_{2}(3 \mathrm{~mL})$. The cooling bath was removed and the mixture was allowed to warm to RT over $1 \mathrm{~h}$. Solvent was removed in vacuo and the residue was purified by flash column chromatography $\left(\mathrm{SiO}_{2}, \mathrm{EtOAc:Hex}=1: 20\right)$ to provide $(E)$-(3-chloroprop-1-en-1-yl)cyclohexane as a pale yellow oil (164.0 mg, 69\%).

Step 4. Alkylation with the (E)-(3-chloroprop-1-en-1-yl)cyclohexane (164.0 mg, $1.0 \mathrm{mmol})$ was conducted similarly to Step 2 in GP1 (pale yellow oil, $202.0 \mathrm{mg}, 78 \%$ ).

\section{General Procedure 7 (6r and 6s)}
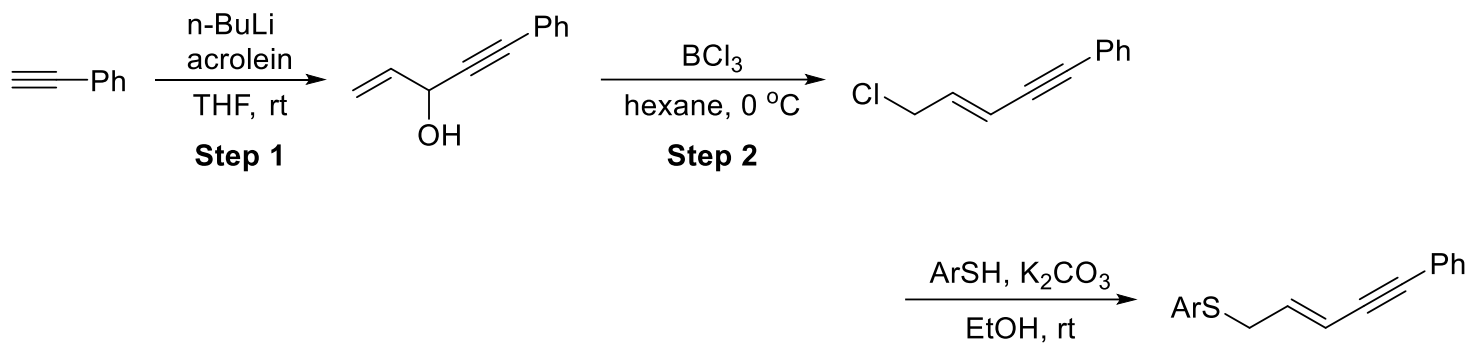

Step 3

Step 1. To a solution of phenylacetylene $(204.3 \mathrm{mg}, 2.0 \mathrm{mmol})$ in THF $(10 \mathrm{~mL})$ in a flamedried flask at $-78{ }^{\circ} \mathrm{C}$, was added $n$-butyllithium $(2.5 \mathrm{M}$ in hexane, $960.0 \mu \mathrm{L}, 2.4 \mathrm{mmol})$ dropwise and the mixture was stirred $2 \mathrm{~h}$ at $-78{ }^{\circ} \mathrm{C}$. To this was added acrolein $(134.5 \mathrm{mg}, 2.4$ mmol). the cooling bath was removed, the mixture was allowed to warm to RT and stirred overnight. The mixture was quenched with saturated aq. $\mathrm{NH}_{4} \mathrm{Cl}(5 \mathrm{~mL})$ at $0{ }^{\circ} \mathrm{C}$, extracted with $\mathrm{Et}_{2} \mathrm{O}(10 \mathrm{~mL} \times 3)$ and the combined organic phases were washed with brine, dried $\left(\mathrm{Na}_{2} \mathrm{SO}_{4}\right)$, filtered and concentrated in vacuo. The residue was purified by flash column chromatography $\left(\mathrm{SiO}_{2}\right.$, EtOAc:Hex = 1:3) to provide 5-phenylpent-1-en-4-yn-3-ol as a pale yellow oil (254.2 mg, 80\%).

Step 2. To a solution of the 5-phenylpent-1-en-4-yn-3-ol (158.2 mg, $1.0 \mathrm{mmol})$ in hexane (5 $\mathrm{mL})$ in a flame-dried flask at $0{ }^{\circ} \mathrm{C}$, was added boron trichloride $(1.0 \mathrm{M}$ in heptane, $1.2 \mathrm{~mL}, 1.2$ 
mmol) and the mixture was stirred $1 \mathrm{~h}$ at $0{ }^{\circ} \mathrm{C}$. The mixture was quenched with water $(1 \mathrm{~mL})$ and the aqueous layer was extracted with pentane $(10 \mathrm{~mL} \times 3)$. The combined organic phases were washed with brine, dried $\left(\mathrm{Na}_{2} \mathrm{SO}_{4}\right)$, filtered and concentrated in vacuo. The residue was purified by flash column chromatography $\left(\mathrm{SiO}_{2}\right.$, EtOAc:Hex $\left.=1: 10\right)$ to provide $(E)-(5-$ chloropent-3-en-1-yn-1-yl)benzene as a pale yellow oil (125.2 mg, 70\%).

Step 3. Alkylation with the (E)-(5-chloropent-3-en-1-yn-1-yl)benzene (117.9 mg, $0.70 \mathrm{mmol})$ was conducted similarly to Step 2 in GP1 (pale yellow oil, $159.6 \mathrm{mg}, 90 \%$ ).

\section{General Procedure 8 (6t)}

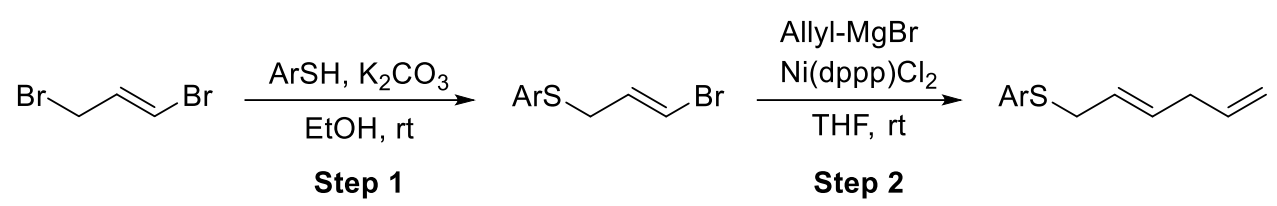

Step 1. Alkylation with (E)-1,3-dibromoprop-1-ene (599.6 mg, $3.0 \mathrm{mmol}$ ) was conducted similarly to Step 2 in GP1 (colorless oil, $691.7 \mathrm{mg}, 93 \%$ ).

Step 2. $\mathrm{Ni}(\mathrm{dppp}) \mathrm{Cl}_{2}(27.1 \mathrm{mg}, 0.050 \mathrm{mmol})$ was dissolved in THF (5 mL) in a flame-dried flask. To this was added the (E)-(3-bromoallyl)(4-fluorophenyl)sulfane (247.1 mg, $1.0 \mathrm{mmol})$ and allylmagnesium bromide $\left(1.0 \mathrm{M}\right.$ in $\left.\mathrm{Et}_{2} \mathrm{O}, 3.0 \mathrm{~mL}, 3.0 \mathrm{mmol}\right)$ at $0{ }^{\circ} \mathrm{C}$ and the mixture was stirred $4 \mathrm{~h}$ at RT. The mixture was quenched with saturated aq. $\mathrm{NH}_{4} \mathrm{Cl}(2 \mathrm{~mL})$, extracted with $\mathrm{Et}_{2} \mathrm{O}(3 \mathrm{~mL} \times 3)$ and the combined organic phases were washed with brine, dried $\left(\mathrm{MgSO}_{4}\right)$, filtered and concentrated in vacuo. The residue was purified by flash column chromatography $\left(\mathrm{SiO}_{2}\right.$, EtOAc:Hex $\left.=1: 10\right)$ to provide $(E)$-(4-fluorophenyl)-(hexa-2,5-dien-1-yl)sulfane as a colorless oil (42.8 mg, 69\%). 
General Procedure 9 (9f)

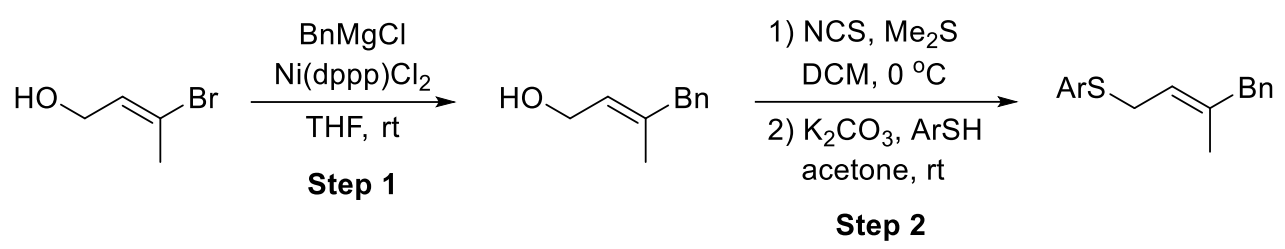

Step 1. $\mathrm{Ni}(\mathrm{dppp}) \mathrm{Cl}_{2}(16.3 \mathrm{mg}, 0.030 \mathrm{mmol})$ was dissolved in THF (3 mL) in flame-dried vial. To this was added $(E)$-3-bromobut-2-en-1-ol $(75.5 . \mathrm{mg}, 0.50 \mathrm{mmol})$ and benzylmagnesium chloride (1.0 M in $\left.\mathrm{Et}_{2} \mathrm{O}, 1.5 \mathrm{~mL}, 1.5 \mathrm{mmol}\right)$ at $0{ }^{\circ} \mathrm{C}$ and the mixture was stirred $4 \mathrm{~h}$ at RT. The mixture was quenched with saturated aq. $\mathrm{NH}_{4} \mathrm{Cl}(3 \mathrm{~mL})$ at $0{ }^{\circ} \mathrm{C}$, extracted with $\mathrm{Et}_{2} \mathrm{O}(3 \mathrm{~mL} x$ 3) and the combined organic phase was washed with brine, dried $\left(\mathrm{MgSO}_{4}\right)$, filtered and concentrated in vacuo. The residue was purified by flash column chromatography $\left(\mathrm{SiO}_{2}\right.$, EtOAc:Hex $=1: 10)$ to provide $(E)-3$-methyl-4-phenylbut-2-en-1-ol as a colorless oil $(80 \%$, $64.8 \mathrm{mg})$.

Step 2. To a solution of $N$-chlorosuccinimide $(58.8 \mathrm{mg}, 0.44 \mathrm{mmol})$ in $\mathrm{CH}_{2} \mathrm{Cl}_{2}(2 \mathrm{~mL})$ in a flame-dried flask at $0{ }^{\circ} \mathrm{C}$, was added $\mathrm{Me}_{2} \mathrm{~S}(29.8 \mathrm{mg}, 0.48 \mathrm{mmol})$ for $10 \mathrm{~min}$. To this was added the $(E)$-3-methyl-4-phenylbut-2-en-1-ol $(64.8 \mathrm{mg}, 0.40 \mathrm{mmol})$ and the mixture was stirred for $2 \mathrm{~h}$ at $0{ }^{\circ} \mathrm{C}$. When the reaction was completed (TLC), The mixture was concentrated in vacuo. The crude $(E)$-(4-chloro-2-methylbut-2-en-1-yl)benzene was dissolved in acetone $(2 \mathrm{~mL})$ and was added $\mathrm{K}_{2} \mathrm{CO}_{3}(55.3 \mathrm{mg}, 0.40 \mathrm{mmol})$ and 4-fluorobenzenethiol $(51.3 \mathrm{mg}, 0.40 \mathrm{mmol})$ and the mixture was stirred overnight at RT. When the reaction was complete $\left({ }^{1} \mathrm{H}\right.$ NMR), solvent was removed in vacuo and the residue was purified by flash column chromatography $\left(\mathrm{SiO}_{2}\right.$, hexanes) to provide (E)-(4-fluorophenyl)(3-methyl-4-phenylbut-2-en-1-yl)sulfane as a colorless oil (91.4 mg, 84\%). 


\section{General Procedure 10 (9g and 9h)}

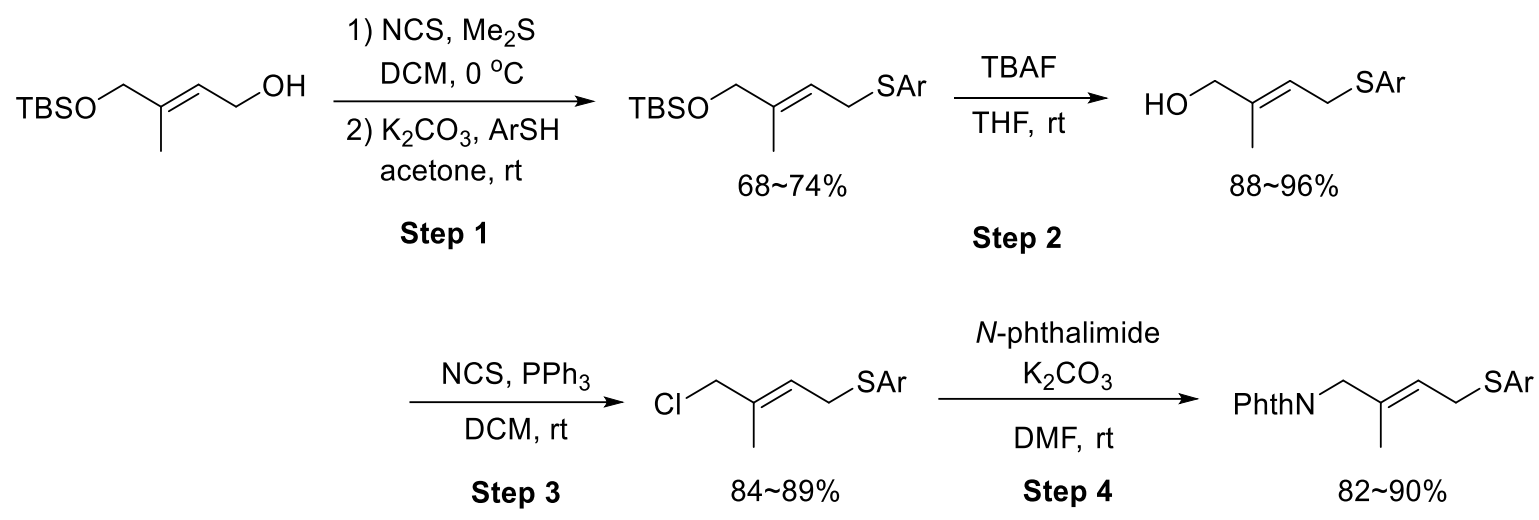

Step 1. Alkylation with (E)-4-(tert-butyldimethylsilyloxy)-3-methylbut-2-en-1-ol (258.5 mg, $1.0 \mathrm{mmol}$ ) was conducted similarly to Step 2 in GP9 (colorless oil, $278.6 \mathrm{mg}, 74 \%$ ).

Step 2. To a solution of the (E)-tert-butyldimethyl(2-methyl-4-(4-(trifluoromethyl)phenyl)thiobut-2-en-1-yl)oxysilane (278.6 $\mathrm{mg}, 0.74 \mathrm{mmol})$ in THF $(3 \mathrm{~mL})$ in a flame-dried vial at 0 ${ }^{\circ} \mathrm{C}$, was added tetrabutylammonium fluoride (1.0 M in THF, $1.1 \mathrm{~mL}, 1.1 \mathrm{mmol}$ ) and the mixture was stirred $2 \mathrm{~h}$ at RT. The mixture was diluted with water $(10 \mathrm{~mL})$, extracted with $\mathrm{Et}_{2} \mathrm{O}(10 \mathrm{~mL}$ x 2) and the combined organic layers were dried $\left(\mathrm{MgSO}_{4}\right)$, filtered and concentrated in vacuo. The crude (E)-2-methyl-4-(4-(trifluoromethyl)phenyl)thiobut-2-en-1-ol was used in the next step without further purification.

Step 3. To solution of triphenylphosphine $(209.8 \mathrm{mg}, 0.80 \mathrm{mmol})$ and the crude $(E)$-2-methyl4-(4-(trifluoromethyl)phenyl)thiobut-2-en-1-ol (0.74 mmol) prepared above in $\mathrm{CH}_{2} \mathrm{Cl}_{2}(3 \mathrm{~mL})$ at $-20{ }^{\circ} \mathrm{C}$, was added $\mathrm{N}$-chlorosuccinimide $(106.8 \mathrm{mg}, 0.80 \mathrm{mmol})$ in $\mathrm{CH}_{2} \mathrm{Cl}_{2}(3 \mathrm{~mL})$. The cooling bath was removed and the mixture was allowed to warm to RT over $1 \mathrm{~h}$. Solvent was removed in vacuo and the residue was purified by flash column chromatography ( $\mathrm{SiO}_{2}$, hexanes) to provide (E)-(4-chloro-3-methylbut-2-en-1-yl)(4-(trifluoromethyl)phenyl)sulfane as a colorless oil (182.8 mg, 88\%).

Step 4. Alkylation with (E)-(4-chloro-3-methylbut-2-en-1-yl)(4-(trifluoromethyl)phenyl)sulfane (182.8 mg, $0.65 \mathrm{mmol}$ ) was conducted similarly to Step 2 in GP1 (pale yellow solid, $228.9 \mathrm{mg}, 90 \%)$. 


\section{General Procedure 11 (11a)}

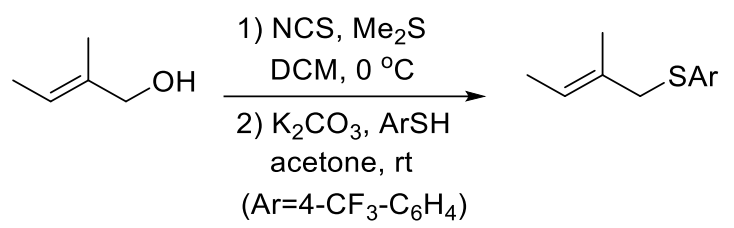

Alkylation with $(E)-2$-methylbut-2-en-1-ol $(86.1 \mathrm{mg}, 1.0 \mathrm{mmol})$ was conducted similarly to Step 2 in GP9 (colorless oil, $191.9 \mathrm{mg}, 78 \%$ ).

\section{General Procedure 12 (11b)}

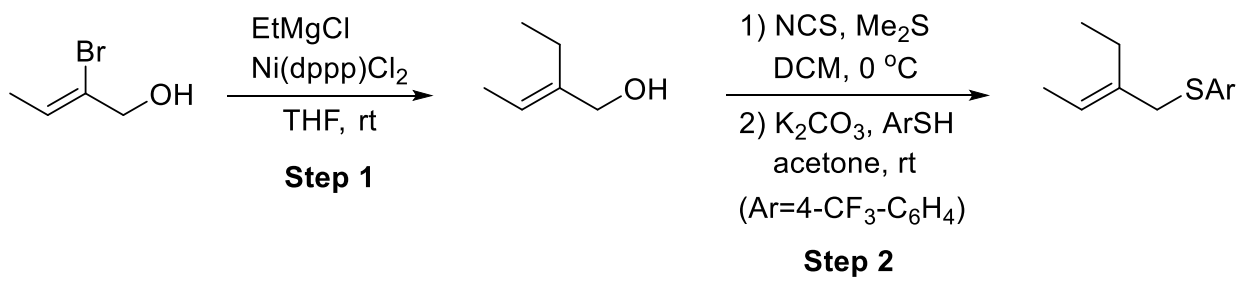

Step 1. $\mathrm{Ni}(\mathrm{dppp}) \mathrm{Cl}_{2}(16.3 \mathrm{mg}, 0.030 \mathrm{mmol})$ was dissolved in THF (3 mL) in a flame-dried flask. To this was added (Z)-2-bromobut-2-en-1-ol (75.5. $\mathrm{mg}, 0.50 \mathrm{mmol})$ and ethylmagnesium bromide (3.0 $\mathrm{M}$ in $\left.\mathrm{Et}_{2} \mathrm{O}, 0.5 \mathrm{~mL}, 3.0 \mathrm{mmol}\right)$ at $0{ }^{\circ} \mathrm{C}$. The reaction mixture was allowed to warm to RT over $4 \mathrm{~h}$. The mixture was quenched with saturated aq. $\mathrm{NH}_{4} \mathrm{Cl}(3 \mathrm{~mL})$ at $0{ }^{\circ} \mathrm{C}$, extracted with $\mathrm{Et}_{2} \mathrm{O}(3 \mathrm{~mL} \times 3)$ and the combined organic phases were washed with brine, dried $\left(\mathrm{MgSO}_{4}\right)$, filtered and concentrated in vacuo. The residue was purified by flash column chromatography $\left(\mathrm{SiO}_{2}\right.$, EtOAc:Hex $\left.=1: 10\right)$ to provide $(E)$-2-ethylbut-2-en-1-ol as a colorless oil $(40.1 \mathrm{mg}, 80 \%)$.

Step 2. Alkylation with the (E)-2-ethylbut-2-en-1-ol $(40.1 \mathrm{mg}, 0.40 \mathrm{mmol})$ was conducted similarly to Step 2 in GP9 (colorless oil, $80.1 \mathrm{mg}, 77 \%)(E / Z=13: 1)$. 


\section{General Procedure 12 (11g)}

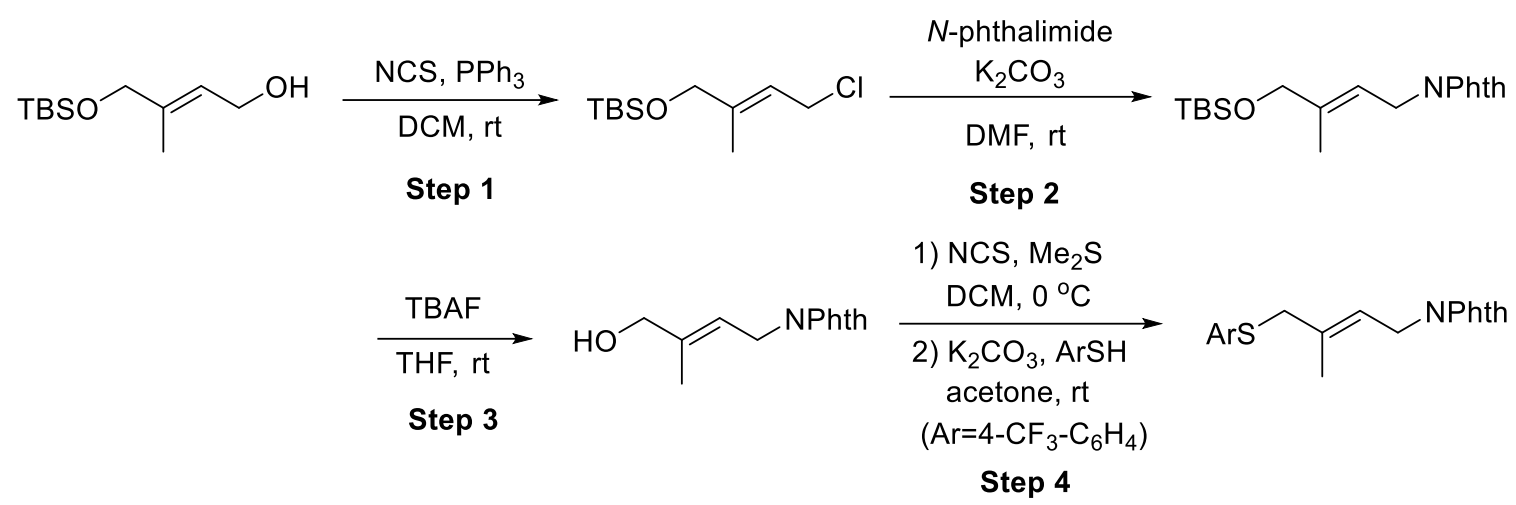

Step 1. To a solution of triphenylphosphine $(314.7 \mathrm{mg}, 1.2 \mathrm{mmol})$ and (E)-4-(tertbutyldimethylsilyloxy)-3-methylbut-2-en-1-ol (216.4 mg, $1.0 \mathrm{mmol})$ in $\mathrm{CH}_{2} \mathrm{Cl}_{2}(3 \mathrm{~mL})$ at -20 ${ }^{\circ} \mathrm{C}$, was added $\mathrm{N}$-chlorosuccinimide $(146.9 \mathrm{mg}, 1.1 \mathrm{mmol})$. The cooling bath was removed and the mixture was allowed to warm to RT over $1 \mathrm{~h}$. Solvent was concentrated in vacuo and the residue was purified by flash column chromatography $\left(\mathrm{SiO}_{2}\right.$, hexanes) to provide $(E)$-tertbutyl(4-chloro-2-methylbut-2-en-1-yloxy)dimethylsilane as a colorless oil (210.7 mg, 90\%).

Step 2. Alkylation with the (E)-tert-butyl((4-chloro-2-methylbut-2-en-1-yl)oxy)dimethylsilane (210.7 mg, $0.9 \mathrm{mmol}$ ) was conducted similarly to Step 2 in GP1 (colorless oil, $276.4 \mathrm{mg}, 90 \%$ ).

Step 3. To a solution of the (E)-2-(4-(tert-butyldimethylsilyloxy)-3-methylbut-2-en-1yl)isoindoline-1,3-dione $(276.4 \mathrm{mg}, 0.80 \mathrm{mmol})$ in THF $(3 \mathrm{~mL})$ in a flame-dried flask at $0{ }^{\circ} \mathrm{C}$, was added tetrabutylammonium fluoride $(1.0 \mathrm{M}$ in THF, $1.1 \mathrm{~mL}, 1.1 \mathrm{mmol})$ and the mixture was stirred $2 \mathrm{~h}$ at RT. The mixture was diluted with water $(10 \mathrm{~mL})$, extracted with $\mathrm{Et}_{2} \mathrm{O}(10 \mathrm{~mL}$ x 3$)$ and the combined organic layers were dried $\left(\mathrm{MgSO}_{4}\right)$, filtered and concentrated in vacuo. The crude (E)-2-(4-hydroxy-3-methylbut-2-en-1-yl)isoindoline-1,3-dione was used in the next step without further purification.

Step 4. Alkylation with the crude (E)-2-(4-hydroxy-3-methylbut-2-en-1-yl)isoindoline-1,3dione $(185.0 \mathrm{mg}, 0.80 \mathrm{mmol})$ prepared above was conducted similarly to Step 2 in GP9 (colorless oil, $208.1 \mathrm{mg}, 66 \%)(E / Z=13: 1)$. 


\section{Characterization of Substrates}<smiles>CCC/C=C/CSc1ccc(F)cc1</smiles>

Colorless oil (EtOAc:Hex $=1: 10) ;{ }^{1} \mathrm{H}$ NMR (400 MHz, $\left.\mathrm{CDCl}_{3}\right): \delta 7.32(\mathrm{dd}, J=8.9,5.3 \mathrm{~Hz}$, 2H), 6.97 (t, $J=8.8 \mathrm{~Hz}, 2 \mathrm{H}), 5.56-5.36(\mathrm{~m}, 2 \mathrm{H}), 3.43(\mathrm{~d}, J=5.6 \mathrm{~Hz}, 2 \mathrm{H}), 1.97-1.90(\mathrm{~m}, 2 \mathrm{H})$, 1.29 (sextet, $J=7.4 \mathrm{~Hz}, 2 \mathrm{H}), 0.82(\mathrm{t}, J=7.3 \mathrm{~Hz}, 3 \mathrm{H}) ;{ }^{13} \mathrm{C}$ NMR $\left(100 \mathrm{MHz}, \mathrm{CDCl}_{3}\right): \delta 161.9$ (d, $J=245.0 \mathrm{~Hz}), 134.5,133.3$ (d, $J=7.8 \mathrm{~Hz}), 130.8$ (d, $J=3.0 \mathrm{~Hz}), 125.1,115.8$ (d, $J=21.5$ $\mathrm{Hz}$ ), 37.9, 34.3, 22.3, 13.5; ${ }^{19} \mathrm{~F}$ NMR (376 MHz, $\left.\mathrm{CDCl}_{3}\right): \delta$-115.6; IR (ATR): $\tilde{\mathrm{v}}=2959,2929$, 2871, 1590, 1490, 1227, 1156, 1092, 964, 908, 827, $733 \mathrm{~cm}^{-1}$; HRMS (ESI) Calcd for $\mathrm{C}_{12} \mathrm{H}_{15} \mathrm{FNaS}^{+}[\mathrm{M}+\mathrm{Na}]^{+}$233.0771, found 233.0773.

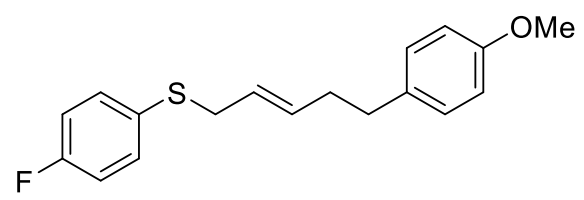

\section{$(E)-6 \mathbf{b}$}

White solid (EtOAc:Hex = 1:10), mp: $=47 \sim 49{ }^{\circ} \mathrm{C} ;{ }^{1} \mathrm{H}$ NMR $\left(400 \mathrm{MHz}, \mathrm{CDCl}_{3}\right): \delta 7.31$ (dd, $J$ $=8.9,5.2 \mathrm{~Hz}, 2 \mathrm{H}), 7.02(\mathrm{~d}, J=8.7 \mathrm{~Hz}, 2 \mathrm{H}), 6.98(\mathrm{t}, J=8.7 \mathrm{~Hz}, 2 \mathrm{H}), 6.80(\mathrm{~d}, J=8.7 \mathrm{~Hz}, 2 \mathrm{H})$, 5.55-5.39 (m, 2H), $3.78(\mathrm{~s}, 3 \mathrm{H}), 3.42(\mathrm{~d}, J=5.6 \mathrm{~Hz}, 2 \mathrm{H}), 2.54(\mathrm{t}, J=7.3 \mathrm{~Hz}, 2 \mathrm{H}), 2.29-2.22$ $(\mathrm{m}, 2 \mathrm{H}) ;{ }^{13} \mathrm{C} \mathrm{NMR}\left(100 \mathrm{MHz}, \mathrm{CDCl}_{3}\right): \delta 161.9(\mathrm{~d}, J=245.1 \mathrm{~Hz}), 157.8,133.7,133.5,133.3$ (d, $J=7.9 \mathrm{~Hz}), 130.8(\mathrm{~d}, J=3.1 \mathrm{~Hz}), 129.3,125.6,115.8$ (d, $J=21.5 \mathrm{~Hz}), 113.7,55.3,37.8$, 34.7, 34.2; ${ }^{19} \mathrm{~F}$ NMR (376 MHz, $\left.\mathrm{CDCl}_{3}\right): \delta$-115.4; IR (ATR): $\tilde{\mathrm{v}}=3030,3008,2933,2837$, 1737, 1611, 1589, 1512, 1490, 1245, 1221, 1036, 966, 912, 824, $733 \mathrm{~cm}^{-1}$; HRMS (ESI) Calcd for $\mathrm{C}_{18} \mathrm{H}_{19} \mathrm{FNaOS}^{+}[\mathrm{M}+\mathrm{Na}]^{+}$325.1033, found 325.1036.<smiles>COc1ccc(CC/C=C\CSc2ccc(F)cc2)cc1</smiles>

Colorless oil (EtOAc:Hex $=1: 10) ;{ }^{1} \mathrm{H}$ NMR (400 MHz, $\left.\mathrm{CDCl}_{3}\right): \delta 7.35(\mathrm{dd}, J=8.8,5.2 \mathrm{~Hz}$, 2H), $7.03(\mathrm{~d}, J=8.5 \mathrm{~Hz}, 2 \mathrm{H}), 6.97(\mathrm{t}, J=8.8 \mathrm{~Hz}, 2 \mathrm{H}), 6.81(\mathrm{~d}, J=8.6 \mathrm{~Hz}, 2 \mathrm{H}), 5.58-5.41(\mathrm{~m}$, 2H), $3.79(\mathrm{~s}, 3 \mathrm{H}), 3.41(\mathrm{~d}, J=6.7 \mathrm{~Hz}, 2 \mathrm{H}), 2.48(\mathrm{t}, J=7.3 \mathrm{~Hz}, 2 \mathrm{H}), 2.22-2.13(\mathrm{~m}, 2 \mathrm{H}) ;{ }^{13} \mathrm{C}$ NMR (100 MHz, $\left.\mathrm{CDCl}_{3}\right): \delta 162.1(\mathrm{~d}, J=245.0 \mathrm{~Hz}), 157.9,133.6,133.5(\mathrm{~d}, J=8.0 \mathrm{~Hz}), 132.5$, 
$131.0(\mathrm{~d}, J=3.1 \mathrm{~Hz}), 129.3,125.3,115.9(\mathrm{~d}, J=21.4 \mathrm{~Hz}), 113.8,55.3,34.7,32.6,29.2 ;{ }^{19} \mathrm{~F}$ $\operatorname{NMR}\left(376 \mathrm{MHz}, \mathrm{CDCl}_{3}\right): \delta$-115.1; IR (ATR): $\tilde{\mathrm{v}}=3012,2937,2836,1735,1611,1589,1512$, 1489, 1300, 1244, 1176, 1090, 1036, 907, 823, $731 \mathrm{~cm}^{-1}$; HRMS (ESI) Calcd for $\mathrm{C}_{18} \mathrm{H}_{19} \mathrm{FNaOS}^{+}[\mathrm{M}+\mathrm{Na}]^{+}$325.1033, found 325.1036.

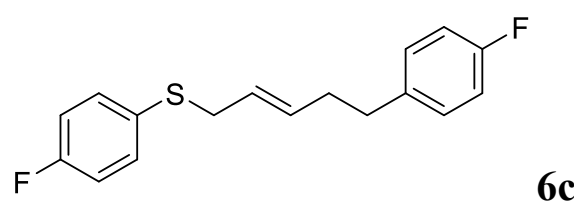

Colorless oil (EtOAc:Hex = 1:10); ${ }^{1} \mathrm{H}$ NMR (400 MHz, $\left.\mathrm{CDCl}_{3}\right): \delta 7.31$ (dd, $J=8.9,5.2 \mathrm{~Hz}$, $2 \mathrm{H}), 7.05(\mathrm{dd}, J=8.7,5.5 \mathrm{~Hz}, 2 \mathrm{H}), 6.98(\mathrm{t}, J=8.6 \mathrm{~Hz}, 2 \mathrm{H}), 6.94(\mathrm{t}, J=8.7 \mathrm{~Hz}, 2 \mathrm{H}), 5.56-5.38$ $(\mathrm{m}, 2 \mathrm{H}), 3.42(\mathrm{~d}, J=5.9 \mathrm{~Hz}, 2 \mathrm{H}), 2.57$ (t, $J=7.3 \mathrm{~Hz}, 2 \mathrm{H}), 2.32-2.21(\mathrm{~m}, 2 \mathrm{H}) ;{ }^{13} \mathrm{C} \mathrm{NMR}(100$ MHz, $\left.\mathrm{CDCl}_{3}\right): \delta 161.9(\mathrm{~d}, J=245.1 \mathrm{~Hz}), 161.3(\mathrm{~d}, J=242.1 \mathrm{~Hz}), 137.1(\mathrm{~d}, J=3.4 \mathrm{~Hz}), 133.2$ (d, $J=8.0 \mathrm{~Hz}), 133.1,130.7(\mathrm{~d}, J=3.2 \mathrm{~Hz}), 129.7$ (d, $J=7.8 \mathrm{~Hz}), 125.9,115.8(\mathrm{~d}, J=21.8$ $\mathrm{Hz}), 115.0$ (d, $J=21.0 \mathrm{~Hz}), 37.8,34.8,34.0 ;{ }^{19} \mathrm{~F} \mathrm{NMR}\left(376 \mathrm{MHz}, \mathrm{CDCl}_{3}\right): \delta-113.3,-117.8$; IR (ATR): $\tilde{\mathrm{v}}=3034,2933,2890,1737,1590,1509,1490,1219,1157,1092,966,907,823$, $731 \mathrm{~cm}^{-1}$; HRMS (ESI) Calcd for $\mathrm{C}_{17} \mathrm{H}_{16} \mathrm{~F}_{2} \mathrm{NaS}^{+}[\mathrm{M}+\mathrm{Na}]^{+} 313.0833$, found 313.0836.

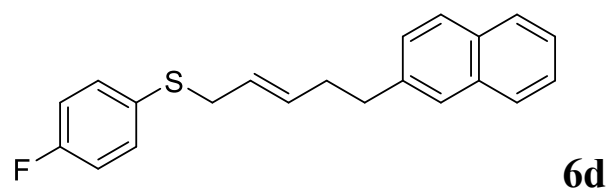

White solid (EtOAc:Hex $=1: 10), \mathrm{mp}=45 \sim 47{ }^{\circ} \mathrm{C} ;{ }^{1} \mathrm{H}$ NMR $\left(400 \mathrm{MHz}, \mathrm{CDCl}_{3}\right): \delta 7.85-7.72$ (m, 3H), $7.55(\mathrm{~s}, 1 \mathrm{H}), 7.50-7.38(\mathrm{~m}, 2 \mathrm{H}), 7.35-7.23(\mathrm{~m}, 3 \mathrm{H}), 6.94(\mathrm{t}, J=8.7 \mathrm{~Hz}, 2 \mathrm{H}), 5.57-5.43$ $(\mathrm{m}, 2 \mathrm{H}), 3.41(\mathrm{~d}, J=5.2 \mathrm{~Hz}, 2 \mathrm{H}), 2.76(\mathrm{t}, J=7.3 \mathrm{~Hz}, 2 \mathrm{H}), 2.45-2.33(\mathrm{~m}, 2 \mathrm{H}) ;{ }^{13} \mathrm{C}$ NMR $(100$ $\left.\mathrm{MHz}, \mathrm{CDCl}_{3}\right): \delta 161.9(\mathrm{~d}, J=245.2 \mathrm{~Hz}), 139.1,133.6,133.3,133.3(\mathrm{~d}, J=7.9 \mathrm{~Hz}), 132.0$, 130.7 (d, $J=3.4 \mathrm{~Hz}), 127.9,127.6,127.4,127.3,126.4,125.9$, 125.8, 125.2, 115.8 (d, $J=21.7$ $\mathrm{Hz}$ ), 37.8, 35.8, 33.8; ${ }^{19} \mathrm{~F}$ NMR (376 MHz, $\left.\mathrm{CDCl}_{3}\right): \delta-115.3$; IR (ATR): $\tilde{\mathrm{v}}=3017,2971,2938$, 2845, 1740, 1589, 1489, 1434, 1366, 1218, 1092, 964, 907, 816, $744 \mathrm{~cm}^{-1}$; HRMS (ESI) Calcd for $\mathrm{C}_{21} \mathrm{H}_{19} \mathrm{FNaS}^{+}[\mathrm{M}+\mathrm{Na}]^{+}$345.1084, found 345.1087. 
$\overbrace{6 \mathrm{OH}}^{\mathrm{S}}$

Colorless oil (EtOAc:Hex = 1:2); ${ }^{1} \mathrm{H}$ NMR (400 MHz, $\left.\mathrm{CDCl}_{3}\right): \delta 7.34(\mathrm{dd}, J=8.9,5.2 \mathrm{~Hz}, 2 \mathrm{H})$, $6.99(\mathrm{t}, J=8.7 \mathrm{~Hz}, 2 \mathrm{H}), 5.79-5.68(\mathrm{~m}, 1 \mathrm{H}), 5.67-5.57(\mathrm{~m}, 1 \mathrm{H}), 4.06(\mathrm{t}, J=5.0 \mathrm{~Hz}, 2 \mathrm{H}), 3.48$ $(\mathrm{dd}, J=6.8,1.0 \mathrm{~Hz}, 2 \mathrm{H}), 1.29$ (s, br, $1 \mathrm{H}) ;{ }^{13} \mathrm{C} \mathrm{NMR}\left(100 \mathrm{MHz}, \mathrm{CDCl}_{3}\right): \delta 162.0(\mathrm{~d}, J=245.4$ Hz), $133.3(\mathrm{~d}, J=7.9 \mathrm{~Hz}), 132.5,130.4$ (d, $J=3.4 \mathrm{~Hz}), 127.0,115.9$ (d, $J=21.8 \mathrm{~Hz}), 62.9$, 37.3; ${ }^{19} \mathrm{~F}$ NMR (376 MHz, $\mathrm{CDCl}_{3}$ ): $\delta$-114.9; IR (ATR): $\tilde{\mathrm{v}}=3345,2863,1726,1589,1490$, 1220, 1157, 1089, 1012, 967, 826, $772 \mathrm{~cm}^{-1}$; HRMS (ESI) Calcd for $\mathrm{C}_{10} \mathrm{H}_{11} \mathrm{FNaOS}^{+}[\mathrm{M}+\mathrm{Na}]^{+}$ 221.0407, found 221.0413 .<smiles>Fc1ccc(SC/C=C/CO[SnH3])cc1</smiles>

$(E)-6 \mathbf{f}$

Colorless oil (EtOAc:Hex = 1:10); ${ }^{1} \mathrm{H}$ NMR (400 MHz, $\left.\mathrm{CDCl}_{3}\right): \delta 7.33(\mathrm{dd}, J=8.8,5.2 \mathrm{~Hz}$, 2H), $6.96(\mathrm{t}, J=8.8 \mathrm{~Hz}, 2 \mathrm{H}), 5.81-5.68(\mathrm{~m}, 1 \mathrm{H}), 5.61-5.50(\mathrm{~m}, 1 \mathrm{H}), 4.16(\mathrm{dd}, J=4.4,1.4 \mathrm{~Hz}$, $2 \mathrm{H}), 3.48(\mathrm{dd}, J=7.0,1.1 \mathrm{~Hz}, 2 \mathrm{H}), 1.15-0.98(\mathrm{~m}, 21 \mathrm{H}) ;{ }^{13} \mathrm{C} \mathrm{NMR}\left(100 \mathrm{MHz}, \mathrm{CDCl}_{3}\right): \delta 162.0$ $(\mathrm{d}, J=245.0 \mathrm{~Hz}), 133.3(\mathrm{~d}, J=8.0 \mathrm{~Hz}), 133.0,130.6(\mathrm{~d}, J=3.4 \mathrm{~Hz}), 124.7,115.8(\mathrm{~d}, J=21.7$ $\mathrm{Hz}$ ), 63.1, 37.4, 18.0, 12.0; ${ }^{19} \mathrm{~F}$ NMR (376 MHz, $\left.\mathrm{CDCl}_{3}\right)$ : $\delta$-115.4; IR (ATR): $\tilde{\mathrm{v}}=3017,2970$, 2943, 2866, 1739, 1491, 1462, 1366, 1218, 1124, 1092, 965, 883, $828 \mathrm{~cm}^{-1}$; HRMS (ESI) Calcd for $\mathrm{C}_{19} \mathrm{H}_{31} \mathrm{FNaOSSi}^{+}[\mathrm{M}+\mathrm{Na}]^{+}$377.1742, found 377.1747.

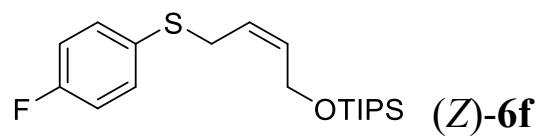

Colorless oil (EtOAc:Hex = 1:10); ${ }^{1} \mathrm{H}$ NMR (400 MHz, $\left.\mathrm{CDCl}_{3}\right): \delta 7.37$ (dd, $J=8.9,5.2 \mathrm{~Hz}$, 2H), $6.98(\mathrm{t}, J=8.7 \mathrm{~Hz}, 2 \mathrm{H}), 5.68-5.59(\mathrm{~m}, 1 \mathrm{H}), 5.56-5.48(\mathrm{~m}, 1 \mathrm{H}), 4.03$ (dd, $J=5.8,0.8 \mathrm{~Hz}$, 2H), 3.49 (dd, $J=7.8,0.7 \mathrm{~Hz}, 2 \mathrm{H}), 1.13-0.94(\mathrm{~m}, 21 \mathrm{H}) ;{ }^{13} \mathrm{C} \mathrm{NMR}\left(100 \mathrm{MHz}, \mathrm{CDCl}_{3}\right): \delta 162.3$ (d, $J=245.6 \mathrm{~Hz}), 134.0$ (d, $J=8.1 \mathrm{~Hz}), 133.2,130.5$ (d, $J=3.5 \mathrm{~Hz}), 125.1,115.9$ (d, $J=21.7$ $\mathrm{Hz}$ ), 59.2, 33.1, 18.0, 11.9; ${ }^{19} \mathrm{~F}$ NMR (376 MHz, $\left.\mathrm{CDCl}_{3}\right): \delta$-114.8; IR (ATR): $\tilde{\mathrm{v}}=2944,2866$, 1590, 1491, 1462, 1383, 1230, 1155, 1092, 1065, 1014, 882, 830, $748 \mathrm{~cm}^{-1}$; HRMS (ESI) Calcd for $\mathrm{C}_{19} \mathrm{H}_{31} \mathrm{FNaOSSi}^{+}[\mathrm{M}+\mathrm{Na}]^{+}$377.1742, found 377.1747 . 
$\overbrace{6 \mathrm{OBn}}^{\mathrm{S}}$

Colorless oil (EtOAc:Hex = 1:10); ${ }^{1} \mathrm{H}$ NMR (400 MHz, $\left.\mathrm{CDCl}_{3}\right): \delta$ 7.37-7.23 (m, 7H), $6.97(\mathrm{t}$, $J=8.7 \mathrm{~Hz}, 2 \mathrm{H}), 5.81-5.70(\mathrm{~m}, 1 \mathrm{H}), 5.64-5.53(\mathrm{~m}, 1 \mathrm{H}), 4.40$ (s, 2H), 3.93 (dd, $J=5.8,1.2 \mathrm{~Hz}$, $2 \mathrm{H}), 3.48(\mathrm{dd}, J=7.0,1.0 \mathrm{~Hz}, 2 \mathrm{H}) ;{ }^{13} \mathrm{C} \mathrm{NMR}\left(100 \mathrm{MHz}, \mathrm{CDCl}_{3}\right): \delta 162.0(\mathrm{~d}, J=245.1 \mathrm{~Hz})$, $138.2,133.3(\mathrm{~d}, J=8.0 \mathrm{~Hz}), 130.4(\mathrm{~d}, J=3.5 \mathrm{~Hz}), 130.0,128.6,128.4,127.7,127.6,115.9$ (d, $J=21.6 \mathrm{~Hz}), 71.9,69.9,37.4 ;{ }^{19} \mathrm{~F}$ NMR $\left(376 \mathrm{MHz}, \mathrm{CDCl}_{3}\right): \delta-115.0$; IR (ATR): $\tilde{\mathrm{v}}=3029$, 2971, 2946, 2855, 1739, 1589, 1490, 1454, 1366, 1217, 1091, 968, 912, 828, 735, $698 \mathrm{~cm}^{-1}$; HRMS (ESI) Calcd for $\mathrm{C}_{17} \mathrm{H}_{17} \mathrm{FNaOS}^{+}[\mathrm{M}+\mathrm{Na}]^{+} 311.0876$, found 311.0891 .

$\overbrace{6 h}(E / Z=21: 1)$

Pale yellow oil (EtOAc:Hex = 1:10); ${ }^{1} \mathrm{H}$ NMR (400 MHz, $\left.\mathrm{CDCl}_{3}\right): \delta 7.33$ (dd, $J=8.8,5.2 \mathrm{~Hz}$, $2 \mathrm{H}), 6.98(\mathrm{t}, J=8.7 \mathrm{~Hz}, 2 \mathrm{H}), 5.53-5.42(\mathrm{~m}, 1 \mathrm{H}), 5.42-5.32(\mathrm{~m}, 1 \mathrm{H}), 4.12(\mathrm{q}, J=7.2 \mathrm{~Hz}, 2 \mathrm{H})$, $3.42(\mathrm{dd}, J=6.7,0.5 \mathrm{~Hz}, 2 \mathrm{H}), 2.17(\mathrm{t}, J=7.6 \mathrm{~Hz}, 2 \mathrm{H}), 2.00(\mathrm{dt}, J=7.2,6.6 \mathrm{~Hz}, 2 \mathrm{H}), 1.61$ (quintet, $J=7.6 \mathrm{~Hz}, 2 \mathrm{H}), 1.25(\mathrm{t}, J=7.1 \mathrm{~Hz}, 3 \mathrm{H}) ;{ }^{13} \mathrm{C} \mathrm{NMR}\left(100 \mathrm{MHz}, \mathrm{CDCl}_{3}\right): \delta 173.5,162.0$ $(\mathrm{d}, J=245.2 \mathrm{~Hz}), 133.4$ (d, $J=7.9 \mathrm{~Hz}), 133.1,130.6$ (d, $J=3.2 \mathrm{~Hz}), 126.1,115.8$ (d, $J=21.8$ $\mathrm{Hz}$ ), 60.2, 37.8, 33.4, 31.5, 24.3, 14.2; ${ }^{19} \mathrm{~F}$ NMR (376 MHz, $\left.\mathrm{CDCl}_{3}\right): \delta-115.3$; IR (ATR): $\tilde{\mathrm{v}}=$ 3017, 2971, 2946, 1737, 1490, 1441, 1366, 1218, 1092, 913, 829, $733 \mathrm{~cm}^{-1}$; HRMS (ESI) Calcd for $\mathrm{C}_{15} \mathrm{H}_{19} \mathrm{FNaO}_{2} \mathrm{~S}^{+}[\mathrm{M}+\mathrm{Na}]^{+}$305.0982, found 305.0988.

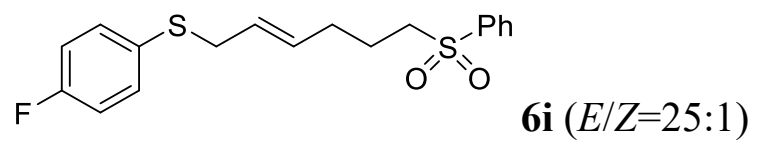

Colorless oil (EtOAc:Hex = 1:2); ${ }^{1} \mathrm{H}$ NMR (400 MHz, $\left.\mathrm{CDCl}_{3}\right): \delta 7.88(\mathrm{~d}, J=7.1 \mathrm{~Hz}, 2 \mathrm{H})$, 7.71-7.62 (m, 1H), 7.57 (t, $J=7.2 \mathrm{~Hz}, 2 \mathrm{H}), 7.30(\mathrm{dd}, J=8.8,5.2 \mathrm{~Hz}, 2 \mathrm{H}), 6.96(\mathrm{t}, J=8.7 \mathrm{~Hz}$, $2 \mathrm{H}), 5.52-5.49(\mathrm{~m}, 1 \mathrm{H}), 5.43-5.20(\mathrm{~m}, 1 \mathrm{H}), 3.40(\mathrm{dd}, J=7.0,0.7 \mathrm{~Hz}, 2 \mathrm{H}), 3.02-2.87(\mathrm{~m}, 2 \mathrm{H})$, $2.05(\mathrm{q}, J=6.8 \mathrm{~Hz}, 2 \mathrm{H}), 1.79-1.57(\mathrm{~m}, 2 \mathrm{H}) ;{ }^{13} \mathrm{C} \mathrm{NMR}\left(100 \mathrm{MHz}, \mathrm{CDCl}_{3}\right): \delta 161.9(\mathrm{~d}, J=245.2$ 
Hz), 139.1, 133.7, 133.3 (d, $J=8.0 \mathrm{~Hz}), 131.5,130.4$ (d, $J=3.4 \mathrm{~Hz}), 129.3,128.0,127.3,115.9$ $(\mathrm{d}, J=21.8 \mathrm{~Hz}), 55.3,37.6,30.6,22.1 ;{ }^{19} \mathrm{~F} \mathrm{NMR}\left(376 \mathrm{MHz}, \mathrm{CDCl}_{3}\right): \delta-114.6$; IR (ATR): $\tilde{\mathrm{v}}=$ 3017, 2971, 2946, 1740, 1491, 1448, 1365, 1217, 1147, 1087, 913, 743, cm-1. HRMS (ESI) Calcd for $\mathrm{C}_{18} \mathrm{H}_{19} \mathrm{FNaO}_{2} \mathrm{~S}_{2}{ }^{+}[\mathrm{M}+\mathrm{Na}]^{+}$373.0703, found 373.0708.<smiles>CC(=O)OCCC/C=C/CSc1ccc(F)cc1</smiles>

Colorless oil (EtOAc:Hex = 1:5); ${ }^{1} \mathrm{H}$ NMR (400 MHz, $\left.\mathrm{CDCl}_{3}\right): \delta 7.33$ (dd, $\left.J=8.9,5.2 \mathrm{~Hz}, 2 \mathrm{H}\right)$, $6.98(\mathrm{t}, J=8.8 \mathrm{~Hz}, 2 \mathrm{H}), 5.55-5.34(\mathrm{~m}, 2 \mathrm{H}), 3.97$ (t, $J=6.7 \mathrm{~Hz}, 2 \mathrm{H}), 3.43(\mathrm{dd}, J=6.7,0.7 \mathrm{~Hz}$, 2H), 2.04 (s, 3H), 2.03 (dt, $J=7.5,5.0 \mathrm{~Hz}, 2 \mathrm{H}), 1.61$ (quintet, $J=6.6 \mathrm{~Hz}, 2 \mathrm{H}$ ); ${ }^{13} \mathrm{C} \mathrm{NMR}(100$ $\left.\mathrm{MHz}, \mathrm{CDCl}_{3}\right): \delta 171.1,161.9(\mathrm{~d}, J=245.0 \mathrm{~Hz}), 133.4(\mathrm{~d}, J=8.0 \mathrm{~Hz}), 132.8,130.6(\mathrm{~d}, J=3.5$ $\mathrm{Hz}), 126.1,115.8$ (d, $J=21.6 \mathrm{~Hz}), 63.7,37.8,28.5,28.1,20.9 ;{ }^{19} \mathrm{~F}$ NMR (376 $\left.\mathrm{MHz}, \mathrm{CDCl}_{3}\right)$ : $\delta$-115.3; IR (ATR): $\tilde{\mathrm{v}}=3017,2971,2942,1737,1590,1491,1434,1366,1218,1091,1042$, 966, 914, 827, $733 \mathrm{~cm}^{-1}$; HRMS (ESI) Calcd for $\mathrm{C}_{14} \mathrm{H}_{17} \mathrm{FNaO}_{2} \mathrm{~S}^{+}[\mathrm{M}+\mathrm{Na}]^{+}$291.0825, found 291.0831.

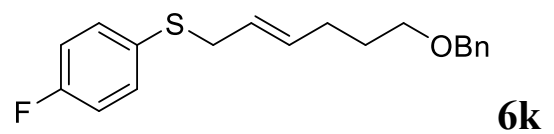

Pale yellow oil (EtOAc:Hex = 1:5); ${ }^{1} \mathrm{H}$ NMR (400 MHz, $\left.\mathrm{CDCl}_{3}\right): \delta$ 7.38-7.23 (m, 7H), $6.96(\mathrm{t}$, $J=8.7 \mathrm{~Hz}, 2 \mathrm{H}), 5.52-5.36(\mathrm{~m}, 2 \mathrm{H}), 4.45(\mathrm{~s}, 2 \mathrm{H}), 3.41(\mathrm{~d}, J=5.9 \mathrm{~Hz}, 2 \mathrm{H}), 3.37(\mathrm{t}, J=6.5 \mathrm{~Hz}$, $2 \mathrm{H}), 2.06(\mathrm{td}, J=7.1,6.7 \mathrm{~Hz}, 2 \mathrm{H}), 1.60$ (quintet, $J=6.6 \mathrm{~Hz}, 2 \mathrm{H}) ;{ }^{13} \mathrm{C} \mathrm{NMR}\left(100 \mathrm{MHz}, \mathrm{CDCl}_{3}\right)$ : $\delta 161.9(\mathrm{~d}, J=245.1 \mathrm{~Hz}), 138.6,133.7,133.2(\mathrm{~d}, J=8.0 \mathrm{~Hz}), 130.8(\mathrm{~d}, J=3.1 \mathrm{~Hz}), 128.4$, 127.6, 127.6, 125.5, $115.8(\mathrm{~d}, J=21.5 \mathrm{~Hz}), 72.9,69.5,37.8,29.3,28.8 ;{ }^{19} \mathrm{~F}$ NMR $(376 \mathrm{MHz}$, $\mathrm{CDCl}_{3}$ ): $\delta$-115.4; IR (ATR): $\tilde{\mathrm{v}}=3029,2971,2940,2856,1740,1590,1490,1454,1366,1218$, 1156, 1092, 866, 912, 828, $736 \mathrm{~cm}^{-1}$; HRMS (ESI) Calcd for $\mathrm{C}_{19} \mathrm{H}_{21} \mathrm{FNaOS}^{+}[\mathrm{M}+\mathrm{Na}]^{+}$ 339.1189 , found 339.1194 . 
<smiles>NCC=CCSc1ccc(F)cc1</smiles>

Pale yellow oil (EtOAc:Hex = 1:0); ${ }^{1} \mathrm{H}$ NMR (400 MHz, $\left.\mathrm{CDCl}_{3}\right): \delta 7.34(\mathrm{dd}, J=8.9,5.2 \mathrm{~Hz}$, 2H), $7.00(\mathrm{t}, J=8.7 \mathrm{~Hz}, 2 \mathrm{H}), 5.68-5.57(\mathrm{~m}, 1 \mathrm{H}), 5.49-5.37(\mathrm{~m}, 1 \mathrm{H}), 5.28(\mathrm{~s}, \mathrm{br}, 1 \mathrm{H}), 3.77(\mathrm{t}, J$ $=5.8 \mathrm{~Hz}, 2 \mathrm{H}), 3.45(\mathrm{dd}, J=7.1,1.0 \mathrm{~Hz}, 2 \mathrm{H}), 1.96(\mathrm{~s}, 3 \mathrm{H}) ;{ }^{13} \mathrm{C} \mathrm{NMR}\left(100 \mathrm{MHz}, \mathrm{CDCl}_{3}\right): \delta$ $169.9,162.0(\mathrm{~d}, J=245.5 \mathrm{~Hz}), 133.6(\mathrm{~d}, J=8.0 \mathrm{~Hz}), 130.3$ (d, $J=3.5 \mathrm{~Hz}), 129.5,127.7,115.9$ $(\mathrm{d}, J=21.6 \mathrm{~Hz}), 40.8,37.3,23.1 ;{ }^{19} \mathrm{~F}$ NMR $\left(376 \mathrm{MHz}, \mathrm{CDCl}_{3}\right): \delta-114.7$; IR (ATR): $\tilde{\mathrm{v}}=3283$, 3082, 3021, 2971, 2941, 1740, 1649, 1547, 1490, 1426, 1366, 1217, 1156, 1092, 966, 914, 826, $742 \mathrm{~cm}^{-1}$; HRMS (ESI) Calcd for $\mathrm{C}_{12} \mathrm{H}_{14} \mathrm{FNNaOS}^{+}[\mathrm{M}+\mathrm{Na}]^{+}$262.0672, found 262.0678.<smiles>Fc1ccc(SC/C=C/C[NH+]c2ccccc2)cc1</smiles>

Pale yellow solid (EtOAc:Hex $=1: 4), \mathrm{mp}=74 \sim 76{ }^{\circ} \mathrm{C} ;{ }^{1} \mathrm{H}$ NMR $\left(400 \mathrm{MHz}, \mathrm{CDCl}_{3}\right): \delta 7.85-$ $7.83(\mathrm{~m}, 2 \mathrm{H}), 7.74-7.71(\mathrm{~m}, 2 \mathrm{H}), 7.30-7.26(\mathrm{dd}, J=8.9,5.3 \mathrm{~Hz}, 2 \mathrm{H}), 6.83(\mathrm{t}, J=8.7 \mathrm{~Hz}, 2 \mathrm{H})$, 5.77-5.69 (m, 1H), 5.44-5.37 (m, 1H), $4.17(\mathrm{~d}, J=6.2 \mathrm{~Hz}, 2 \mathrm{H}), 3.38(\mathrm{~d}, J=7.2 \mathrm{~Hz}, 2 \mathrm{H}) ;{ }^{13} \mathrm{C}$ NMR (100 MHz, $\left.\mathrm{CDCl}_{3}\right): \delta 167.7,162.1$ (d, $\left.J=245.9 \mathrm{~Hz}\right), 134.5$ (d, $\left.J=8.1 \mathrm{~Hz}\right), 134.0,132.0$, 129.7, $129.6(\mathrm{~d}, J=3.1 \mathrm{~Hz}), 126.7,123.3,115.7(\mathrm{~d}, J=21.8 \mathrm{~Hz}), 38.8,37.5 ;{ }^{19} \mathrm{~F}$ NMR $(376$ $\mathrm{MHz}, \mathrm{CDCl}_{3}$ ): $\delta$-114.5; IR (ATR): $\tilde{\mathrm{v}}=3091,3056,3034,2933,1773,1709,1589,1490,1468$, 1427, 1391, 1352, 1219, 1111, 955, 932, 829, $721 \mathrm{~cm}^{-1}$; HRMS (ESI) Calcd for $\mathrm{C}_{18} \mathrm{H}_{14} \mathrm{FNNaO}_{2} \mathrm{~S}^{+}[\mathrm{M}+\mathrm{Na}]^{+}$350.0621, found 350.0627 .<smiles>Fc1ccc(SC/C=C/CCl)cc1</smiles>

Colorless oil (EtOAc:Hex = 1:20); ${ }^{1} \mathrm{H}$ NMR (400 MHz, $\left.\mathrm{CDCl}_{3}\right): \delta 7.35$ (dd, $J=8.9,5.2 \mathrm{~Hz}$, 2H), $7.00(\mathrm{t}, J=8.7 \mathrm{~Hz}, 2 \mathrm{H}), 5.85-5.74(\mathrm{~m}, 1 \mathrm{H}), 5.62-5.50(\mathrm{~m}, 1 \mathrm{H}), 3.97(\mathrm{dd}, J=7.0,1.0 \mathrm{~Hz}$, 2H), 3.45 (dd, $J=7.1,0.5 \mathrm{~Hz}, 2 \mathrm{H}) ;{ }^{13} \mathrm{C} \mathrm{NMR}\left(100 \mathrm{MHz}, \mathrm{CDCl}_{3}\right): \delta 162.2(\mathrm{~d}, J=245.7 \mathrm{~Hz})$, $133.9(\mathrm{~d}, J=8.1 \mathrm{~Hz}), 130.3,129.9(\mathrm{~d}, J=3.3 \mathrm{~Hz}), 129.0,116.0(\mathrm{~d}, J=21.8 \mathrm{~Hz}), 44.2,37.2$; 
${ }^{19} \mathrm{~F}$ NMR (376 MHz, $\mathrm{CDCl}_{3}$ ): $\delta$-114.6; IR (ATR): $\tilde{\mathrm{v}}=3021,2971,2946,1740,1590,1490$, 1441, 1366, 1218, 1156, 1091, 964, 913, 825, $742 \mathrm{~cm}^{-1}$; HRMS (ESI) Calcd for $\mathrm{C}_{10} \mathrm{H}_{10} \mathrm{ClFNaS}^{+}$ $[\mathrm{M}+\mathrm{Na}]^{+}$239.0068, found 239.0070.

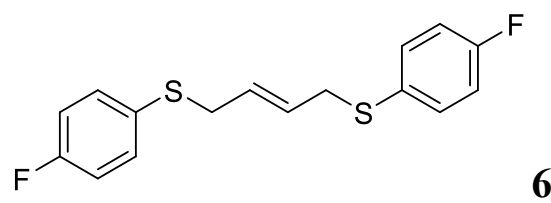

White solid (EtOAc:Hex $=1: 10), \mathrm{mp}=77 \sim 79{ }^{\circ} \mathrm{C} ;{ }^{1} \mathrm{H} \mathrm{NMR}\left(400 \mathrm{MHz}, \mathrm{CDCl}_{3}\right): \delta 7.26(\mathrm{dd}, J$ $=8.9,5.2 \mathrm{~Hz}, 4 \mathrm{H}), 6.95(\mathrm{t}, J=8.7 \mathrm{~Hz}, 4 \mathrm{H}), 5.52-5.44(\mathrm{~m}, 2 \mathrm{H}), 3.44-3.33(\mathrm{~m}, 4 \mathrm{H}) ;{ }^{13} \mathrm{C} \mathrm{NMR}$ $\left(100 \mathrm{MHz}, \mathrm{CDCl}_{3}\right): \delta 162.0(\mathrm{~d}, J=245.3 \mathrm{~Hz}), 133.1(\mathrm{~d}, J=8.0 \mathrm{~Hz}), 130.4(\mathrm{~d}, J=3.3 \mathrm{~Hz})$, 128.7, 115.9 (d, $J=21.7 \mathrm{~Hz}), 37.2 ;{ }^{19} \mathrm{~F}$ NMR (376 MHz, $\left.\mathrm{CDCl}_{3}\right): \delta-115.1$; IR (ATR): $\tilde{\mathrm{v}}=3091$, 3030, 2971, 2942, 2863, 1740, 1597, 1496, 1437, 1366, 1218, 1092, 962, 914, 821, $743 \mathrm{~cm}^{-1}$; HRMS (ESI) Calcd for $\mathrm{C}_{16} \mathrm{H}_{14} \mathrm{~F}_{2} \mathrm{NaS}_{2}{ }^{+}[\mathrm{M}+\mathrm{Na}]^{+}$331.0397, found 331.0399.

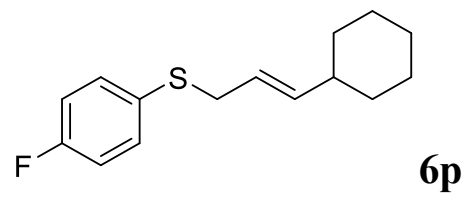

Colorless oil (EtOAc:Hex = 1:10); ${ }^{1} \mathrm{H}$ NMR (400 MHz, $\left.\mathrm{CDCl}_{3}\right): \delta 7.32$ (dd, $J=8.9,5.2 \mathrm{~Hz}$, 2H), 6.97 (t, $J=8.8 \mathrm{~Hz}, 2 \mathrm{H}), 5.44-5.28(\mathrm{~m}, 2 \mathrm{H}), 3.41$ (d, $J=6.4 \mathrm{~Hz}, 2 \mathrm{H}), 1.94-1.81(\mathrm{~m}, 1 \mathrm{H})$, 1.72-1.54 (m, 4H), 1.35-1.12 (m, 4H), 1.12-0.84 (m, 2H); ${ }^{13} \mathrm{C}$ NMR (100 MHz, $\left.\mathrm{CDCl}_{3}\right): \delta$ $162.0(\mathrm{~d}, J=244.7 \mathrm{~Hz}), 140.5,133.6$ (d, $J=8.0 \mathrm{~Hz}), 130.7$ (d, $J=3.3 \mathrm{~Hz}), 122.4,115.7$ (d, $J$ $=21.7 \mathrm{~Hz}), 40.4,38.2,32.8,26.1,25.9 ;{ }^{19} \mathrm{~F} \mathrm{NMR}\left(376 \mathrm{MHz}, \mathrm{CDCl}_{3}\right): \delta-115.5$; IR (ATR): $\tilde{\mathrm{v}}=$ 3021, 2971, 2924, 2852, 1740, 1590, 1490, 1449, 1366, 1218, 1155, 1092, 965, 914, 827, 743 $\mathrm{cm}^{-1}$; HRMS (ESI) Calcd for $\mathrm{C}_{15} \mathrm{H}_{19} \mathrm{FNaS}^{+}[\mathrm{M}+\mathrm{Na}]^{+}$273.1084, found 273.1086.<smiles>CC(C)C/C=C/CSc1ccc(F)cc1</smiles> 
Colorless oil (EtOAc:Hex $=1: 10) ;{ }^{1} \mathrm{H}$ NMR $\left(400 \mathrm{MHz}, \mathrm{CDCl}_{3}\right): \delta 7.33(\mathrm{dd}, J=8.9,5.2 \mathrm{~Hz}$, 2H), 6.97 (t, $J=8.8 \mathrm{~Hz}, 2 \mathrm{H}), 5.44-5.37(\mathrm{~m}, 2 \mathrm{H}), 3.48-3.42(\mathrm{~m}, 2 \mathrm{H}), 1.90-1.80(\mathrm{~m}, 2 \mathrm{H}), 1.51$ (septet, $J=6.7 \mathrm{~Hz}, 1 \mathrm{H}), 0.79(\mathrm{~d}, J=6.6 \mathrm{~Hz}, 6 \mathrm{H}) ;{ }^{13} \mathrm{C} \mathrm{NMR}\left(100 \mathrm{MHz}, \mathrm{CDCl}_{3}\right): \delta 161.9(\mathrm{~d}, J$ $=245.0 \mathrm{~Hz}), 133.3,133.2(\mathrm{~d}, J=8.0 \mathrm{~Hz}), 130.8(\mathrm{~d}, J=3.2 \mathrm{~Hz}), 126.0,115.8(\mathrm{~d}, J=21.6 \mathrm{~Hz})$, 41.6, 37.9, 28.3, 22.1; $\left.{ }^{19} \mathrm{~F} \mathrm{NMR} \mathrm{(376} \mathrm{MHz,} \mathrm{CDCl}_{3}\right): \delta$-115.6; IR (ATR): $\tilde{\mathrm{v}}=3030,2957,2870$, 2841, 1740, 1590, 1490, 1366, 1218, 1156, 1092, 967, 912, 827, $738 \mathrm{~cm}^{-1}$; HRMS (ESI) Calcd for $\mathrm{C}_{13} \mathrm{H}_{17} \mathrm{FNaS}^{+}[\mathrm{M}+\mathrm{Na}]^{+}$247.0927, found 247.0929.

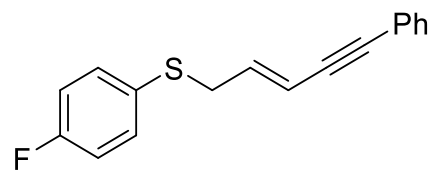

\section{6r $(E / Z=20: 1)$}

Pale yellow oil (EtOAc:Hex = 1:10); ${ }^{1} \mathrm{H}$ NMR (400 MHz, $\left.\mathrm{CDCl}_{3}\right): \delta 7.50-7.27(\mathrm{~m}, 7 \mathrm{H}), 7.01$ $(\mathrm{t}, J=8.6 \mathrm{~Hz}, 2 \mathrm{H}), 6.20(\mathrm{dt}, J=15.6,7.4 \mathrm{~Hz}, 1 \mathrm{H}), 5.63$ (d, $J=15.6 \mathrm{~Hz}, 1 \mathrm{H}), 3.54$ (dd, $J=7.3$, $1.2 \mathrm{~Hz}, 2 \mathrm{H}) ;{ }^{13} \mathrm{C} \mathrm{NMR}\left(100 \mathrm{MHz}, \mathrm{CDCl}_{3}\right): \delta 162.3(\mathrm{~d}, J=245.7 \mathrm{~Hz}), 138.3,133.9(\mathrm{~d}, J=8.0$ $\mathrm{Hz}), 131.5,129.9$ (d, $J=3.2 \mathrm{~Hz}), 128.3,128.3,123.1,116.1$ (d, $J=21.8 \mathrm{~Hz}), 112.5,90.0,87.2$, 38.3; ${ }^{19} \mathrm{~F}$ NMR (376 MHz, $\mathrm{CDCl}_{3}$ ): $\delta$-114.4; IR (ATR): $\tilde{\mathrm{v}}=3087,3025,2971,1740,1589$, 1489, 1442, 1366, 1218, 1092, 949, 914, 829, $755 \mathrm{~cm}^{-1}$; HRMS (ESI) Calcd for $\mathrm{C}_{17} \mathrm{H}_{13} \mathrm{FNaS}^{+}$ $[\mathrm{M}+\mathrm{Na}]^{+}$291.0614, found 291.0618.

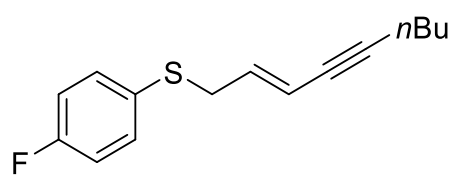

\section{$(E)-6 \mathbf{s}$}

Pale yellow oil (EtOAc:Hex = 1:10); ${ }^{1} \mathrm{H}$ NMR (400 MHz, $\left.\mathrm{CDCl}_{3}\right): \delta 7.34$ (dd, $J=8.8,5.2 \mathrm{~Hz}$, 2H), 6.99 (t, $J=8.7 \mathrm{~Hz}, 2 \mathrm{H}), 6.00(\mathrm{dt}, J=15.6,7.4 \mathrm{~Hz}, 1 \mathrm{H}), 5.40(\mathrm{~d}, J=15.6 \mathrm{~Hz}, 1 \mathrm{H}), 3.47$ $(\mathrm{dd}, J=7.3,1.2 \mathrm{~Hz}, 2 \mathrm{H}), 2.27$ (td, $J=6.8,1.9 \mathrm{~Hz}, 2 \mathrm{H}), 1.58-1.32(\mathrm{~m}, 4 \mathrm{H}), 0.90$ (t, $J=7.3 \mathrm{~Hz}$, $3 \mathrm{H}) ;{ }^{13} \mathrm{C}$ NMR $\left(100 \mathrm{MHz}, \mathrm{CDCl}_{3}\right): \delta 162.2(\mathrm{~d}, J=245.8 \mathrm{~Hz}), 136.6,133.6(\mathrm{~d}, J=8.0 \mathrm{~Hz})$, $130.1(\mathrm{~d}, J=3.2 \mathrm{~Hz}), 116.0(\mathrm{~d}, J=21.7 \mathrm{~Hz}), 113.1,91.2,78.3,38.0,30.8,22.0,19.1,13.6 ;{ }^{19} \mathrm{~F}$ NMR (376 MHz, $\left.\mathrm{CDCl}_{3}\right): \delta$-114.8; IR (ATR): $\tilde{\mathrm{v}}=2959,2934,2874,1737,1590,1491,1366$, 
1229, 1156, 1089, 1013, 953, 913, 831, $735 \mathrm{~cm}^{-1}$; HRMS (ESI) Calcd for $\mathrm{C}_{15} \mathrm{H}_{17} \mathrm{FNaS}^{+}$ $[\mathrm{M}+\mathrm{Na}]^{+}$271.0927, found 271.0931.

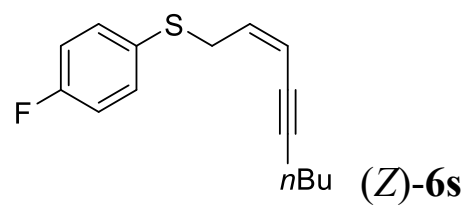

Pale yellow oil (EtOAc:Hex = 1:10); ${ }^{1} \mathrm{H}$ NMR (400 MHz, $\left.\mathrm{CDCl}_{3}\right): \delta 7.40(\mathrm{dd}, J=8.9,5.2 \mathrm{~Hz}$, 2H), 7.00 (t, $J=8.6 \mathrm{~Hz}, 2 \mathrm{H}), 5.85(\mathrm{dt}, J=10.4,7.6 \mathrm{~Hz}, 1 \mathrm{H}), 5.53(\mathrm{~d}, J=10.5 \mathrm{~Hz}, 1 \mathrm{H}), 3.74$ $(\mathrm{dd}, J=7.6,0.8 \mathrm{~Hz}, 2 \mathrm{H}), 2.33(\mathrm{td}, J=6.9,2.2 \mathrm{~Hz}, 2 \mathrm{H}), 1.61-1.38(\mathrm{~m}, 4 \mathrm{H}), 0.95$ (t, $J=7.3 \mathrm{~Hz}$, $3 \mathrm{H}) ;{ }^{13} \mathrm{C} \mathrm{NMR}\left(100 \mathrm{MHz}, \mathrm{CDCl}_{3}\right): \delta 162.0(\mathrm{~d}, J=245.0 \mathrm{~Hz}), 136.3,133.0(\mathrm{~d}, J=8.0 \mathrm{~Hz})$, $130.3(\mathrm{~d}, J=3.3 \mathrm{~Hz}), 115.8(\mathrm{~d}, J=21.6 \mathrm{~Hz}), 112.3,96.5,76.3,34.3,30.8,22.0,19.2,13.6 ;{ }^{19} \mathrm{~F}$ NMR (376 MHz, $\mathrm{CDCl}_{3}$ ): $\delta$-115.3; IR (ATR): $\tilde{\mathrm{v}}=3010,2960,2938,2801,1737,1595,1499$, 1391, 1233, 1172, 1096, 1015, 956, 918, 830, $738 \mathrm{~cm}^{-1}$; HRMS (ESI) Calcd for $\mathrm{C}_{15} \mathrm{H}_{17} \mathrm{FNaS}^{+}$ $[\mathrm{M}+\mathrm{Na}]^{+}$271.0927, found 271.0931.

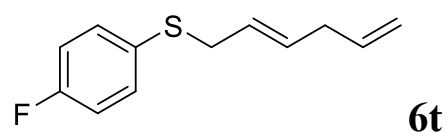

Colorless oil (EtOAc:Hex = 1:10); ${ }^{1} \mathrm{H}$ NMR (400 MHz, $\left.\mathrm{CDCl}_{3}\right): \delta 7.32$ (dd, $J=8.9,5.2 \mathrm{~Hz}$, 2H), 6.97 (t, $J=8.8 \mathrm{~Hz}, 2 \mathrm{H}), 5.72(\mathrm{ddt}, J=16.6,10.2,6.4 \mathrm{~Hz}, 1 \mathrm{H}), 5.58-5.37$ (m, 2H), 4.96 $(\mathrm{dq}, J=10.1,1.4 \mathrm{~Hz}, 1 \mathrm{H}), 4.92(\mathrm{dq}, J=17.0,1.7 \mathrm{~Hz}, 1 \mathrm{H}), 3.44$ (d, $J=6.2 \mathrm{~Hz}, 2 \mathrm{H}), 2.71$ (t, $J$ $=6.1 \mathrm{~Hz}, 2 \mathrm{H}) ;{ }^{13} \mathrm{C} \mathrm{NMR}\left(100 \mathrm{MHz}, \mathrm{CDCl}_{3}\right): \delta 162.0(\mathrm{~d}, J=245.2 \mathrm{~Hz}), 136.3,133.4(\mathrm{~d}, J=$ $8.0 \mathrm{~Hz}), 131.7,130.7$ (d, $J=3.3 \mathrm{~Hz}), 126.3,115.8$ (d, $J=21.6 \mathrm{~Hz}), 115.4,37.8,36.3 ;{ }^{19} \mathrm{~F}$ NMR (376 MHz, $\mathrm{CDCl}_{3}$ ): $\delta$-115.4; IR (ATR): $\tilde{\mathrm{v}}=3082,3017,2971,2902,2828,1740,1639,1590$, 1490, 1426, 1366, 1218, 1156, 1092, 967, 914, 827, $742 \mathrm{~cm}^{-1}$; HRMS (ESI) Calcd for $\mathrm{C}_{12} \mathrm{H}_{13} \mathrm{FNaS}^{+}[\mathrm{M}+\mathrm{Na}]^{+}$231.0614, found 231.0616.<smiles>CCCC/C(C)=C/CSc1ccc(F)cc1</smiles> 
Pale yellow oil (EtOAc:Hex =1:10); ${ }^{1} \mathrm{H}$ NMR (400 MHz, $\left.\mathrm{CDCl}_{3}\right): \delta 7.37$ (dd, $J=8.9,5.3 \mathrm{~Hz}$, 2H), 6.99 (t, $J=8.7 \mathrm{~Hz}, 2 \mathrm{H}), 5.28$ (tq, $J=7.8,1.3 \mathrm{~Hz}, 1 \mathrm{H}), 3.50$ (dd, $J=7.8,0.3 \mathrm{~Hz}, 2 \mathrm{H}), 1.99$ $(\mathrm{t}, J=7.2 \mathrm{~Hz}, 2 \mathrm{H}), 1.50(\mathrm{~d}, J=0.5 \mathrm{~Hz}, 3 \mathrm{H}), 1.41-1.18(\mathrm{~m}, 4 \mathrm{H}), 0.90(\mathrm{t}, J=7.3 \mathrm{~Hz}, 3 \mathrm{H}) ;{ }^{13} \mathrm{C}$ NMR (100 MHz, $\left.\mathrm{CDCl}_{3}\right): \delta 162.0(\mathrm{~d}, J=244.8 \mathrm{~Hz}), 140.3,133.4(\mathrm{~d}, J=8.0 \mathrm{~Hz}), 131.2(\mathrm{~d}, J$ $=3.3 \mathrm{~Hz}), 119.1,115.7(\mathrm{~d}, J=21.7 \mathrm{~Hz}), 39.2,33.6,29.9,22.3,15.8,14.0 ;{ }^{19} \mathrm{~F}$ NMR $(376 \mathrm{MHz}$, $\mathrm{CDCl}_{3}$ ): $\delta$-115.6; IR (ATR): $\tilde{\mathrm{v}}=2958,2931,2867,1739,1590,1490,1454,1366,1228,1556$, 1092, 913, 829, $738 \mathrm{~cm}^{-1}$; HRMS (ESI) Calcd for $\mathrm{C}_{14} \mathrm{H}_{19} \mathrm{FNaS}^{+}[\mathrm{M}+\mathrm{Na}]^{+}$261.1084, found 261.1086 .<smiles>CC(=CCSc1ccc(F)cc1)CCc1ccccc1</smiles>

Colorless oil (EtOAc:Hex $=1: 10)$; ${ }^{1} \mathrm{H}$ NMR $\left(400 \mathrm{MHz}, \mathrm{CDCl}_{3}\right): \delta 7.32(\mathrm{dd}, J=8.9,5.3 \mathrm{~Hz}$, 2H), 7.30-7.23 (m, 2H), 7.22-7.12 (m, 3H), 6.96 (t, $J=8.8 \mathrm{~Hz}, 2 \mathrm{H}), 5.29$ (tq, $J=7.8,1.2 \mathrm{~Hz}$, $1 \mathrm{H}), 3.46(\mathrm{~d}, J=7.8 \mathrm{~Hz}, 2 \mathrm{H}), 2.69-2.57(\mathrm{~m}, 2 \mathrm{H}), 2.32-2.20(\mathrm{~m}, 2 \mathrm{H}), 1.54(\mathrm{~d}, J=0.9 \mathrm{~Hz}, 3 \mathrm{H})$; ${ }^{13} \mathrm{C}$ NMR $\left(100 \mathrm{MHz}, \mathrm{CDCl}_{3}\right): \delta 162.0(\mathrm{~d}, J=245.2 \mathrm{~Hz}), 142.0,139.4,133.5(\mathrm{~d}, J=8.0 \mathrm{~Hz})$, $131.2(\mathrm{~d}, J=3.1 \mathrm{~Hz}), 128.4,126.0,125.9,119.9,115.8(\mathrm{~d}, J=21.8 \mathrm{~Hz}), 41.4,34.5,33.5,16.1$; ${ }^{19} \mathrm{~F}$ NMR (376 MHz, $\mathrm{CDCl}_{3}$ ): $\delta$-115.4; IR (ATR): $\tilde{\mathrm{v}}=3065,3030,2973,2933,2859,1737$, 1589, 1489, 1453, 1366, 1218, 1155, 1092, 914, 828, 744, $698 \mathrm{~cm}^{-1}$; HRMS (ESI) Calcd for $\mathrm{C}_{18} \mathrm{H}_{19} \mathrm{FNaS}^{+}[\mathrm{M}+\mathrm{Na}]^{+}$309.1084, found 309.1087.

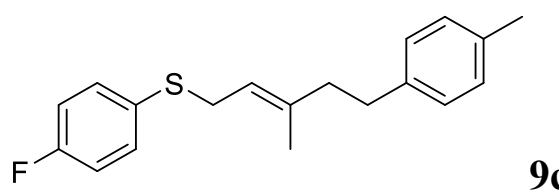

White solid (EtOAc:Hex $=1: 20), \mathrm{mp}=41 \sim 43{ }^{\circ} \mathrm{C} ;{ }^{1} \mathrm{H}$ NMR $\left(400 \mathrm{MHz}, \mathrm{CDCl}_{3}\right): \delta 7.31(\mathrm{dd}, J$ $=8.9,5.3 \mathrm{~Hz}, 2 \mathrm{H}), 7.08(\mathrm{~d}, J=8.0 \mathrm{~Hz}, 2 \mathrm{H}), 7.04(\mathrm{~d}, J=8.0 \mathrm{~Hz}, 2 \mathrm{H}), 6.95(\mathrm{t}, J=8.8 \mathrm{~Hz}, 2 \mathrm{H})$, $5.28(\mathrm{tq}, J=7.8,1.2 \mathrm{~Hz}, 1 \mathrm{H}), 3.46(\mathrm{~d}, J=7.8 \mathrm{~Hz}, 2 \mathrm{H}), 2.66-2.58(\mathrm{~m}, 2 \mathrm{H}), 2.31(\mathrm{~s}, 3 \mathrm{H}), 2.29-$ $2.21(\mathrm{~m}, 2 \mathrm{H}), 1.52(\mathrm{~d}, J=1.2 \mathrm{~Hz}, 3 \mathrm{H}) ;{ }^{13} \mathrm{C} \mathrm{NMR}\left(100 \mathrm{MHz}, \mathrm{CDCl}_{3}\right): \delta 162.0(\mathrm{~d}, J=245.2 \mathrm{~Hz})$, 139.5, 138.9, 135.3, 133.4 (d, $J=7.9 \mathrm{~Hz}), 131.2(\mathrm{~d}, J=3.1 \mathrm{~Hz}) 129.0,128.2,119.8,115.7$ (d, $J=21.8 \mathrm{~Hz}), 41.5,34.0,33.5,21.0,16.1 ;{ }^{19} \mathrm{~F} \mathrm{NMR}\left(376 \mathrm{MHz}, \mathrm{CDCl}_{3}\right): \delta-115.4$; IR (ATR): $\tilde{\mathrm{v}}$ 
$=3052,2977,2924,2863,1589,1515,1489,1450,1219,1155,1091,1053,816 \mathrm{~cm}^{-1}$; HRMS (ESI) Calcd for $\mathrm{C}_{19} \mathrm{H}_{21} \mathrm{FNaS}^{+}[\mathrm{M}+\mathrm{Na}]^{+}$323.1240, found 323.1243.

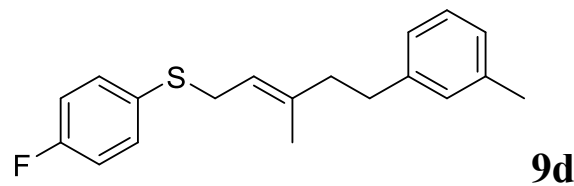

Colorless oil (EtOAc:Hex $=0: 1) ;{ }^{1} \mathrm{H}$ NMR $\left(400 \mathrm{MHz}, \mathrm{CDCl}_{3}\right): \delta 7.32(\mathrm{dd}, J=8.9,5.3 \mathrm{~Hz}, 2 \mathrm{H})$, $7.16(\mathrm{t}, J=7.5 \mathrm{~Hz}, 1 \mathrm{H}), 7.03-6.92(\mathrm{~m}, 3 \mathrm{H}), 6.95(\mathrm{t}, J=8.7 \mathrm{~Hz}, 2 \mathrm{H}), 5.29(\mathrm{tq}, J=7.8,1.2 \mathrm{~Hz}$, $1 \mathrm{H}), 3.46(\mathrm{~d}, J=7.4 \mathrm{~Hz}, 2 \mathrm{H}), 2.66-2.58(\mathrm{~m}, 2 \mathrm{H}), 2.32(\mathrm{~s}, 3 \mathrm{H}), 2.30-2.22(\mathrm{~m}, 2 \mathrm{H}), 1.54(\mathrm{~s}, 3 \mathrm{H})$; ${ }^{13} \mathrm{C}$ NMR $\left(100 \mathrm{MHz}, \mathrm{CDCl}_{3}\right): \delta 162.0(\mathrm{~d}, J=244.7 \mathrm{~Hz}), 141.9,139.5,137.9,133.5(\mathrm{~d}, J=7.9$ Hz), 133.1 (d, $J=3.1 \mathrm{~Hz}), 129.2,128.2,126.6,125.3,119.8,115.7$ (d, $J=21.8 \mathrm{~Hz}), 41.4,34.4$, 33.6, 21.4, 16.1; ${ }^{19} \mathrm{~F} \mathrm{NMR} \mathrm{(376} \mathrm{MHz,} \mathrm{CDCl}_{3}$ ): $\delta$-115.4; IR (ATR): $\tilde{\mathrm{v}}=3030,2973,2920,2854$, 1740, 1589, 1489, 1450, 1381, 1218, 1155, 1092, 1014, 829, 776, 743, $698 \mathrm{~cm}^{-1}$; HRMS (ESI) Calcd for $\mathrm{C}_{19} \mathrm{H}_{21} \mathrm{FNaS}^{+}[\mathrm{M}+\mathrm{Na}]^{+}$323.1240, found 323.1243.<smiles>CC(=CCSc1ccc(F)cc1)CCc1ccccc1C</smiles>

Pale yellow oil (EtOAc:Hex $=0: 1) ;{ }^{1} \mathrm{H}$ NMR $\left(400 \mathrm{MHz}, \mathrm{CDCl}_{3}\right): \delta 7.34(\mathrm{dd}, J=8.9,5.3 \mathrm{~Hz}$, 2H), 7.16-7.05 (m, 4H), 6.97 (t, $J=8.7 \mathrm{~Hz}, 2 \mathrm{H}), 5.31$ (tq, $J=7.8,1.2 \mathrm{~Hz}, 1 \mathrm{H}), 3.48$ (d, $J=7.8$ $\mathrm{Hz}, 2 \mathrm{H}), 2.67-2.59$ (m, 2H), 2.29 (s, 3H), 2.25-2.17 (m, 2H), 1.56 (s, 3H); ${ }^{13} \mathrm{C}$ NMR (100 MHz, $\left.\mathrm{CDCl}_{3}\right): \delta 162.1(\mathrm{~d}, J=245.0 \mathrm{~Hz}), 140.2,139.7,135.8,133.7(\mathrm{~d}, J=8.0 \mathrm{~Hz}), 131.1(\mathrm{~d}, J=3.0$ $\mathrm{Hz}), 130.2,128.7,126.1,119.8,115.8$ (d, $J=21.7 \mathrm{~Hz}), 40.2,33.6,32.1,19.3,16.1 ;{ }^{19} \mathrm{~F}$ NMR (376 MHz, $\mathrm{CDCl}_{3}$ ): $\delta$-115.3; IR (ATR): $\tilde{\mathrm{v}}=3069,3021,2968,2942,2863,1737,1589,1489$, 1461, 1366, 1218, 1155, 1092, 914, 829, $750 \mathrm{~cm}^{-1}$; HRMS (ESI) Calcd for $\mathrm{C}_{19} \mathrm{H}_{21} \mathrm{FNaS}^{+}$ $[\mathrm{M}+\mathrm{Na}]^{+}$323.1240, found 323.1243 .<smiles>C/C(=C\CSc1ccc(F)cc1)Cc1ccccc1</smiles> 
Colorless oil (EtOAc:Hex = 1:100); ${ }^{1} \mathrm{H}$ NMR (400 MHz, $\left.\mathrm{CDCl}_{3}\right): \delta 7.32$ (dd, $J=8.9,5.3 \mathrm{~Hz}$, 2H), 7.25 (t, $J=6.9 \mathrm{~Hz}, 2 \mathrm{H}), 7.18(\mathrm{t}, J=7.2 \mathrm{~Hz}, 1 \mathrm{H}), 7.05$ (d, $J=6.8 \mathrm{~Hz}, 2 \mathrm{H}), 6.91$ (t, $J=8.8$ $\mathrm{Hz}, 2 \mathrm{H}), 5.36$ (tq, $J=7.8,1.2 \mathrm{~Hz}, 1 \mathrm{H}), 3.48(\mathrm{~d}, J=7.8 \mathrm{~Hz}, 2 \mathrm{H}), 3.25(\mathrm{~s}, 2 \mathrm{H}), 1.40(\mathrm{~s}, 3 \mathrm{H}) ;{ }^{13} \mathrm{C}$ NMR (100 MHz, $\left.\mathrm{CDCl}_{3}\right): \delta 162.1(\mathrm{~d}, J=245.1 \mathrm{~Hz}), 139.5,139.0,133.9(\mathrm{~d}, J=8.0 \mathrm{~Hz}), 130.8$ $(\mathrm{d}, J=3.4 \mathrm{~Hz}), 128.9,128.3,126.2,121.6,115.8$ (d, $J=21.5 \mathrm{~Hz}), 46.1,33.6,15.8 ;{ }^{19} \mathrm{~F}$ NMR (376 MHz, $\mathrm{CDCl}_{3}$ ): $\delta$-115.2; IR (ATR): $\tilde{\mathrm{v}}=3026,2978,2811,2854,1588,1488,1452,1395$, 1383, 1221, 1155, 1088, 1013, 828, 734, $698 \mathrm{~cm}^{-1}$; HRMS (ESI) Calcd for $\mathrm{C}_{17} \mathrm{H}_{17} \mathrm{FNaS}^{+}$ $[\mathrm{M}+\mathrm{Na}]^{+}$295.0927, found 295.0930.

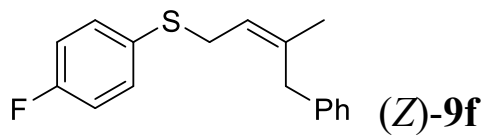

Colorless oil (EtOAc:Hex =1:100); ${ }^{1} \mathrm{H}$ NMR (400 MHz, $\left.\mathrm{CDCl}_{3}\right): \delta 7.43$ (dd, $J=8.9,5.3 \mathrm{~Hz}$, 2H), 7.31 (t, $J=7.0 \mathrm{~Hz}, 2 \mathrm{H}), 7.23(\mathrm{t}, J=7.2 \mathrm{~Hz}, 1 \mathrm{H}), 7.12$ (d, $J=6.9 \mathrm{~Hz}, 2 \mathrm{H}), 7.04$ (t, $J=8.7$ $\mathrm{Hz}, 2 \mathrm{H}), 5.51(\mathrm{td}, J=7.8,1.2 \mathrm{~Hz}, 1 \mathrm{H}), 3.66(\mathrm{dd}, J=7.8,0.6 \mathrm{~Hz}, 2 \mathrm{H}), 3.31(\mathrm{~s}, 2 \mathrm{H}), 1.68(\mathrm{~s}$, $3 \mathrm{H}) ;{ }^{13} \mathrm{C} \mathrm{NMR}\left(100 \mathrm{MHz}, \mathrm{CDCl}_{3}\right): \delta 162.1(\mathrm{~d}, J=245.3 \mathrm{~Hz}), 139.2,138.5,133.4(\mathrm{~d}, J=8.1$ Hz), 131.1 (d, $J=3.1 \mathrm{~Hz}), 128.6,128.4,126.2,121.3,115.9$ (d, $J=21.6 \mathrm{~Hz}), 37.6,33.7,23.3$; ${ }^{19} \mathrm{~F}$ NMR (376 MHz, $\mathrm{CDCl}_{3}$ ): $\delta$-115.2; IR (ATR): $\tilde{\mathrm{v}}=3028,2971,2916,2850,1737,1589$, 1490, 1453, 1377, 1222, 1156, 1090, 1049, 1030, 1013, 831, 732, $699 \mathrm{~cm}^{-1}$; HRMS (ESI) Calcd for $\mathrm{C}_{17} \mathrm{H}_{17} \mathrm{FNaS}^{+}[\mathrm{M}+\mathrm{Na}]^{+} 295.0927$, found 295.0930.<smiles>C/C(=C\CSc1ccc(C(F)(F)F)cc1)CNc1ccccc1</smiles>

Pale yellow solid (EtOAc:Hex $=1: 20), \mathrm{mp}=63 \sim 65{ }^{\circ} \mathrm{C} ;{ }^{1} \mathrm{H} \mathrm{NMR}\left(400 \mathrm{MHz}, \mathrm{CDCl}_{3}\right): \delta 7.87-$ $7.81(\mathrm{~m}, 2 \mathrm{H}), 7.75-7.69(\mathrm{~m}, 2 \mathrm{H}), 7.45$ (d, $J=8.2 \mathrm{~Hz}, 2 \mathrm{H}), 7.35$ (d, $J=8.2 \mathrm{~Hz}, 2 \mathrm{H}), 5.50$ (tq, $J$ $=7.7,1.2 \mathrm{~Hz}, 1 \mathrm{H}), 4.20(\mathrm{~s}, 2 \mathrm{H}), 3.56(\mathrm{~d}, J=7.6 \mathrm{~Hz}, 2 \mathrm{H}), 1.62(\mathrm{~s}, 3 \mathrm{H}) ;{ }^{13} \mathrm{C} \mathrm{NMR}(100 \mathrm{MHz}$, $\mathrm{CDCl}_{3}$ ): $\delta 168.0,141.4,134.3,134.1,131.9,129.3,128.0$ (q, $\left.J=32.2 \mathrm{~Hz}\right), 125.5$ (q, $J=3.6$ $\mathrm{Hz}), 124.1$ (q, $J=269.6 \mathrm{~Hz}), 123.4,121.7,44.4,31.0,14.7 ;{ }^{19} \mathrm{~F} \mathrm{NMR}\left(376 \mathrm{MHz}, \mathrm{CDCl}_{3}\right): \delta$ 62.5; IR (ATR): $\tilde{\mathrm{v}}=3017,2973,2924,1773,1711,1606,1468,1425,1392,1324,1163,1119$, $1095,1062,1012,938,823,722,712 \mathrm{~cm}^{-1}$; HRMS (ESI) Calcd for $\mathrm{C}_{12} \mathrm{H}_{12} \mathrm{~F}_{3} \mathrm{NaS}^{+}[\mathrm{M}+\mathrm{Na}]^{+}$ 
<smiles>C/C(=C\CSc1ccc(F)cc1)CO</smiles>

White solid (EtOAc:Hex $=1: 5), \mathrm{mp}=34 \sim 36{ }^{\circ} \mathrm{C} ;{ }^{1} \mathrm{H}$ NMR $\left(400 \mathrm{MHz}, \mathrm{CDCl}_{3}\right): \delta 7.36(\mathrm{dd}, J=$ 8.8, $5.3 \mathrm{~Hz}, 2 \mathrm{H}), 6.98$ (t, $J=8.7 \mathrm{~Hz}, 2 \mathrm{H}), 5.55$ (tq, $J=7.8,1.3 \mathrm{~Hz}, 1 \mathrm{H}), 3.99$ (d, $J=6.0 \mathrm{~Hz}$, $2 \mathrm{H}), 3.51(\mathrm{~d}, J=7.8 \mathrm{~Hz}, 2 \mathrm{H}), 1.53(\mathrm{~s}, 3 \mathrm{H}), 1.28(\mathrm{t}, J=6.2 \mathrm{~Hz}, 1 \mathrm{H}) ;{ }^{13} \mathrm{C}$ NMR $(100 \mathrm{MHz}$, $\left.\mathrm{CDCl}_{3}\right): \delta 162.1(\mathrm{~d}, J=245.2 \mathrm{~Hz}), 138.9,133.4(\mathrm{~d}, J=8.0 \mathrm{~Hz}), 130.8(\mathrm{~d}, J=3.5 \mathrm{~Hz}), 120.2$, $115.8(\mathrm{~d}, J=21.6 \mathrm{~Hz}), 68.0,33.0,13.5 ;{ }^{19} \mathrm{~F} \mathrm{NMR}\left(376 \mathrm{MHz}, \mathrm{CDCl}_{3}\right): \delta-115.0$; IR (ATR): $\tilde{\mathrm{v}}=$ 3342, 2982, 2913, 2858, 1589, 1489, 1452, 1222, 1156, 1090, 1013, $829 \mathrm{~cm}^{-1}$; HRMS (ESI) Calcd for $\mathrm{C}_{11} \mathrm{H}_{13} \mathrm{FNaOS}^{+}[\mathrm{M}+\mathrm{Na}]^{+} 235.0563$, found 235.0569 .<smiles>C/C(=C\CCC(C)CS)CSc1ccc(F)cc1</smiles>

Colorless oil (EtOAc:Hex = 1:20); ${ }^{1} \mathrm{H}$ NMR $\left(400 \mathrm{MHz}, \mathrm{CDCl}_{3}\right): \delta 7.36(\mathrm{dd}, J=8.9,5.3 \mathrm{~Hz}$, 2H), $6.98(\mathrm{t}, J=8.8 \mathrm{~Hz}, 2 \mathrm{H}), 5.31(\mathrm{td}, J=7.8,1.3 \mathrm{~Hz}, 1 \mathrm{H}), 3.49(\mathrm{~d}, J=7.8 \mathrm{~Hz}, 2 \mathrm{H}), 2.01-1.92$ $(\mathrm{m}, 2 \mathrm{H}), 1.52(\mathrm{~s}, 3 \mathrm{H}), 0.62-0.53(\mathrm{~m}, 2 \mathrm{H}), 0.00(\mathrm{~s}, 9 \mathrm{H}) ;{ }^{13} \mathrm{C} \mathrm{NMR}\left(100 \mathrm{MHz}, \mathrm{CDCl}_{3}\right): \delta 163.6$ $(\mathrm{d}, J=244.8 \mathrm{~Hz}), 144.5,135.0(\mathrm{~d}, J=7.8 \mathrm{~Hz}), 133.1$ (d, $J=3.1 \mathrm{~Hz}) 119.4,117.4(\mathrm{~d}, J=21.4$ $\mathrm{Hz}), 35.4,35.3,17.5,16.6,0.0 ;{ }^{19} \mathrm{~F}$ NMR $\left(376 \mathrm{MHz}, \mathrm{CDCl}_{3}\right): \delta$-115.7; IR (ATR): $\tilde{\mathrm{v}}=2954$, 2907, 2845, 1590, 1490, 1444, 1248, 1227, 1155, 1092, 863, 830, 747, $691 \mathrm{~cm}^{-1}$; HRMS (ESI) Calcd for $\mathrm{C}_{15} \mathrm{H}_{23} \mathrm{FNaSSi}^{+}[\mathrm{M}+\mathrm{Na}]^{+}$305.1166, found 305.1170 .<smiles>CCOCCC/C(C)=C/CSc1ccc(F)cc1</smiles>

Colorless oil (EtOAc:Hex = 1:0); ${ }^{1} \mathrm{H}$ NMR (400 MHz, $\left.\mathrm{CDCl}_{3}\right): \delta 7.34(\mathrm{dd}, J=8.9,5.3 \mathrm{~Hz}, 2 \mathrm{H})$, $6.97(\mathrm{t}, J=8.7 \mathrm{~Hz}, 2 \mathrm{H}), 5.31(\mathrm{tq}, J=7.8,1.3 \mathrm{~Hz}, 1 \mathrm{H}), 4.17-4.01(\mathrm{~m}, 4 \mathrm{H}), 3.45$ (d, $J=7.8 \mathrm{~Hz}$, 2H), 2.30-2.19 (m, 2H), 1.82-1.70 (m, 2H), $1.49(\mathrm{~s}, 3 \mathrm{H}), 1.32(\mathrm{t}, J=7.1 \mathrm{~Hz}, 6 \mathrm{H}) ;{ }^{13} \mathrm{C}$ NMR $\left(100 \mathrm{MHz}, \mathrm{CDCl}_{3}\right): \delta 162.0(\mathrm{~d}, J=245.7 \mathrm{~Hz}), 138.4(\mathrm{~d}, J=17.5 \mathrm{~Hz}), 133.6(\mathrm{~d}, J=8.0 \mathrm{~Hz})$, 
$130.8(\mathrm{~d}, J=3.1 \mathrm{~Hz}), 120.0,115.7(\mathrm{~d}, J=21.6 \mathrm{~Hz}), 61.5(\mathrm{~d}, J=6.4 \mathrm{~Hz}), 33.4,31.8(\mathrm{~d}, J=4.3$ $\mathrm{Hz}), 24.3$ (d, $J=139.5 \mathrm{~Hz}), 16.4(\mathrm{~d}, J=5.9 \mathrm{~Hz}), 15.6 ;{ }^{31} \mathrm{P} \mathrm{NMR}\left(162 \mathrm{MHz}, \mathrm{CDCl}_{3}\right): \delta 31.6$; ${ }^{19} \mathrm{~F}$ NMR (376 MHz, $\mathrm{CDCl}_{3}$ ): $\delta$-115.1; IR (ATR): $\tilde{\mathrm{v}}=2983,2929,2907,2876,1717,1589$, 1490, 1444, 1392, 1220, 1158, 1092, 1055, 1025, 961, 831, $789 \mathrm{~cm}^{-1}$; HRMS (ESI) Calcd for $\mathrm{C}_{16} \mathrm{H}_{24} \mathrm{FNaO}_{3} \mathrm{PS}^{+}[\mathrm{M}+\mathrm{Na}]^{+}$369.1060, found 369.1061.

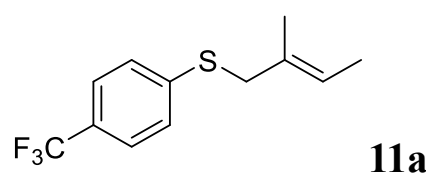

Colorless oil (EtOAc:Hex =0:1); ${ }^{1} \mathrm{H}$ NMR $\left(400 \mathrm{MHz}, \mathrm{CDCl}_{3}\right): \delta 7.48(\mathrm{~d}, J=8.2 \mathrm{~Hz}, 2 \mathrm{H}), 7.35$ (d, $J=8.2 \mathrm{~Hz}, 2 \mathrm{H}$ ), 5.44 (qq, $J=6.8,1.3 \mathrm{~Hz}, 1 \mathrm{H}$ ), 3.57 (s, 2H), 1.73 (s, $3 \mathrm{H}$ ), 1.58 (dd, $J=6.7$, $1.0 \mathrm{~Hz}, 3 \mathrm{H}) ;{ }^{13} \mathrm{C}$ NMR $\left(100 \mathrm{MHz}, \mathrm{CDCl}_{3}\right): \delta 142.5,130.3,128.6,128.3,127.5$ (q, $J=32.5 \mathrm{~Hz}$ ), 126.6, 125.4 (q, $J=3.8 \mathrm{~Hz}), 124.2$ (q, $J=270.4 \mathrm{~Hz}), 123.8,42.7,15.0,13.6 ;{ }^{19} \mathrm{~F}$ NMR $(376$ $\mathrm{MHz}, \mathrm{CDCl}_{3}$ ): $\delta$-62.4; IR (ATR): $\tilde{\mathrm{v}}=2973,2921,2859,1607,1445,1402,1324,1163,1121$, 1109, 1095, 1063, 1013, $824 \mathrm{~cm}^{-1}$; HRMS (ESI) Calcd for $\mathrm{C}_{12} \mathrm{H}_{13} \mathrm{~F}_{3} \mathrm{NaS}^{+}[\mathrm{M}+\mathrm{Na}]^{+}$269.0582, found 269.0584 .

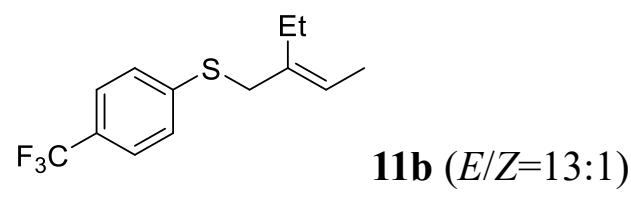

Colorless oil (EtOAc:Hex =0:1); ${ }^{1} \mathrm{H}$ NMR $\left(400 \mathrm{MHz}, \mathrm{CDCl}_{3}\right): \delta 7.51(\mathrm{~d}, J=8.3 \mathrm{~Hz}, 2 \mathrm{H}), 7.37$ (d, $J=8.3 \mathrm{~Hz}, 2 \mathrm{H}), 5.46$ (q, $J=6.7 \mathrm{~Hz}, 1 \mathrm{H}), 3.62$ (s, 2H), 2.22 (q, $J=7.6 \mathrm{~Hz}, 2 \mathrm{H}), 1.62$ (d, $J$ $=6.8 \mathrm{~Hz}, 3 \mathrm{H}), 1.03$ (t, $J=7.6 \mathrm{~Hz}, 3 \mathrm{H}) ;{ }^{13} \mathrm{C} \mathrm{NMR}\left(100 \mathrm{MHz}, \mathrm{CDCl}_{3}\right): \delta 135.9,128.3,128.1$, $127.4(\mathrm{q}, J=32.4 \mathrm{~Hz}), 125.4$ (q, $J=3.7 \mathrm{~Hz}), 124.2$ (q, $J=269.8 \mathrm{~Hz}), 123.5,40.0,21.9,13.2$, 12.7; ${ }^{19} \mathrm{~F} \mathrm{NMR} \mathrm{(376} \mathrm{MHz,} \mathrm{CDCl}_{3}$ ): $\delta$-62.4; IR (ATR): $\tilde{\mathrm{v}}=2970,2935,2880,1607,1461,1402$, $1325,1164,1122,1096,1064,1014,824 \mathrm{~cm}^{-1}$; HRMS (ESI) Calcd for $\mathrm{C}_{13} \mathrm{H}_{15} \mathrm{~F}_{3} \mathrm{NaS}^{+}[\mathrm{M}+\mathrm{Na}]^{+}$ 283.0739, found 283.0741 . 


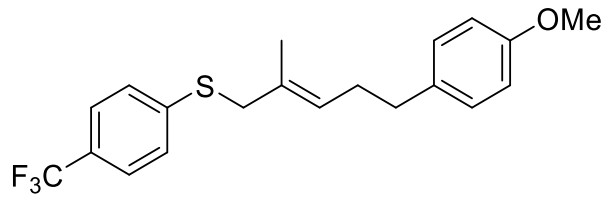

White solid (EtOAc:Hex $=1: 10), \mathrm{mp}=49 \sim 51{ }^{\circ} \mathrm{C} ;{ }^{1} \mathrm{H}$ NMR $\left(400 \mathrm{MHz}, \mathrm{CDCl}_{3}\right): \delta 7.47(\mathrm{~d}, J=$ $8.3 \mathrm{~Hz}, 2 \mathrm{H}), 7.33$ (d, $J=8.2 \mathrm{~Hz}, 2 \mathrm{H}), 7.02(\mathrm{~d}, J=8.6 \mathrm{~Hz}, 2 \mathrm{H}), 6.79$ (d, $J=8.6 \mathrm{~Hz}, 2 \mathrm{H}), 5.38$ (t, $J=7.2 \mathrm{~Hz}, 1 \mathrm{H}), 3.77(\mathrm{~s}, 3 \mathrm{H}), 3.54(\mathrm{~s}, 2 \mathrm{H}), 2.52$ (t, $J=7.3 \mathrm{~Hz}, 2 \mathrm{H}), 2.27$ (dt, $J=7.6,7.4 \mathrm{~Hz}$, 2H), $1.68(\mathrm{~s}, 3 \mathrm{H}) ;{ }^{13} \mathrm{C} \mathrm{NMR}\left(100 \mathrm{MHz}, \mathrm{CDCl}_{3}\right): \delta 157.8,142.4,133.8,130.3,129.3,128.8$, 128.5, 127.6 (q, $J=32.6 \mathrm{~Hz}), 125.4$ (q, $J=3.7 \mathrm{~Hz}), 124.2$ (q, $J=270.0 \mathrm{~Hz}), 113.7,55.2,42.7$, 34.6, 30.1, 15.3; ${ }^{19} \mathrm{~F}$ NMR (376 MHz, $\left.\mathrm{CDCl}_{3}\right): \delta-62.4$; IR (ATR): $\tilde{\mathrm{v}}=3003,2837,2916,2938$, 1607, 1512, 1442, 1402, 1324, 1245, 1163, 1120, 1095, 1063, 1036, 1013, $822 \mathrm{~cm}^{-1}$; HRMS (ESI) Calcd for $\mathrm{C}_{20} \mathrm{H}_{21} \mathrm{~F}_{3} \mathrm{NaOS}^{+}[\mathrm{M}+\mathrm{Na}]^{+} 389.1157$, found 389.1160 .<smiles>C/C(=C\CCc1ccc(F)cc1)CSc1ccc(C(F)(F)F)cc1</smiles>

Colorless oil (EtOAc:Hex = 1:50); ${ }^{1} \mathrm{H}$ NMR (400 MHz, $\left.\mathrm{CDCl}_{3}\right): \delta 7.48(\mathrm{~d}, J=8.3 \mathrm{~Hz}, 2 \mathrm{H})$, $7.34(\mathrm{~d}, J=8.3 \mathrm{~Hz}, 2 \mathrm{H}), 7.05(\mathrm{dd}, J=8.2,5.8 \mathrm{~Hz}, 2 \mathrm{H}), 6.93(\mathrm{t}, J=8.7 \mathrm{~Hz}, 2 \mathrm{H}), 5.37$ (t, $J=7.0$ $\mathrm{Hz}, 1 \mathrm{H}), 3.54$ (s, 2H), 2.55 (t, $J=7.4 \mathrm{~Hz}, 2 \mathrm{H}), 2.28$ (q, $J=7.5 \mathrm{~Hz}, 2 \mathrm{H}), 1.67$ (s, 3H); ${ }^{13} \mathrm{C} \mathrm{NMR}$ $\left(100 \mathrm{MHz}, \mathrm{CDCl}_{3}\right): \delta 161.3(\mathrm{~d}, J=242.2 \mathrm{~Hz}), 142.3,137.2(\mathrm{~d}, J=3.5 \mathrm{~Hz}), 130.6,129.7(\mathrm{~d}, J$ $=7.4 \mathrm{~Hz}), 128.5,128.3,127.6(\mathrm{q}, J=32.2 \mathrm{~Hz}), 125.4(\mathrm{q}, J=3.7 \mathrm{~Hz}), 124.2(\mathrm{q}, J=270.1 \mathrm{~Hz})$, $115.0(\mathrm{~d}, J=21.1 \mathrm{~Hz}), 42.7,34.7,30.0,15.3 ;{ }^{19} \mathrm{~F} \mathrm{NMR}\left(376 \mathrm{MHz}, \mathrm{CDCl}_{3}\right): \delta-117.7,-62.4$; IR (ATR): $\tilde{\mathrm{v}}=3034,2938,2863,1737,1607,1510,1402,1324,1220,1158,1121,1095,1063$, 1013, 914, 822, $744 \mathrm{~cm}^{-1}$; HRMS (ESI) Calcd for $\mathrm{C}_{19} \mathrm{H}_{18} \mathrm{~F}_{4} \mathrm{NaS}^{+}[\mathrm{M}+\mathrm{Na}]^{+}$377.0958, found 377.0961 .

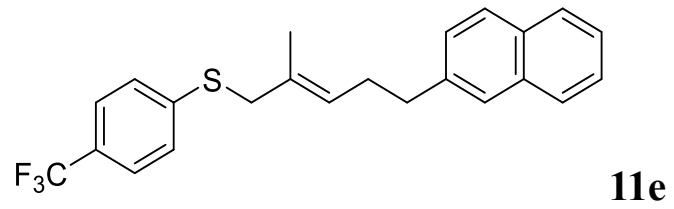

White solid (EtOAc:Hex $=1: 50), \mathrm{mp}=47 \sim 49{ }^{\circ} \mathrm{C} ;{ }^{1} \mathrm{H}$ NMR $\left(400 \mathrm{MHz}, \mathrm{CDCl}_{3}\right): \delta 7.83-7.71$ 
(m, 3H), $7.57(\mathrm{~s}, 1 \mathrm{H}), 7.48-7.37(\mathrm{~m}, 2 \mathrm{H}), 7.44(\mathrm{~d}, J=8.2 \mathrm{~Hz}, 2 \mathrm{H}), 7.32(\mathrm{~d}, J=8.2 \mathrm{~Hz}, 2 \mathrm{H})$, 7.27 (dd, $J=8.4,1.7 \mathrm{~Hz}, 1 \mathrm{H}), 5.44$ (td, $J=7.1,1.1 \mathrm{~Hz}, 1 \mathrm{H}), 3.54$ (s, 2H), 2.75 (t, $J=7.4 \mathrm{~Hz}$, $2 \mathrm{H}), 2.41(\mathrm{dt}, J=7.5,7.4 \mathrm{~Hz}, 2 \mathrm{H}), 1.70(\mathrm{~s}, 3 \mathrm{H}) ;{ }^{13} \mathrm{C} \mathrm{NMR}\left(100 \mathrm{MHz}, \mathrm{CDCl}_{3}\right): \delta 142.4,139.2$, 133.6, 132.0, 130.5, 128.6, 128.5, 127.9, 127.6, 127.6 (q, $J=32.3 \mathrm{~Hz}), 127.4,127.2,126.4$, 125.9, 125.4 (q, $J=3.7 \mathrm{~Hz}), 125.2,124.2$ (q, $J=270.0 \mathrm{~Hz}), 42.8,35.6,29.7,15.4 ;{ }^{19} \mathrm{~F}$ NMR (376 MHz, $\mathrm{CDCl}_{3}$ ): $\delta$-62.4; IR (ATR): $\tilde{\mathrm{v}}=3056,2977,2938,2859,1737,1605,1324,1163$, $1118,1095,1063,1013,914,818,744 \mathrm{~cm}^{-1}$; HRMS (ESI) Calcd for $\mathrm{C}_{23} \mathrm{H}_{21} \mathrm{~F}_{3} \mathrm{NaS}^{+}[\mathrm{M}+\mathrm{Na}]^{+}$ 409.1208, found 409.1211.

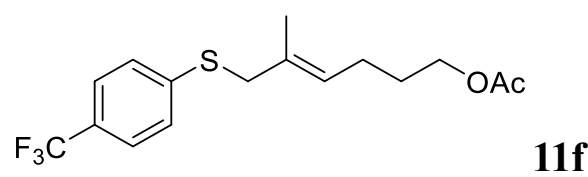

Colorless oil (EtOAc:Hex = 1:20); ${ }^{1} \mathrm{H}$ NMR (400 MHz, $\left.\mathrm{CDCl}_{3}\right): \delta 7.49(\mathrm{~d}, J=8.2 \mathrm{~Hz}, 2 \mathrm{H})$, $7.36(\mathrm{~d}, J=8.2 \mathrm{~Hz}, 2 \mathrm{H}), 5.31(\mathrm{td}, J=7.3,1.1 \mathrm{~Hz}, 1 \mathrm{H}), 3.94(\mathrm{t}, J=6.7 \mathrm{~Hz}, 2 \mathrm{H}), 3.56(\mathrm{~s}, 2 \mathrm{H})$, 2.09-2.01 (m, 2H), $2.04(\mathrm{~s}, 3 \mathrm{H}), 1.73(\mathrm{~s}, 3 \mathrm{H}), 1.58$ (quintet, $J=6.8 \mathrm{~Hz}, 2 \mathrm{H}) ;{ }^{13} \mathrm{C} \mathrm{NMR}(100$ $\mathrm{MHz}, \mathrm{CDCl}_{3}$ ): $\delta 171.1,142.0,130.7,128.9,128.2,127.7$ (q, $\left.J=32.7 \mathrm{~Hz}\right), 125.4$ (q, $J=3.7$ $\mathrm{Hz}), 124.2$ (q, $J=272.0 \mathrm{~Hz}), 63.7,42.9,28.2,24.4,20.9,15.2 ;{ }^{19} \mathrm{~F}$ NMR $\left(376 \mathrm{MHz}, \mathrm{CDCl}_{3}\right)$ : $\delta$-62.5; IR (ATR): $\tilde{\mathrm{v}}=3021,2968,2859,1737,1607,1366,1325,1233,1163,1121,1095$, 1063, 1013, 914, 825, $744 \mathrm{~cm}^{-1}$; HRMS (ESI) Calcd for $\mathrm{C}_{16} \mathrm{H}_{19} \mathrm{~F}_{3} \mathrm{NaO}_{2} \mathrm{~S}^{+}[\mathrm{M}+\mathrm{Na}]^{+} 355.0950$, found 355.0956 .

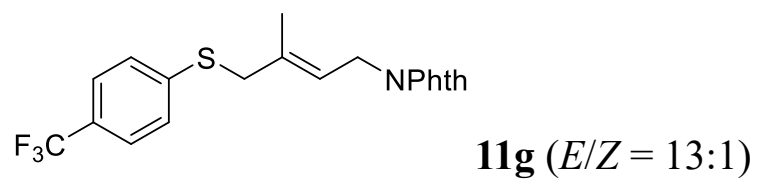

Colorless oil (EtOAc:Hex $=1: 10), \mathrm{mp}=55 \sim 57{ }^{\circ} \mathrm{C} ;{ }^{1} \mathrm{H}$ NMR $\left(400 \mathrm{MHz}, \mathrm{CDCl}_{3}\right): \delta 7.84-7.78$ (m, 2H), 7.74-7.68 (m, 2H), $7.36(\mathrm{~d}, J=8.4 \mathrm{~Hz}, 2 \mathrm{H}), 7.31$ (d, $J=8.5 \mathrm{~Hz}, 2 \mathrm{H}), 5.38$ (td, $J=6.1$, $1.2 \mathrm{~Hz}, 1 \mathrm{H}), 4.24(\mathrm{~d}, J=7.2 \mathrm{~Hz}, 2 \mathrm{H}), 3.52(\mathrm{~s}, 2 \mathrm{H}), 1.97(\mathrm{~d}, J=0.5 \mathrm{~Hz}, 3 \mathrm{H}) ;{ }^{13} \mathrm{C} \mathrm{NMR}(100$ $\left.\mathrm{MHz}, \mathrm{CDCl}_{3}\right): \delta 167.9,141.1,135.2,134.0,132.0,129.6,128.0(\mathrm{q}, J=32.4 \mathrm{~Hz}), 125.3(\mathrm{q}, J=$ $3.6 \mathrm{~Hz}), 124.3$ (q, $J=269.3 \mathrm{~Hz}), 123.2,122.6,42.7,35.5,15.5 ;{ }^{19} \mathrm{~F}$ NMR $\left(376 \mathrm{MHz}, \mathrm{CDCl}_{3}\right)$ : $\delta$-62.6; IR (ATR): $\tilde{\mathrm{v}}=3030,2973,2938,1710,1606,1428,1392,1366,1323,1163,1095$, 1062, 1012, 946, 825, $720 \mathrm{~cm}^{-1}$; HRMS (ESI) Calcd for $\mathrm{C}_{20} \mathrm{H}_{16} \mathrm{~F}_{3} \mathrm{NNaO}_{2} \mathrm{~S}^{+}[\mathrm{M}+\mathrm{Na}]^{+} 414.0746$, 


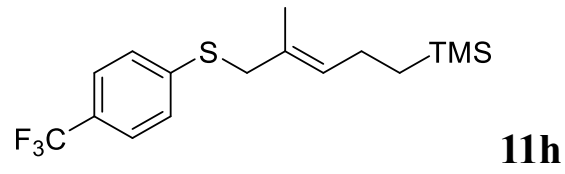

Colorless oil (EtOAc:Hex = 1:100); ${ }^{1} \mathrm{H}$ NMR (400 MHz, $\left.\mathrm{CDCl}_{3}\right): \delta 7.48(\mathrm{~d}, J=8.3 \mathrm{~Hz}, 2 \mathrm{H})$, $7.36(\mathrm{~d}, J=8.3 \mathrm{~Hz}, 2 \mathrm{H}), 5.37(\mathrm{t}, J=6.4 \mathrm{~Hz}, 1 \mathrm{H}), 3.55(\mathrm{~s}, 2 \mathrm{H}), 2.02-1.92(\mathrm{~m}, 2 \mathrm{H}), 1.72(\mathrm{~s}, 3 \mathrm{H})$, 0.49-0.41 (m, 2H), -0.03 (s, 9H); ${ }^{13} \mathrm{C}$ NMR (100 MHz, $\left.\mathrm{CDCl}_{3}\right): \delta$ 144.1, 134.6, 130.4, 129.5, $129.3(\mathrm{q}, J=32.3 \mathrm{~Hz}), 127.1$ (q, $J=3.7 \mathrm{~Hz}), 125.9$ (q, $J=269.8 \mathrm{~Hz}), 44.7,24.1,18.3,16.8$, $0.0 ;{ }^{19} \mathrm{~F}$ NMR (376 MHz, $\mathrm{CDCl}_{3}$ ): $\delta$-62.4; IR (ATR): $\tilde{\mathrm{v}}=2955,2902,1743,1607,1405,1326$, 1251, 1165, 1126, 1096, 1064, 1013, $833 \mathrm{~cm}^{-1}$; HRMS (ESI) Calcd for $\mathrm{C}_{16} \mathrm{H}_{23} \mathrm{~F}_{3} \mathrm{NaSSi}^{+}$ $[\mathrm{M}+\mathrm{Na}]^{+}$355.1134, found 355.1138 . 


\section{Representative Procedures for Thioallylation}

\section{General Procedure 14: representative procedure (7a)}<smiles>CCC/C=C/CSc1ccc(F)cc1</smiles>

6a

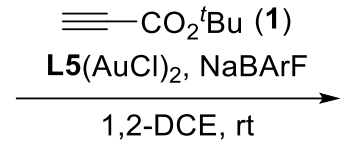<smiles>C=CC(CCC)C(=CSc1ccc(F)cc1)C(=O)OCC</smiles>

$7 a$

$\left(R, S_{p}\right)$-1-naphthyl/DM-Josiphos $(\mathrm{AuCl})_{2} \mathbf{L 5}(6.0 \mathrm{mg}, 0.0050 \mathrm{mmol})$ and sodium tetrakis[3,5bis(trifluoro-methyl)phenyl]borate $(4.4 \mathrm{mg}, 0.0050 \mathrm{mmol})$ was placed in a flame-dried vial. To this was added 1,2-DCE $(0.5 \mathrm{~mL})$ and the mixture was stirred $30 \mathrm{~min}$ at RT. To this was added 6a $(21.0 \mathrm{mg}, 0.10 \mathrm{mmol})$ and tert-butyl propiolate $1(37.8 \mathrm{mg}, 0.30 \mathrm{mmol})$ and the resulting mixture was stirred. When the reaction was complete (TLC), the mixture was concentrated in vacuo and the residue was purified by flash column chromatography $\left(\mathrm{SiO}_{2}\right)$ to provide $7 \mathbf{a}$ as a pale yellow oil (31.0 mg, 92\%).

\section{General Procedure 15: gram-scale synthesis}<smiles>CC(=CCSc1ccc(F)cc1)Cc1ccccc1</smiles>

$(E)-9 f$

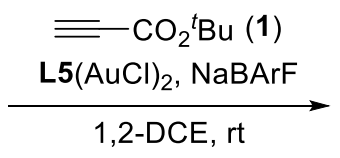

$F$<smiles>C=CC(C=C)(c1ccccc1)[N+](=O)[O-]</smiles>

$10 f$

$\left(R, S_{p}\right)$-1-naphthyl/DM-Josiphos $(\mathrm{AuCl})_{2} \mathbf{L 5}(180.5 \mathrm{mg}, 0.15 \mathrm{mmol})$ and sodium tetrakis[3,5bis(trifluoromethyl)phenyl]borate $(132.9 \mathrm{mg}, 0.15 \mathrm{mmol})$ was placed in a flame-dried vial. To this was added 1,2-DCE $(15 \mathrm{~mL})$ and the mixture was stirred $20 \mathrm{~min}$ at $\mathrm{RT}$. To this was added (E)-9f $(817.1 \mathrm{mg}, 3.0 \mathrm{mmol})$ and tert-butyl propiolate $\mathbf{1}(1.14 \mathrm{~g}, 9.0 \mathrm{mmol})$ and the resulting mixture was stirred. When the reaction was complete (TLC), the reaction mixture was concentrated in vacuo and the residue was purified by flash column chromatography $\left(\mathrm{SiO}_{2}\right.$, EtOAc:Hex = 1:10) to provide 10f as a colorless oil $(1.06 \mathrm{~g}, 89 \%)$.

\section{Derivatization for HPLC Analysis}

The enantiomeric excess of thioallylation products were determined by HPLC analysis directly when possible. Otherwise, the thioallylation products were derivatized by one of methods (AD) described below. 
Method A (7n and 7t)<smiles>C=CC(CCl)C(C=C(C)C(=O)OCCCC)C(=O)Oc1ccc(F)cc1</smiles>

To a solution of $7 \mathbf{n}(17.1 \mathrm{mg}, 0.050 \mathrm{mmol})$ in $\mathrm{CH}_{2} \mathrm{Cl}_{2}(0.3 \mathrm{~mL})$ in a flame-dried vial at $0{ }^{\circ} \mathrm{C}$, was added $m$-chloroperbenzoic acid $(22.4 \mathrm{mg}, 0.13 \mathrm{mmol})$ and the mixture was stirred $20 \mathrm{~min}$ at $0{ }^{\circ} \mathrm{C}$. The reaction mixture was quenched with saturated aq. $\mathrm{NaHCO}_{3}(0.5 \mathrm{~mL})$, extracted with $\mathrm{CH}_{2} \mathrm{Cl}_{2}(0.5 \mathrm{~mL} \times 3)$ and the combined organic phases were washed with brine, dried $\left(\mathrm{MgSO}_{4}\right)$, filtered and concentrated in vacuo. The residue was purified by flash column chromatography $\left(\mathrm{SiO}_{2}, \mathrm{EtOAc:Hex} \mathrm{=} \mathrm{1:5)} \mathrm{to} \mathrm{provide} \mathrm{tert-butyl} \mathrm{(S,Z)-3-(chloromethyl)-2-((4-}\right.$ fluorophenyl)sulfonyl)methylene)pent-4-enoate as a white solid (15.4 mg, 82\%).

Method B (7f, 10i, 19fb and 19fc)

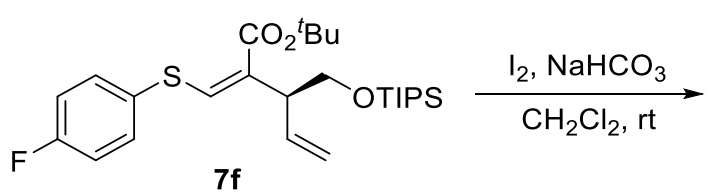<smiles>O=C1OC(CI)C(CO[SbH2])C1=CSc1ccc(F)cc1</smiles>

To a solution of $7 \mathbf{f}(24.0 \mathrm{mg}, 0.050 \mathrm{mmol})$ in $\mathrm{CH}_{2} \mathrm{Cl}_{2}(0.3 \mathrm{~mL})$ was added iodine $(15.2 \mathrm{mg}$, $0.060 \mathrm{mmol})$ and $\mathrm{NaHCO}_{3}(6.3 \mathrm{mg}, 0.075 \mathrm{mmol})$ and the mixture was stirred $30 \mathrm{~min}$ at RT. The mixture was quenched with saturated aq. $\mathrm{Na}_{2} \mathrm{~S}_{2} \mathrm{O}_{3}(1 \mathrm{~mL})$, extracted with $\mathrm{CH}_{2} \mathrm{Cl}_{2}(0.5 \mathrm{~mL}$ $\mathrm{x} 3)$ and the combined organic phases were washed with brine, dried $\left(\mathrm{MgSO}_{4}\right)$, filtered and concentrated in vacuo. The residue was purified by flash column chromatography $\left(\mathrm{SiO}_{2}\right.$, EtOAc:Hex = 1:5) to provide (4S,Z)-3-(((4-fluorophenyl)thio)methylene)-5-(iodomethyl)-4(((triisopropylsilyl)oxy)methyl)dihydrofuran-2(3H)-one as a colorless oil $(25.0 \mathrm{mg}, 91 \%)(\mathrm{dr}$ $=1.5: 1)$. 


\section{Method C (10h)}

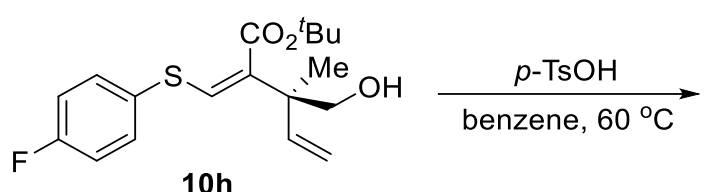<smiles>C=C[C@]1(C)COC(=O)C1=CSc1ccc(F)cc1</smiles>

To a solution of $\mathbf{1 0 h}(16.9 \mathrm{mg}, 0.050 \mathrm{mmol})$ in benzene $(0.5 \mathrm{~mL})$ was added $p$-toluenesulfonic acid $(1.7 \mathrm{mg}, 0.010 \mathrm{mmol})$ and the mixture was stirred $12 \mathrm{~h}$ at $60{ }^{\circ} \mathrm{C}$. The mixture was diluted with water $(1 \mathrm{~mL})$, extracted with ethyl acetate $(1 \mathrm{~mL} \mathrm{x} 3)$ and the combined organic phases were washed with brine, dried $\left(\mathrm{MgSO}_{4}\right)$, filtered and concentrated in vacuo. The residue was purified by flash column chromatography $\left(\mathrm{SiO}_{2}, \mathrm{EtOAc:Hex} \mathrm{=} \mathrm{1:5)} \mathrm{to} \mathrm{provide}(S, Z)-3-(((4-\right.$ fluorophenyl)thio)methylene)-4-methyl-4-vinyldihydrofuran-2(3H)-one as a colorless oil (11.8 mg, 89\%)

\section{Method D (17fb)}

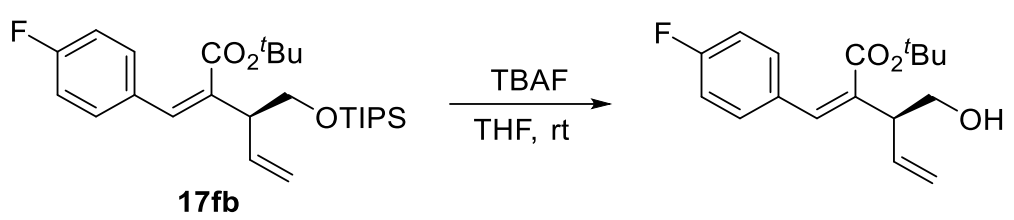

To a solution of $\mathbf{1 7 f b}(22.4 \mathrm{mg}, 0.050 \mathrm{mmol})$ in THF $(0.3 \mathrm{~mL})$ in a flame-dried vial at $0{ }^{\circ} \mathrm{C}$, was added tetrabutylammonium fluoride $(1.0 \mathrm{M}$ in THF, $60.0 \mu \mathrm{L}, 0.060 \mathrm{mmol})$ and the mixture was allowed to warm to RT over $1 \mathrm{~h}$. The mixture was diluted with water $(1 \mathrm{~mL})$, extracted with $\mathrm{Et}_{2} \mathrm{O}(1 \mathrm{~mL} \times 3)$ and the combined organic phases were washed with brine, dried $\left(\mathrm{MgSO}_{4}\right)$, filtered and concentrated in vacuo. The residue was purified by flash column chromatography $\left(\mathrm{SiO}_{2}\right.$, EtOAc:Hex = 1:3) to provide tert-butyl $(S, Z)$-2-(4-fluorobenzylidene)-3-(hydroxymethyl)pent-4-enoate as a colorless oil (13.4 mg, 92\%). 


\section{Characterization of Products}<smiles>C=CC(CCC)C(=CSc1ccc(F)cc1)C(=O)OC</smiles>

Pale yellow oil (31.0 mg, 92\%, EtOAc:Hex = 1:20); $[\alpha]^{20}{ }_{\mathrm{D}}=38.4^{\circ}$ (c 1.00, $\mathrm{CHCl}_{3}, 93 \%$ ee); ${ }^{1} \mathrm{H}$ NMR (400 MHz, $\left.\mathrm{CDCl}_{3}\right): \delta 7.44(\mathrm{dd}, J=8.8,5.2 \mathrm{~Hz}, 2 \mathrm{H}), 7.06(\mathrm{t}, J=8.7 \mathrm{~Hz}, 2 \mathrm{H}), 6.75(\mathrm{~d}$, $J=0.6 \mathrm{~Hz}, 1 \mathrm{H}), 5.76(\mathrm{ddd}, J=17.0,10.4,7.6 \mathrm{~Hz}, 1 \mathrm{H}), 5.03(\mathrm{~d}, J=17.5 \mathrm{~Hz}, 1 \mathrm{H}), 5.02(\mathrm{~d}, J=$ $10.2 \mathrm{~Hz}, 1 \mathrm{H}), 3.21$ (td, $J=7.4,7.0 \mathrm{~Hz}, 1 \mathrm{H}), 1.65-1.19$ (m, 4H), 1.55 (s, 9H), 0.89 (t, $J=7.3$ $\mathrm{Hz}, 3 \mathrm{H}) ;{ }^{13} \mathrm{C} \mathrm{NMR}\left(100 \mathrm{MHz}, \mathrm{CDCl}_{3}\right): \delta 166.0,162.6(\mathrm{~d}, J=246.6 \mathrm{~Hz}), 142.3,140.6,133.2$ (d, $J=8.4 \mathrm{~Hz}), 132.9$ (d, $J=3.3 \mathrm{~Hz}), 130.2,116.4(\mathrm{~d}, J=21.9 \mathrm{~Hz}), 114.8,81.5,45.8,36.1$, 28.3, 20.6, 14.0; ${ }^{19} \mathrm{~F}$ NMR (376 MHz, $\left.\mathrm{CDCl}_{3}\right): \delta$-113.6; IR (ATR): $\tilde{\mathrm{v}}=3074,3003,2961,2929$, 2872, 1690, 1592, 1492, 1368, 1230, 1156, 1092, 914, 829, $755 \mathrm{~cm}^{-1}$; HRMS (ESI) Calcd for $\mathrm{C}_{19} \mathrm{H}_{25} \mathrm{FNaO}_{2} \mathrm{~S}^{+}[\mathrm{M}+\mathrm{Na}]^{+}$359.1452, found 359.1454.

Chiral assay was conducted on Chiralpak ${ }^{\circledR}$ IA column using IPA: $n$ Hex $(0.5: 99.5)$ as an eluent $(1.0 \mathrm{~mL} / \mathrm{min})$.
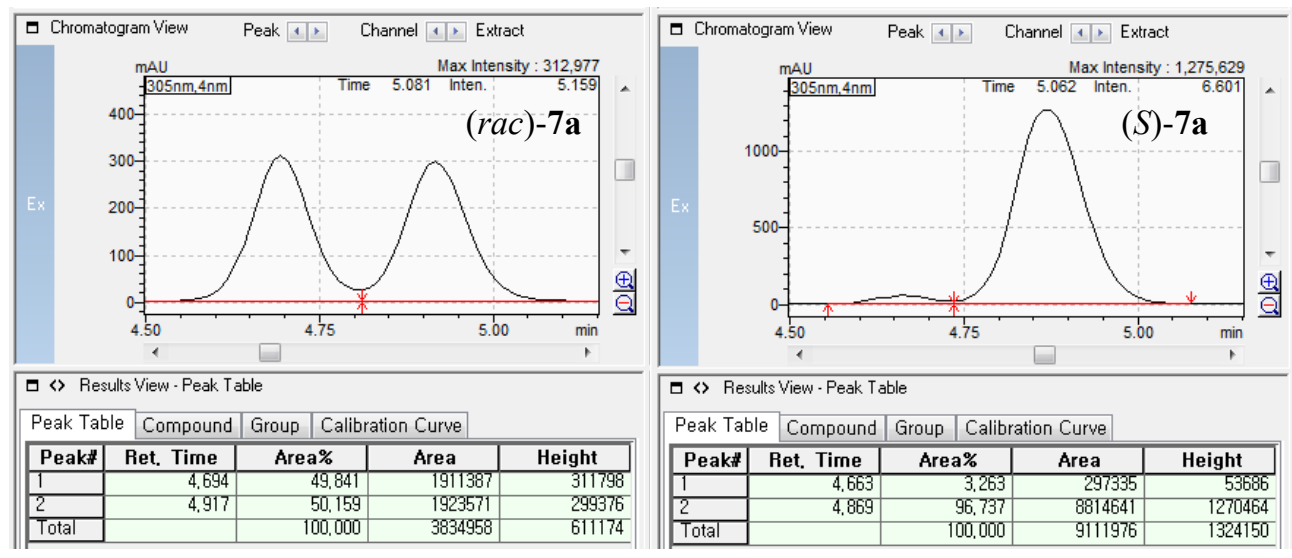
<smiles>C=CC(CCc1ccc(OC)cc1)/C(=C/Sc1ccc(F)cc1)C(=O)OCC</smiles>

$(S)$-Colorless oil (35.3 mg, 82\%, EtOAc:Hex = 1:20); $[\alpha]^{20}{ }_{\mathrm{D}}=-4.5^{\circ}$ (c 1.00, $\mathrm{CHCl}_{3}, 93 \%$ ee), (R)-Colorless oil (35.6 mg, 83\%, EtOAc:Hex = 1:20); $[\alpha]^{20} \mathrm{D}=4.4^{\circ}$ (c 1.00, $\mathrm{CHCl}_{3}, 90 \%$ ee); ${ }^{1} \mathrm{H}$ NMR (400 MHz, $\mathrm{CDCl}_{3}$ ): $\delta 7.44(\mathrm{dd}, J=8.8,5.2 \mathrm{~Hz}, 2 \mathrm{H}), 7.06(\mathrm{~d}, J=8.4 \mathrm{~Hz}, 2 \mathrm{H}), 7.05$ (t, $J=8.4 \mathrm{~Hz}, 2 \mathrm{H}), 6.80(\mathrm{~d}, J=8.6 \mathrm{~Hz}, 2 \mathrm{H}), 6.76(\mathrm{~s}, 1 \mathrm{H}), 5.80(\mathrm{ddd}, J=17.5,9.7,7.6 \mathrm{~Hz}, 2 \mathrm{H})$, $5.07(\mathrm{~d}, J=10.6 \mathrm{~Hz}, 1 \mathrm{H}), 5.06(\mathrm{~d}, J=17.2 \mathrm{~Hz}, 1 \mathrm{H}), 3.78(\mathrm{~s}, 3 \mathrm{H}), 3.21(\mathrm{td}, J=7.5,7.1 \mathrm{~Hz}, 1 \mathrm{H})$, 2.58-2.46 (m, 2H), 1.96-1.71 (m, 2H), $\left.1.54(\mathrm{~s}, 9 \mathrm{H}) ;{ }^{13} \mathrm{C} \mathrm{NMR} \mathrm{(100} \mathrm{MHz,} \mathrm{CDCl}_{3}\right): \delta$ 165.9, $162.7(\mathrm{~d}, J=247.0 \mathrm{~Hz}), 157.8,143.0,140.3,134.1,133.3$ (d, $J=8.1 \mathrm{~Hz}), 132.8$ (d, $J=3.4 \mathrm{~Hz})$, $129.5,129.3,116.4(\mathrm{~d}, J=21.8 \mathrm{~Hz}), 115.3,113.8,81.6,55.3,45.9,35.8,32.9,28.3 ;{ }^{19} \mathrm{~F} \mathrm{NMR}$ (376 MHz, $\mathrm{CDCl}_{3}$ ): $\delta$-113.4; IR (ATR): $\tilde{\mathrm{v}}=3074,3003,2971,2927,2841,1737,1696,1592$, 1513, 1491, 1366, 1230, 1156, 1038, 914, 828, $750 \mathrm{~cm}^{-1}$; HRMS (ESI) Calcd for $\mathrm{C}_{25} \mathrm{H}_{29} \mathrm{FNaO}_{3} \mathrm{~S}^{+}[\mathrm{M}+\mathrm{Na}]^{+}$451.1714, found 451.1717 .

Chiral assay was conducted on Chiralpak ${ }^{\circledR}$ IA column using IPA: $n$ Hex $(0.5: 99.5)$ as an eluent $(1.0 \mathrm{~mL} / \mathrm{min})$.
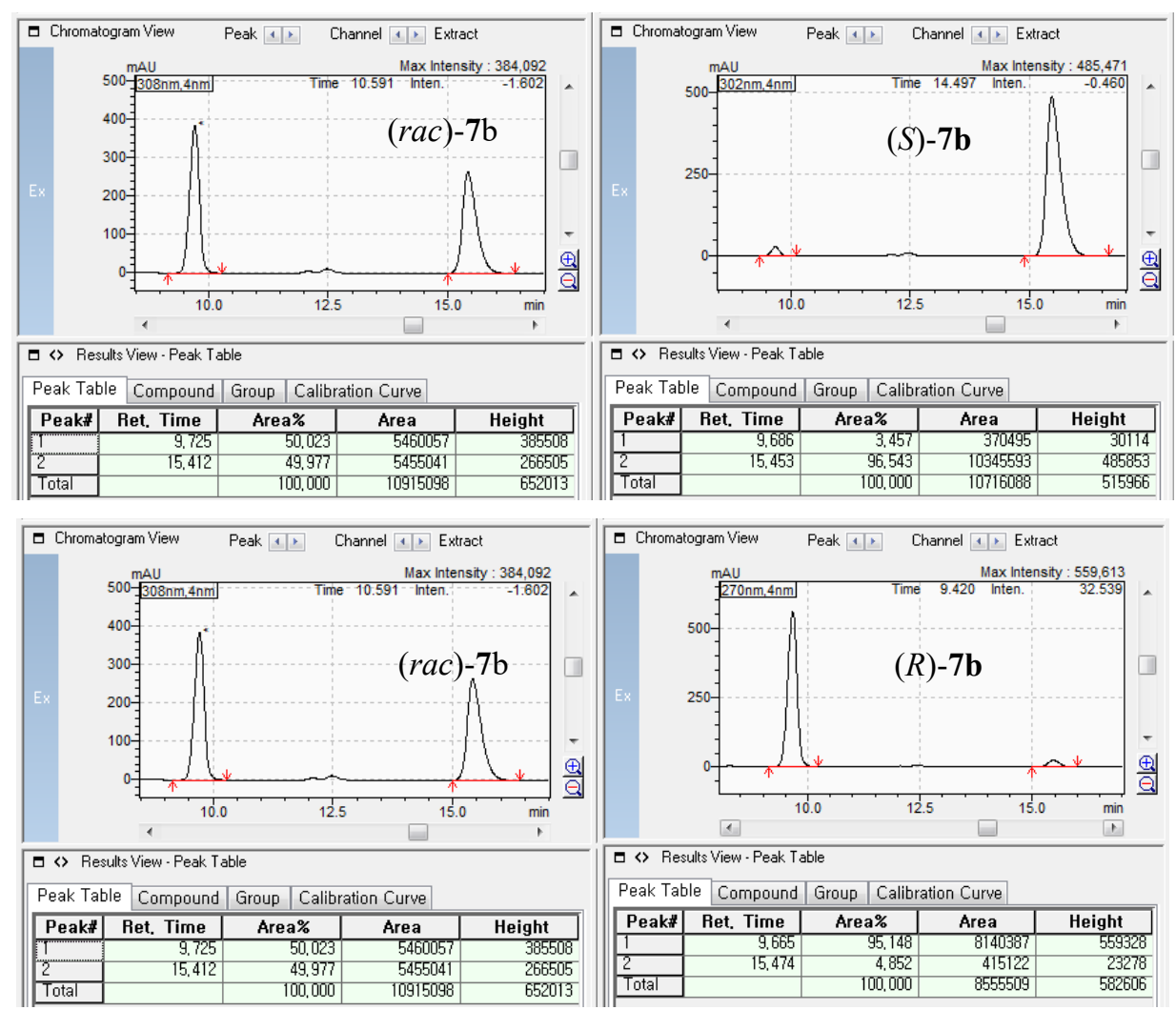
<smiles>C=CC(CCc1ccc(F)cc1)/C(=C/Sc1ccc(F)cc1)C(=O)OCc1ccccc1</smiles>

Colorless oil (34.8 mg, 83\%, EtOAc:Hex = 1:20); $[\alpha]^{20}{ }_{\mathrm{D}}=4.1^{\circ}\left(\mathrm{c} 1.00, \mathrm{CHCl}_{3}, 90 \%\right.$ ee); ${ }^{1} \mathrm{H}$ NMR (400 MHz, $\left.\mathrm{CDCl}_{3}\right): \delta 7.43(\mathrm{dd}, J=8.8,5.2 \mathrm{~Hz}, 2 \mathrm{H}), 7.09$ (dd, $\left.J=8.8,5.4 \mathrm{~Hz}, 2 \mathrm{H}\right), 7.05$ (t, $J=8.7 \mathrm{~Hz}, 2 \mathrm{H}), 6.94$ (t, $J=8.8 \mathrm{~Hz}, 2 \mathrm{H}), 6.76$ (d, $J=0.5 \mathrm{~Hz}, 1 \mathrm{H}), 5.80$ (ddd, $J=16.9,10.5$, $7.7 \mathrm{~Hz}, 1 \mathrm{H}), 5.07$ (d, $J=10.5 \mathrm{~Hz}, 1 \mathrm{H}), 5.08$ (d, $J=17.0 \mathrm{~Hz}, 1 \mathrm{H}), 3.20$ (td, $J=7.6,6.8 \mathrm{~Hz}, 1 \mathrm{H})$, 2.66-2.47 (m, 2H), 1.95-1.72 (m, 2H), $\left.1.53(\mathrm{~s}, 9 \mathrm{H}) ;{ }^{13} \mathrm{C} \mathrm{NMR} \mathrm{(100} \mathrm{MHz,} \mathrm{CDCl}_{3}\right): \delta 165.8$, 162.7 (d, $J=247.2 \mathrm{~Hz}), 161.2(\mathrm{~d}, J=242.3 \mathrm{~Hz}), 143.1,140.0,137.6$ (d, $J=3.3 \mathrm{~Hz}), 133.3$ (d, $J=8.1 \mathrm{~Hz}), 132.7$ (d, $J=3.5 \mathrm{~Hz}), 129.7$ (d, $J=7.9 \mathrm{~Hz}), 129.4,116.4$ (d, $J=21.8 \mathrm{~Hz}), 115.5$, $115.1(\mathrm{~d}, J=20.9 \mathrm{~Hz}), 81.6,45.8,35.7,33.0,28.3 ;{ }^{19} \mathrm{~F} \mathrm{NMR}\left(376 \mathrm{MHz}, \mathrm{CDCl}_{3}\right): \delta-113.3$, 117.8; IR (ATR): $\tilde{\mathrm{v}}=3074,3008,2979,2933,2867,1690,1592,1510,1491,1368,1228,1157$, 919, 828, $755 \mathrm{~cm}^{-1}$; HRMS (ESI) Calcd for $\mathrm{C}_{24} \mathrm{H}_{26} \mathrm{~F}_{2} \mathrm{NaO}_{2} \mathrm{~S}^{+}[\mathrm{M}+\mathrm{Na}]^{+}$439.1514, found 439.1517.

Chiral assay was conducted on Chiralpak ${ }^{\circledR}$ IG column using IPA: $n$ Hex $(0.5: 99.5)$ as an eluent $(1.0 \mathrm{~mL} / \mathrm{min})$.
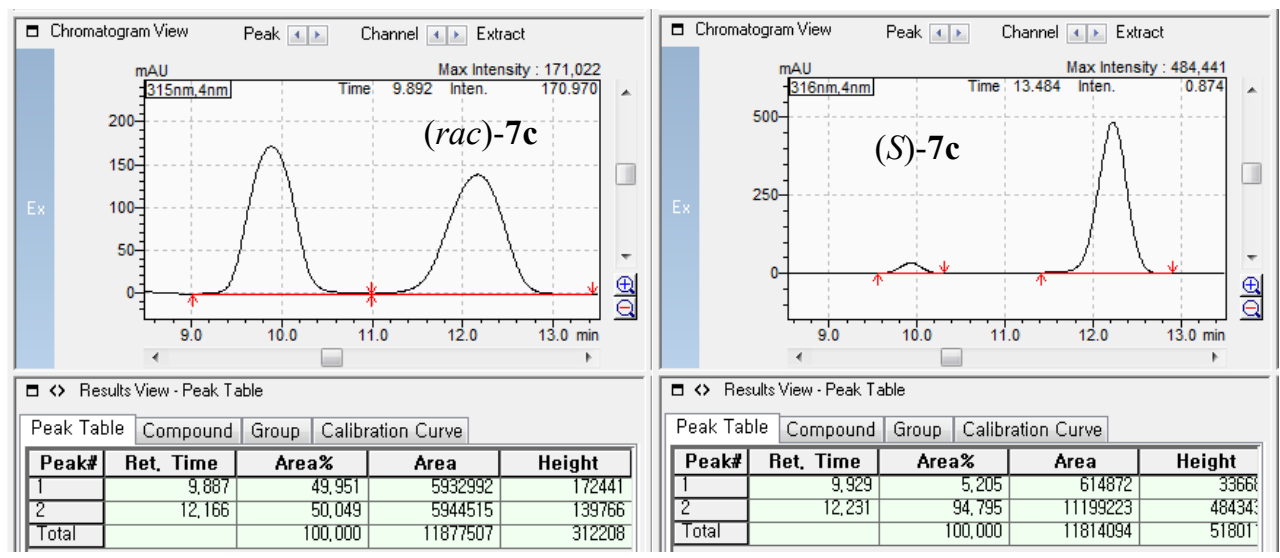
<smiles>C=CC(CCc1ccc2ccccc2c1)C(=CSc1ccc(F)cc1)C(=O)OCc1ccccc1</smiles>

Colorless oil (37.5 mg, 84\%, EtOAc:Hex = 1:20); $[\alpha]^{20}{ }_{\mathrm{D}}=-15.1^{\circ}\left(\mathrm{c} 1.00, \mathrm{CHCl}_{3}, 95 \% \mathrm{ee}\right) ;{ }^{1} \mathrm{H}$ NMR (400 MHz, $\left.\mathrm{CDCl}_{3}\right): \delta$ 7.84-7.60 (m, 3H), 7.58 (s, 1H), 7.49-7.37 (m, 4H), 7.30 (dd, $J=$ $8.3,1.6 \mathrm{~Hz}, 1 \mathrm{H}), 7.03(\mathrm{t}, J=8.6 \mathrm{~Hz}, 2 \mathrm{H}), 6.78(\mathrm{~s}, 1 \mathrm{H}), 5.85(\mathrm{ddd}, J=17.5,9.8,7.6 \mathrm{~Hz}, 1 \mathrm{H})$, $5.10(\mathrm{~d}, J=10.6 \mathrm{~Hz}, 1 \mathrm{H}), 5.09$ (d, $J=17.2 \mathrm{~Hz}, 1 \mathrm{H}), 3.25$ (td, $J=7.5,7.2 \mathrm{~Hz}, 1 \mathrm{H}), 2.88-2.78$ $(\mathrm{m}, 2 \mathrm{H}), 2.10-1.85(\mathrm{~m}, 2 \mathrm{H}), 1.53(\mathrm{~s}, 9 \mathrm{H}) ;{ }^{13} \mathrm{C} \mathrm{NMR}\left(100 \mathrm{MHz}, \mathrm{CDCl}_{3}\right): \delta 165.9,162.6(\mathrm{~d}, J=$ $247.0 \mathrm{~Hz}), 143.2,140.2,139.6,133.6,133.3$ (d, $J=8.4 \mathrm{~Hz}), 132.7$ (d, $J=3.2 \mathrm{~Hz}), 132.0,129.3$, 127.9, 127.6, 127.3, 127.3, 126.4, 125.9, 125.2, 116.4 (d, $J=21.8 \mathrm{~Hz}), 115.4,81.6,46.1,35.4$, 33.9, 28.3; ${ }^{19} \mathrm{~F}$ NMR (376 MHz, $\mathrm{CDCl}_{3}$ ): $\delta$-113.4; IR (ATR): $\tilde{\mathrm{v}}=3047,3007,2933,2858$, 1690, 1490, 1366, 1229, 1156, 1013, 914, 827, $752 \mathrm{~cm}^{-1}$; HRMS (ESI) Calcd for $\mathrm{C}_{28} \mathrm{H}_{29} \mathrm{FNaO}_{2} \mathrm{~S}^{+}[\mathrm{M}+\mathrm{Na}]^{+} 471.1765$, found 471.1768 .

Chiral assay was conducted on Chiralpak ${ }^{\circledR}$ IA column using IPA: $n$ Hex $(0.5: 99.5)$ as an eluent $(1.0 \mathrm{~mL} / \mathrm{min})$.
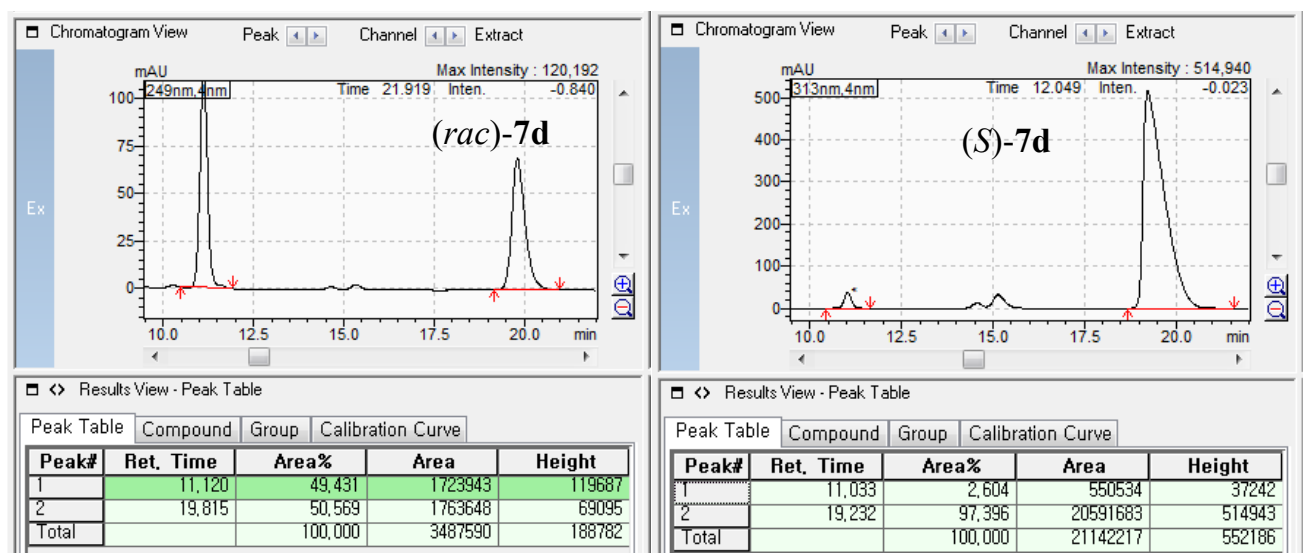
<smiles>C=CC(CO)C(=CSc1ccc(F)cc1)C(=O)OCc1ccccc1</smiles>

Colorless oil (19.2 mg, 60\%, EtOAc:Hex =1:4); $[\alpha]^{20}{ }_{\mathrm{D}}=50.2^{\circ}\left(\mathrm{c} 1.00, \mathrm{CHCl}_{3}, 90 \%\right.$ ee); ${ }^{1} \mathrm{H}$ NMR (400 MHz, $\left.\mathrm{CDCl}_{3}\right): \delta 7.45(\mathrm{dd}, J=8.8,5.2 \mathrm{~Hz}, 2 \mathrm{H}), 7.06(\mathrm{t}, J=8.7 \mathrm{~Hz}, 2 \mathrm{H}), 6.92(\mathrm{~d}, J$ $=0.5 \mathrm{~Hz}, 1 \mathrm{H}), 5.86(\mathrm{ddd}, J=16.6,11.0,7.3 \mathrm{~Hz}, 1 \mathrm{H}), 5.19(\mathrm{~d}, J=11.0 \mathrm{~Hz}, 1 \mathrm{H}), 5.18(\mathrm{dt}, J=$ $16.7 \mathrm{~Hz}, 1 \mathrm{H}), 3.83-3.65(\mathrm{~m}, 2 \mathrm{H}), 3.45$ (dt, $J=6.6,6.5 \mathrm{~Hz}, 1 \mathrm{H}), 1.68(\mathrm{~s}, \mathrm{br}, 1 \mathrm{H}), 1.56(\mathrm{~s}, 9 \mathrm{H})$; ${ }^{13} \mathrm{C}$ NMR (100 MHz, $\left.\mathrm{CDCl}_{3}\right): \delta 165.8,162.7(\mathrm{~d}, J=247.1 \mathrm{~Hz}), 145.0,136.9,133.3(\mathrm{~d}, J=8.4$ $\mathrm{Hz}), 132.4(\mathrm{~d}, J=3.3 \mathrm{~Hz}), 126.2,117.4,116.5$ (d, $J=21.9 \mathrm{~Hz}), 82.1,64.5,49.0,28.3 ;{ }^{19} \mathrm{~F}$ NMR (376 MHz, $\mathrm{CDCl}_{3}$ ): $\delta$-113.1; IR (ATR): $\tilde{\mathrm{v}}=3446,3069,2933,2876,1689,1592,1491,1368$, 1230, 1156, 920, $833 \mathrm{~cm}^{-1}$; HRMS (ESI) Calcd for $\mathrm{C}_{17} \mathrm{H}_{21} \mathrm{FNaO}_{3} \mathrm{~S}^{+}[\mathrm{M}+\mathrm{Na}]^{+} 347.1088$, found 347.1094 .

Chiral assay was conducted on Chiralpak ${ }^{\circledR}$ IG column using IPA: $n$ Hex (10:90) as an eluent (1.0 $\mathrm{mL} / \mathrm{min})$.
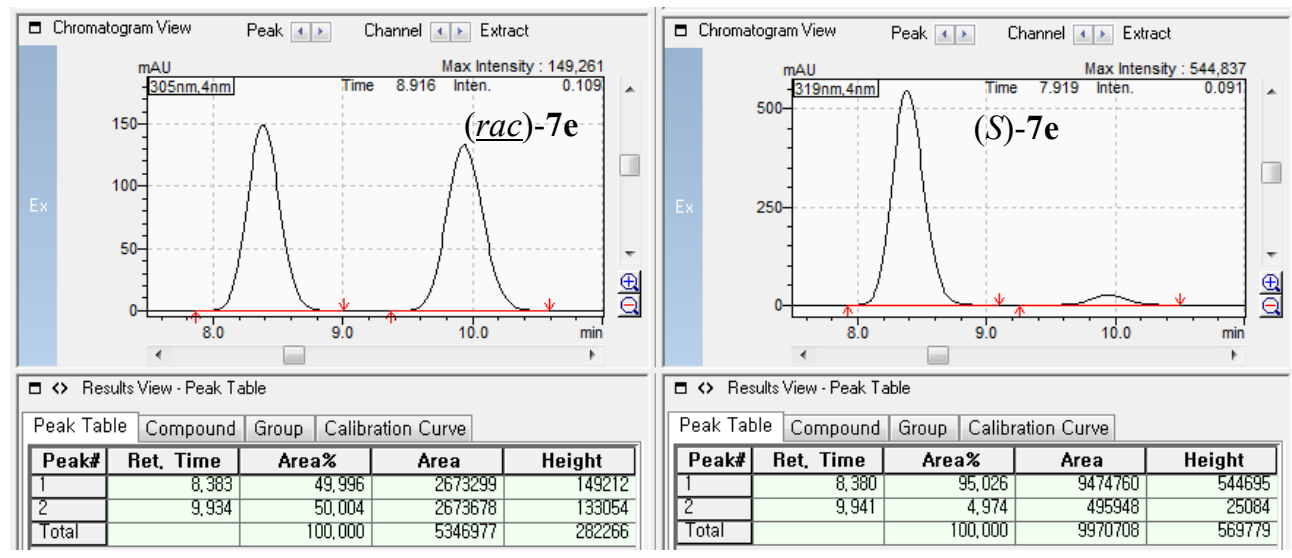
<smiles>C=CC(COP)C(=CSc1ccc(F)cc1)C(=O)OCC</smiles>

$(S)$-Colorless oil (40.5 mg, 84\%, EtOAc:Hex = 1:20); $[\alpha]^{20}{ }_{\mathrm{D}}=27.4^{\circ}$ (c 1.00, $\mathrm{CHCl}_{3}, 99 \%$ ee), $(R)$-Colorless oil (40.4 mg, 84\%, EtOAc:Hex = 1:20); $[\alpha]^{20}{ }_{\mathrm{D}}=-26.0^{\circ}$ (c 1.09, $\left.\mathrm{CHCl}_{3}, 94 \% \mathrm{ee}\right)$; ${ }^{1} \mathrm{H}$ NMR (400 MHz, $\mathrm{CDCl}_{3}$ ): $\delta 7.45(\mathrm{dd}, J=8.9,5.2 \mathrm{~Hz}, 2 \mathrm{H}), 7.04(\mathrm{t}, J=8.6 \mathrm{~Hz}, 2 \mathrm{H}), 6.97$ (s, 1H), 5.91 (ddd, $J=17.4,10.3,7.2 \mathrm{~Hz}, 1 \mathrm{H}), 5.13$ (d, $J=17.3 \mathrm{~Hz}, 1 \mathrm{H}), 5.09$ (d, $J=10.4 \mathrm{~Hz}$, $1 \mathrm{H}), 3.87$ (dd of ABq, $J=9.7,5.8 \mathrm{~Hz}, 1 \mathrm{H}), 3.78$ (dd of ABq, $J=9.7,5.5 \mathrm{~Hz}, 1 \mathrm{H}), 3.41(\mathrm{dt}, J=$ 6.6, $5.8 \mathrm{~Hz}, 1 \mathrm{H}), 1.54(\mathrm{~s}, 9 \mathrm{H}), 1.10-0.97(\mathrm{~m}, 21 \mathrm{H}) ;{ }^{13} \mathrm{C} \mathrm{NMR}\left(100 \mathrm{MHz}, \mathrm{CDCl}_{3}\right): \delta 165.9$, $162.6(\mathrm{~d}, J=247.1 \mathrm{~Hz}), 145.1,137.8,133.4(\mathrm{~d}, J=8.1 \mathrm{~Hz}), 132.8(\mathrm{~d}, J=3.0 \mathrm{~Hz}), 126.5,116.3$ $(\mathrm{d}, J=21.8 \mathrm{~Hz}), 116.1,81.5,65.3,48.8,28.3,18.0,11.9 ;{ }^{19} \mathrm{~F}$ NMR $\left(376 \mathrm{MHz}, \mathrm{CDCl}_{3}\right): \delta$ 113.6; IR (ATR): $\tilde{\mathrm{v}}=2942,2866,1695,1592,1566,1491,1462,1367,1230,1155,1013,918$, 882, $826 \mathrm{~cm}^{-1}$; HRMS (ESI) Calcd for $\mathrm{C}_{26} \mathrm{H}_{41} \mathrm{FNaO}_{3} \mathrm{SSi}^{+}[\mathrm{M}+\mathrm{Na}]^{+}$503.2422, found 503.2427.

The product was derivatized into the corresponding lactone according to Method B, and chiral assay of the lactone was conducted on Chiralpak ${ }^{\circledR}$ OD-H column using IPA: $n$ Hex (1:99) as an eluent $(1.0 \mathrm{~mL} / \mathrm{min})$.
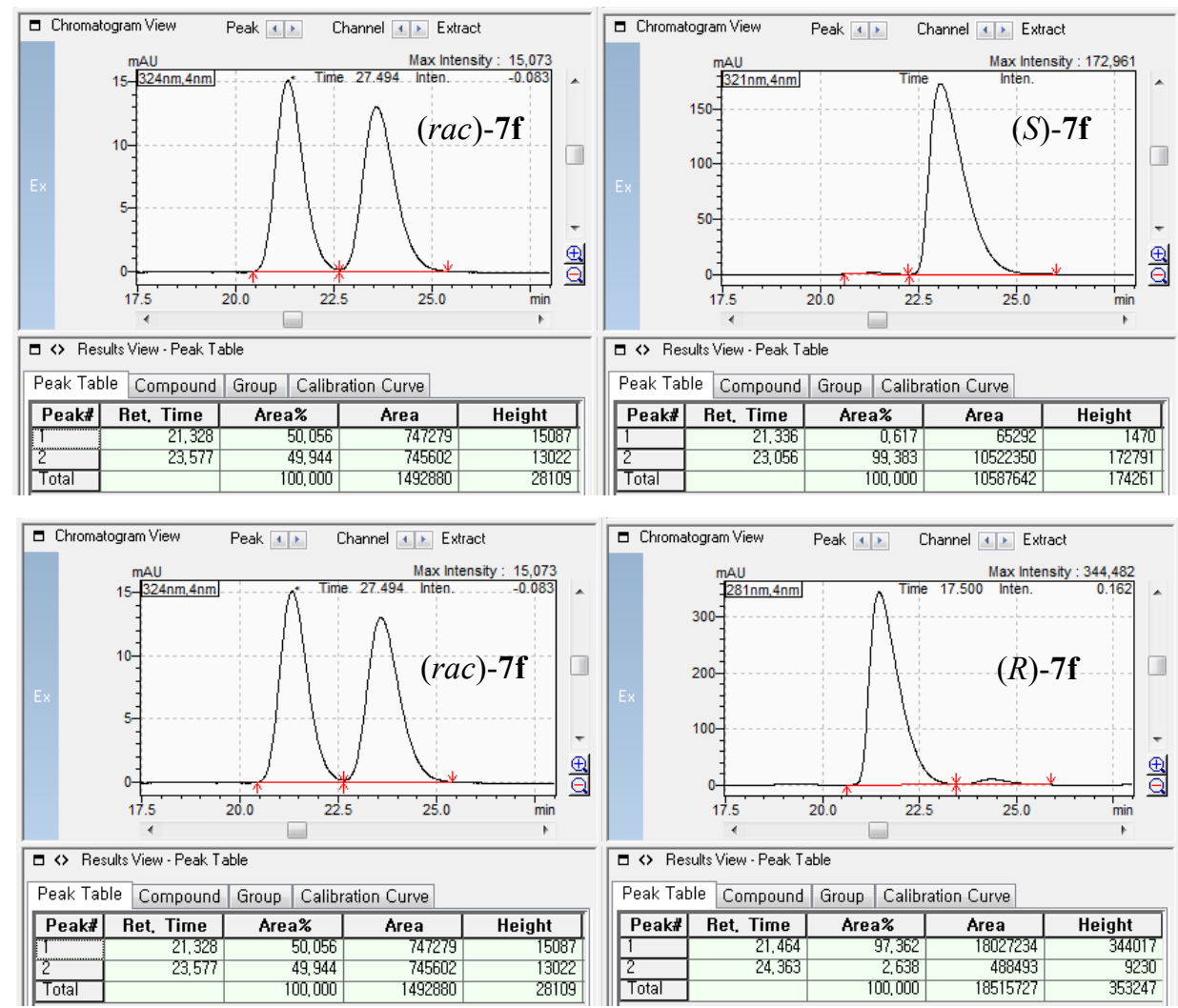


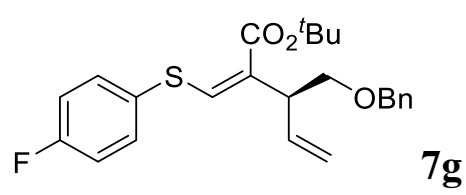

Pale yellow oil (34.9 mg, 84\%, EtOAc:Hex = 1:20); $[\alpha]^{20}{ }_{\mathrm{D}}=5.4^{\circ}\left(\mathrm{c} 1.00, \mathrm{CHCl}_{3}, 98 \%\right.$ ee); ${ }^{1} \mathrm{H}$ NMR (400 MHz, $\left.\mathrm{CDCl}_{3}\right): \delta 7.40(\mathrm{dd}, J=8.8,5.2 \mathrm{~Hz}, 2 \mathrm{H}), 7.34-7.23(\mathrm{~m}, 5 \mathrm{H}), 7.01(\mathrm{t}, J=8.6$ Hz, 2H), 6.93 (s, 1H), 5.87 (ddd, $J=17.1,10.5,6.8 \mathrm{~Hz}, 1 \mathrm{H}), 5.14$ (d, $J=17.4 \mathrm{~Hz}, 1 \mathrm{H}), 5.12$ $(\mathrm{d}, J=10.3 \mathrm{~Hz}, 1 \mathrm{H}), 4.52$ (d of ABq, $J=12.1,1 \mathrm{H}), 4.48$ (d of ABq, $J=12.1 \mathrm{~Hz}, 1 \mathrm{H}), 3.67-$ $3.51(\mathrm{~m}, 3 \mathrm{H}), 1.52(\mathrm{~s}, 9 \mathrm{H}) ;{ }^{13} \mathrm{C} \mathrm{NMR}\left(100 \mathrm{MHz}, \mathrm{CDCl}_{3}\right): \delta 165.7,162.6(\mathrm{~d}, J=246.8 \mathrm{~Hz})$, 144.7, 138.2, 137.6, 133.1 (d, $J=8.4 \mathrm{~Hz}), 132.7$ (d, $J=3.5 \mathrm{~Hz}), 128.3,127.6,127.6$ 126.5, 116.4, $116.3(\mathrm{~d}, J=21.8 \mathrm{~Hz}), 81.6,73.0,71.9,46.0,28.3 ;{ }^{19} \mathrm{~F} \mathrm{NMR}\left(376 \mathrm{MHz}, \mathrm{CDCl}_{3}\right): \delta$ 113.5; IR (ATR): $\tilde{\mathrm{v}}=2980,2928,2862,1692,1592,1454,1156,1092,919,828,754,697 \mathrm{~cm}^{-}$ 1; HRMS (ESI) Calcd for $\mathrm{C}_{24} \mathrm{H}_{27} \mathrm{FNaO}_{3} \mathrm{~S}^{+}[\mathrm{M}+\mathrm{Na}]^{+}$437.1557, found 437.1562.

Chiral assay was conducted on Chiralpak ${ }^{\circledR}$ OD-H column using IPA:nHex $(0.5: 99.5)$ as an eluent $(1.0 \mathrm{~mL} / \mathrm{min})$.
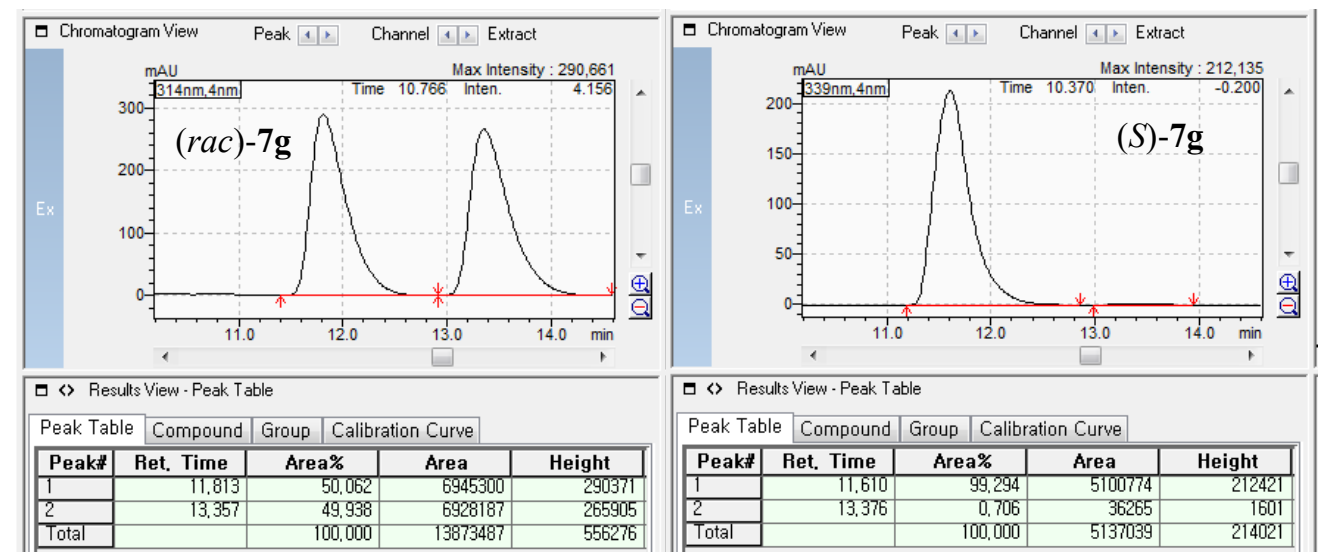
<smiles>C=CC(CCCC(=O)OCC)C(=CSc1ccc(F)cc1)C(=O)OC</smiles>

Colorless oil (33.3 mg, 81\%, EtOAc:Hex =1:10); $[\alpha]^{20} \mathrm{D}=19.5^{\circ}\left(\mathrm{c} 1.00, \mathrm{CHCl}_{3}, 90 \%\right.$ ee); ${ }^{1} \mathrm{H}$ NMR (400 MHz, $\left.\mathrm{CDCl}_{3}\right): \delta 7.44(\mathrm{dd}, J=8.8,5.2 \mathrm{~Hz}, 2 \mathrm{H}), 7.06(\mathrm{t}, J=8.6 \mathrm{~Hz}, 2 \mathrm{H}), 6.78(\mathrm{~d}, J$ $=0.4 \mathrm{~Hz}, 1 \mathrm{H}), 5.76(\mathrm{ddd}, J=16.8,10.5,7.6 \mathrm{~Hz}, 1 \mathrm{H}), 5.05(\mathrm{~d}, J=16.9 \mathrm{~Hz}, 1 \mathrm{H}), 5.04(\mathrm{~d}, J=$ $10.7 \mathrm{~Hz}, 1 \mathrm{H}), 4.11(\mathrm{q}, J=7.1 \mathrm{~Hz}, 2 \mathrm{H}), 3.20(\mathrm{td}, J=7.4,6.2 \mathrm{~Hz}, 1 \mathrm{H}), 2.29(\mathrm{t}, J=7.0 \mathrm{~Hz}, 2 \mathrm{H})$, $1.63-1.48(\mathrm{~m}, 4 \mathrm{H}), 1.55(\mathrm{~s}, 9 \mathrm{H}), 1.24(\mathrm{t}, J=7.2 \mathrm{~Hz}, 3 \mathrm{H}) ;{ }^{13} \mathrm{C} \mathrm{NMR}\left(100 \mathrm{MHz}, \mathrm{CDCl}_{3}\right): \delta 173.5$, $165.9,162.6(\mathrm{~d}, J=246.7 \mathrm{~Hz}), 142.9,140.0,133.3$ (d, $J=8.2 \mathrm{~Hz}), 132.8$ (d, $J=3.4 \mathrm{~Hz}), 129.5$, $116.4(\mathrm{~d}, J=21.9 \mathrm{~Hz}), 115.3,81.6,60.2,45.9,34.1,33.3,28.3,23.0,14.3 ;{ }^{19} \mathrm{~F}$ NMR $(376 \mathrm{MHz}$, $\mathrm{CDCl}_{3}$ ): $\delta$-113.4; IR (ATR): $\tilde{\mathrm{v}}=3073,2979,2933,2871,1734,1690,1592,1491,1368,1229$, 1156, 918, 830, $755 \mathrm{~cm}^{-1}$; HRMS (ESI) Calcd for $\mathrm{C}_{22} \mathrm{H}_{29} \mathrm{FNaO}_{4} \mathrm{~S}^{+}[\mathrm{M}+\mathrm{Na}]^{+} 431.1663$, found 431.1669 .

Chiral assay was conducted on Chiralpak ${ }^{\circledR}$ IA column using IPA: $n$ Hex $(0.5: 99.5)$ as an eluent $(1.0 \mathrm{~mL} / \mathrm{min})$.
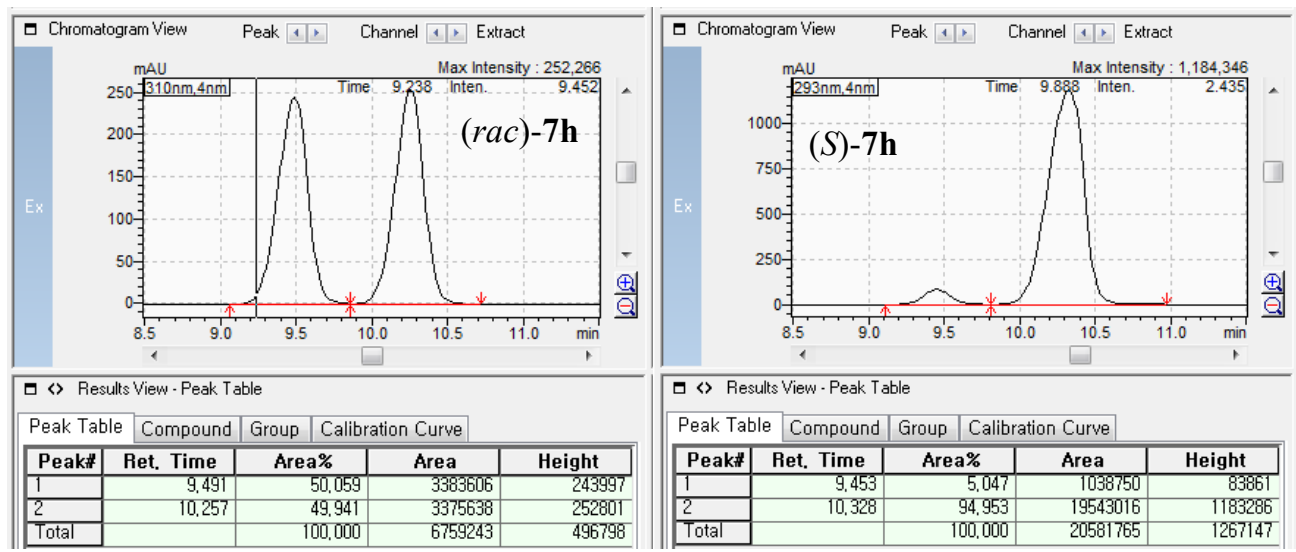
<smiles>C=CC(CCCS(=O)(=O)c1ccccc1)C(=CSc1ccc(F)cc1)C(=O)OC</smiles>

Colorless oil (40.1 mg, 84\%, EtOAc:Hex = 1:4); $[\alpha]^{20} \mathrm{D}=7.1^{\circ}\left(\mathrm{c} 1.00, \mathrm{CHCl}_{3}, 90 \%\right.$ ee); ${ }^{1} \mathrm{H}$ NMR (400 MHz, $\left.\mathrm{CDCl}_{3}\right): \delta$ 7.93-7.86 (m, 2H), 7.69-7.61 (m, 1H), 7.60-7.52 (m, 2H), 7.43 (dd, $J=8.8,5.2 \mathrm{~Hz}, 2 \mathrm{H}), 7.06(\mathrm{t}, J=8.6 \mathrm{~Hz}, 2 \mathrm{H}), 6.74(\mathrm{~d}, J=0.4 \mathrm{~Hz}, 1 \mathrm{H}), 5.70(\mathrm{ddd}, J=17.1$, $10.3,7.7 \mathrm{~Hz}, 1 \mathrm{H}), 5.03(\mathrm{~d}, J=10.2 \mathrm{~Hz}, 1 \mathrm{H}), 5.00(\mathrm{~d}, J=17.1 \mathrm{~Hz}, 1 \mathrm{H}), 3.13(\mathrm{td}, J=7.6,6.5$ $\mathrm{Hz}, 1 \mathrm{H}), 3.08(\mathrm{t}, J=7.7 \mathrm{~Hz}, 2 \mathrm{H}), 1.86-1.40(\mathrm{~m}, 4 \mathrm{H}), 1.53(\mathrm{~s}, 9 \mathrm{H}) ;{ }^{13} \mathrm{C} \mathrm{NMR}\left(100 \mathrm{MHz}, \mathrm{CDCl}_{3}\right)$ : $\delta 165.6,162.7(\mathrm{~d}, J=247.1 \mathrm{~Hz}), 143.5,139.2,133.7,133.4(\mathrm{~d}, J=8.4 \mathrm{~Hz}), 132.5(\mathrm{~d}, J=3.7$ $\mathrm{Hz}), 129.3,128.9,128.0,116.5(\mathrm{~d}, J=21.9 \mathrm{~Hz}), 115.9,81.9,56.0,45.8,32.5,28.3,20.8 ;{ }^{19} \mathrm{~F}$ NMR (376 MHz, $\mathrm{CDCl}_{3}$ ): $\delta$-113.1; IR (ATR): $\tilde{\mathrm{v}}=3012,2978,2933,1688,1592,1491,1307$, 1229, 1149, 1088, 920, 831, $754 \mathrm{~cm}^{-1}$; HRMS (ESI) Calcd for $\mathrm{C}_{25} \mathrm{H}_{29} \mathrm{FNaO}_{4} \mathrm{~S}_{2}{ }^{+}[\mathrm{M}+\mathrm{Na}]^{+}$ 499.1384, found 499.1411.

Chiral assay was conducted on Chiralpak ${ }^{\circledR}$ IA column using IPA: $n$ Hex $(5: 95)$ as an eluent $(1.0$ $\mathrm{mL} / \mathrm{min})$.
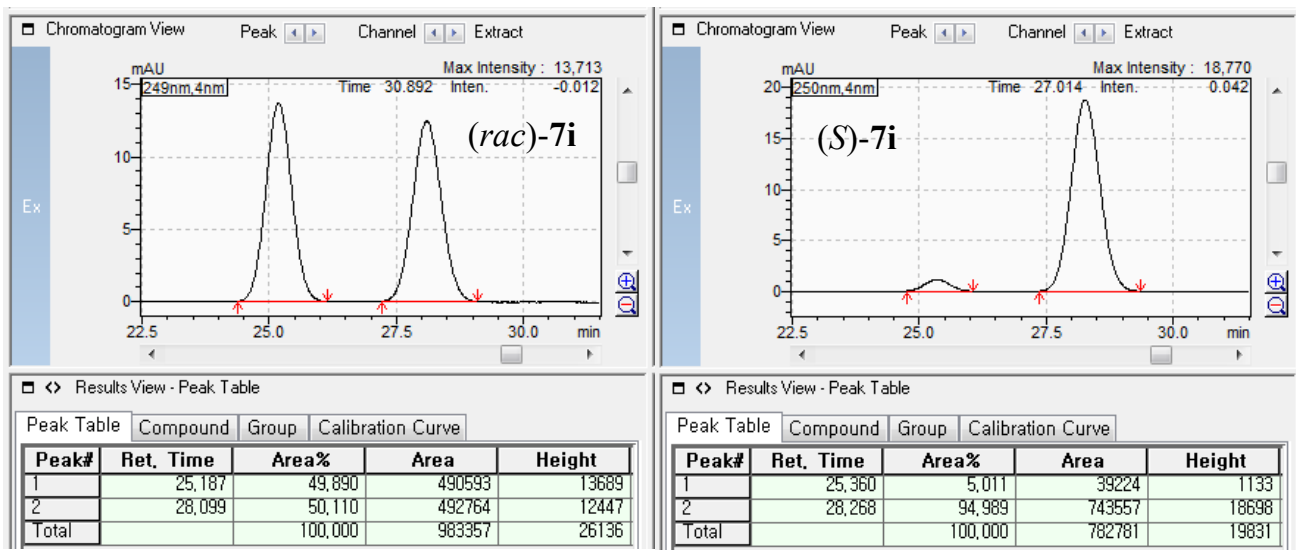
<smiles>C=CC(CCCOC(=O)O)C(=CSc1ccc(F)cc1)C(=O)OCc1ccccc1</smiles>

Colorless oil (27.4 mg, 70\%, EtOAc:Hex =1:4); $[\alpha]^{20}{ }_{\mathrm{D}}=21.4^{\circ}\left(\mathrm{c} 1.00, \mathrm{CHCl}_{3}, 86 \% \mathrm{ee}\right) ;{ }^{1} \mathrm{H}$ NMR (400 MHz, $\left.\mathrm{CDCl}_{3}\right): \delta 7.44(\mathrm{dd}, J=8.8,5.2 \mathrm{~Hz}, 2 \mathrm{H}), 7.06(\mathrm{t}, J=8.7 \mathrm{~Hz}, 2 \mathrm{H}), 6.77(\mathrm{~d}, J$ $=0.5 \mathrm{~Hz}, 1 \mathrm{H}), 5.76(\mathrm{ddd}, J=17.5,9.8,7.6 \mathrm{~Hz}, 1 \mathrm{H}), 5.05(\mathrm{~d}, J=10.2 \mathrm{~Hz}, 1 \mathrm{H}), 5.04(\mathrm{~d}, J=17.2$ $\mathrm{Hz}, 1 \mathrm{H}), 4.10-3.99$ (m, 2H), 3.18 (dt, $J=6.7,6.6 \mathrm{~Hz}, 1 \mathrm{H}), 2.02(\mathrm{~s}, 3 \mathrm{H}), 1.72-1.44(\mathrm{~m}, 4 \mathrm{H})$, $1.55(\mathrm{~s}, 9 \mathrm{H}) ;{ }^{13} \mathrm{C} \mathrm{NMR}\left(100 \mathrm{MHz}, \mathrm{CDCl}_{3}\right): \delta 171.1,165.8,162.7(\mathrm{~d}, J=247.2 \mathrm{~Hz}), 143.1$, 139.9, $133.3(\mathrm{~d}, J=8.1 \mathrm{~Hz}), 132.7(\mathrm{~d}, J=3.5 \mathrm{~Hz}), 129.4,116.4(\mathrm{~d}, J=21.8 \mathrm{~Hz}), 115.4,81.7$, 64.4, 46.0, 30.2, 28.3, 26.7, 21.0; ${ }^{19} \mathrm{~F}$ NMR (376 MHz, $\left.\mathrm{CDCl}_{3}\right): \delta$-113.3; IR (ATR): $\tilde{\mathrm{v}}=2979$, 2933, 2876, 1739, 1690, 1592, 1492, 1368, 1231, 1157, 1043, 919, 830, $755 \mathrm{~cm}^{-1}$; HRMS (ESI) Calcd for $\mathrm{C}_{21} \mathrm{H}_{27} \mathrm{FNaO}_{4} \mathrm{~S}^{+}[\mathrm{M}+\mathrm{Na}]^{+} 417.1506$, found 417.1512 .

Chiral assay was conducted on Chiralpak ${ }^{\circledR}$ OD-H column using IPA:nHex (1:99) as an eluent $(1.0 \mathrm{~mL} / \mathrm{min})$.
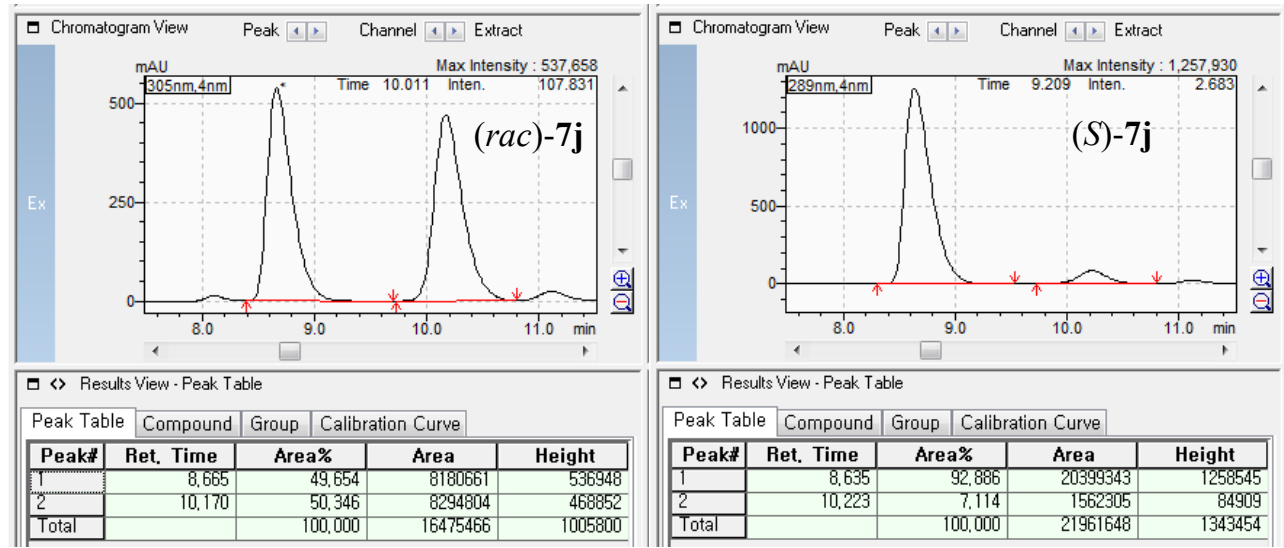
<smiles>C=CC(CCCOCc1ccccc1)C(=CSc1ccc(F)cc1)C(=O)OC</smiles>

Pale yellow oil (35.2 mg, 80\%, EtOAc:Hex = 1:10); $[\alpha]^{20}{ }_{\mathrm{D}}=15.8^{\circ}$ (c 1.00, $\mathrm{CHCl}_{3}, 90 \%$ ee); ${ }^{1} \mathrm{H}$ NMR (400 MHz, $\left.\mathrm{CDCl}_{3}\right): \delta 7.43(\mathrm{dd}, J=8.8,5.2 \mathrm{~Hz}, 2 \mathrm{H}), 7.36-7.23(\mathrm{~m}, 5 \mathrm{H}), 7.04(\mathrm{t}, J=$ $8.8 \mathrm{~Hz}, 2 \mathrm{H}), 6.77$ (d, $J=0.5 \mathrm{~Hz}, 1 \mathrm{H}), 5.76(\mathrm{ddd}, J=16.9,10.4,7.6 \mathrm{~Hz}, 1 \mathrm{H}), 5.03$ (d, $J=17.1$ $\mathrm{Hz}, 1 \mathrm{H}), 5.02$ (d, $J=10.4 \mathrm{~Hz}, 1 \mathrm{H}), 4.48$ (s, 2H), 3.52-3.39 (m, 2H), 3.19 (td, $J=6.9,5.9 \mathrm{~Hz}$, 1H), 1.74-1.45 (m, 4H), $1.54(\mathrm{~s}, 9 \mathrm{H}) ;{ }^{13} \mathrm{C} \mathrm{NMR}\left(100 \mathrm{MHz}, \mathrm{CDCl}_{3}\right): \delta 165.9,162.6(\mathrm{~d}, J=246.5$ Hz), 142.7, 140.3, 138.6, 133.3 (d, $J=8.3 \mathrm{~Hz}), 132.8$ (d, $J=3.3 \mathrm{~Hz}), 129.7,128.4,127.6127 .5$, $116.4(\mathrm{~d}, J=21.9 \mathrm{~Hz}), 115.1,81.6,72.9,70.2,46.1,30.4,28.3,27.8 ;{ }^{19} \mathrm{~F}$ NMR $(376 \mathrm{MHz}$, $\mathrm{CDCl}_{3}$ ): $\delta$-113.5; IR (ATR): $\tilde{\mathrm{v}}=3069,2978,2938,2858,1670,1592,1491,1230,1156,1094$, 916, 829, $755 \mathrm{~cm}^{-1}$; HRMS (ESI) Calcd for $\mathrm{C}_{26} \mathrm{H}_{31} \mathrm{FNaO}_{3} \mathrm{~S}^{+}[\mathrm{M}+\mathrm{Na}]^{+}$465.1870, found 465.1875 .

Chiral assay was conducted on Chiralpak ${ }^{\circledR}$ IC column using IPA: $n$ Hex $(0.5: 99.5)$ as an eluent $(1.0 \mathrm{~mL} / \mathrm{min})$.

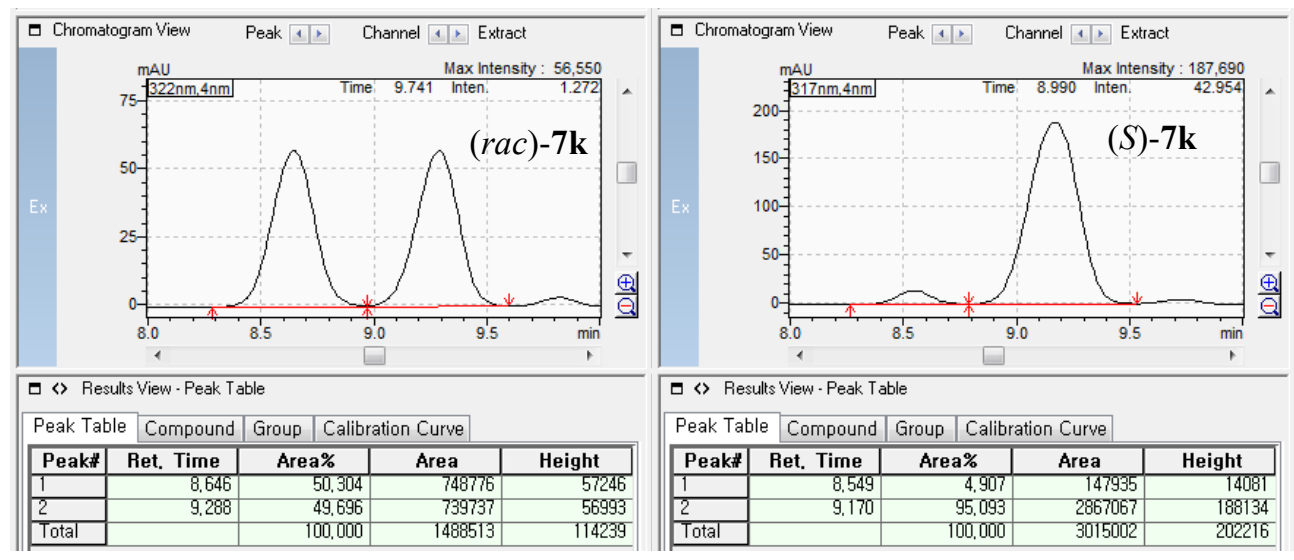




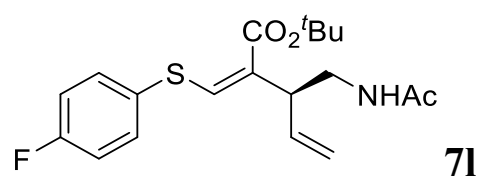

Pale yellow oil (29.3 mg, 80\%, EtOAc: $\mathrm{Hex}=1: 1) ;[\alpha]^{20} \mathrm{D}=-2.3^{\circ}\left(\mathrm{c} 1.00, \mathrm{CHCl}_{3}, 94 \% \mathrm{ee}\right) ;{ }^{1} \mathrm{H}$ NMR (400 MHz, $\left.\mathrm{CDCl}_{3}\right): \delta 7.44(\mathrm{dd}, J=8.8,5.2 \mathrm{~Hz}, 2 \mathrm{H}), 7.06(\mathrm{t}, J=8.6 \mathrm{~Hz}, 2 \mathrm{H}), 6.88(\mathrm{~s}$, 1H), 5.80 (ddd, $J=17.4,10.6,7.0 \mathrm{~Hz}, 1 \mathrm{H}), 5.58$ (s, br, 1H), 5.13 (d, $J=9.3 \mathrm{~Hz}, 1 \mathrm{H}), 5.12$ (d, $J=17.2 \mathrm{~Hz}, 1 \mathrm{H}), 3.58-3.31(\mathrm{~m}, 3 \mathrm{H}), 1.95(\mathrm{~s}, 3 \mathrm{H}), 1.57(\mathrm{~s}, 9 \mathrm{H}) ;{ }^{13} \mathrm{C} \mathrm{NMR}\left(100 \mathrm{MHz}, \mathrm{CDCl}_{3}\right)$ : $\delta 169.9,165.8,162.8(\mathrm{~d}, J=247.2 \mathrm{~Hz}), 145.3,137.4,133.4(\mathrm{~d}, J=8.2 \mathrm{~Hz}), 132.1(\mathrm{~d}, J=3.5$ $\mathrm{Hz}), 126.5,116.9,116.5$ (d, $J=21.9 \mathrm{~Hz}), 82.3,46.2,42.5,28.3,23.3 ;{ }^{19} \mathrm{~F}$ NMR (376 MHz, $\mathrm{CDCl}_{3}$ ): $\delta$-112.9; IR (ATR): $\tilde{\mathrm{v}}=3293,3082,2978,2933,1690,1562,1491,1368,1231,1156$, 917, 833, $760 \mathrm{~cm}^{-1}$; HRMS (ESI) Calcd for $\mathrm{C}_{19} \mathrm{H}_{24} \mathrm{FNNaO}_{3} \mathrm{~S}^{+}[\mathrm{M}+\mathrm{Na}]^{+}$388.1353, found 388.1359 .

Chiral assay was conducted on Chiralpak ${ }^{\circledR}$ IC column using IPA: $n$ Hex $(20: 80)$ as an eluent $(1.0$ $\mathrm{mL} / \mathrm{min})$.
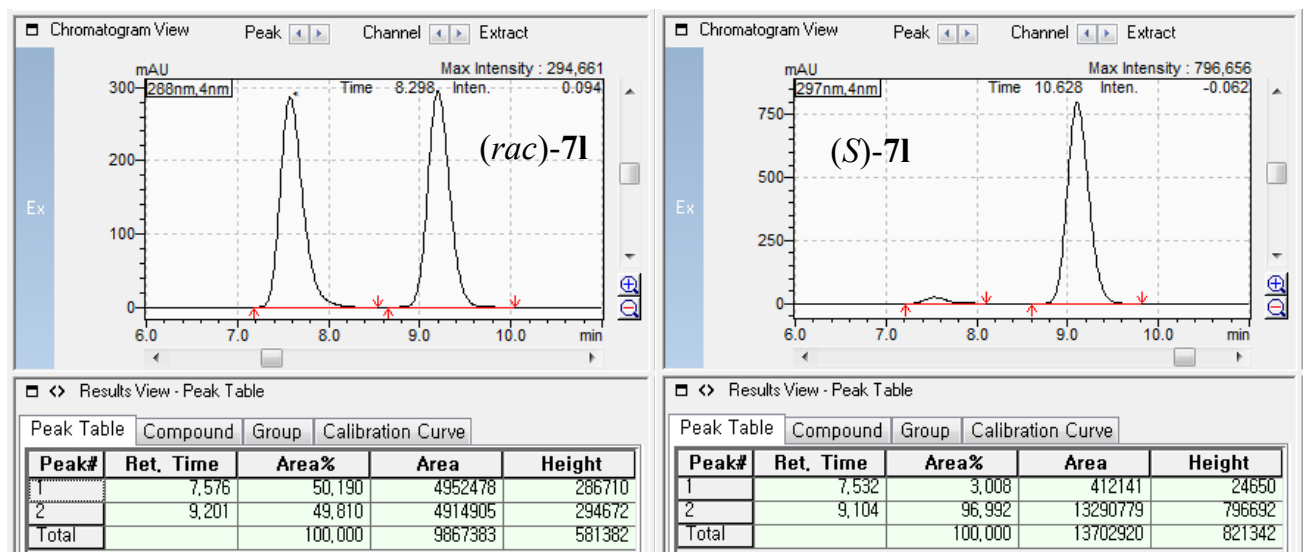
$\overbrace{7 m}$

White solid (29.8 mg, 97\%, EtOAc:Hex =1:4), $\mathrm{mp}=63 \sim 64{ }^{\circ} \mathrm{C} ;[\alpha]^{20} \mathrm{D}=-37.2^{\circ}\left(\mathrm{c} 1.35, \mathrm{CHCl}_{3}\right.$, $92 \%$ ee); ${ }^{1} \mathrm{H}$ NMR (400 MHz, $\left.\mathrm{CDCl}_{3}\right): \delta$ 7.85-7.81 (m, 2H), 7.73-7.69 (m, 2H), 7.35 (dd, $J=$ 8.8, 5.2 Hz, 2H), 7.01 (t, $J=8.6 \mathrm{~Hz}, 2 \mathrm{H}), 6.93$ (s, 1H), 5.94 (ddd, $J=17.2,10.2,8.0 \mathrm{~Hz}, 1 \mathrm{H})$, $5.06(\mathrm{~d}, J=17.2 \mathrm{~Hz}, 1 \mathrm{H}), 5.04(\mathrm{~d}, J=10.2 \mathrm{~Hz}, 1 \mathrm{H}), 3.99-3.85(\mathrm{~m}, 2 \mathrm{H}), 3.73(\mathrm{dt}, J=8.0,7.7 \mathrm{~Hz}$, 1H), $1.56(\mathrm{~s}, 9 \mathrm{H}) ;{ }^{13} \mathrm{C} \mathrm{NMR}\left(100 \mathrm{MHz}, \mathrm{CDCl}_{3}\right): \delta 168.1,165.3,162.7(\mathrm{~d}, J=247.1 \mathrm{~Hz}), 146.4$, 136.9, 134.0, $133.5(\mathrm{~d}, J=8.1 \mathrm{~Hz}), 132.4(\mathrm{~d}, J=3.3 \mathrm{~Hz}), 132.0,125.7,123.2,117.3,116.4(\mathrm{~d}$, $J=21.8 \mathrm{~Hz}), 82.0,46.4,41.3,28.3 ;{ }^{19} \mathrm{~F}$ NMR (376 MHz, $\left.\mathrm{CDCl}_{3}\right): \delta-113.1$; IR (ATR): $\tilde{\mathrm{v}}=$ 3074, 2977, 2942, 1765, 1713, 1493, 1392, 1361, 1230, 1137, 313, 834, $716 \mathrm{~cm}^{-1}$; HRMS (ESI) calcd for $\mathrm{C}_{25} \mathrm{H}_{24} \mathrm{FNNaO}_{4} \mathrm{~S}^{+}[\mathrm{M}+\mathrm{Na}]^{+}$476.1302, found 476.1308 .

Chiral assay was conducted on Chiralpak ${ }^{\circledR}$ IG column using IPA: $n$ Hex (20:80) as an eluent (1.0 $\mathrm{mL} / \mathrm{min})$.
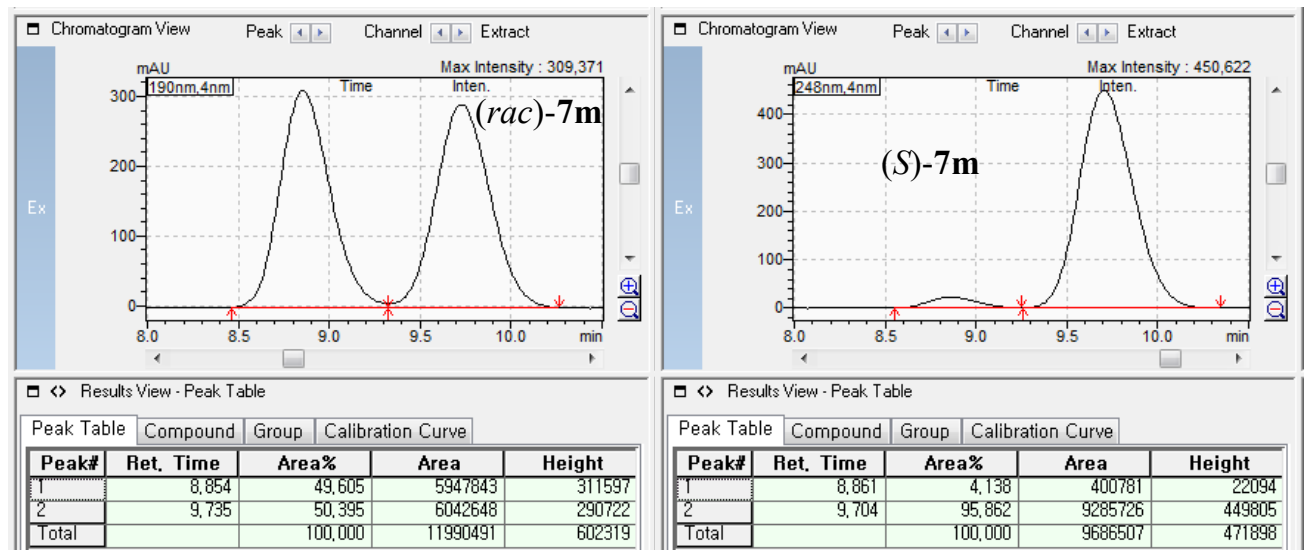
<smiles>C=CC(CCl)/C(=C/Sc1ccc(F)cc1)C(=O)OCC</smiles>

Colorless oil (23.1 mg, 67\%, EtOAc:Hex = 1:10); $[\alpha]^{20} \mathrm{D}=12.2^{\circ}\left(\mathrm{c} 1.00, \mathrm{CHCl}_{3}, 91 \%\right.$ ee); ${ }^{1} \mathrm{H}$ NMR (400 MHz, $\left.\mathrm{CDCl}_{3}\right): \delta 7.46(\mathrm{dd}, J=8.6,5.2 \mathrm{~Hz}, 2 \mathrm{H}), 7.07(\mathrm{t}, J=8.6 \mathrm{~Hz}, 2 \mathrm{H}), 6.93(\mathrm{~s}$, 1H), 5.88 (ddd, $J=16.6,11.0,7.1 \mathrm{~Hz}, 1 \mathrm{H}), 5.19$ (d, $J=10.2 \mathrm{~Hz}, 1 \mathrm{H}), 5.18$ (d, $J=17.0 \mathrm{~Hz}$, 1H), 3.76 (dd of ABq, $J=10.7,6.4 \mathrm{~Hz}, 1 \mathrm{H}), 3.65$ (dd of ABq, $J=10.7,6.8 \mathrm{~Hz}, 1 \mathrm{H}), 3.55$ (q, $J$ $=6.8 \mathrm{~Hz}, 1 \mathrm{H}), 1.57(\mathrm{~s}, 9 \mathrm{H}) ;{ }^{13} \mathrm{C} \mathrm{NMR}\left(100 \mathrm{MHz}, \mathrm{CDCl}_{3}\right): \delta 165.2,162.8(\mathrm{~d}, J=247.4 \mathrm{~Hz})$, 146.5, 136.4, 133.4 (d, $J=8.3 \mathrm{~Hz}), 132.4$ (d, $J=3.5 \mathrm{~Hz}), 125.6,117.5,116.5$ (d, $J=21.9 \mathrm{~Hz})$, 82.2, 48.9, 46.3, 28.3; $\left.{ }^{19} \mathrm{~F} \mathrm{NMR} \mathrm{(376} \mathrm{MHz,} \mathrm{CDCl}_{3}\right): \delta$-113.0; IR (ATR): $\tilde{\mathrm{v}}=3082,2980,2933$, 1692, 1592, 1491, 1368, 1232, 1157, 923, 833, $755 \mathrm{~cm}^{-1}$; HRMS (ESI) Calcd for $\mathrm{C}_{17} \mathrm{H}_{20} \mathrm{ClFNaO}_{2} \mathrm{~S}^{+}[\mathrm{M}+\mathrm{Na}]^{+}$365.0749, found 365.0751.

The product was derivatized into the corresponding sulfone according to Method A, and chiral assay of the sulfone Chiral assay was conducted on Chiralpak ${ }^{\circledR}$ IC column using IPA: $n$ Hex $(10: 90)$ as an eluent $(1.0 \mathrm{~mL} / \mathrm{min})$.
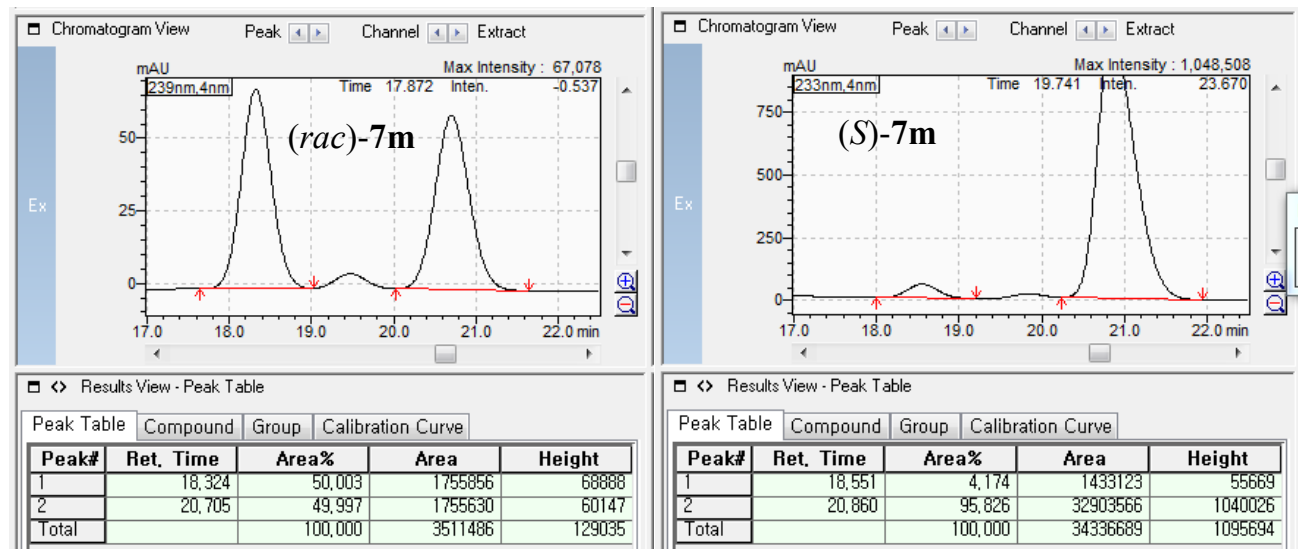
<smiles>C=CC(CSc1ccc(F)cc1)C(=CSc1ccc(F)cc1)C(=O)OC(C)(C)C</smiles>

Colorless oil (39.7 mg, 91\%, EtOAc:Hex = 1:10); $[\alpha]^{20} \mathrm{D}=-30.8^{\circ}\left(\mathrm{c} 1.00, \mathrm{CHCl}_{3}, 93 \% \mathrm{ee}\right) ;{ }^{1} \mathrm{H}$ $\operatorname{NMR}\left(400 \mathrm{MHz}, \mathrm{CDCl}_{3}\right): \delta 7.43(\mathrm{dd}, J=8.9,5.2 \mathrm{~Hz}, 2 \mathrm{H}), 7.33(\mathrm{dd}, J=8.9,5.2 \mathrm{~Hz}, 2 \mathrm{H}), 7.06$ (t, $J=8.6 \mathrm{~Hz}, 2 \mathrm{H}), 6.97$ (t, $J=8.6 \mathrm{~Hz}, 2 \mathrm{H}), 6.81$ (d, $J=0.5 \mathrm{~Hz}, 1 \mathrm{H}), 5.89$ (ddd, $J=17.4,10.3$, $7.3 \mathrm{~Hz}, 1 \mathrm{H}), 5.11(\mathrm{~d}, J=10.2 \mathrm{~Hz}, 1 \mathrm{H}), 5.07$ (d, $J=17.1 \mathrm{~Hz}, 1 \mathrm{H}), 3.38$ (dt, $J=7.3,7.1 \mathrm{~Hz}, 1 \mathrm{H})$, $3.20(\mathrm{dd}$ of ABq, $J=13.0,7.2 \mathrm{~Hz}, 1 \mathrm{H}), 3.08$ (dd of ABq, $J=13.0,7,4 \mathrm{~Hz}, 1 \mathrm{H}), 1.51$ (s, 9H); ${ }^{13} \mathrm{C} \mathrm{NMR}\left(100 \mathrm{MHz}, \mathrm{CDCl}_{3}\right): \delta 165.3,162.7(\mathrm{~d}, J=247.0 \mathrm{~Hz}), 161.8(\mathrm{~d}, J=245.1 \mathrm{~Hz}), 145.3$, 138.3, 133.3 (d, $J=8.4 \mathrm{~Hz}), 132.7$ (d, $J=8.0 \mathrm{~Hz}), 132.5$ (d, $J=3.2 \mathrm{~Hz}), 131.2(\mathrm{~d}, J=3.1 \mathrm{~Hz})$, 127.2, 116.4, 116.4 (d, $J=21.8 \mathrm{~Hz}), 116.0$ (d, $J=21.7 \mathrm{~Hz}), 81.9,46.8,39.1,28.3 ;{ }^{19} \mathrm{~F}$ NMR (376 MHz, $\mathrm{CDCl}_{3}$ ): $\delta$-113.1, -115.4; IR (ATR): $\tilde{\mathrm{v}}=3078,2979,2929,1692,1591,1491,1368$, 1230, 1156, 1091, 920, 829, $755 \mathrm{~cm}^{-1}$; HRMS (ESI) Calcd for $\mathrm{C}_{23} \mathrm{H}_{24} \mathrm{~F}_{2} \mathrm{NaO}_{2} \mathrm{~S}_{2}{ }^{+}[\mathrm{M}+\mathrm{Na}]^{+}$ 457.1078, found 457.1080 .

Chiral assay was conducted on Chiralpak ${ }^{\circledR}$ IC column using IPA: $n$ Hex $(0.5: 99.5)$ as an eluent $(1.0 \mathrm{~mL} / \mathrm{min})$.
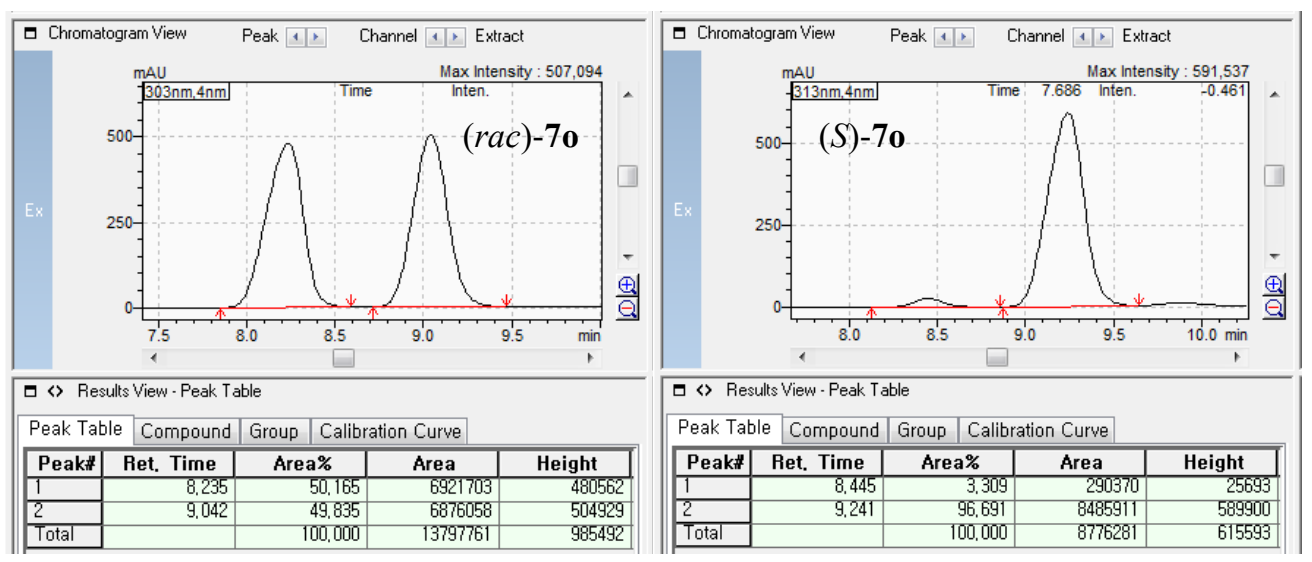
<smiles>C=CC(C=Cc1ccc(F)cc1)C(=CC(=O)OCc1ccccc1)C(=O)O</smiles>

Colorless oil (32.3 mg, 86\%, EtOAc:Hex = 1:10); $[\alpha]^{20}{ }_{\mathrm{D}}=42.3^{\circ}\left(\mathrm{c} 1.00, \mathrm{CHCl}_{3}, 95 \% \mathrm{ee}\right) ;{ }^{1} \mathrm{H}$ NMR (400 MHz, $\left.\mathrm{CDCl}_{3}\right): \delta 7.44(\mathrm{dd}, J=8.8,5.2 \mathrm{~Hz}, 2 \mathrm{H}), 7.06(\mathrm{t}, J=8.8 \mathrm{~Hz}, 2 \mathrm{H}), 6.72(\mathrm{~s}$, 1H), 5.84 (ddd, $J=16.8,10.3,9.0 \mathrm{~Hz}, 1 \mathrm{H}), 5.00$ (d, $J=10.3 \mathrm{~Hz}, 1 \mathrm{H}), 4.99$ (d, $J=16.8 \mathrm{~Hz}$, $1 \mathrm{H}), 2.84(\mathrm{t}, J=8.9 \mathrm{~Hz}, 1 \mathrm{H}), 1.84-1.48(\mathrm{~m}, 5 \mathrm{H}), 1.55(\mathrm{~s}, 9 \mathrm{H}), 1.36-1.02(\mathrm{~m}, 4 \mathrm{H}), 0.95-0.73(\mathrm{~m}$, $2 \mathrm{H}) ;{ }^{13} \mathrm{C} \mathrm{NMR}\left(100 \mathrm{MHz}, \mathrm{CDCl}_{3}\right): \delta 166.0,162.3(\mathrm{~d}, J=246.9 \mathrm{~Hz}), 142.6,139.5,133.2(\mathrm{~d}, J$ $=8.1 \mathrm{~Hz}), 133.0(\mathrm{~d}, J=3.5 \mathrm{~Hz}), 129.5,116.4(\mathrm{~d}, J=21.8 \mathrm{~Hz}), 115.6,81.5,54.5,40.5,31.5$, 31.2, 28.4, 26.5, 26.5, 26.4; ${ }^{19} \mathrm{~F}$ NMR (376 MHz, $\left.\mathrm{CDCl}_{3}\right): \delta$-113.6; IR (ATR): $\tilde{\mathrm{v}}=3078,3008$, 2978, 2927, 2853, 1690, 1592, 1491, 1449, 1392, 1368, 1230, 1156, 914, 830, $755 \mathrm{~cm}^{-1}$; HRMS (ESI) Calcd for $\mathrm{C}_{22} \mathrm{H}_{29} \mathrm{FNaO}_{2} \mathrm{~S}^{+}[\mathrm{M}+\mathrm{Na}]^{+} 399.1765$, found 399.1767.

Chiral assay was conducted on Chiralpak ${ }^{\circledR}$ IA column using IPA:nHex (0.5:99.5) as an eluent $(1.0 \mathrm{~mL} / \mathrm{min})$.

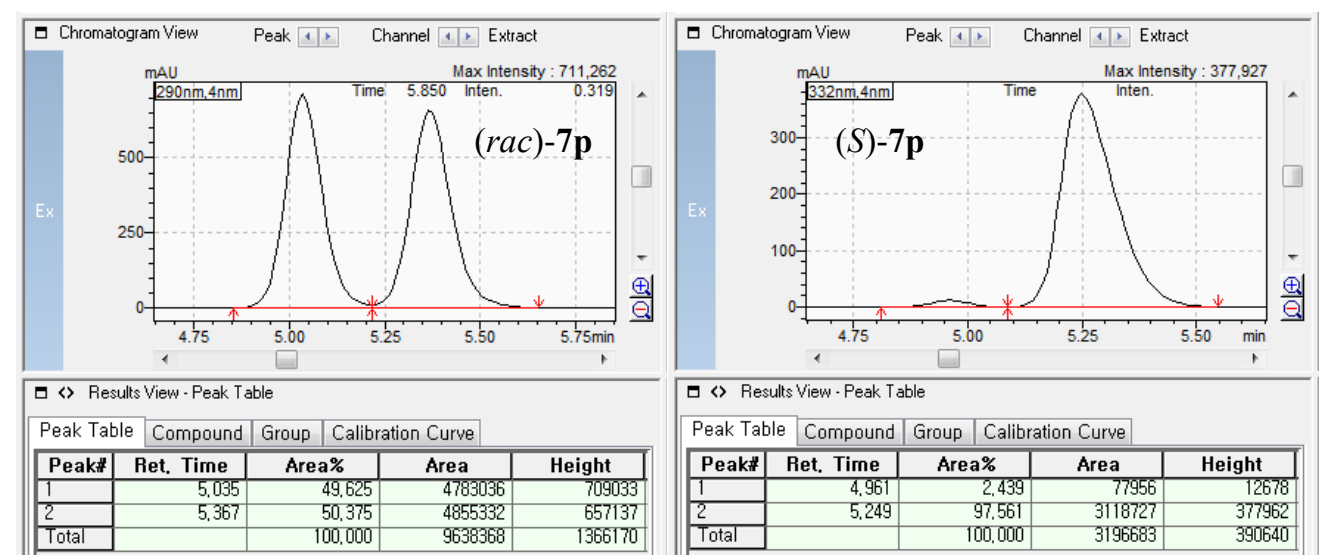


<smiles>C=CC(CC(C)C)C(=CSc1ccc(F)cc1)C(=O)OCC</smiles>

Pale yellow oil (32.2 mg, 92\%, EtOAc:Hex = 1:10); $[\alpha]^{20}{ }_{\mathrm{D}}=44.2^{\circ}$ (c 1.00, $\mathrm{CHCl}_{3}, 89 \%$ ee); ${ }^{1} \mathrm{H}$ NMR (400 MHz, $\mathrm{CDCl}_{3}$ ): $\delta 7.43(\mathrm{dd}, J=8.9,5.2 \mathrm{~Hz}, 2 \mathrm{H}), 7.06(\mathrm{t}, J=8.6 \mathrm{~Hz}, 2 \mathrm{H}), 6.75(\mathrm{~d}$, $J=0.6 \mathrm{~Hz}, 1 \mathrm{H}), 5.75$ (ddd, $J=17.2,10.2,7.7 \mathrm{~Hz}, 1 \mathrm{H}), 5.03$ (d, $J=17.2 \mathrm{~Hz}, 1 \mathrm{H}), 5.01$ (d, $J=$ $10.2 \mathrm{~Hz}, 1 \mathrm{H}), 3.30(\mathrm{td}, J=7.8,6.9 \mathrm{~Hz}, 1 \mathrm{H}), 1.65-1.50(\mathrm{~m}, 1 \mathrm{H}), 1.56(\mathrm{~s}, 9 \mathrm{H}), 1.48-1.30(\mathrm{~m}, 2 \mathrm{H})$, 0.89 (dd, $J=6.6,1.5 \mathrm{~Hz}, 6 \mathrm{H}) ;{ }^{13} \mathrm{C} \mathrm{NMR}\left(100 \mathrm{MHz}, \mathrm{CDCl}_{3}\right): \delta 166.0,162.6$ (d, $\left.J=246.5 \mathrm{~Hz}\right)$, 142.5, 140.1, 133.2 (d, $J=8.2 \mathrm{~Hz}), 133.0$ (d, $J=3.2 \mathrm{~Hz}), 130.2,116.4$ (d, $J=21.8 \mathrm{~Hz}), 114.7$, 81.5, 43.9, 43.3, 28.3, 25.5, 23.0, 22.2; $\left.{ }^{19} \mathrm{~F} \mathrm{NMR} \mathrm{(376} \mathrm{MHz,} \mathrm{CDCl}_{3}\right): \delta-113.6$; IR (ATR): $\tilde{\mathrm{v}}=$ 3008, 2957, 2928, 2872, 1690, 1592, 1491, 1368, 1230, 1156, 1092, 915, 830, $756 \mathrm{~cm}^{-1}$; HRMS (ESI) Calcd for $\mathrm{C}_{20} \mathrm{H}_{27} \mathrm{FNaO}_{2} \mathrm{~S}^{+}[\mathrm{M}+\mathrm{Na}]^{+} 373.1608$, found 373.1610 .

Chiral assay was conducted on Chiralpak ${ }^{\circledR}$ IG column using IPA: $n$ Hex $(0.5: 99.5)$ as an eluent $(1.0 \mathrm{~mL} / \mathrm{min})$.
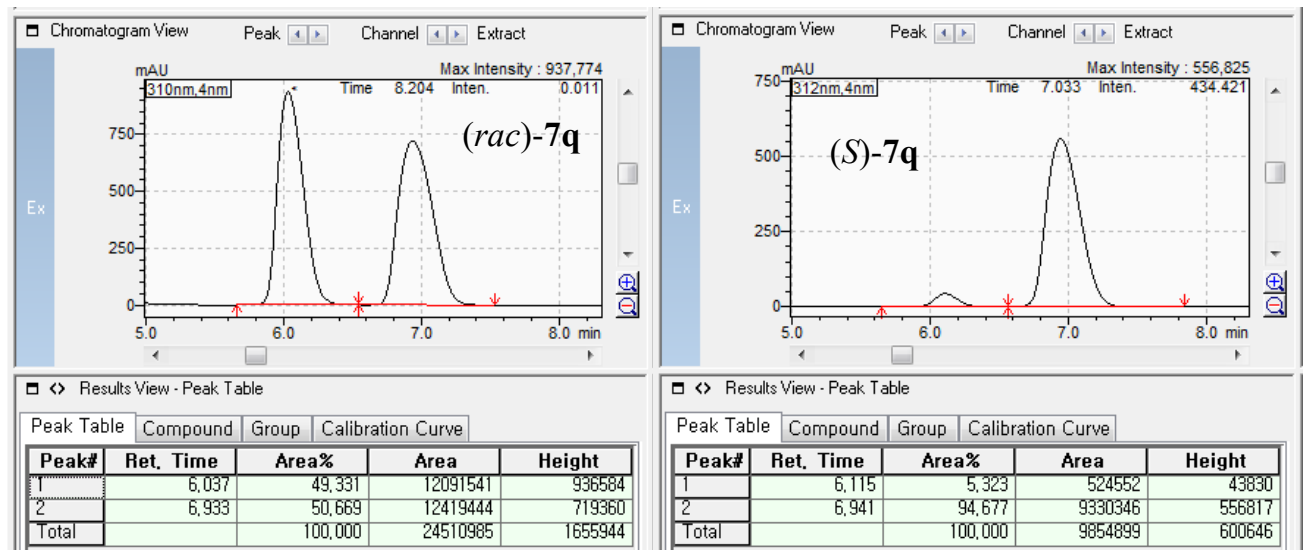
<smiles>C=CC(C#Cc1ccccc1)C(=CSc1ccc(F)cc1)C(=O)O</smiles>

Colorless oil (33.5 mg, 85\%, EtOAc:Hex = 1:10); $[\alpha]^{20}{ }_{\mathrm{D}}=-72.7^{\circ}\left(\mathrm{c} 1.00, \mathrm{CHCl}_{3}, 91 \% \mathrm{ee}\right) ;{ }^{1} \mathrm{H}$ $\operatorname{NMR}\left(400 \mathrm{MHz}, \mathrm{CDCl}_{3}\right): \delta 7.47(\mathrm{dd}, J=8.8,5.2 \mathrm{~Hz}, 2 \mathrm{H}), 7.42(\mathrm{~d}, J=0.7 \mathrm{~Hz}, 1 \mathrm{H}), 7.38-7.23$ (m, 5H), 7.04 (t, $J=8.6 \mathrm{~Hz}, 2 \mathrm{H}), 5.87$ (ddd, $J=16.9,9.9,5.8 \mathrm{~Hz}, 1 \mathrm{H}), 5.41(\mathrm{dt}, J=16.9,1.4$ $\mathrm{Hz}, 1 \mathrm{H}), 5.15$ (dt, $J=9.9,1.4 \mathrm{~Hz}, 1 \mathrm{H}), 4.54(\mathrm{dd}, J=5.8,0.6 \mathrm{~Hz}, 1 \mathrm{H}), 1.57$ (s, 9H); ${ }^{13} \mathrm{C} \mathrm{NMR}$ $\left(100 \mathrm{MHz}, \mathrm{CDCl}_{3}\right): \delta 164.9,162.7(\mathrm{~d}, J=247.0 \mathrm{~Hz}), 145.5,136.0,133.0(\mathrm{~d}, J=8.1 \mathrm{~Hz}), 132.6$ (d, $J=3.2 \mathrm{~Hz}), 131.5,128.3,128.1,125.2,123.2,116.4$ (d, $J=21.9 \mathrm{~Hz}), 115.8,87.7,86.0$, 82.0, 38.6, 28.3; ${ }^{19} \mathrm{~F}$ NMR (376 MHz, $\mathrm{CDCl}_{3}$ ): $\delta$-113.4; IR (ATR): $\tilde{\mathrm{v}}=3065,2980,2933,1696$, $1590,1491,1369,1230,1156,833,756 \mathrm{~cm}^{-1}$; HRMS (ESI) Calcd for $\mathrm{C}_{24} \mathrm{H}_{23} \mathrm{FNaO}_{2} \mathrm{~S}^{+}[\mathrm{M}+\mathrm{Na}]^{+}$ 417.1295, found 417.1299.

Chiral assay was conducted on Chiralpak ${ }^{\circledR}$ IG column using IPA: $n$ Hex $(0.5: 99.5)$ as an eluent $(1.0 \mathrm{~mL} / \mathrm{min})$.
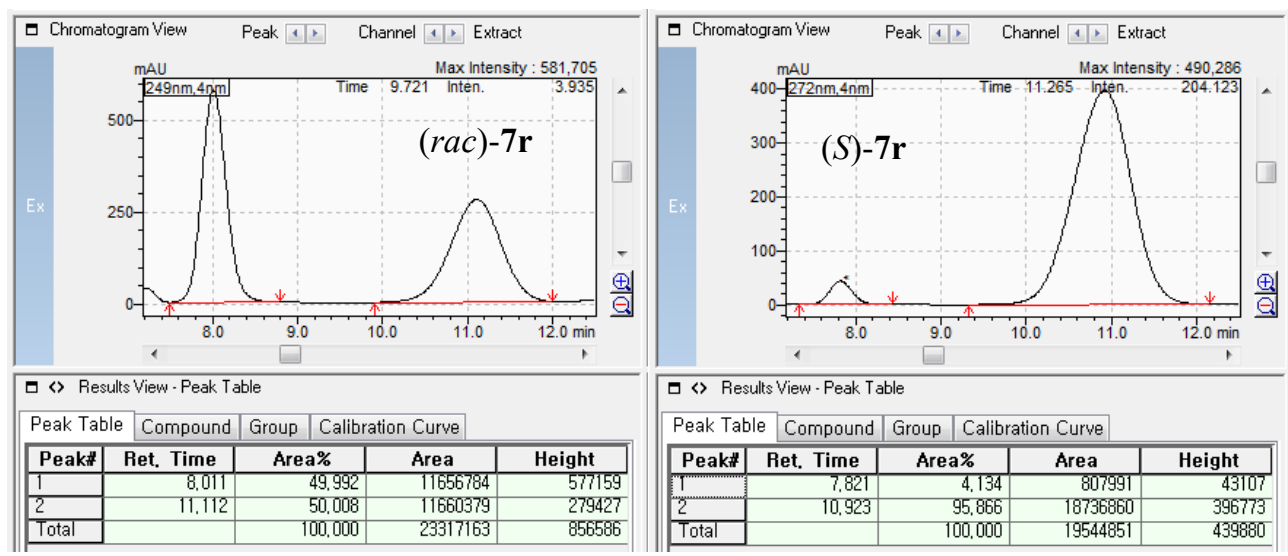


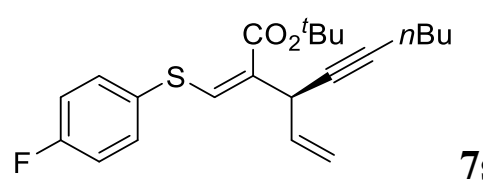

$(S)$ - Yellow oil (32.2 mg, 86\%, EtOAc:Hex =1:10); $[\alpha]^{20}{ }_{\mathrm{D}}=-103.2^{\circ}$ (c 1.00, $\mathrm{CHCl}_{3}, 95 \%$ ee), $(R)$ - Yellow oil (31.8 mg, 85\%, EtOAc:Hex = 1:10); $[\alpha]^{20}{ }_{\mathrm{D}}=92.6^{\circ}$ (c 1.00, $\mathrm{CHCl}_{3}, 87 \%$ ee); ${ }^{1} \mathrm{H}$ NMR (400 MHz, $\left.\mathrm{CDCl}_{3}\right): \delta 7.46(\mathrm{dd}, J=8.9,5.2 \mathrm{~Hz}, 2 \mathrm{H}), 7.34(\mathrm{~d}, J=0.8 \mathrm{~Hz}, 1 \mathrm{H}), 7.05$ (t, $J=8.6 \mathrm{~Hz}, 2 \mathrm{H}), 5.79(\mathrm{ddd}, J=16.9,9.9,5.9 \mathrm{~Hz}, 1 \mathrm{H}), 5.29$ (dt, $J=16.9,1.5 \mathrm{~Hz}, 1 \mathrm{H}), 5.06$ (dt, $J=9.9,1.4 \mathrm{~Hz}, 1 \mathrm{H}), 4.32-4.25(\mathrm{~m}, 1 \mathrm{H}), 2.19(\mathrm{dt}, J=6.8,2.2 \mathrm{~Hz}, 2 \mathrm{H}), 1.54(\mathrm{~s}, 9 \mathrm{H}), 1.48-1.26$ $(\mathrm{m}, 4 \mathrm{H}), 0.83(\mathrm{t}, J=7.3 \mathrm{~Hz}, 3 \mathrm{H}) ;{ }^{13} \mathrm{C}$ NMR $\left(100 \mathrm{MHz}, \mathrm{CDCl}_{3}\right): \delta 165.0,162.4(\mathrm{~d}, J=246.9$ Hz), 145.0, 136.8, 133.1 (d, $J=8.1 \mathrm{~Hz}), 132.6$ (d, $J=3.6 \mathrm{~Hz}), 125.7,116.3$ (d, $J=21.9 \mathrm{~Hz})$, 115.0, 86.6, 81.8, 78.0, 38.1, 31.0, 28.3, 21.9, 18.4, 13.6; $\left.{ }^{19} \mathrm{~F} \mathrm{NMR} \mathrm{(376} \mathrm{MHz}, \mathrm{CDCl}_{3}\right): \delta$ 113.5; IR (ATR): $\tilde{\mathrm{v}}=3016,2961,2933,2858,1693,1592,1491,1368,1230,1155,1092,920$, 845, $751 \mathrm{~cm}^{-1}$; HRMS (ESI) Calcd for $\mathrm{C}_{22} \mathrm{H}_{27} \mathrm{FNaO}_{2} \mathrm{~S}^{+}[\mathrm{M}+\mathrm{Na}]^{+}$397.1608, found 397.1612.

Chiral assay was conducted on Chiralpak ${ }^{\circledR}$ IG column using IPA: $n$ Hex $(0.5: 99.5)$ as an eluent $(1.0 \mathrm{~mL} / \mathrm{min})$.
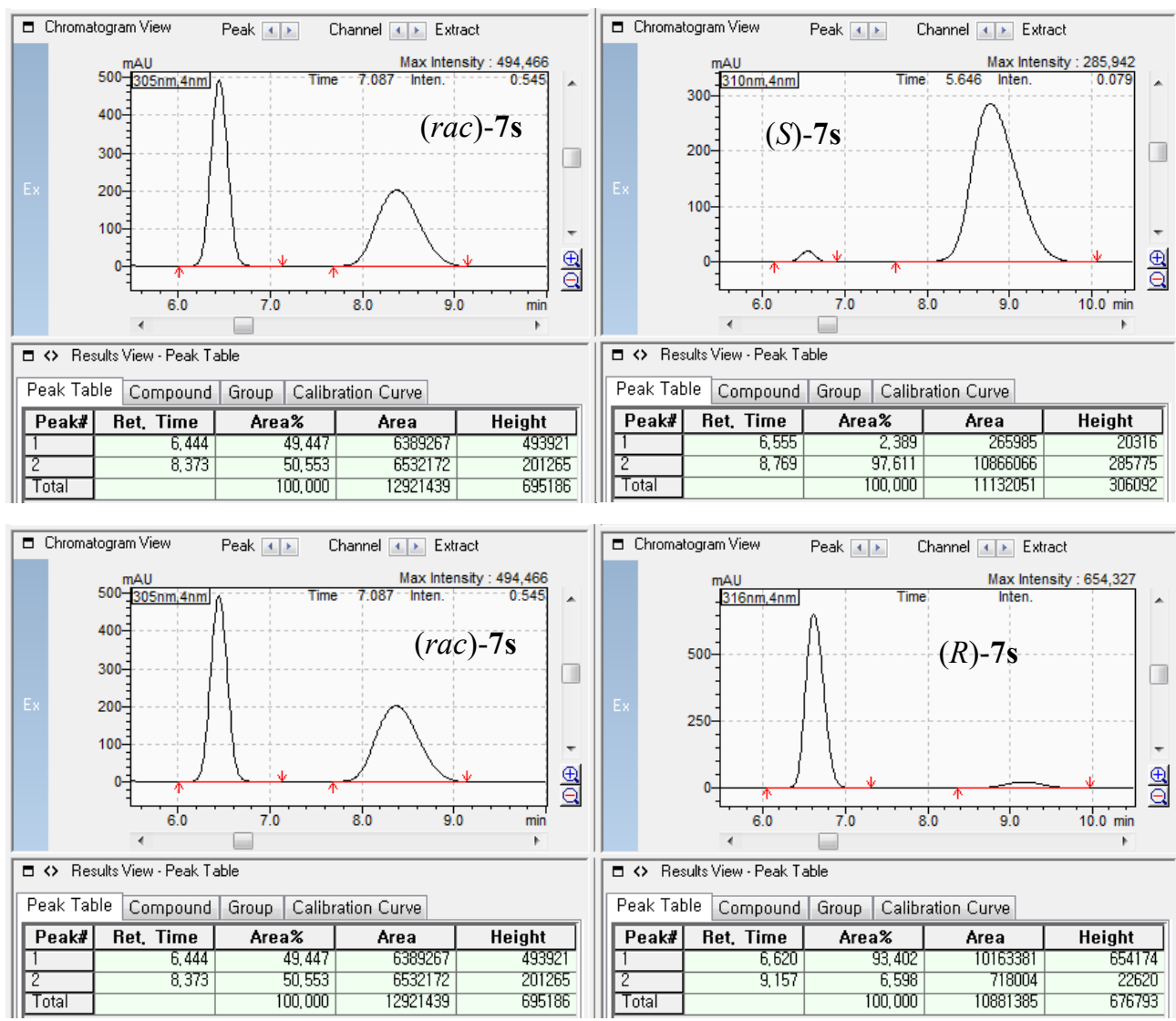
<smiles>C=CCC(C=C)C(=CSc1ccc(F)cc1)C(=O)OCc1ccccc1</smiles>

Pale yellow oil (25.3 mg, 76\%, EtOAc:Hex = 1:20); $[\alpha]^{20}{ }_{\mathrm{D}}=14.7^{\circ}$ (c 1.00, $\mathrm{CHCl}_{3}, 90 \%$ ee); ${ }^{1} \mathrm{H} \mathrm{NMR}\left(400 \mathrm{MHz}, \mathrm{CDCl}_{3}\right): \delta 7.44(\mathrm{dd}, J=8.6,5.2 \mathrm{~Hz}, 2 \mathrm{H}), 7.06(\mathrm{t}, J=8.6 \mathrm{~Hz}, 2 \mathrm{H}), 6.78$ (s, 1H), 5.86-5.66 (m, 2H), 5.10-4.95 (m, 4H), $3.31(\mathrm{td}, J=7.3,7.2 \mathrm{~Hz}, 1 \mathrm{H}), 2.42-2.25(\mathrm{~m}, 2 \mathrm{H})$, $1.55(\mathrm{~s}, 9 \mathrm{H}) ;{ }^{13} \mathrm{C}$ NMR $\left(100 \mathrm{MHz}, \mathrm{CDCl}_{3}\right): \delta 165.8,162.6(\mathrm{~d}, J=246.5 \mathrm{~Hz}), 143.3,139.8$, 136.5, $133.2(\mathrm{~d}, J=8.3 \mathrm{~Hz}), 132.8(\mathrm{~d}, J=3.5 \mathrm{~Hz}), 129.1,116.4(\mathrm{~d}, J=21.8 \mathrm{~Hz}), 116.3,115.2$, 81.6, 45.8, 38.1, 28.3; $\left.{ }^{19} \mathrm{~F} \mathrm{NMR} \mathrm{(376} \mathrm{MHz,} \mathrm{CDCl}_{3}\right): \delta$-113.5; IR (ATR): $\tilde{\mathrm{v}}=3074,2979,2929$, 1692, 1592, 1492, 1368, 1230, 1156, 914, 828, $771 \mathrm{~cm}^{-1}$; HRMS (ESI) Calcd for $\mathrm{C}_{19} \mathrm{H}_{23} \mathrm{FNaO}_{2} \mathrm{~S}^{+}[\mathrm{M}+\mathrm{Na}]^{+}$357.1295, found 357.1297.

The product was derivatized into the corresponding sulfone according to $\operatorname{Method} \mathbf{A}$, and chiral assay of the sulfone Chiral assay was conducted on Chiralpak ${ }^{\circledR}$ IC column using IPA: $n$ Hex (5:95) as an eluent (1.0 $\mathrm{mL} / \mathrm{min})$.

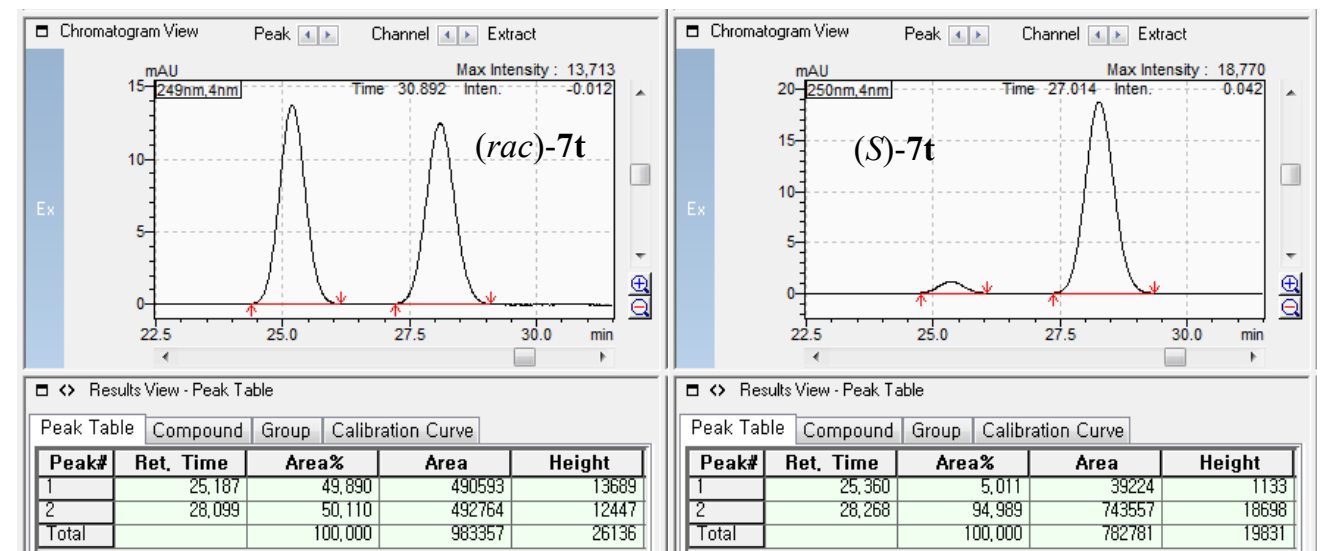


<smiles>C=CC(CC(C)(C)C)(CC(C)(C)C)C(=O)OCc1ccc(F)cc1</smiles>

Colorless oil (27.3 mg, 75\%, EtOAc:Hex = 1:20); $[\alpha]^{20}{ }_{\mathrm{D}}=13.6^{\circ}\left(\mathrm{c} 1.00, \mathrm{CHCl}_{3}, 86 \%\right.$ ee); ${ }^{1} \mathrm{H}$ NMR (400 MHz, $\left.\mathrm{CDCl}_{3}\right): \delta 7.40(\mathrm{dd}, J=8.8,5.2 \mathrm{~Hz}, 2 \mathrm{H}), 7.04(\mathrm{t}, J=8.6 \mathrm{~Hz}, 2 \mathrm{H}), 6.66(\mathrm{~s}$, 1H), $5.93(\mathrm{dd}, J=17.4,10.8 \mathrm{~Hz}, 1 \mathrm{H}), 5.01(\mathrm{~d}, J=10.8 \mathrm{~Hz}, 1 \mathrm{H}), 4.99(\mathrm{~d}, J=17.4 \mathrm{~Hz}, 1 \mathrm{H})$, 1.84-1.73 (m, 1H), 1.66-1.55 (m ,1H), $1.55(\mathrm{~s}, 9 \mathrm{H}), 1.35-1.24(\mathrm{~m}, 2 \mathrm{H}), 1.25(\mathrm{~s}, 3 \mathrm{H}), 1.23-1.12$ $(\mathrm{m}, 2 \mathrm{H}), 0.89$ (t, $J=7.1 \mathrm{~Hz}, 3 \mathrm{H}) ;{ }^{13} \mathrm{C} \mathrm{NMR}\left(100 \mathrm{MHz}, \mathrm{CDCl}_{3}\right): \delta 166.4,162.4(\mathrm{~d}, J=246.6$ $\mathrm{Hz}), 145.5,138.0,135.8132 .7$ (d, $J=8.1 \mathrm{~Hz}), 116.3$ (d, $J=21.8 \mathrm{~Hz}), 112.1,81.8,44.9,38.9$, 28.3, 26.9, 24.5, 23.3, 14.1; ${ }^{19} \mathrm{~F}$ NMR (376 MHz, $\left.\mathrm{CDCl}_{3}\right): \delta$-114.1; IR (ATR): $\tilde{\mathrm{v}}=2964,2931$, 2867, 1713, 1589, 1491, 1368, 1230, 1156, 1093, 1028, 922, 834, $778 \mathrm{~cm}^{-1}$; HRMS (ESI) Calcd for $\mathrm{C}_{21} \mathrm{H}_{29} \mathrm{FNaO}_{2} \mathrm{~S}^{+}[\mathrm{M}+\mathrm{Na}]^{+}$387.1765, found 387.1767.

Chiral assay was conducted on Chiralpak ${ }^{\circledR}$ IA column using IPA: $n$ Hex $(0.5: 99.5)$ as an eluent $(1.0 \mathrm{~mL} / \mathrm{min})$.
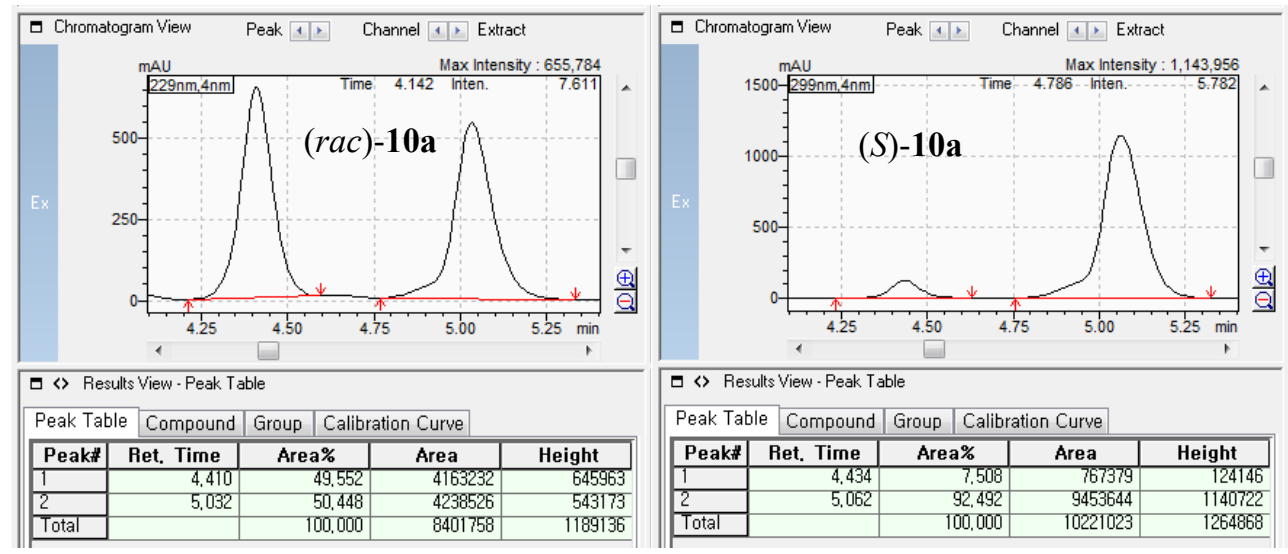
<smiles>C=CC(CCc1ccccc1)(CC(C)(C)C)C(=O)CSc1ccc(F)cc1</smiles>

Colorless oil (31.9 mg, 77\%, EtOAc:Hex = 1:10); $[\alpha]^{20} \mathrm{D}=11.3^{\circ}\left(\mathrm{c} 1.00, \mathrm{CHCl}_{3}, 92 \%\right.$ ee); ${ }^{1} \mathrm{H}$ NMR (400 MHz, $\left.\mathrm{CDCl}_{3}\right): \delta 7.42(\mathrm{dd}, J=8.8,5.2 \mathrm{~Hz}, 2 \mathrm{H}), 7.30-7.22(\mathrm{~m}, 2 \mathrm{H}), 7.20-7.11$ (m, 3H), 7.05 (t, $J=8.7 \mathrm{~Hz}, 2 \mathrm{H}), 6.75(\mathrm{~s}, 1 \mathrm{H}), 5.99(\mathrm{dd}, J=17.3,11.0 \mathrm{~Hz}, 1 \mathrm{H}), 5.07(\mathrm{~d}, J=10.9$ $\mathrm{Hz}, 1 \mathrm{H}), 5.06$ (d, $J=17.4 \mathrm{~Hz}, 1 \mathrm{H}), 2.58-2.42(\mathrm{~m}, 2 \mathrm{H}), 2.20-2.08(\mathrm{~m}, 1 \mathrm{H}), 1.98-1.86(\mathrm{~m}, 1 \mathrm{H})$, $1.56(\mathrm{~s}, 9 \mathrm{H}), 1.33(\mathrm{~s}, 3 \mathrm{H}) ;{ }^{13} \mathrm{C} \mathrm{NMR}\left(100 \mathrm{MHz}, \mathrm{CDCl}_{3}\right): \delta 166.3,162.5(\mathrm{~d}, J=246.4 \mathrm{~Hz}), 145.1$, 142.8, 139.2, 134.8, 132.9 (d, $J=8.2 \mathrm{~Hz}), 132.6$ (d, $J=3.5 \mathrm{~Hz}), 128.4,128.3,125.7,116.4$ (d, $J=21.8 \mathrm{~Hz}$ ), 112.6, 82.0, 45.0, 41.2, 31.4, 28.4, 24.6; ${ }^{19} \mathrm{~F}$ NMR (376 MHz, $\left.\mathrm{CDCl}_{3}\right): \delta-113.8$; IR (ATR): $\tilde{\mathrm{v}}=3082,3016,2978,2928,2872$, 1712, 1591, 1491, 1368, 1231, 1156, 828, 755 , $\mathrm{cm}^{-1}$; HRMS (ESI) Calcd for $\mathrm{C}_{25} \mathrm{H}_{29} \mathrm{FNaO}_{2} \mathrm{~S}^{+}[\mathrm{M}+\mathrm{Na}]^{+} 435.1765$, found 435.1768.

Chiral assay was conducted on Chiralpak ${ }^{\circledR}$ IG column using IPA: $n$ Hex $(0.5: 99.5)$ as an eluent $(1.0 \mathrm{~mL} / \mathrm{min})$.
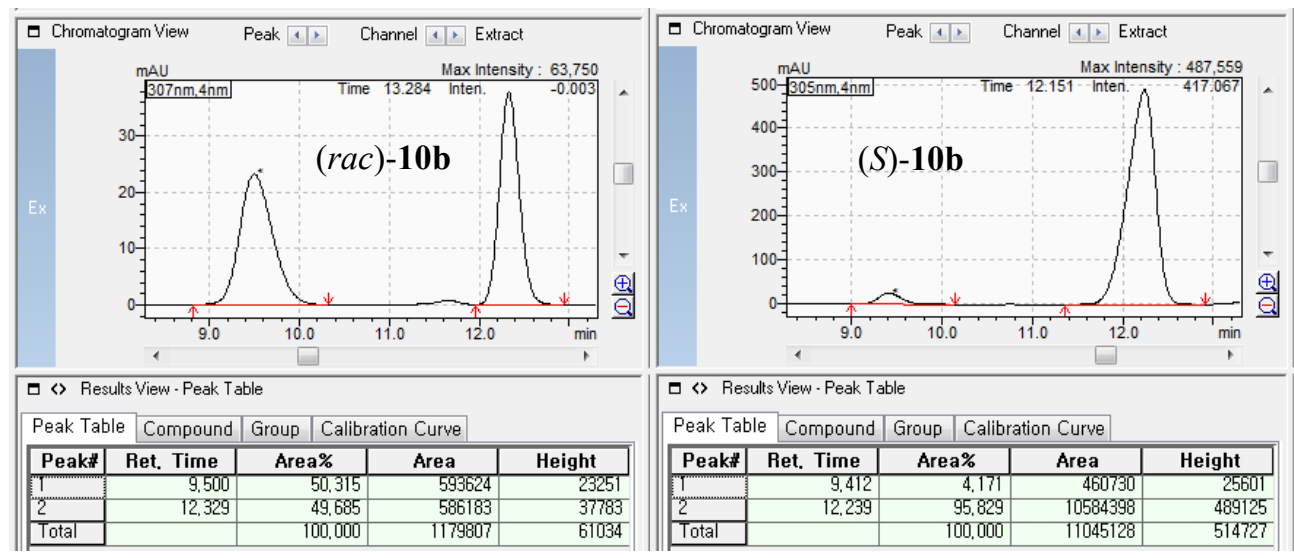
<smiles>C=CC(CCc1ccc(Nc2ccccc2)cc1)(CC(C)(C)C)C(=CSc1ccc(F)cc1)C(=O)OC</smiles>

Colorless oil (35.9 mg, 84\%, EtOAc:Hex = 1:10); $[\alpha]^{20}{ }_{\mathrm{D}}=10.9^{\circ}\left(\mathrm{c} 2.18, \mathrm{CHCl}_{3}, 95 \%\right.$ ee); ${ }^{1} \mathrm{H}$ NMR (400 MHz, $\left.\mathrm{CDCl}_{3}\right): \delta 7.42(\mathrm{dd}, J=8.9,5.2 \mathrm{~Hz}, 2 \mathrm{H}), 7.10-7.00(\mathrm{~m}, 6 \mathrm{H}), 6.74(\mathrm{~s}, 1 \mathrm{H})$, $5.98(\mathrm{dd}, J=17.3,11.0 \mathrm{~Hz}, 1 \mathrm{H}), 5.05$ (d, $J=17.3 \mathrm{~Hz}, 1 \mathrm{H}), 5.04$ (d, $J=11.0 \mathrm{~Hz}, 1 \mathrm{H}), 2.50-2.41$ (m, 2H), 2.31 (s, 3H), 2.17-2.05 (m, 1H), 1.95-1.84 (m, 1H), $1.56(\mathrm{~s}, 9 \mathrm{H}), 1.33(\mathrm{~s}, 3 \mathrm{H}) ;{ }^{13} \mathrm{C}$ NMR (100 MHz, $\left.\mathrm{CDCl}_{3}\right): \delta 166.3,162.4$ (d, $\left.J=246.4 \mathrm{~Hz}\right), 145.2,139.7,139.1,135.1,134.8$, $132.9(\mathrm{~d}, J=8.3 \mathrm{~Hz}), 132.6(\mathrm{~d}, J=3.4 \mathrm{~Hz}), 129.1,128.2,116.3(\mathrm{~d}, J=21.9 \mathrm{~Hz}) 112.5,82.0$, 45.0, 41.4, 30.9, 28.4, 24.6, 21.0; ${ }^{19} \mathrm{~F}$ NMR (376 MHz, $\left.\mathrm{CDCl}_{3}\right): \delta$-113.8; IR (ATR): $\tilde{\mathrm{v}}=3005$, 2974, 2931, 2866, 1706, 1491, 1368, 1328, 1229, 1155, 1093, 842, $827 \mathrm{~cm}^{-1}$; HRMS (ESI) calcd for $\mathrm{C}_{26} \mathrm{H}_{31} \mathrm{FNaO}_{2} \mathrm{~S}^{+}[\mathrm{M}+\mathrm{Na}]^{+}$449.1921, found 449.1924 .

Chiral assay was conducted on Chiralpak ${ }^{\circledR}$ IG column using IPA: $n$ Hex $(0.5: 99.5)$ as an eluent $(1.0 \mathrm{~mL} / \mathrm{min})$.

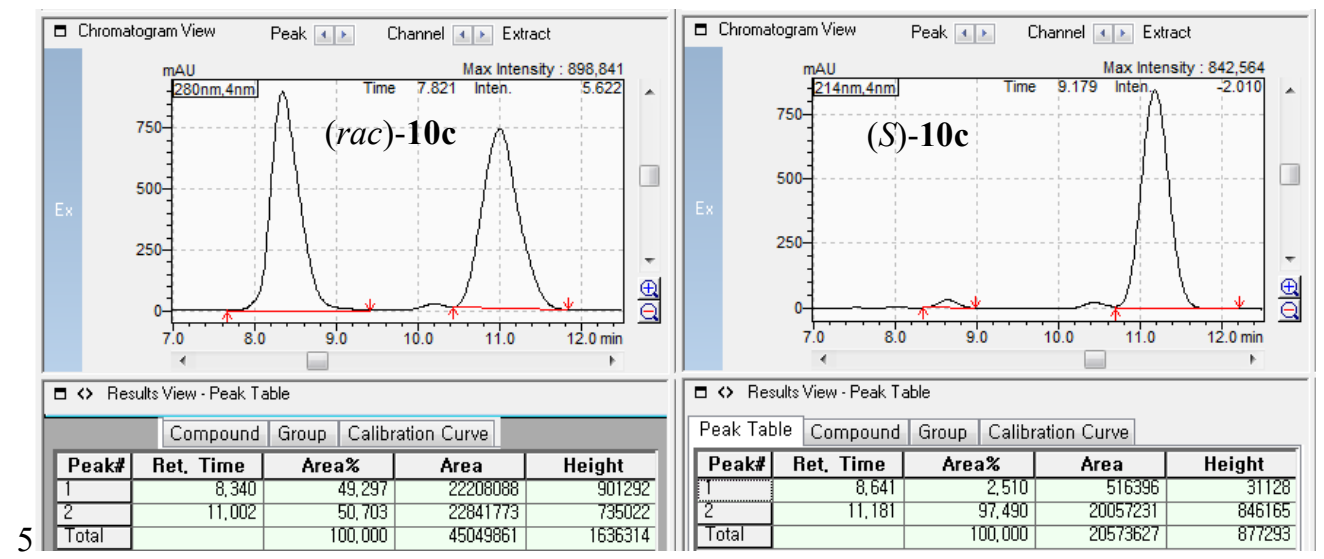


<smiles>C=CC(CCc1cccc(C)c1)(C(=O)OCc1ccccc1)C(=O)OCc1ccc(F)cc1</smiles>

Colorless oil (30.9 mg, 75\%, EtOAc:Hex = 1:10); $[\alpha]^{20}{ }_{\mathrm{D}}=6.1^{\circ}\left(\mathrm{c} 0.44, \mathrm{CHCl}_{3}, 97 \%\right.$ ee); ${ }^{1} \mathrm{H}$ $\operatorname{NMR}\left(400 \mathrm{MHz}, \mathrm{CDCl}_{3}\right): \delta 7.41(\mathrm{dd}, J=8.8,5.2 \mathrm{~Hz}, 2 \mathrm{H}), 7.15(\mathrm{t}, J=7.4 \mathrm{~Hz}, 1 \mathrm{H}), 7.04(\mathrm{t}, J=$ $8.7 \mathrm{~Hz}, 2 \mathrm{H}), 7.00-6.91(\mathrm{~m}, 3 \mathrm{H}), 6.74(\mathrm{~s}, 1 \mathrm{H}), 5.99$ (dd, $J=17.3,11.0 \mathrm{~Hz}, 1 \mathrm{H}), 5.06$ (d, $J=17.4$ Hz, 1H), 5.04 (d, J=10.8 Hz, 1H), 2.50-2.42 (m, 2H), 2.31 (s, 3H), 2.18-2.06 (m, 1H), 1.97$1.85(\mathrm{~m}, 1 \mathrm{H}), 1.56(\mathrm{~s}, 9 \mathrm{H}), 1.33(\mathrm{~s}, 3 \mathrm{H}) ;{ }^{13} \mathrm{C} \mathrm{NMR}\left(100 \mathrm{MHz}, \mathrm{CDCl}_{3}\right): \delta 166.3,162.5(\mathrm{~d}, J=$ $246.5 \mathrm{~Hz}), 145.1,142.7,139.1,137.9,134.8,132.9$ (d, $J=8.2 \mathrm{~Hz}), 132.6$ (d, $J=3.2 \mathrm{~Hz}), 129.2$, $128.3,126.5,125.3,116.4(\mathrm{~d}, J=21.8 \mathrm{~Hz}) 112.5,82.0,45.0,41.3,31.3,24.6,21.4 ;{ }^{19} \mathrm{~F}$ NMR (376 MHz, $\mathrm{CDCl}_{3}$ ): $\delta$-114.0; IR (ATR): $\tilde{\mathrm{v}}=3005,2974,2931,2866,1706,1591,1491,1368$, 1333, 1229, 1154, 843, 828, $782 \mathrm{~cm}^{-1}$; HRMS (ESI) calcd for $\mathrm{C}_{26} \mathrm{H}_{31} \mathrm{FNaO}_{2} \mathrm{~S}^{+}[\mathrm{M}+\mathrm{Na}]^{+}$ 449.1921, found 449.1924 .

Chiral assay was conducted on Chiralpak ${ }^{\circledR}$ IG column using IPA: $n$ Hex $(0.5: 99.5)$ as an eluent $(1.0 \mathrm{~mL} / \mathrm{min})$.
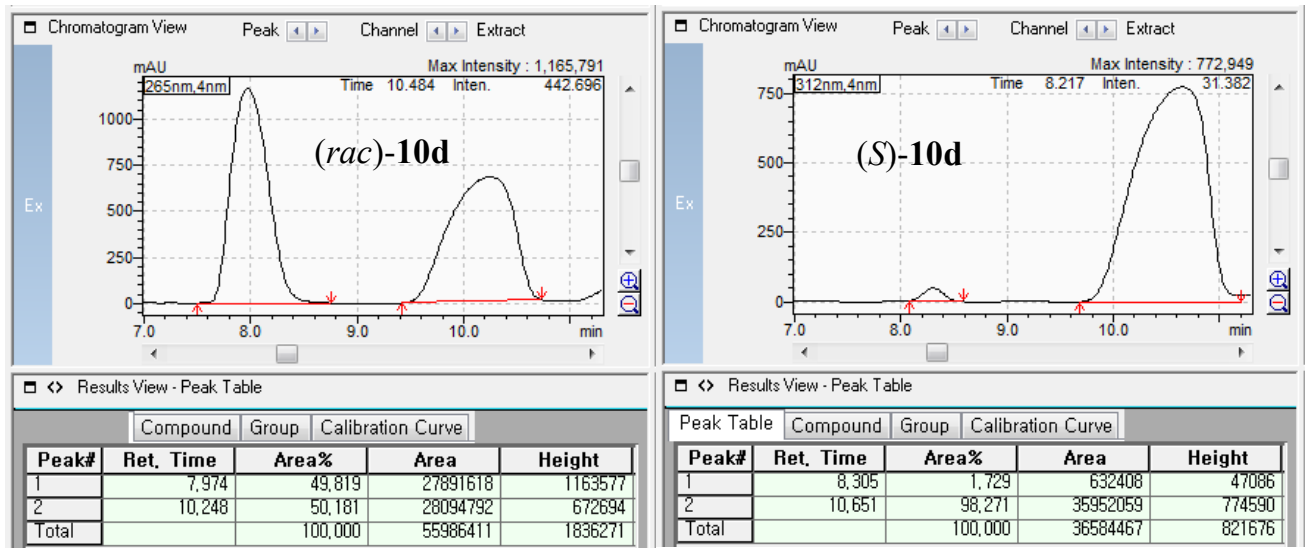
<smiles>C=CC(CCc1ccc(Br)cc1C)(CC(C)(C)C)C(=O)OCc1ccc(F)cc1</smiles>

Colorless oil (32.1 mg, 78\%, EtOAc:Hex = 1:10); $[\alpha]^{20} \mathrm{D}=8.3^{\circ}\left(\mathrm{c} 0.52, \mathrm{CHCl}_{3}, 97 \%\right.$ ee $) ;{ }^{1} \mathrm{H}$ NMR (400 MHz, $\left.\mathrm{CDCl}_{3}\right): \delta 7.42(\mathrm{dd}, J=8.4,5.2 \mathrm{~Hz}, 2 \mathrm{H}), 7.16-7.05$ (m, 4H), 7.04 (t, $J=8.5$ Hz, 2H), 6.77 (s, 1H), 6.01 (dd, $J=17.4,10.9 \mathrm{~Hz}, 1 \mathrm{H}), 5.08$ (d, $J=10.7 \mathrm{~Hz}, 1 \mathrm{H}), 5.06$ (d, $J=$ $17.6 \mathrm{~Hz}, 1 \mathrm{H}), 2.52-2.44(\mathrm{~m}, 2 \mathrm{H}), 2.28(\mathrm{~s}, 3 \mathrm{H}), 2.14-2.02(\mathrm{~m}, 1 \mathrm{H}), 1.89-1.77(\mathrm{~m}, 1 \mathrm{H}), 1.56(\mathrm{~s}$, 9H), 1.36 (s, 3H); $\left.{ }^{13} \mathrm{C} \mathrm{NMR} \mathrm{(100} \mathrm{MHz,} \mathrm{CDCl}_{3}\right): \delta 166.3,162.5(\mathrm{~d}, J=246.4 \mathrm{~Hz}), 145.2,140.9$, $139.3,135.7,134.7,133.0(\mathrm{~d}, J=8.1 \mathrm{~Hz}), 132.6(\mathrm{~d}, J=3.5 \mathrm{~Hz}), 130.2,128.9,126.0,125.9$, $116.3(\mathrm{~d}, J=21.8 \mathrm{~Hz}), 112.7,82.1,45.1,39.8,28.7,28.4,24.5,19.3 ;{ }^{19} \mathrm{~F}$ NMR $(376 \mathrm{MHz}$, $\mathrm{CDCl}_{3}$ ): $\delta$-113.8; IR (ATR): $\tilde{\mathrm{v}}=3008,2977,2938,2880,1704,1490,1368,1332,1229,1154$, 1091, 827, 842, $742 \mathrm{~cm}^{-1}$; HRMS (ESI) calcd for $\mathrm{C}_{26} \mathrm{H}_{31} \mathrm{FNaO}_{2} \mathrm{~S}^{+}[\mathrm{M}+\mathrm{Na}]^{+}$449.1921, found 449.1924.

Chiral assay was conducted on Chiralpak ${ }^{\circledR}$ IG column using IPA: $n$ Hex $(0.5: 99.5)$ as an eluent $(1.0 \mathrm{~mL} / \mathrm{min})$.

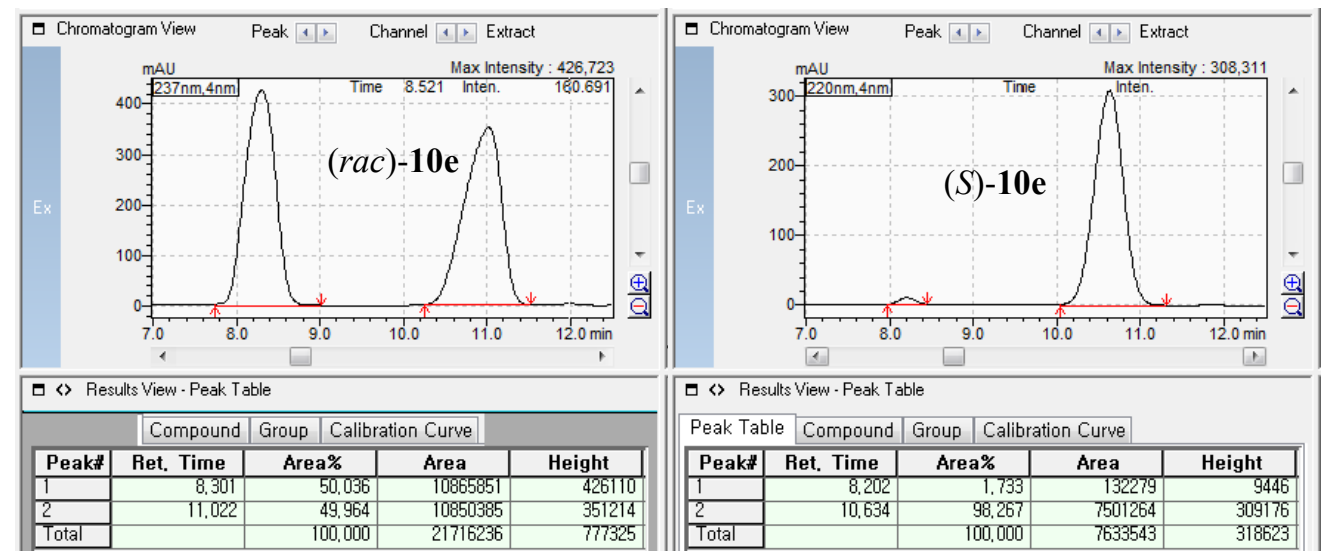


<smiles>C=CC(C=[SH]c1ccc(F)cc1)(C(=O)O)C(=O)OCc1ccccc1</smiles>

$(S)$-Colorless oil (35.6 mg, 89\%, EtOAc:Hex = 1:50); $[\alpha]^{20}{ }_{\mathrm{D}}=10.9^{\circ}$ (c 2.18, $\mathrm{CHCl}_{3}, 98 \%$ ee), (R)-Colorless oil (33.4 mg, 84\%, EtOAc:Hex = 1:50); $[\alpha]^{20}{ }_{\mathrm{D}}=-9.8^{\circ}$ (c 1.32, $\mathrm{CHCl}_{3}, 90 \%$ ee); ${ }^{1} \mathrm{H}$ NMR (400 MHz, $\left.\mathrm{CDCl}_{3}\right): \delta$ 7.30-7.18 (m, 3H), 7.13-7.05 (m, 4H), 6.93 (t, J=7.9 Hz, 2H), $6.33(\mathrm{~s}, 1 \mathrm{H}), 6.06(\mathrm{dd}, J=17.5,10.8 \mathrm{~Hz}, 1 \mathrm{H}), 5.04$ (d, $J=10.8 \mathrm{~Hz}, 1 \mathrm{H}), 5.02$ (d, $J=17.4 \mathrm{~Hz}$, $1 \mathrm{H}), 3.34$ (d of ABq, $J=13.0 \mathrm{~Hz}, 1 \mathrm{H}), 2.87$ (d of ABq, $J=12.9 \mathrm{~Hz}, 1 \mathrm{H}), 1.61$ (s, 9H), 1.17 (s, $3 \mathrm{H}) ;{ }^{13} \mathrm{C} \mathrm{NMR}\left(100 \mathrm{MHz}, \mathrm{CDCl}_{3}\right): \delta 166.5,162.3$ (d, $\left.J=246.1 \mathrm{~Hz}\right), 145.4,140.0,138.4,133.7$, $132.7(\mathrm{~d}, J=4.5 \mathrm{~Hz}), 132.6$ (d, $J=8.3 \mathrm{~Hz}), 131.0,127.7,126.0,116.1$ (d, $J=21.8 \mathrm{~Hz}), 112.6$, 82.1, 45.8, 44.9, 28.4, 24.8; ${ }^{19} \mathrm{~F}$ NMR (376 MHz, $\left.\mathrm{CDCl}_{3}\right): \delta$-114.2; IR (ATR): $\tilde{\mathrm{v}}=3025,2977$, 2933, 2867, 1703, 1491, 1368, 1228, 1154, 826, 734, $702 \mathrm{~cm}^{-1}$; HRMS (ESI) calcd for $\mathrm{C}_{24} \mathrm{H}_{27} \mathrm{FNaO}_{2} \mathrm{~S}^{+}[\mathrm{M}+\mathrm{Na}]^{+} 421.1608$, found 421.1611 .

Chiral assay was conducted on Chiralpak ${ }^{\circledR}$ IG column using IPA: $n$ Hex $(0.5: 99.5)$ as an eluent $(1.0 \mathrm{~mL} / \mathrm{min})$.
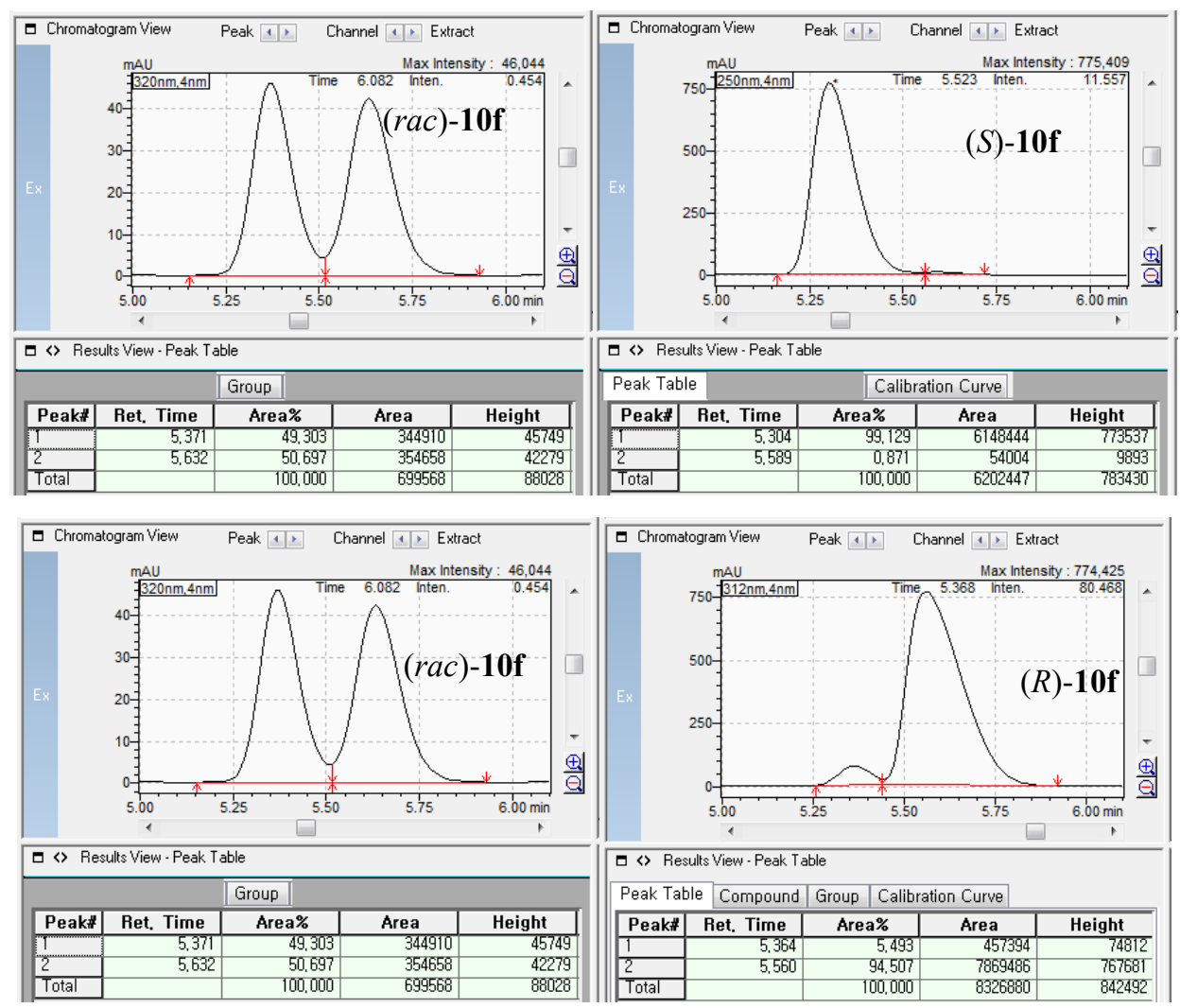
NPhth

White solid (36.8 mg, 71\%, EtOAc:Hex $=1: 10), \mathrm{mp}=64 \sim 65^{\circ} \mathrm{C} ;[\alpha]^{20}{ }_{\mathrm{D}}=33.9^{\circ}\left(\mathrm{c} 1.57, \mathrm{CHCl}_{3}\right.$, $99 \%$ ee); ${ }^{1} \mathrm{H}$ NMR (400 MHz, $\left.\mathrm{CDCl}_{3}\right): \delta 7.87-7.81(\mathrm{~m}, 2 \mathrm{H}), 7.74-7.68(\mathrm{~m}, 2 \mathrm{H}), 7.51$ (d, $J=8.4$ $\mathrm{Hz}, 2 \mathrm{H}), 7.43$ (d, $J=8.4 \mathrm{~Hz}, 2 \mathrm{H}), 6.96$ (s, 1H), 6.20 (dd, $J=17.5,10.8 \mathrm{~Hz}, 1 \mathrm{H}), 5.12$ (d, $J=$ $10.8 \mathrm{~Hz}, 1 \mathrm{H}), 5.05(\mathrm{~d}, J=17.6 \mathrm{~Hz}, 1 \mathrm{H}), 4.30(\mathrm{~d}$ of ABq, $J=13.5 \mathrm{~Hz}, 1 \mathrm{H}), 4.03$ (d of ABq, $J=$ $13.5 \mathrm{~Hz}, 1 \mathrm{H}), 1.65$ (s, 9H), 1.34 (s, 3H); $\left.{ }^{13} \mathrm{C} \mathrm{NMR} \mathrm{(100} \mathrm{MHz,} \mathrm{CDCl}_{3}\right): \delta 168.7,165.7,143.0$, 142.5, 140.2, 134.0, 133.1, 132.0, 129.9, 129.5 (q, $J=32.5 \mathrm{~Hz}), 126.0$ (q, $J=3.7 \mathrm{~Hz}), 123.9$ $(\mathrm{q}, J=270.5 \mathrm{~Hz}), 123.3,114.5,82.7,47.2,45.4,28.4,23.3 ;{ }^{19} \mathrm{~F} \mathrm{NMR}\left(376 \mathrm{MHz}, \mathrm{CDCl}_{3}\right): \delta$ 62.7; IR (ATR): $\tilde{\mathrm{v}}=2977,2933,1717,1391,1323,1244,1160,1127,1063,1015,839 \mathrm{~cm}^{-1}$; HRMS (ESI) calcd for $\mathrm{C}_{26} \mathrm{H}_{26} \mathrm{FNNaO}_{4} \mathrm{~S}^{+}[\mathrm{M}+\mathrm{Na}]^{+} 490.1459$, found 490.1465 .

Chiral assay was conducted on Chiralpak ${ }^{\circledR}$ IG column using IPA: $n$ Hex $(20: 80)$ as an eluent (1.0 $\mathrm{mL} / \mathrm{min})$.
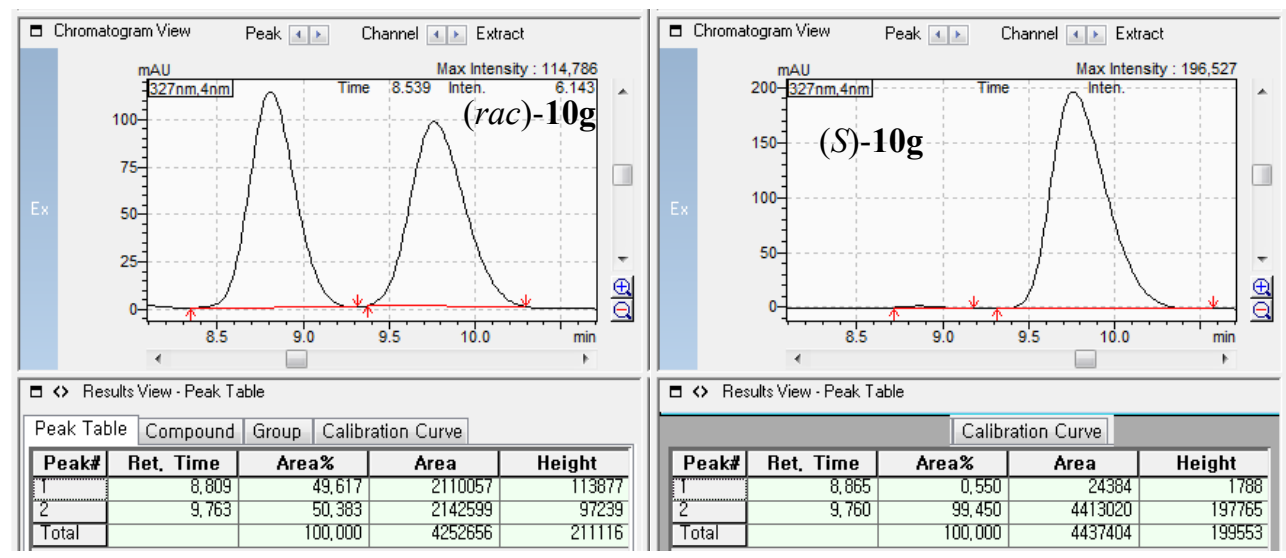
<smiles>C=CC(CO)(C(=O)O)C(=O)OCc1ccc(F)cc1</smiles>

Colorless oil (17.6 mg, 52\%, EtOAc:Hex =1:5); $[\alpha]^{20}{ }_{\mathrm{D}}=14.2^{\circ}\left(\mathrm{c} 0.87, \mathrm{CHCl}_{3}, 81 \% \mathrm{ee}\right) ;{ }^{1} \mathrm{H}$ NMR (400 MHz, $\left.\mathrm{CDCl}_{3}\right): \delta 7.40(\mathrm{dd}, J=8.8,5.2 \mathrm{~Hz}, 2 \mathrm{H}), 7.04(\mathrm{t}, J=8.6 \mathrm{~Hz}, 2 \mathrm{H}), 6.82(\mathrm{~s}, 1 \mathrm{H})$, $5.94(\mathrm{dd}, J=17.6,10.8 \mathrm{~Hz}, 1 \mathrm{H}), 5.16(\mathrm{~d}, J=10.8 \mathrm{~Hz}, 1 \mathrm{H}), 5.10(\mathrm{~d}, J=17.6 \mathrm{~Hz}, 1 \mathrm{H}), 3.77-3.64$ $(\mathrm{m}, 2 \mathrm{H}), 2.12(\mathrm{t}, J=6.6 \mathrm{~Hz}, 1 \mathrm{H}), 1.57$ (s, 9H), 1.27 (s, 3H); ${ }^{13} \mathrm{C} \mathrm{NMR}\left(100 \mathrm{MHz}, \mathrm{CDCl}_{3}\right): \delta$ $166.7,162.5$ (d, $J=246.6 \mathrm{~Hz}), 142.3,140.0,132.9,132.8$ (d, $J=8.4 \mathrm{~Hz}), 132.0$ (d, $J=2.4 \mathrm{~Hz})$, $116.4(\mathrm{~d}, J=21.8 \mathrm{~Hz}), 114.5,82.7,68.8,47.7,28.3,21.9 ;{ }^{19} \mathrm{~F}$ NMR $\left(376 \mathrm{MHz}, \mathrm{CDCl}_{3}\right): \delta$ 115.0; IR (ATR): $\tilde{\mathrm{v}}=3345,2981,2918,2862,1589,1489,1222,1156,1090,1013,829 \mathrm{~cm}^{-1}$; HRMS (ESI) calcd for $\mathrm{C}_{18} \mathrm{H}_{23} \mathrm{FNaO}_{3} \mathrm{~S}^{+}[\mathrm{M}+\mathrm{Na}]^{+}$361.1244, found 361.1250.

The product was derivatized into the corresponding lactone according to Method $\mathbf{C}$, and chiral assay of the lactone was conducted on Chiralpak ${ }^{\circledR}$ OJ-H column using IPA:nHex (10:90) as an eluent (1.0 $\mathrm{mL} / \mathrm{min})$.

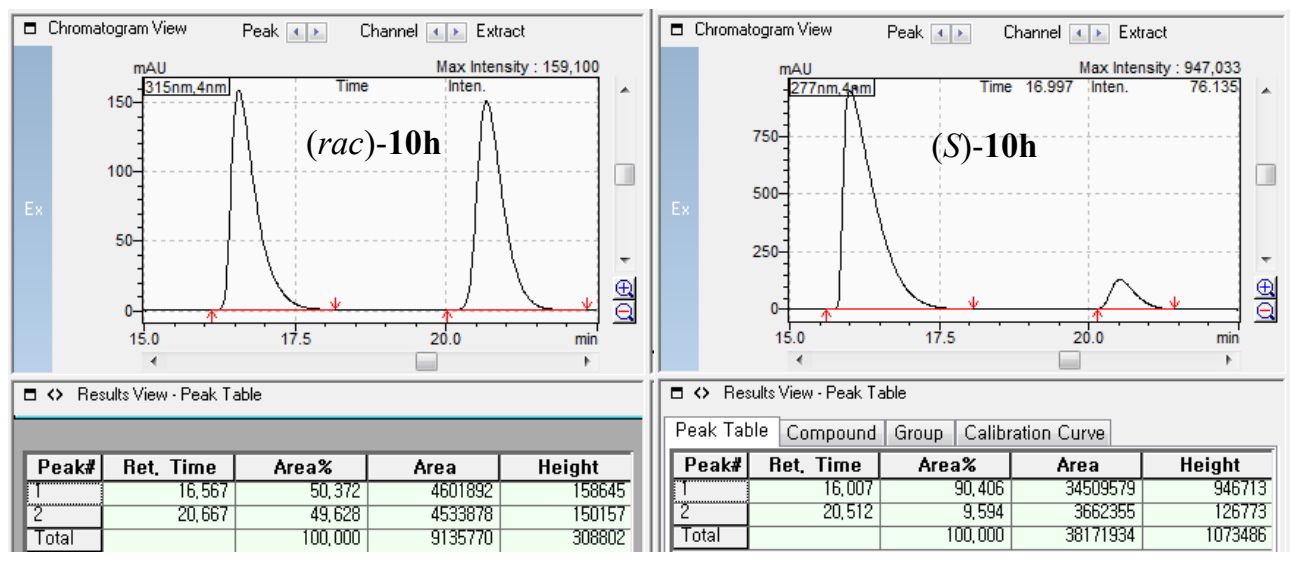


<smiles>C=CC(CCC(C)(C)C)(CC(C)(C)C)C(=O)OCc1ccc(F)cc1</smiles>

Colorless oil (33.1 mg, 81\%, EtOAc:Hex = 1:10); $[\alpha]^{20}{ }_{\mathrm{D}}=10.3^{\circ}\left(\mathrm{c} 0.72, \mathrm{CHCl}_{3}, 91 \% \mathrm{ee}\right) ;{ }^{1} \mathrm{H}$ NMR (400 MHz, $\left.\mathrm{CDCl}_{3}\right): \delta 7.41(\mathrm{dd}, J=8.8,5.2 \mathrm{~Hz}, 2 \mathrm{H}), 7.04(\mathrm{t}, J=8.6 \mathrm{~Hz}, 2 \mathrm{H}), 6.68(\mathrm{~s}, 1 \mathrm{H})$, $5.94(\mathrm{dd}, J=17.5,10.8 \mathrm{~Hz}, 1 \mathrm{H}), 5.02$ (d, $J=10.8 \mathrm{~Hz}, 1 \mathrm{H}), 4.98$ (d, $J=17.6 \mathrm{~Hz}, 1 \mathrm{H}), 1.86-1.74$ $(\mathrm{m}, 1 \mathrm{H}), 1.65-1.56(\mathrm{~m}, 1 \mathrm{H}), 1.55(\mathrm{~s}, 9 \mathrm{H}), 1.23(\mathrm{~s}, 3 \mathrm{H}), 0.40-0.26(\mathrm{~m}, 2 \mathrm{H}),-0.03(\mathrm{~s}, 9 \mathrm{H}) ;{ }^{13} \mathrm{C}$ $\operatorname{NMR}\left(100 \mathrm{MHz}, \mathrm{CDCl}_{3}\right): \delta 168.2,164.2(\mathrm{~d}, J=246.4 \mathrm{~Hz}), 147.2,140.8,136.9,134.6(\mathrm{~d}, J=$ $2.5 \mathrm{~Hz}), 134.5(\mathrm{~d}, J=8.2 \mathrm{~Hz}), 118.0$ (d, $J=21.8 \mathrm{~Hz}), 114.1,83.6,47.8,35.0,30.1,25.7,12.8$, $0.0 ;{ }^{19} \mathrm{~F} \mathrm{NMR}\left(376 \mathrm{MHz}, \mathrm{CDCl}_{3}\right): \delta$-114.0; IR (ATR): $\tilde{\mathrm{v}}=2977,2955,1706,1490,1367,1229$, 1154, 826, $733 \mathrm{~cm}^{-1}$; HRMS (ESI) calcd for $\mathrm{C}_{22} \mathrm{H}_{33} \mathrm{FNaO}_{2} \mathrm{SSi}^{+}[\mathrm{M}+\mathrm{Na}]^{+}$431.1847, found 431.1851 .

The product was derivatized into the corresponding lactone according to Method $\mathbf{B}$, and chiral assay of the lactone was conducted on Chiralpak ${ }^{\circledR}$ OD-H column using IPA: $n$ Hex $(0.5: 99.5)$ as an eluent $(1.0 \mathrm{~mL} / \mathrm{min})$.
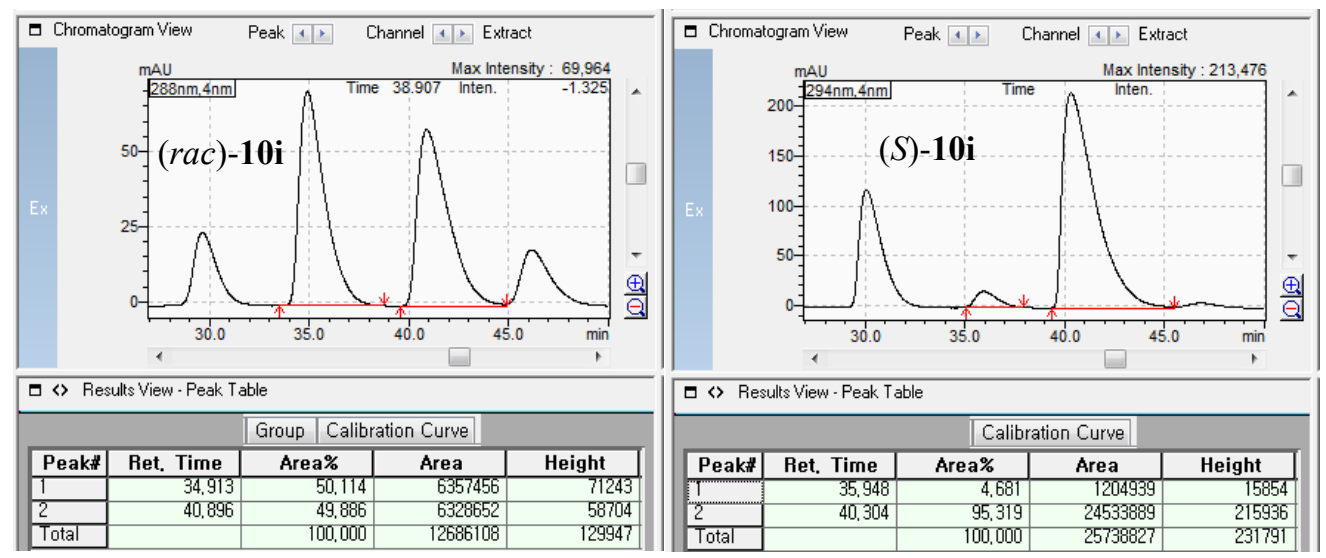


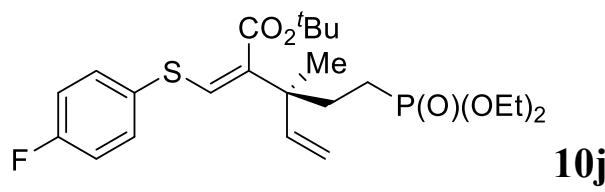

Colorless oil (39.3 mg, 83\%, EtOAc:Hex = 1:1); $[\alpha]^{20}{ }_{\mathrm{D}}=8.0^{\circ}\left(\mathrm{c} 1.32, \mathrm{CHCl}_{3}, 99 \%\right.$ ee $) ;{ }^{1} \mathrm{H}$ NMR (400 MHz, $\left.\mathrm{CDCl}_{3}\right): \delta 7.40(\mathrm{dd}, J=8.8,5.2 \mathrm{~Hz}, 2 \mathrm{H}), 7.05(\mathrm{t}, J=8.7 \mathrm{~Hz}, 2 \mathrm{H}), 6.73(\mathrm{~s}, 1 \mathrm{H})$, $5.87(\mathrm{dd}, J=17.5,10.8 \mathrm{~Hz}, 1 \mathrm{H}), 5.07$ (d, $J=10.8 \mathrm{~Hz}, 1 \mathrm{H}), 5.04$ (d, $J=17.6 \mathrm{~Hz}, 1 \mathrm{H}), 4.16-3.99$ (m, 4H), 2.22-2.08 (m, 1H), 1.99-1.86 (m, 1H), 1.68-1.55 (m, 2H), $1.56(\mathrm{~s}, 9 \mathrm{H}), 1.31(\mathrm{t}, J=7.1$ $\mathrm{Hz}, 6 \mathrm{H}), 1.25(\mathrm{~s}, 3 \mathrm{H}) ;{ }^{13} \mathrm{C} \mathrm{NMR}\left(100 \mathrm{MHz}, \mathrm{CDCl}_{3}\right): \delta 166.0,162.6(\mathrm{~d}, J=246.8 \mathrm{~Hz}), 144.1$, 140.5, 133.4, 133.0 (d, $J=8.4 \mathrm{~Hz}), 132.4$ (d, $J=3.5 \mathrm{~Hz}), 116.4$ (d, $J=21.9 \mathrm{~Hz}), 113.3,82.2$, $61.5(\mathrm{~d}, J=6.5 \mathrm{~Hz}), 44.8(\mathrm{~d}, J=18.3 \mathrm{~Hz}), 31.1(\mathrm{~d}, J=3.7 \mathrm{~Hz}), 28.3,24.1,21.5(\mathrm{~d}, J=140.4$ $\mathrm{Hz}), 16.5(\mathrm{~d}, J=5.9 \mathrm{~Hz}) ;{ }^{31} \mathrm{P} \mathrm{NMR}\left(162 \mathrm{MHz}, \mathrm{CDCl}_{3}\right): \delta 32.8 ;{ }^{19} \mathrm{~F} \mathrm{NMR}\left(376 \mathrm{MHz}, \mathrm{CDCl}_{3}\right)$ : $\delta$-113.6; IR (ATR): $\tilde{\mathrm{v}}=2981,2933,1712,1491,1368,1225,1154,1025,958,828,789 \mathrm{~cm}^{-1}$; HRMS (ESI) calcd for $\mathrm{C}_{23} \mathrm{H}_{34} \mathrm{FNaO}_{5} \mathrm{PS}^{+}[\mathrm{M}+\mathrm{Na}]^{+} 495.1741$, found 495.1742 .

Chiral assay was conducted on Chiralpak ${ }^{\circledR}$ OD-H column using IPA: $n$ Hex (2:98) as an eluent $(1.0 \mathrm{~mL} / \mathrm{min})$.
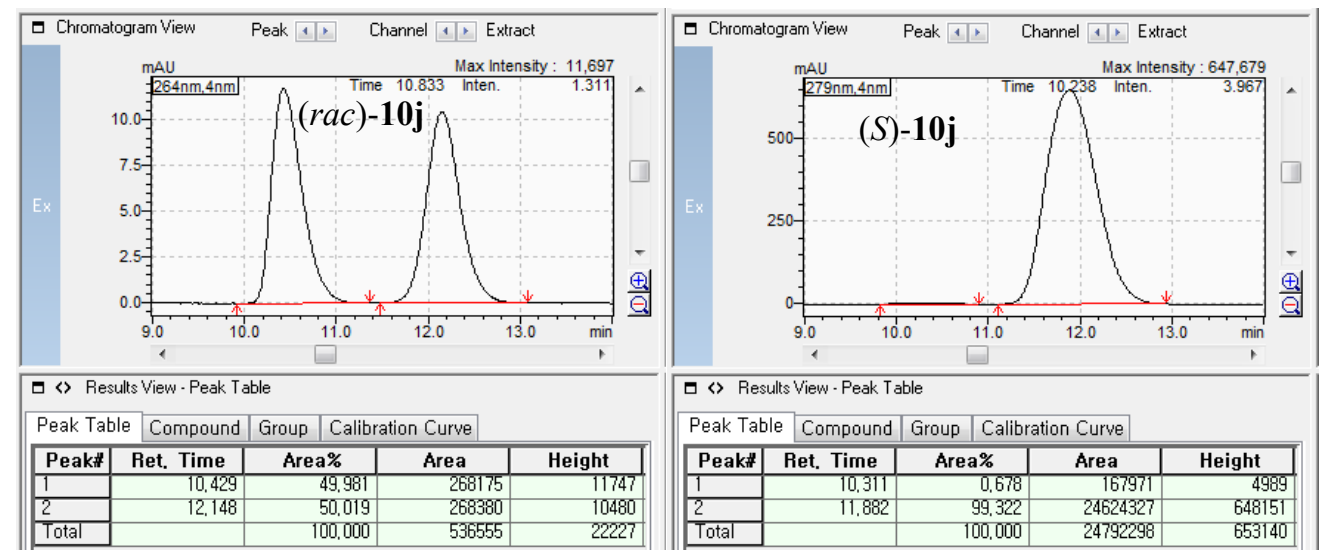
<smiles>C[C@H]1/C(=C/Sc2ccc(C(F)(F)F)cc2)C(=O)OC1(C)C</smiles>

Colorless oil (26.5 mg, 84\%, EtOAc:Hex =1:4); $[\alpha]^{20}{ }_{\mathrm{D}}=94.2^{\circ}\left(\mathrm{c} 1.00, \mathrm{CHCl}_{3}, 88 \%\right.$ ee $) ;{ }^{1} \mathrm{H}$ NMR (400 MHz, $\left.\mathrm{CDCl}_{3}\right): \delta 7.63(\mathrm{~d}, J=8.4 \mathrm{~Hz}, 2 \mathrm{H}), 7.58(\mathrm{~d}, J=8.4 \mathrm{~Hz}, 2 \mathrm{H}), 6.84(\mathrm{~d}, J=2.5$ $\mathrm{Hz}, 1 \mathrm{H}), 2.89(\mathrm{qd}, J=6.9,2.5 \mathrm{~Hz}, 1 \mathrm{H}), 1.48(\mathrm{~s}, 3 \mathrm{H}), 1.26(\mathrm{~s}, 3 \mathrm{H}), 1.17(\mathrm{~d}, J=6.9 \mathrm{~Hz}, 3 \mathrm{H}) ;{ }^{13} \mathrm{C}$ $\operatorname{NMR}\left(100 \mathrm{MHz}, \mathrm{CDCl}_{3}\right): \delta 168.9,140.6,136.4,130.4,130.0$ (q, $\left.J=32.5 \mathrm{~Hz}\right), 128.1,126.3$ (q, $J=3.7 \mathrm{~Hz}), 123.8(\mathrm{q}, J=270.5 \mathrm{~Hz}), 85.8,45.9,27.3,22.9,13.5 ;{ }^{19} \mathrm{~F} \mathrm{NMR}\left(376 \mathrm{MHz}, \mathrm{CDCl}_{3}\right)$ : $\delta$-62.7; IR (ATR): $\tilde{\mathrm{v}}=2974,2939,1736,1603,1322,1298,1165,1122,1062,833 \mathrm{~cm}^{-1}$; HRMS (ESI) Calcd for $\mathrm{C}_{15} \mathrm{H}_{15} \mathrm{~F}_{3} \mathrm{NaO}_{2} \mathrm{~S}^{+}[\mathrm{M}+\mathrm{Na}]^{+} 339.0637$, found 339.0639.

Chiral assay was conducted on Chiralpak ${ }^{\circledR}$ IC column using IPA: $n$ Hex (20:80) as an eluent (1.0 $\mathrm{mL} / \mathrm{min})$.
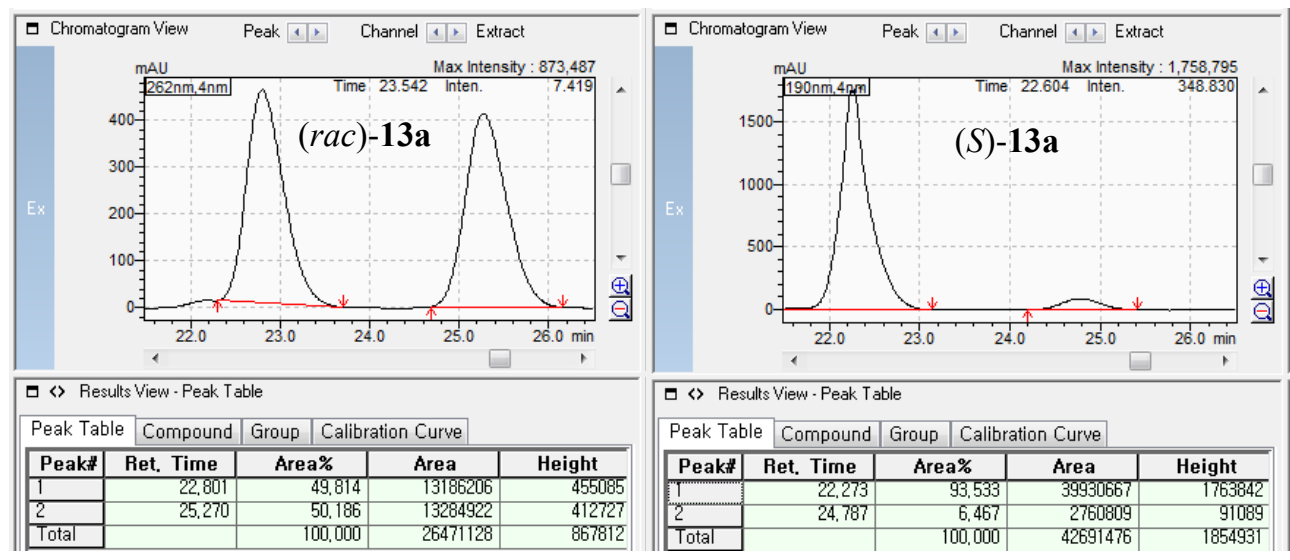
<smiles>CCC1(C)OC(=O)C(=CSc2ccc(C(F)(F)F)cc2)C1C</smiles>

Colorless oil (28.4 mg, 86\%, EtOAc:Hex =1:4); $[\alpha]^{20}{ }_{\mathrm{D}}=-0.72^{\circ}\left(\mathrm{c} 0.86, \mathrm{CHCl}_{3}, 78 \%\right.$ ee); ${ }^{1} \mathrm{H}$ NMR (400 MHz, $\left.\mathrm{CDCl}_{3}\right): \delta 7.65(\mathrm{~d}, J=8.3 \mathrm{~Hz}, 2 \mathrm{H}), 7.60(\mathrm{~d}, J=8.7 \mathrm{~Hz}, 2 \mathrm{H}), 6.87(\mathrm{~d}, J=2.2$ Hz, 1H), 2.96 (qd, $J=6.9,2.5 \mathrm{~Hz}, 1 \mathrm{H}), 1.76$ (q, $J=7.4 \mathrm{~Hz}, 2 \mathrm{H}), 1.25$ (s, 3H), 1.19 (d, $J=6.9$ $\mathrm{Hz}, 3 \mathrm{H}), 1.01(\mathrm{t}, J=7.4 \mathrm{~Hz}, 3 \mathrm{H}) ;{ }^{13} \mathrm{C} \mathrm{NMR}\left(100 \mathrm{MHz}, \mathrm{CDCl}_{3}\right): \delta 169.1,140.6,136.4,130.4$, $130.0(\mathrm{q}, J=32.5 \mathrm{~Hz}), 128.3,126.3(\mathrm{q}, J=4.2 \mathrm{~Hz}), 123.8(\mathrm{q}, J=270.6 \mathrm{~Hz}), 88.1,43.6,33.2$, 20.6, 14.0, 8.0; ${ }^{19} \mathrm{~F}$ NMR (376 MHz, $\left.\mathrm{CDCl}_{3}\right): \delta-62.7$; IR (ATR): $\tilde{\mathrm{v}}=2923,2853,1737,1604$, 1324, 1167, 1125, 1063, 1014, $834 \mathrm{~cm}^{-1}$; HRMS (ESI) calcd for $\mathrm{C}_{16} \mathrm{H}_{17} \mathrm{~F}_{3} \mathrm{NaO}_{2} \mathrm{~S}^{+}[\mathrm{M}+\mathrm{Na}]^{+}$ 353.0794, found 353.0796.

Chiral assay was conducted on Chiralpak ${ }^{\circledR}$ IC column using IPA: $n$ Hex (5:95) as an eluent (1.0 $\mathrm{mL} / \mathrm{min})$.

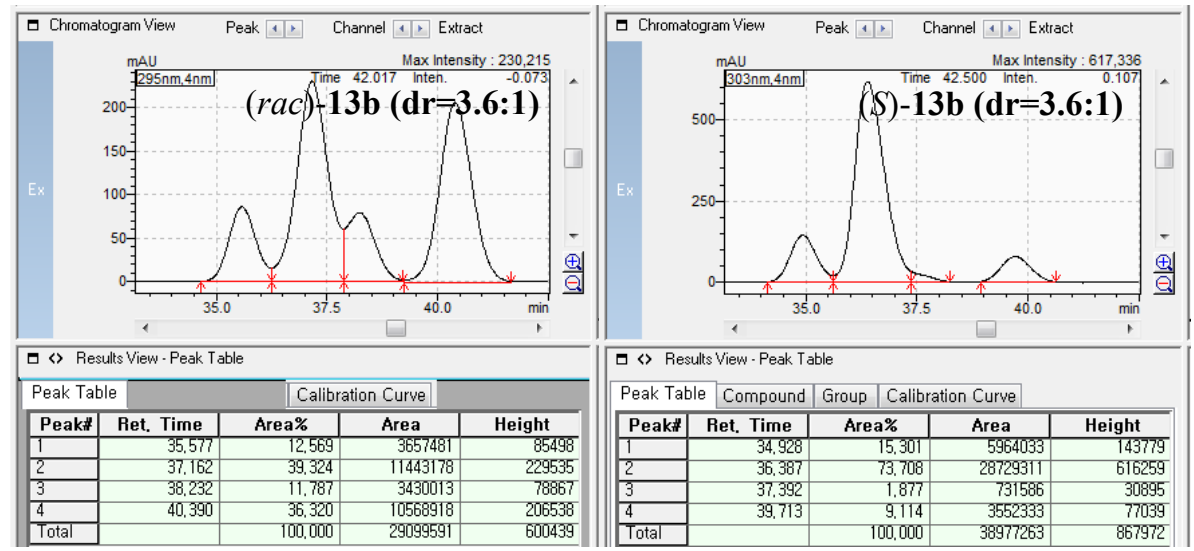


<smiles>COc1ccc(CC[C@H]2/C(=C/Sc3ccc(C(F)(F)F)cc3)C(=O)OC2(C)C)cc1</smiles>

Colorless oil (39.4 mg, 80\%, EtOAc:Hex =1:4); $[\alpha]^{20}{ }_{\mathrm{D}}=23.2^{\circ}\left(\mathrm{c} 1.56, \mathrm{CHCl}_{3}, 78 \%\right.$ ee $) ;{ }^{1} \mathrm{H}$ NMR (400 MHz, $\left.\mathrm{CDCl}_{3}\right): \delta 7.63(\mathrm{~d}, J=8.3 \mathrm{~Hz}, 2 \mathrm{H}), 7.56(\mathrm{~d}, J=8.3 \mathrm{~Hz}, 2 \mathrm{H}), 7.07$ (d, $J=8.6$ $\mathrm{Hz}, 2 \mathrm{H}), 6.90$ (d, $J=2.2 \mathrm{~Hz}, 1 \mathrm{H}), 6.83$ (d, $J=8.6 \mathrm{~Hz}, 2 \mathrm{H}), 3.78$ (s, 3H), 2.80 (td, $J=7.1,2.1$ $\mathrm{Hz}, 1 \mathrm{H}), 2.73-2.56$ (m, 2H), 1.90-1.78 (m, 2H), 1.49 (s, 3H), 1.37 (s, 3H); ${ }^{13} \mathrm{C}$ NMR (100 MHz, $\mathrm{CDCl}_{3}$ ): $168.9,158.2,140.5,137.4,132.8,130.4,130.1$ (q, $\left.J=32.5 \mathrm{~Hz}\right), 129.2,126.9,126.3$ $(\mathrm{q}, J=3.7 \mathrm{~Hz}), 123.8(\mathrm{q}, J=270.6 \mathrm{~Hz}), 85.6,55.3,50.6,32.9,31.6,28.8,22.9 ;{ }^{19} \mathrm{~F}$ NMR $(376$ $\mathrm{MHz}, \mathrm{CDCl}_{3}$ ): $\delta$-62.7; IR (ATR): $\tilde{\mathrm{v}}=2981,2946,2876,1736,1603,1513,1323,1247,1165$, 1125, 1083, 1063, $829 \mathrm{~cm}^{-1}$; HRMS (ESI) Calcd for $\mathrm{C}_{23} \mathrm{H}_{23} \mathrm{~F}_{3} \mathrm{NaO}_{3} \mathrm{~S}^{+}[\mathrm{M}+\mathrm{Na}]^{+} 459.1212$, found 459.1215 .

Chiral assay was conducted on Chiralpak ${ }^{\circledR}$ IC column using IPA: $n$ Hex (10:90) as an eluent (1.0 $\mathrm{mL} / \mathrm{min})$.
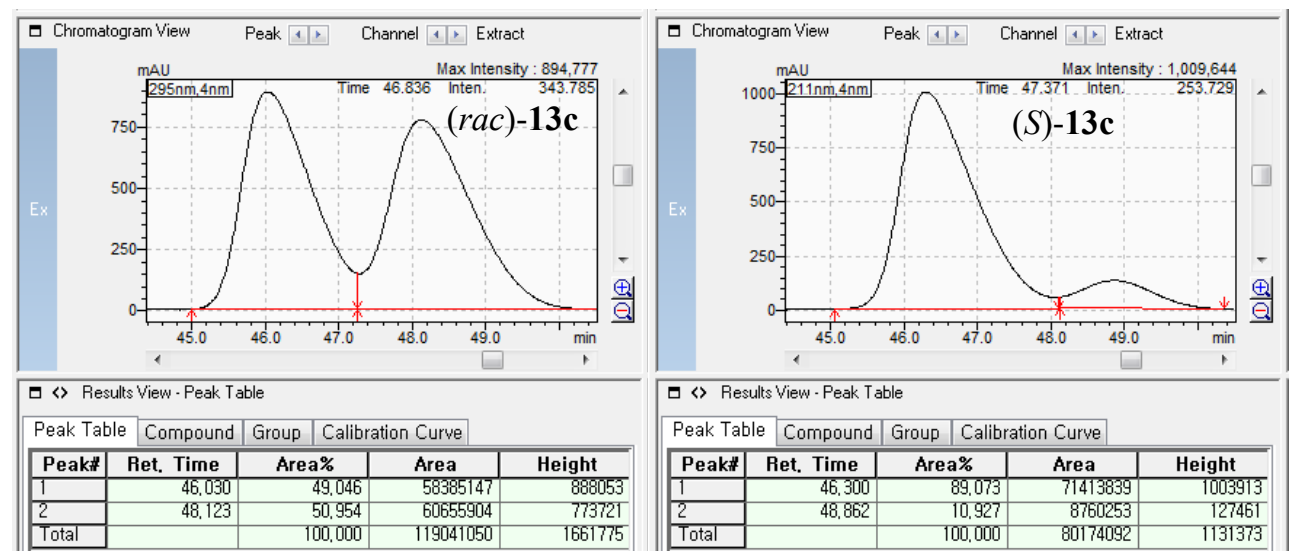
<smiles>COC1C(=O)OC(C)C1CCc1ccc(F)cc1</smiles>

Colorless oil (35.6 mg, 84\%, EtOAc:Hex =1:4); $[\alpha]^{20}{ }_{\mathrm{D}}=29.3^{\circ}\left(\mathrm{c} 1.75, \mathrm{CHCl}_{3}, 78 \%\right.$ ee); ${ }^{1} \mathrm{H}$ NMR (400 MHz, $\left.\mathrm{CDCl}_{3}\right): \delta 7.63(\mathrm{~d}, J=8.3 \mathrm{~Hz}, 2 \mathrm{H}), 7.57$ (d, $\left.J=8.3 \mathrm{~Hz}, 2 \mathrm{H}\right), 7.11$ (dd, $J=8.6$, $5.4 \mathrm{~Hz}, 2 \mathrm{H}), 6.97(\mathrm{t}, J=8.6 \mathrm{~Hz}, 2 \mathrm{H}), 6.91(\mathrm{~d}, J=2.1 \mathrm{~Hz}, 1 \mathrm{H}), 2.80(\mathrm{td}, J=7.2,2.1 \mathrm{~Hz}, 1 \mathrm{H})$, 2.76-2.55 (m, 2H), 1.92-1.76 (m, 2H), 1.49 (s, 3H), 1.38 (s, 3H); $\left.{ }^{13} \mathrm{C} \mathrm{NMR} \mathrm{(100} \mathrm{MHz,} \mathrm{CDCl}_{3}\right)$ : $168.8,161.5(\mathrm{~d}, J=243.3 \mathrm{~Hz}), 140.4,137.7,136.4$ (d, $J=3.2 \mathrm{~Hz}), 130.5,130.2$ (q, $J=32.7$ $\mathrm{Hz}), 129.6(\mathrm{~d}, J=7.6 \mathrm{~Hz}), 126.7,126.3$ (q, $J=3.6 \mathrm{~Hz}), 123.8$ (q, $J=270.5 \mathrm{~Hz}), 115.5$ (d, $J=$ $21.1 \mathrm{~Hz}), 85.5,50.5,33.0,28.8,22.9 ;{ }^{19} \mathrm{~F}$ NMR (376 MHz, $\left.\mathrm{CDCl}_{3}\right): \delta-116.5,-62.7$; IR (ATR): $\tilde{\mathrm{V}}=2981,2937,2867,1736,1603,1510,1324,1219,1166,1125,1063,832 \mathrm{~cm}^{-1}$; HRMS (ESI) Calcd for $\mathrm{C}_{22} \mathrm{H}_{20} \mathrm{~F}_{4} \mathrm{NaO}_{2} \mathrm{~S}^{+}[\mathrm{M}+\mathrm{Na}]^{+}$447.1012, found 447.1015.

Chiral assay was conducted on Chiralpak ${ }^{\circledR}$ IC column using IPA: $n$ Hex $(20: 80)$ as an eluent (1.0 $\mathrm{mL} / \mathrm{min}$ ).
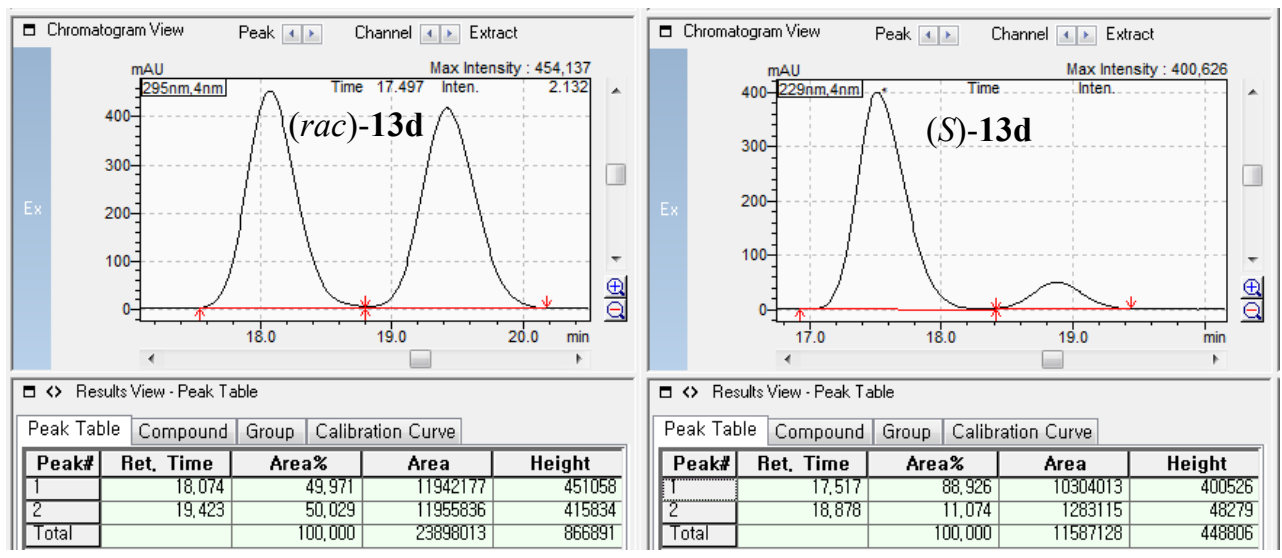
<smiles>CCCC1C(=CSc2ccc(C(F)(F)F)cc2)C(=O)OC1(C)C</smiles>

Colorless oil (32.0 mg, 70\%, EtOAc:Hex =1:4); $[\alpha]^{20}{ }_{\mathrm{D}}=25.4^{\circ}\left(\mathrm{c} 1.05, \mathrm{CHCl}_{3}, 70 \% \mathrm{ee}\right) ;{ }^{1} \mathrm{H}$ NMR (400 MHz, $\left.\mathrm{CDCl}_{3}\right): \delta$ 7.83-7.70 (m, 3H), $7.60(\mathrm{~d}, J=8.4 \mathrm{~Hz}, 2 \mathrm{H}), 7.59(\mathrm{~s}, 1 \mathrm{H}) 7.54$ (d, $J=8.4 \mathrm{~Hz}, 2 \mathrm{H}), 7.51-7.40(\mathrm{~m}, 2 \mathrm{H}), 7.29$ (dd, $J=8.4,1.7 \mathrm{~Hz}, 1 \mathrm{H}), 6.93$ (d, $J=2.1 \mathrm{~Hz}, 1 \mathrm{H})$, 2.96-2.77 (m, 3H), 2.08-1.84 (m, 2H), 1.51 (s, 3H), 1.41 (s, 3H); $\left.{ }^{13} \mathrm{C} \mathrm{NMR} \mathrm{(100} \mathrm{MHz,} \mathrm{CDCl}_{3}\right)$ : $168.8,140.5,138.2,137.7,133.6,132.1,130.4,130.1$ (q, $J=32.5 \mathrm{~Hz}), 128.5,127.7,127.3$, 126.7, 126.7, 126.5, 126.3 (q, $J=3.2 \mathrm{~Hz}$ ), 125.6, 123.8 (q, $J=270.3 \mathrm{~Hz}), 85.6,50.6,33.9,21.2$, 28.8, 22.9; ${ }^{19} \mathrm{~F}$ NMR (376 MHz, $\mathrm{CDCl}_{3}$ ): $\delta$-62.7; IR (ATR): $\tilde{\mathrm{v}}=3056,2977,2928,2862,1733$, 1602, 1321, 1254, 1165, 1122, 1062, 1014, 820, $749 \mathrm{~cm}^{-1}$; HRMS (ESI) Calcd for $\mathrm{C}_{26} \mathrm{H}_{23} \mathrm{~F}_{3} \mathrm{NaO}_{2} \mathrm{~S}^{+}[\mathrm{M}+\mathrm{Na}]^{+}$479.1263, found 479.1266.

Chiral assay was conducted on Chiralpak ${ }^{\circledR}$ IA column using IPA: $n$ Hex (5:95) as an eluent (1.0 $\mathrm{mL} / \mathrm{min})$.
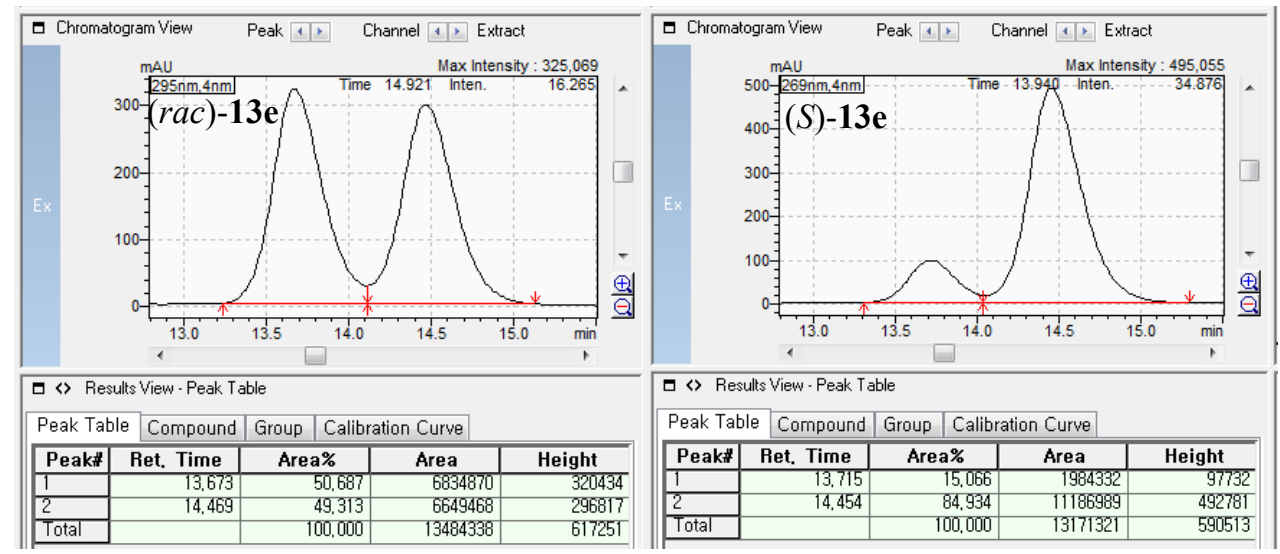
<smiles>CC(Br)(Br)OCCC[C@H]1/C(=C/Sc2ccc(C(F)(F)F)cc2)C(=O)OC1(C)C</smiles>

Colorless oil (25.7 mg, 64\%, EtOAc:Hex = 1:5); $[\alpha]^{20}{ }_{\mathrm{D}}=23.3^{\circ}\left(\mathrm{c} 1.12, \mathrm{CHCl}_{3}, 72 \% \mathrm{ee}\right) ;{ }^{1} \mathrm{H}$ NMR (400 MHz, $\mathrm{CDCl}_{3}$ ): 7.64 (d, J=8.4 Hz, 2H), 7.59 (d, $\left.J=8.3 \mathrm{~Hz}, 2 \mathrm{H}\right), 6.96$ (d, $J=2.1 \mathrm{~Hz}$, $1 \mathrm{H}), 4.10(\mathrm{t}, J=6.2 \mathrm{~Hz}, 2 \mathrm{H}), 2.76(\mathrm{td}, J=7.2,2.1 \mathrm{~Hz}, 1 \mathrm{H}), 2.04(\mathrm{~s}, 3 \mathrm{H}), 1.83-1.54(\mathrm{~m}, 4 \mathrm{H})$, 1.48 (s, 3H), 1.34 (s, 3H); $\left.{ }^{13} \mathrm{C} \mathrm{NMR} \mathrm{(100} \mathrm{MHz,} \mathrm{CDCl}_{3}\right): 171.0,168.7,140.5,137.6,130.4$, $130.1(\mathrm{q}, J=32.8 \mathrm{~Hz}), 126.7,126.3(\mathrm{q}, J=3.7 \mathrm{~Hz}), 123.8(\mathrm{q}, J=270.5 \mathrm{~Hz}), 85.4,63.9,50.5$, 28.8, 26.6, 26.0, 22.8, 20.9; ${ }^{19} \mathrm{~F}$ NMR (376 MHz, $\left.\mathrm{CDCl}_{3}\right): \delta$-62.7; IR (ATR): $\tilde{\mathrm{v}}=2981,2941$, 2871, 1732, 1602, 1389, 1321, 1243, 1165, 1062, 1013, 915, 833, $730 \mathrm{~cm}^{-1}$; HRMS (ESI) Calcd for $\mathrm{C}_{19} \mathrm{H}_{21} \mathrm{~F}_{3} \mathrm{NaO}_{4} \mathrm{~S}^{+}[\mathrm{M}+\mathrm{Na}]^{+} 425.1005$, found 425.1011 .

Chiral assay was conducted on Chiralpak ${ }^{\circledR}$ IG column using IPA: $n$ Hex $(20: 80)$ as an eluent (1.0 $\mathrm{mL} / \mathrm{min})$.
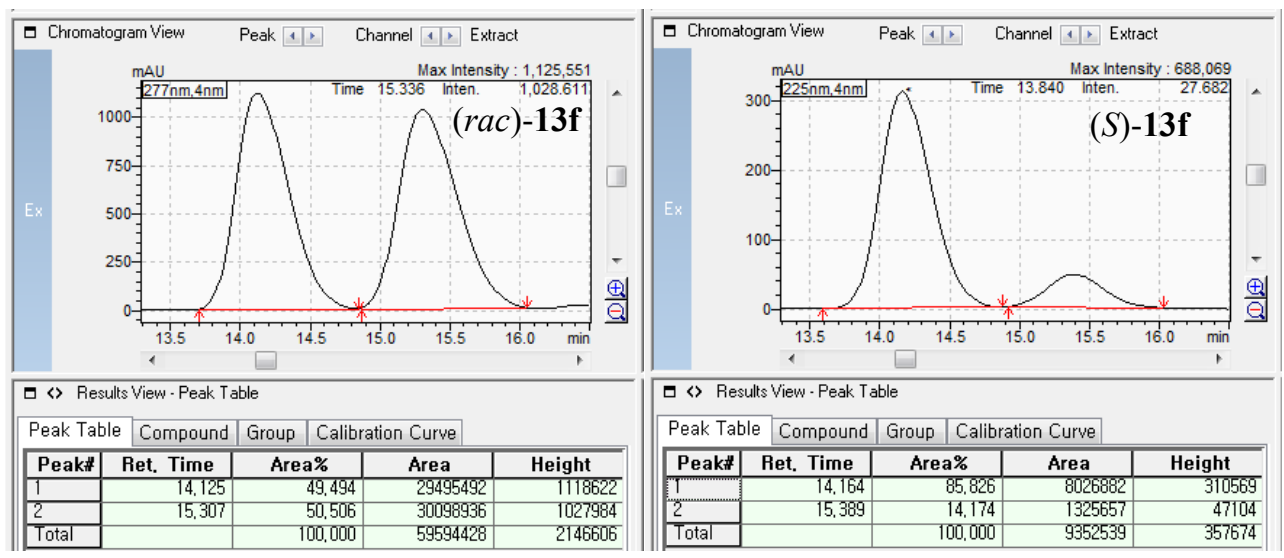
<smiles>CC1(C)OC(=O)C(=CSc2ccc(C(F)(F)F)cc2)[C@@H]1CN[15NH2]</smiles>

Colorless oil (43.8 mg, 95\%, EtOAc:Hex = 1:10), $\mathrm{mp}=122 \sim 124{ }^{\circ} \mathrm{C} ;[\alpha]^{20}{ }_{\mathrm{D}}=-3.8^{\circ}(\mathrm{c} 0.40$, $\mathrm{CHCl}_{3}, 71 \%$ ee); ${ }^{1} \mathrm{H}$ NMR (400 MHz, $\left.\mathrm{CDCl}_{3}\right):$ 7.88-7.82 (m, 2H), 7.78-7.72 (m, 2H), 7.49 (d, $J=8.4 \mathrm{~Hz}, 2 \mathrm{H}), 7.39$ (d, $J=8.4 \mathrm{~Hz}, 2 \mathrm{H}), 7.01$ (d, $J=1.6 \mathrm{~Hz}, 1 \mathrm{H}), 3.94-3.80$ (m, 2H), 3.35 (ddd, $J=8.2,6.0,1.8 \mathrm{~Hz}, 1 \mathrm{H}), 1.50$ (s, 3H), 1.49 (s, 3H); ${ }^{13} \mathrm{C} \mathrm{NMR}\left(100 \mathrm{MHz}, \mathrm{CDCl}_{3}\right): 168.0,140.1$, $139.5,134.5,131.6,130.1,130.0$ (q, $J=29.6 \mathrm{~Hz}), 126.1$ (q, $J=3.7 \mathrm{~Hz}), 123.8$ (q, $J=270.4$ $\mathrm{Hz}), 123.7,123.6,84.1,49.1,37.8,28.5,22.8 ;{ }^{19} \mathrm{~F} \mathrm{NMR}\left(376 \mathrm{MHz}, \mathrm{CDCl}_{3}\right): \delta-62.8$; IR (ATR): $\tilde{\mathrm{V}}=2972,2924,2858,1714,1604,1400,1323,1168,1124,1086,1063,834,719 \mathrm{~cm}^{-1}$; HRMS (ESI) Calcd for $\mathrm{C}_{23} \mathrm{H}_{18} \mathrm{~F}_{3} \mathrm{NNaO}_{4} \mathrm{~S}^{+}[\mathrm{M}+\mathrm{Na}]^{+} 484.0801$, found 484.0807 .

Chiral assay was conducted on Chiralpak ${ }^{\circledR}$ IA column using IPA: $n$ Hex (20:80) as an eluent (1.0 $\mathrm{mL} / \mathrm{min})$.
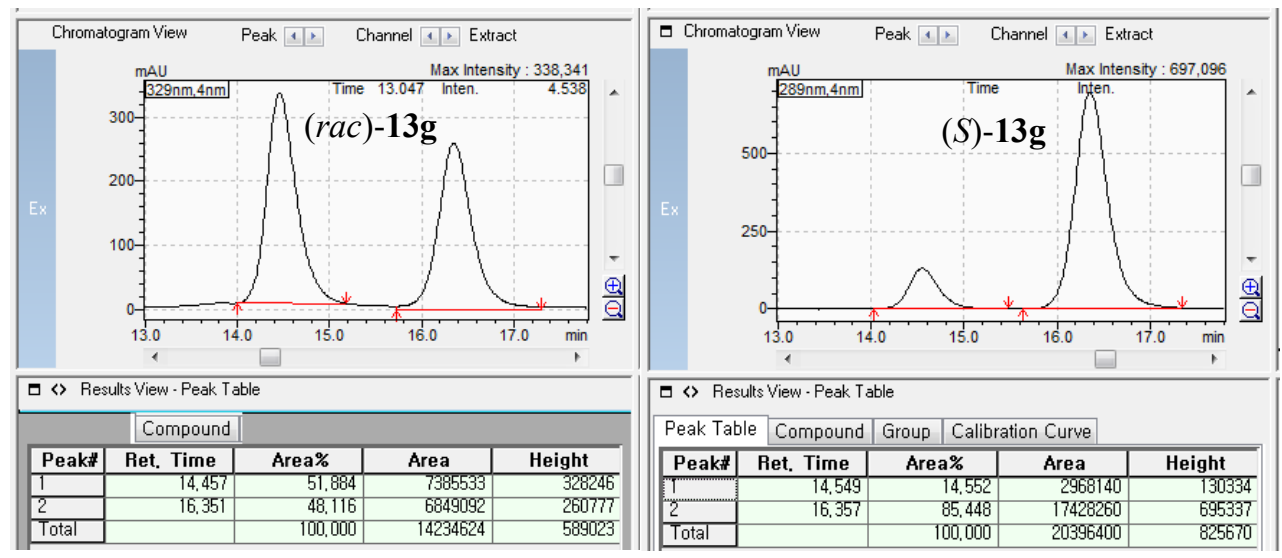
<smiles>CCCC1/C(=C/Sc2ccc(C(F)(F)F)cc2)C(=O)OC1(C)C</smiles>

Colorless oil (29.8 mg, 74\%, EtOAc:Hex =1:10); $[\alpha]^{20}{ }_{\mathrm{D}}=18.8^{\circ}\left(\mathrm{c} 0.55, \mathrm{CHCl}_{3}, 78 \%\right.$ ee); ${ }^{1} \mathrm{H}$ NMR (400 MHz, $\left.\mathrm{CDCl}_{3}\right): \delta 7.65(\mathrm{~d}, J=8.3 \mathrm{~Hz}, 2 \mathrm{H}), 7.59$ (d, $\left.J=8.3 \mathrm{~Hz}, 2 \mathrm{H}\right), 6.95(\mathrm{~d}, J=2.0$ $\mathrm{Hz}, 1 \mathrm{H}), 2.66$ (dt, $J=7.3,2.0 \mathrm{~Hz}, 1 \mathrm{H}), 1.62-1.50(\mathrm{~m}, 2 \mathrm{H}), 1.50(\mathrm{~s}, 3 \mathrm{H}), 1.35$ (s, 3H), 0.66-0.55 (m, 1H), 0.53-0.41 (m, 1H), $0.02(\mathrm{~s}, 9 \mathrm{H}) ;{ }^{13} \mathrm{C} \mathrm{NMR}$ (100 MHz, $\left.\mathrm{CDCl}_{3}\right): \delta 169.0,140.7,136.9$, $130.3,130.2,130.0$ (q, $J=32.9 \mathrm{~Hz}), 127.3,126.3$ (q, $J=3.7 \mathrm{~Hz}), 123.8$ (q, $J=268.6 \mathrm{~Hz}), 85.7$, 53.6, 29.3, 23.9, 22.6, 14.4, -1.8; ${ }^{19} \mathrm{~F}$ NMR (376 MHz, $\left.\mathrm{CDCl}_{3}\right): \delta-62.7$; IR (ATR): $\tilde{\mathrm{v}}=2953$, 2928, 2858, 1736, 1603, 1323, 1249, 1165, 1126, 1063, 1014, $833 \mathrm{~cm}^{-1}$; HRMS (ESI) Calcd for $\mathrm{C}_{19} \mathrm{H}_{25} \mathrm{~F}_{3} \mathrm{NaO}_{2} \mathrm{SSi}^{+}[\mathrm{M}+\mathrm{Na}]^{+} 425.1189$, found 425.1193 .

Chiral assay was conducted on Chiralpak ${ }^{\circledR}$ IA column using IPA: $n$ Hex $(20: 80)$ as an eluent $(1.0$ $\mathrm{mL} / \mathrm{min})$.
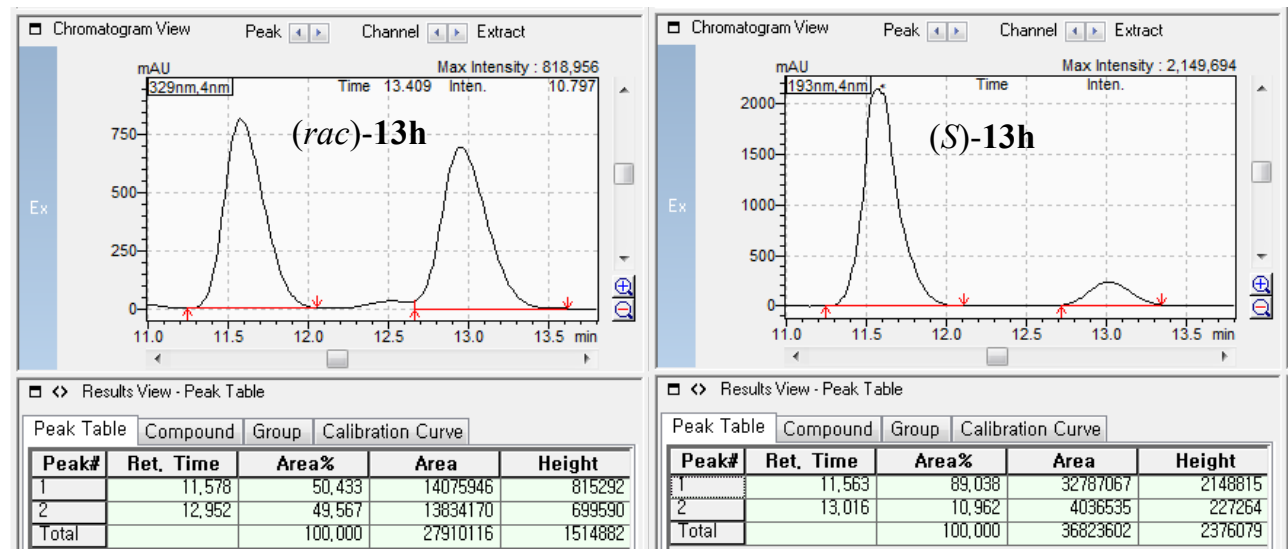


\section{Synthetic Applications}

\subsection{Conversion of $\mathbf{1 0 f}$ into $\mathbf{1 5 f}$}

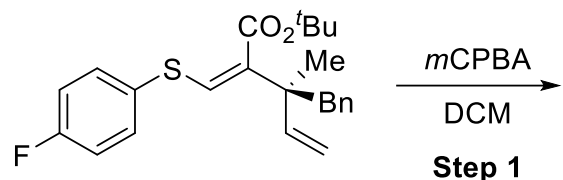

(S)-10f (98\% ee)

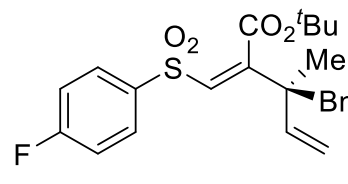

(S)-14f $86 \%(98 \%$ ee $)$

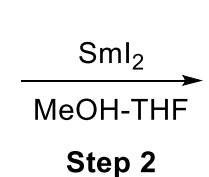

$15 f 77 \%(97 \%$ ee $)$

Step 1. To a solution of $(S)$-10f $(162.6 \mathrm{mg}, 0.41 \mathrm{mmol})$ in $\mathrm{CH}_{2} \mathrm{Cl}_{2}(3.0 \mathrm{~mL})$ in an oven-dried vial, was added $m$-chloroperbenzoic acid $(251.5 \mathrm{mg} 1.0 \mathrm{mmol})$ and the mixture was stirred $1 \mathrm{~h}$ at RT. The mixture was quenched with saturated aq. $\mathrm{NaHCO}_{3}(2 \mathrm{~mL})$, extracted with $\mathrm{CH}_{2} \mathrm{Cl}_{2}$ ( $3 \mathrm{~mL}$ x 3) and the combined organic layers were dried $\left(\mathrm{MgSO}_{4}\right)$, filtered and concentrated in vасио. The residue was purified by flash column chromatography $\left(\mathrm{SiO}_{2}, \mathrm{EtOAc}: \mathrm{Hex}=1: 3\right)$ to provide tert-butyl (S,Z)-3-benzyl-2-(4-fluorophenylsulfonylmethylene)-3-methyl-pent-4enoate as a white solid (151.1 mg, 86\%).

Step $2 .{ }^{13}$ To a solution of $(S)$-14f $(21.5 \mathrm{mg}, 0.050 \mathrm{mmol})$ in $\mathrm{MeOH}(1.0 \mathrm{~mL})$ in a flame-dried Schlenk flask, was added samarium(II) iodide (0.1 M in THF, $1.5 \mathrm{~mL}, 0.15 \mathrm{mmol})$ and the mixture was stirred $50 \mathrm{~min}$ at RT. The mixture was concentrated in vacuo and the residue was purified by flash column chromatography $\left(\mathrm{SiO}_{2}\right.$, EtOAc:Hex $\left.=1: 3\right)$ to provide tert-butyl $(S)$ 3-benzyl-3-methyl-2-methyl-enepent-4-enoate as a colorless oil (10.5 mg, 77\%). 
<smiles>C=CC(=CC(=O)c1ccc(F)cc1)C(=O)OCc1ccccc1</smiles>

\section{$(S)-\mathbf{1 4 f}$}

White solid (EtOAc:Hex $=1: 10), \mathrm{mp}=104 \sim 105^{\circ} \mathrm{C} ;[\alpha]^{20}{ }_{\mathrm{D}}=-16.0^{\circ}\left(\mathrm{c} 1.22, \mathrm{CHCl}_{3}, 98 \%\right.$ ee); ${ }^{1} \mathrm{H}$ NMR (400 MHz, $\left.\mathrm{CDCl}_{3}\right): \delta 7.93(\mathrm{dd}, J=9.0,5.1 \mathrm{~Hz}, 2 \mathrm{H}), 7.19$ (t, $\left.J=8.5 \mathrm{~Hz}, 2 \mathrm{H}\right), 7.17-$ 7.04 (m, 5H), 5.84 (dd, $J=17.4,10.8 \mathrm{~Hz}, 1 \mathrm{H}), 5.80(\mathrm{~s}, 1 \mathrm{H}), 5.15$ (d, $J=10.8 \mathrm{~Hz}, 1 \mathrm{H}), 5.05$ (d, $J=17.4 \mathrm{~Hz}, 1 \mathrm{H}), 2.98(\mathrm{~d}$ of ABq, $J=13.2 \mathrm{~Hz}, 1 \mathrm{H}), 2.85(\mathrm{~d}$ of ABq, $J=13.2 \mathrm{~Hz}, 1 \mathrm{H}), 1.64$ (s, 9H), 1.16 (s, 3H); ${ }^{13} \mathrm{C}$ NMR (100 MHz, $\left.\mathrm{CDCl}_{3}\right): \delta 165.7$ (d, $\left.J=254.8 \mathrm{~Hz}\right), 164.9,154.0,141.3$, $136.7(\mathrm{~d}, J=2.9 \mathrm{~Hz}), 136.1,131.0,130.8(\mathrm{~d}, J=9.5 \mathrm{~Hz}), 127.7,127.4,126.6,116.4(\mathrm{~d}, J=$ $22.6 \mathrm{~Hz}), 115.5,84.4,46.1,44.4,28.1,22.6 ;{ }^{19} \mathrm{~F} \mathrm{NMR}$ (376 MHz, $\mathrm{CDCl}_{3}$ ): $\delta$-103.9; IR (ATR): $\tilde{\mathrm{V}}=3064,1874,2933,1721,1591,1494,1336,1228,1148,1086,926,838,704 \mathrm{~cm}^{-1}$; HRMS (ESI) Calcd for $\mathrm{C}_{24} \mathrm{H}_{27} \mathrm{FNaO}_{4} \mathrm{~S}^{+}[\mathrm{M}+\mathrm{Na}]^{+} 453.1506$, found 453.1508 .

Chiral assay was conducted on Chiralpak ${ }^{\circledR}$ OJ-H column using IPA: $n$ Hex (5:95) as an eluent $(1.0 \mathrm{~mL} / \mathrm{min})$.
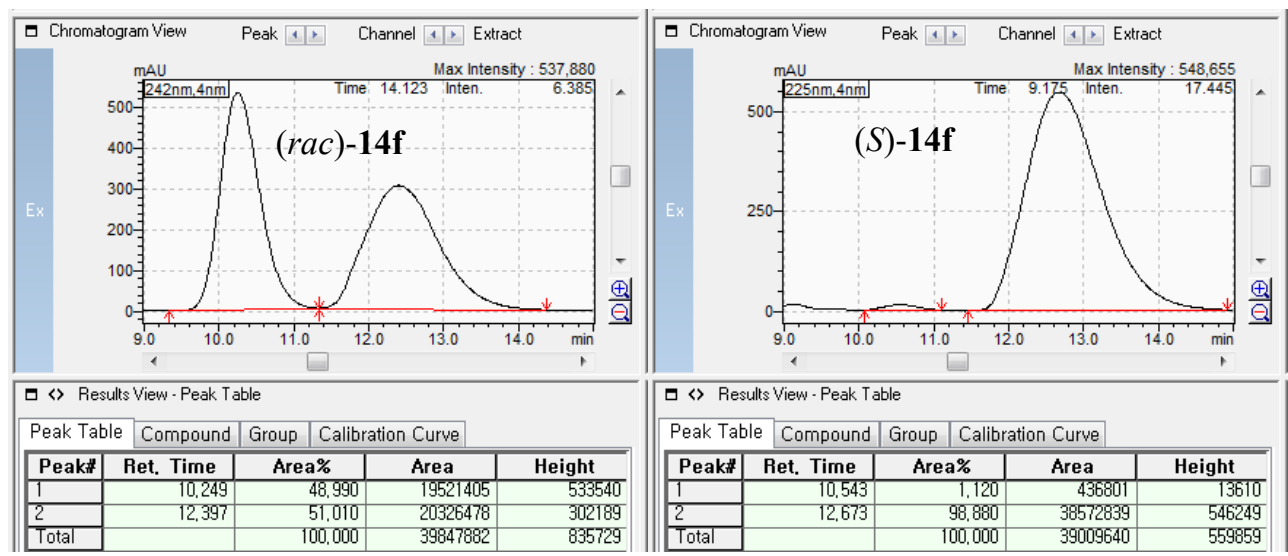
<smiles>C=CC(Br)(Br)C(=O)OCC(=O)O</smiles>

Colorless oil (EtOAc:Hex $=1: 10) ;[\alpha]^{20} \mathrm{D}=-22.6^{\circ}\left(\mathrm{c} 0.40, \mathrm{CHCl}_{3}, 97 \%\right.$ ee); ${ }^{1} \mathrm{H}$ NMR (400 $\left.\mathrm{MHz}, \mathrm{CDCl}_{3}\right): \delta$ 7.25-7.12 (m, 3H), 7.12-7.05 (m, 2H), $6.09(\mathrm{dd}, J=17.5,10.8 \mathrm{~Hz}, 1 \mathrm{H}), 5.92$ (s, 1H), $5.23(\mathrm{~s}, 1 \mathrm{H}), 5.04(\mathrm{~d}, J=10.8 \mathrm{~Hz}, 1 \mathrm{H}), 4.97$ (d, $J=17.5 \mathrm{~Hz}, 1 \mathrm{H}), 3.25$ (d of ABq, $J=$ $13.0 \mathrm{~Hz}, 1 \mathrm{H}), 2.91(\mathrm{~d}$ of ABq, $J=13.0 \mathrm{~Hz}, 1 \mathrm{H}), 1.54(\mathrm{~s}, 9 \mathrm{H}), 1.19(\mathrm{~s}, 3 \mathrm{H}) ;{ }^{13} \mathrm{C} \mathrm{NMR}(100 \mathrm{MHz}$, $\left.\mathrm{CDCl}_{3}\right): \delta 167.2,147.6,145.3,138.4,130.8,127.5,126.0,123.7,112.4,80.9,45.0,44.9,28.2$, 24.0; IR (ATR): $\tilde{\mathrm{v}}=2977,2929,2867,1710,1367,1303,1245,1137,1092,702 \mathrm{~cm}^{-1}$; HRMS (ESI) Calcd for $\mathrm{C}_{18} \mathrm{H}_{24} \mathrm{NaO}_{2}{ }^{+}[\mathrm{M}+\mathrm{Na}]^{+} 295.1669$, found 295.1671 .

Chiral assay was conducted on Chiralpak ${ }^{\circledR}$ OD-H column using IPA: $n$ Hex $(0: 100)$ as an eluent $(0.5 \mathrm{~mL} / \mathrm{min})$.
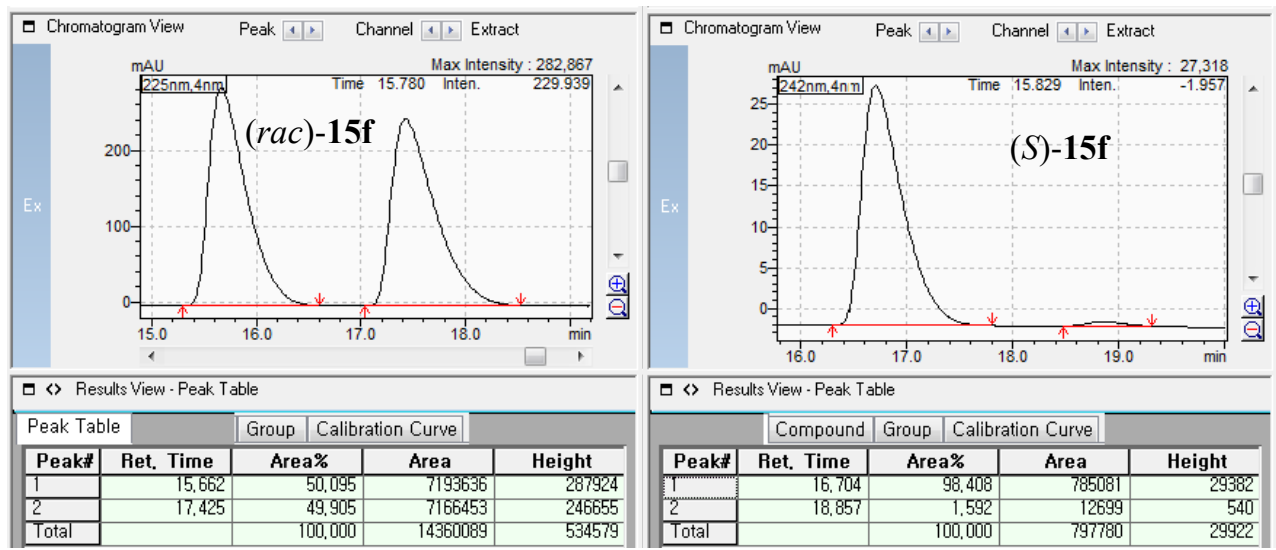
8.2.1 Conversion of $\mathbf{1 6 f}$ and $\mathbf{1 4 f}$ into $\mathbf{1 7 f a - f b}$ and $\mathbf{1 8 f a - f b} .^{14}$
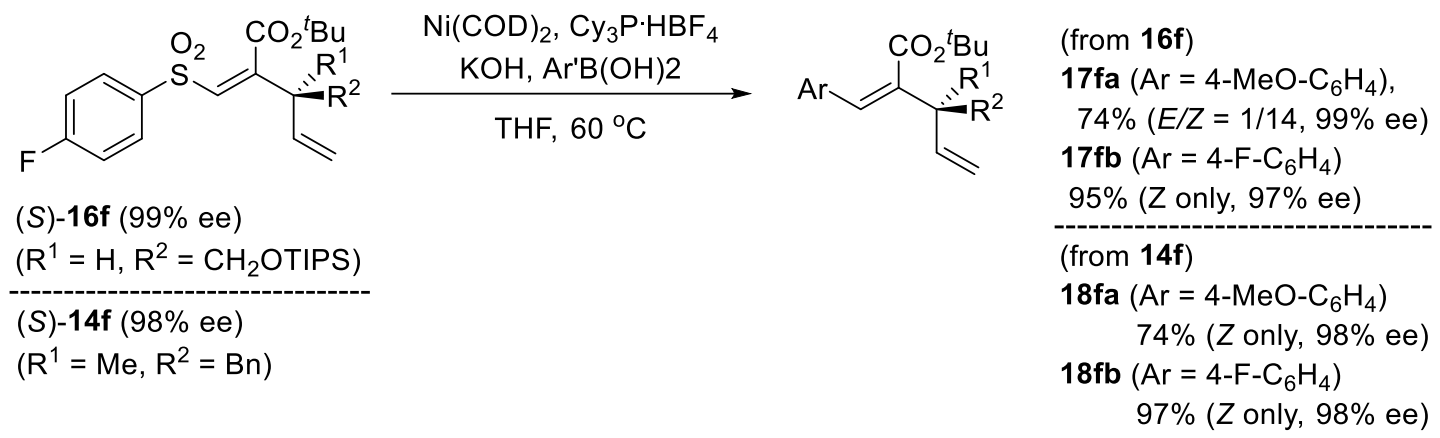

$(S)$-16f or $(S)$-14f $(0.050 \mathrm{mmol})$, aryl boronic acid $(0.10 \mathrm{mmol})$ and tricyclohexylphosphine tetrafluoroborate $(3.7 \mathrm{mg}, 0.010 \mathrm{mmol})$ was placed in a flame-dried vial. The vial was transferred to an argon-filled glovebox. To this was added bis(1,5-cyclooctadiene)nickel(0) $(1.4 \mathrm{mg}, 0.0050 \mathrm{mmol})$, potassium hydroxide $(5.6 \mathrm{mg}, 0.10 \mathrm{mmol})$ and $\mathrm{THF}(0.5 \mathrm{~mL})$ and the mixture was stirred $12 \mathrm{~h}$ at $60^{\circ} \mathrm{C}$. The mixture was quenched with saturated aq. $\mathrm{NH}_{4} \mathrm{Cl}(1 \mathrm{~mL})$, extracted with $\mathrm{Et}_{2} \mathrm{O}(2 \mathrm{~mL} \times 3)$ and the combined organic layers were washed with brind, dried $\left(\mathrm{MgSO}_{4}\right)$, filtered and concentrated in vacuo. The residue was purified by flash column chromatography $\left(\mathrm{SiO}_{2}\right.$, EtOAc:Hex = 1:50). 


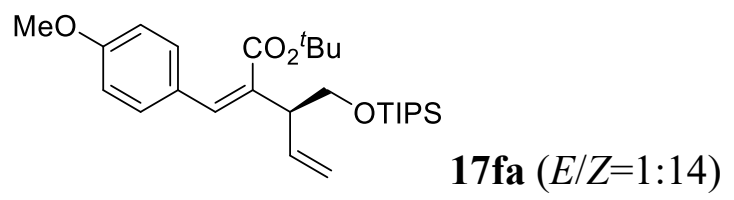

Colorless oil (17.0 mg, 74\%, EtOAc:Hex = 1:50); $[\alpha]^{20}{ }_{\mathrm{D}}=26.4^{\circ}\left(\mathrm{c} 1.48, \mathrm{CHCl}_{3}, 99 \%\right.$ ee); ${ }^{1} \mathrm{H}$ NMR (400 MHz, $\left.\mathrm{CDCl}_{3}\right): \delta 7.23(\mathrm{~d}, J=8.8 \mathrm{~Hz}, 2 \mathrm{H}), 6.84(\mathrm{~d}, J=8.7 \mathrm{~Hz}, 2 \mathrm{H}), 6.59(\mathrm{~s}, 1 \mathrm{H})$, 5.97 (ddd, $J=17.3,10.4,7.6 \mathrm{~Hz}, 1 \mathrm{H}), 5.24$ (d, $J=17.3 \mathrm{~Hz}, 1 \mathrm{H}), 5.17$ (d, $J=10.4 \mathrm{~Hz}, 1 \mathrm{H})$, 3.97 (dd of ABq, $J=9.7,5.9 \mathrm{~Hz}, 1 \mathrm{H}), 3.87$ (dd of ABq, $J=9.6,7.1 \mathrm{~Hz}, 1 \mathrm{H}), 3.82(\mathrm{~s}, 3 \mathrm{H}), 3.32$ $(\mathrm{dt}, J=7.0,6.9 \mathrm{~Hz}, 1 \mathrm{H}), 1.39(\mathrm{~s}, 9 \mathrm{H}), 1.18-0.98(\mathrm{~m}, 21 \mathrm{H}) ;{ }^{13} \mathrm{C} \mathrm{NMR}\left(100 \mathrm{MHz}, \mathrm{CDCl}_{3}\right): \delta$ $168.7,159.1,137.2$, 134.2, 132.7, 129.7, 129.2, 116.8, 113.3, 81.1, 65.4, 55.3, 51.7, 27.9, 18.0, 12.0; IR (ATR): $\tilde{\mathrm{v}}=2941,2866,1708,1607,1511,1366,1253,1107,882 \mathrm{~cm}^{-1}$; HRMS (ESI) Calcd for $\mathrm{C}_{27} \mathrm{H}_{44} \mathrm{NaO}_{4} \mathrm{Si}^{+}[\mathrm{M}+\mathrm{Na}]^{+}$483.2901, found 483.2904.

Chiral assay was conducted on Chiralpak ${ }^{\circledR}$ IC column using IPA:nHex (0.5:99.5) as an eluent $(1.0 \mathrm{~mL} / \mathrm{min})$.

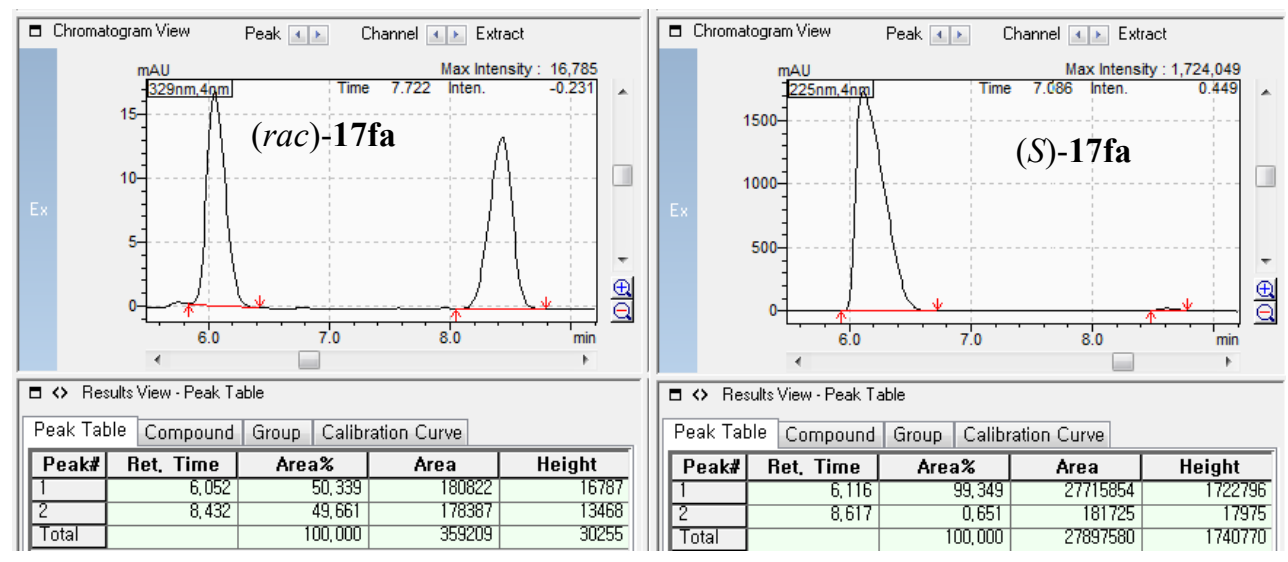




\section{OTIPS}

Colorless oil (21.3 mg, 95\%, EtOAc:Hex = 1:100); $[\alpha]^{20}{ }_{\mathrm{D}}=41.6^{\circ}\left(\mathrm{c} 0.49, \mathrm{CHCl}_{3}, 97 \%\right.$ ee $) ;{ }^{1} \mathrm{H}$ NMR (400 MHz, $\left.\mathrm{CDCl}_{3}\right): \delta 7.22(\mathrm{dd}, J=8.7,5.5 \mathrm{~Hz}, 2 \mathrm{H}), 6.97(\mathrm{t}, J=8.7 \mathrm{~Hz}, 2 \mathrm{H}), 6.60(\mathrm{~s}$, 1H), 5.94 (ddd, $J=17.3,10.3,7.6 \mathrm{~Hz}, 1 \mathrm{H}), 5.22$ (d, $J=17.3 \mathrm{~Hz}, 1 \mathrm{H}), 5.16$ (d, $J=10.3 \mathrm{~Hz}$, $1 \mathrm{H}), 3.95$ (dd of ABq, $J=9.7,6.8 \mathrm{~Hz}, 1 \mathrm{H}), 3.86$ (dd of ABq, $J=9.7,6.7 \mathrm{~Hz}, 1 \mathrm{H}), 3.31$ (q, $J=$ $6.6 \mathrm{~Hz}, 1 \mathrm{H}), 1.33$ (s, 9H), 1.16-0.94 (m, 21H); $\left.{ }^{13} \mathrm{C} \mathrm{NMR} \mathrm{(100} \mathrm{MHz,} \mathrm{CDCl}_{3}\right): \delta 168.2,162.1(\mathrm{~d}$, $J=245.3 \mathrm{~Hz}), 136.9,136.1,132.9$ (d, $J=3.2 \mathrm{~Hz}), 132.1,129.9$ (d, $J=8.0 \mathrm{~Hz}), 117.0,114.8$ $(\mathrm{d}, J=21.3 \mathrm{~Hz}), 81.3,65.2,51.5,27.8,18.0,12.0 ;{ }^{19} \mathrm{~F}$ NMR $\left(376 \mathrm{MHz}, \mathrm{CDCl}_{3}\right): \delta$-114.6; IR (ATR): $\tilde{\mathrm{v}}=2943,2866,1709,1603,1508,1464,1367,1227,1156,1105,881,681 \mathrm{~cm}^{-1}$; HRMS (ESI) Calcd for $\mathrm{C}_{26} \mathrm{H}_{41} \mathrm{FNaO}_{3} \mathrm{Si}^{+}[\mathrm{M}+\mathrm{Na}]^{+}$471.2701, found 471.2704.

The product was derivatized into the corresponding alcohol according to Method $\mathbf{D}$, and chiral assay of the alcohol was conducted on Chiralpak ${ }^{\circledR}$ OJ-H column using IPA: $n$ Hex (5:95) as an eluent $(1.0 \mathrm{~mL} / \mathrm{min})$.
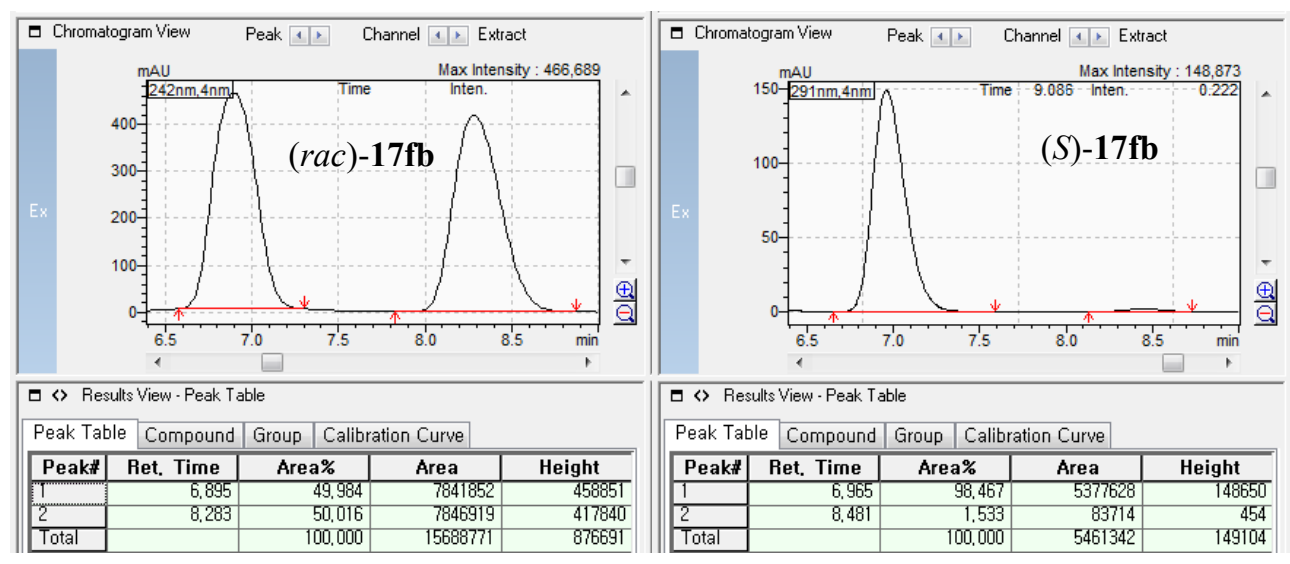
<smiles>C=CC(=Cc1ccc(OC)cc1)C(=O)OCC(=O)OC</smiles>

Colorless oil (14.0 mg, 74\%, EtOAc:Hex = 1:50); $[\alpha]^{20}{ }_{\mathrm{D}}=-21.7^{\circ}\left(\mathrm{c} 0.34, \mathrm{CHCl}_{3}, 98 \% \mathrm{ee}\right) ;{ }^{1} \mathrm{H}$ NMR (400 MHz, $\left.\mathrm{CDCl}_{3}\right): \delta 7.24-7.13(\mathrm{~m}, 5 \mathrm{H}), 7.19(\mathrm{~d}, J=8.8 \mathrm{~Hz}, 2 \mathrm{H}), 6.80(\mathrm{~d}, J=8.8 \mathrm{~Hz}$, 2H), 6.14 (s, 1H), 6.04 (dd, $J=17.5,10.8 \mathrm{~Hz}, 1 \mathrm{H}), 5.12$ (d, $J=10.8 \mathrm{~Hz}, 1 \mathrm{H}), 5.06$ (d, $J=17.5$ $\mathrm{Hz}, 1 \mathrm{H}), 3.80(\mathrm{~s}, 3 \mathrm{H}), 3.14(\mathrm{~d}$ of ABq, $J=13.0 \mathrm{~Hz}, 1 \mathrm{H}), 2.90$ (d of ABq, $J=13.0 \mathrm{~Hz}, 1 \mathrm{H}), 1.39$ $(\mathrm{s}, 9 \mathrm{H}), 1.23(\mathrm{~s}, 3 \mathrm{H}) ;{ }^{13} \mathrm{C} \mathrm{NMR}\left(100 \mathrm{MHz}, \mathrm{CDCl}_{3}\right): \delta 169.5,159.0,144.0,140.4,138.0,131.2$, 129.4, 129.2, 128.5, 127.4, 126.1, 113.4, 81.6, 55.3, 45.4, 44.9, 28.0, 23.0; IR (ATR): $\tilde{\mathrm{v}}=2976$, 2931, 2858, 1711, 1608, 1512, 1366, 1251, 1152, 1034, 917, $703 \mathrm{~cm}^{-1}$; HRMS (ESI) Calcd for $\mathrm{C}_{25} \mathrm{H}_{30} \mathrm{NaO}_{3}{ }^{+}[\mathrm{M}+\mathrm{Na}]^{+} 401.2087$, found 401.2090.

Chiral assay was conducted on Chiralpak ${ }^{\circledR}$ IG column using IPA: $n$ Hex $(0.5: 99.5)$ as an eluent $(1.0 \mathrm{~mL} / \mathrm{min})$.
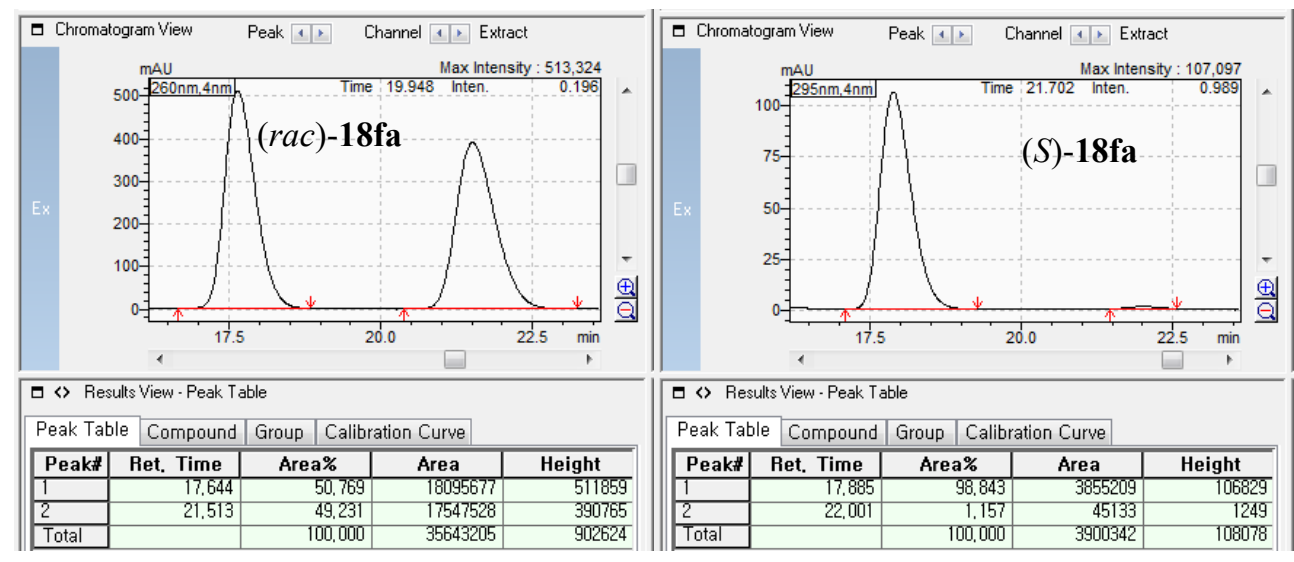


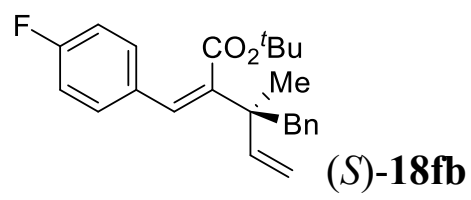

Colorless oil (17.7 mg, 97\%, EtOAc:Hex =1:100); $[\alpha]^{20}{ }_{\mathrm{D}}=-83.2^{\circ}\left(\mathrm{c} 1.64, \mathrm{CHCl}_{3}, 98 \%\right.$ ee); ${ }^{1} \mathrm{H}$ NMR (400 MHz, $\left.\mathrm{CDCl}_{3}\right): \delta$ 7.23-7.17 (m, 7H), $6.96(\mathrm{t}, J=8.8 \mathrm{~Hz}, 2 \mathrm{H}), 6.15(\mathrm{~s}, 1 \mathrm{H}), 6.03$ $(\mathrm{dd}, J=17.5,10.8 \mathrm{~Hz}, 1 \mathrm{H}), 5.13(\mathrm{~d}, J=10.8 \mathrm{~Hz}, 1 \mathrm{H}), 5.07$ (d, $J=17.5 \mathrm{~Hz}, 1 \mathrm{H}), 3.14$ (d of $\mathrm{ABq}, J=13.0 \mathrm{~Hz}, 1 \mathrm{H}), 2.90(\mathrm{~d}$ of ABq, $J=13.0 \mathrm{~Hz}, 1 \mathrm{H}), 1.36(\mathrm{~s}, 9 \mathrm{H}), 1.24(\mathrm{~s}, 3 \mathrm{H}) ;{ }^{13} \mathrm{C} \mathrm{NMR}$ $\left(100 \mathrm{MHz}, \mathrm{CDCl}_{3}\right): \delta 169.0,162.1(\mathrm{~d}, J=245.0 \mathrm{~Hz}), 143.8,142.3,137.8,132.8(\mathrm{~d}, J=3.0 \mathrm{~Hz})$, 131.2, 130.8, 129.8 (d, $J=8.0 \mathrm{~Hz}), 127.9,127.5,126.1,114.9$ (d, $J=21.2 \mathrm{~Hz}), 113.6,81.7$, 45.4, 44.9, 27.9, 23.0; $\left.{ }^{19} \mathrm{~F} \mathrm{NMR} \mathrm{(376} \mathrm{MHz,} \mathrm{CDCl}_{3}\right): \delta$-114.7; IR (ATR): $\tilde{\mathrm{v}}=3056,3025,2977$, 2924, 1713, 1457, 1366, 1229, 1153, $699 \mathrm{~cm}^{-1}$; HRMS (ESI) Calcd for $\mathrm{C}_{24} \mathrm{H}_{27} \mathrm{FNaO}_{2}{ }^{+}[\mathrm{M}+\mathrm{Na}]^{+}$ 389.1887 , found 389.1890 .

Chiral assay was conducted on Chiralpak ${ }^{\circledR}$ IG column using IPA: $n$ Hex $(0.5: 99.5)$ as an eluent $(1.0 \mathrm{~mL} / \mathrm{min})$.
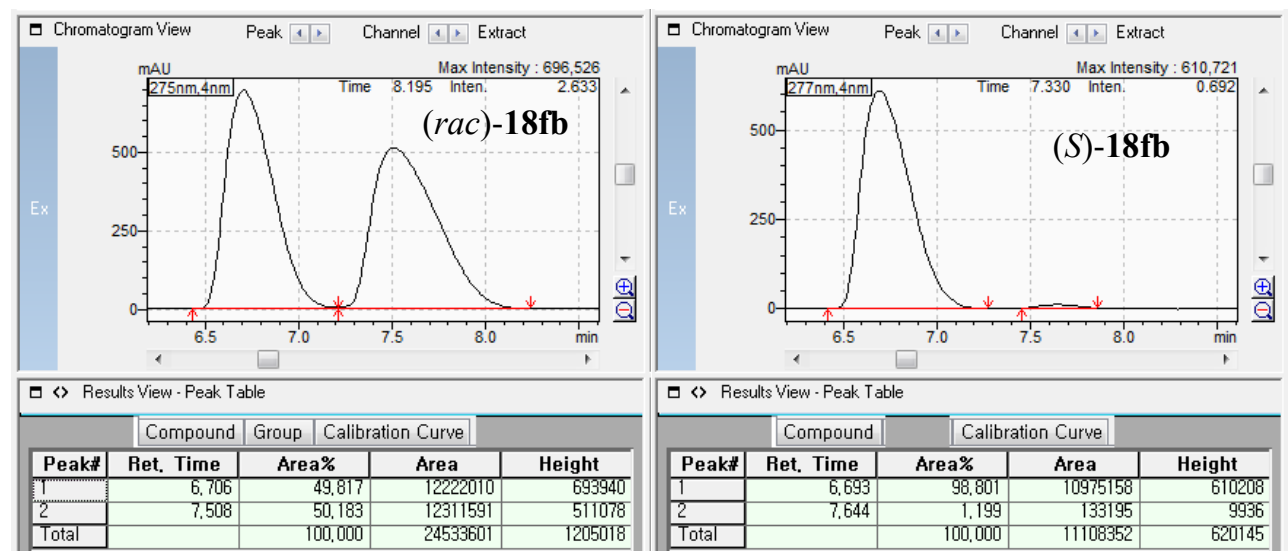
8.2.2 Conversion of $\mathbf{1 4 f}$ into $\mathbf{1 9 f a - f c . ~}{ }^{15}$

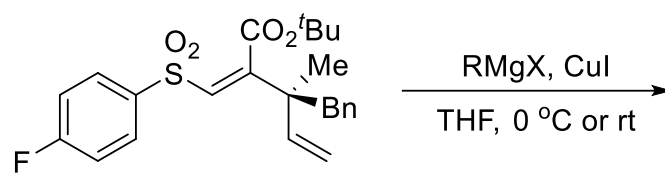

(S)-14f (98\% ee)

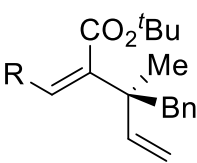

$19 f a(R=$ allyl $) 0^{\circ} \mathrm{C}, 4 \mathrm{~h}$

$86 \%(E / Z=1 / 11,98 \%$ ee $)$

$19 \mathrm{fb}(\mathrm{R}=\mathrm{cHex}) \mathrm{rt}, 24 \mathrm{~h}$

$68 \%(E / Z=1 / 20,98 \%$ ee $)$

$19 \mathrm{fc}(\mathrm{R}=\mathrm{Bn}) 0^{\circ} \mathrm{C}, 6 \mathrm{~h}$

$74 \%(E / Z=1 / 27,95 \%$ ee $)$

Copper(I) iodide $(5.2 \mathrm{mg}, 0.028 \mathrm{mmol})$ and THF $(0.25 \mathrm{~mL})$ were placed in a flame-dried Schlenk flask and the flask was cooled to $-78^{\circ} \mathrm{C}$. To this was added alkyl magnesium bromide $(0.055 \mathrm{mmol})$ dropwise and stirred $30 \mathrm{~min}$ at $-78^{\circ} \mathrm{C}$. To this was added $(S)-\mathbf{1 4 f}(21.5 \mathrm{mg}, 0.050$ $\mathrm{mmol})$ in THF $(0.25 \mathrm{~mL})$ and the mixture was allowed to warm to $0{ }^{\circ} \mathrm{C}$ over $4 \mathrm{~h}$. The mixture was quenched with saturated aq. $\mathrm{NH}_{4} \mathrm{Cl}(1 \mathrm{~mL})$ and the aqueous layer was extracted with $\mathrm{Et}_{2} \mathrm{O}$ $(2 \mathrm{~mL}$ x 3). The combined organic layers were washed with water $(2 \mathrm{~mL})$ and brine $(2 \mathrm{~mL})$, dried $\left(\mathrm{Na}_{2} \mathrm{SO}_{4}\right)$, filtered and concentrated in vacuo. The residue was purified by flash column chromatography $\left(\mathrm{SiO}_{2}\right)$. 
<smiles>C=CC=C(C(=O)OC)C(Br)(Br)C=C</smiles>

$(S)-19 f a(E / Z=1: 11)$

Colorless oil (13.3 mg, 85\%, EtOAc:Hex =1:50); $[\alpha]^{20}{ }_{\mathrm{D}}=-20.3^{\circ}\left(\mathrm{c} 1.12, \mathrm{CHCl}_{3}, 98 \%\right.$ ee); ${ }^{1} \mathrm{H}$ NMR (400 MHz, $\left.\mathrm{CDCl}_{3}\right): \delta 7.26-7.11(\mathrm{~m}, 5 \mathrm{H}), 5.95(\mathrm{dd}, J=17.5,10.8 \mathrm{~Hz}, 1 \mathrm{H}), 5.72(\mathrm{ddt}, J=$ $17.5,12.8,6.4 \mathrm{~Hz}, 1 \mathrm{H}), 5.22(\mathrm{t}, J=7.6 \mathrm{~Hz}, 1 \mathrm{H}), 5.05(\mathrm{~d}, J=10.8 \mathrm{~Hz}, 1 \mathrm{H}), 4.98(\mathrm{~d}, J=17.5$ $\mathrm{Hz}, 1 \mathrm{H}), 5.00-4.92(\mathrm{~m}, 2 \mathrm{H}), 3.04(\mathrm{~d}$ of ABq, $J=13.0 \mathrm{~Hz}, 1 \mathrm{H}), 2.81$ (d of ABq, $J=13.0 \mathrm{~Hz}$, $1 \mathrm{H}), 2.87-2.77(\mathrm{~m}, 2 \mathrm{H}), 1.54(\mathrm{~s}, 9 \mathrm{H}), 1.12(\mathrm{~s}, 3 \mathrm{H}) ;{ }^{13} \mathrm{C} \mathrm{NMR}\left(100 \mathrm{MHz}, \mathrm{CDCl}_{3}\right): \delta 168.9,144.4$, 141.3, 138.0, 135.9, 131.1, 128.4, 127.4, 126.0, 115.5, 113.0, 81.4, 44.9, 44.8, 33.9, 28.3, 23.0; IR (ATR): $\tilde{\mathrm{v}}=3078,2977,2924,2858,1714,1449,1361,1238,1156,913,702 \mathrm{~cm}^{-1}$; HRMS (ESI) Calcd for $\mathrm{C}_{21} \mathrm{H}_{28} \mathrm{NaO}_{2}{ }^{+}[\mathrm{M}+\mathrm{Na}]^{+} 335.1982$, found 335.1984.

Chiral assay was conducted on Chiralpak ${ }^{\circledR}$ OD-H column using IPA: $n$ Hex $(0: 100)$ as an eluent $(0.5 \mathrm{~mL} / \mathrm{min})$.
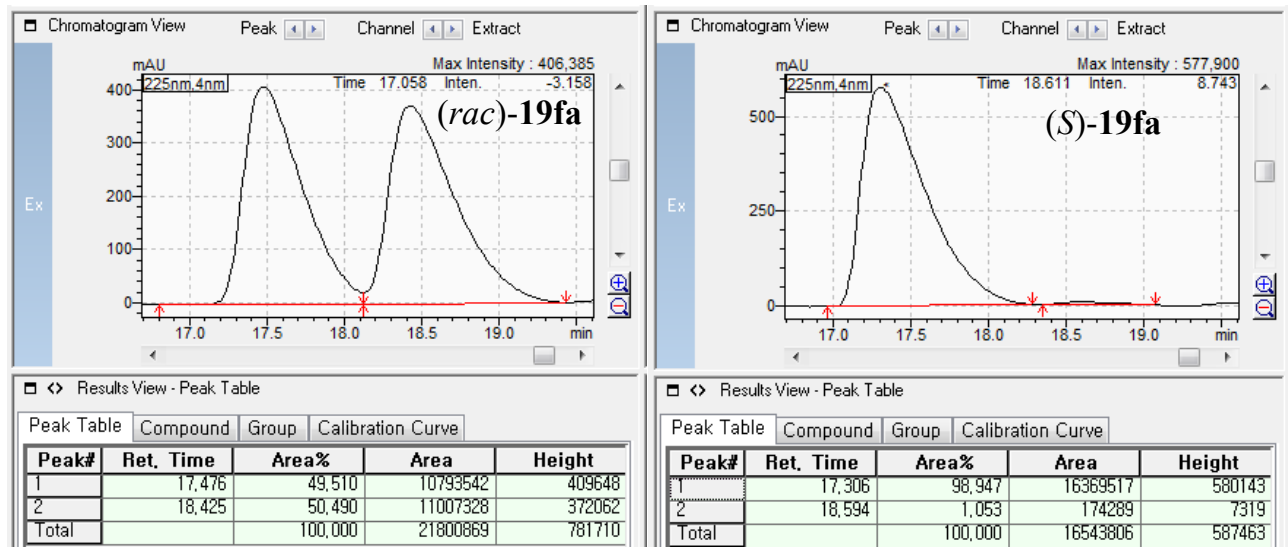


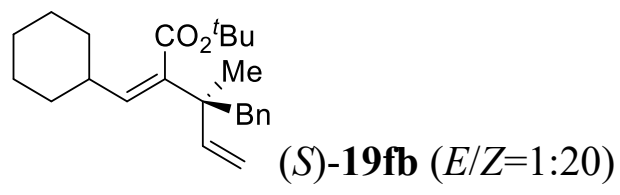

Colorless oil (12.0 mg, 68\%, EtOAc:Hex = 1:100); $[\alpha]^{20}{ }_{\mathrm{D}}=-40.1^{\circ}\left(\mathrm{c} 0.52, \mathrm{CHCl}_{3}, 98 \%\right.$ ee); ${ }^{1} \mathrm{H}$ NMR (400 MHz, $\left.\mathrm{CDCl}_{3}\right): \delta$ 7.25-7.07 (m, 5H), $5.92(\mathrm{dd}, J=17.5,10.8 \mathrm{~Hz}, 1 \mathrm{H}), 5.03(\mathrm{~d}, J$ $=10.8 \mathrm{~Hz}, 1 \mathrm{H}), 4.98(\mathrm{~d}, J=17.3 \mathrm{~Hz}, 1 \mathrm{H}), 4.95(\mathrm{~d}, J=9.7 \mathrm{~Hz}, 1 \mathrm{H}), 3.04(\mathrm{~d}$ of ABq, $J=13.0$ $\mathrm{Hz}, 1 \mathrm{H}), 2.76(\mathrm{~d}$ of ABq, $J=13.0 \mathrm{~Hz}, 1 \mathrm{H}), 2.24-2.11(\mathrm{~m}, 1 \mathrm{H}), 1.71-1.57(\mathrm{~m}, 4 \mathrm{H}), 1.53(\mathrm{~s}, 9 \mathrm{H})$, 1.32-1.09 (m, 4H), $1.08(\mathrm{~s}, 3 \mathrm{H})$ 1.04-0.82 (m, 2H); ${ }^{13} \mathrm{C}$ NMR (100 MHz, $\left.\mathrm{CDCl}_{3}\right): \delta$ 169.4, 144.7, 138.2, 138.1, 136.4, 131.2, 127.3, 125.9, 112.7, 81.0, 44.8, 44.3, 39.1, 32.8, 32.8, 28.3, 25.9, 25.9, 23.2; IR (ATR): $\tilde{\mathrm{v}}=2924,2854,1712,1457,1370,1223,1146 \mathrm{~cm}^{-1}$; HRMS (ESI) Calcd for $\mathrm{C}_{24} \mathrm{H}_{34} \mathrm{NaO}_{2}{ }^{+}[\mathrm{M}+\mathrm{Na}]^{+}$377.2451, found 377.2453

The product was derivatized into the corresponding lactone according to Method $\mathbf{B}$, and chiral assay of the lactone was conducted on Chiralpak ${ }^{\circledR}$ IA column using IPA: $n$ Hex $(5: 95)$ as an eluent $(1.0 \mathrm{~mL} / \mathrm{min})$.
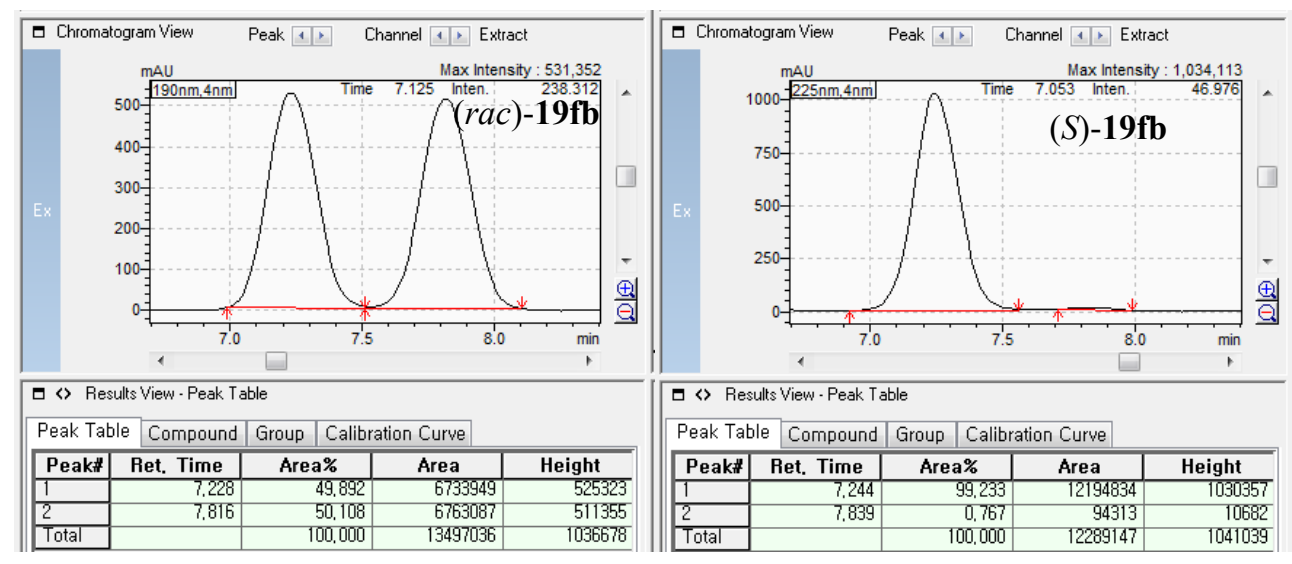


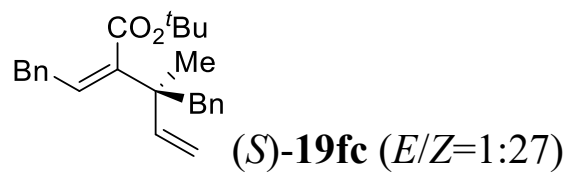

Colorless oil (13.4 mg, 74\%, EtOAc:Hex = 1:50); $[\alpha]^{20} \mathrm{D}=-28.1^{\circ}\left(\mathrm{c} 1.15, \mathrm{CHCl}_{3}, 95 \% \mathrm{ee}\right) ;{ }^{1} \mathrm{H}$ NMR (400 MHz, $\left.\mathrm{CDCl}_{3}\right): \delta$ 7.29-7.24 (m, 2H), 7.25-7.09 (m, 8H), 5.96 (dd, J=17.5, $10.8 \mathrm{~Hz}$, 1H), 5.36 (t, $J=7.6 \mathrm{~Hz}, 1 \mathrm{H}), 5.05$ (d, $J=10.8 \mathrm{~Hz}, 1 \mathrm{H}), 4.99$ (d, $J=17.5 \mathrm{~Hz}, 1 \mathrm{H}), 3.48-3.33$ (m, 2H), $3.06(\mathrm{~d}$ of ABq, $J=13.0 \mathrm{~Hz}, 1 \mathrm{H}), 2.83(\mathrm{~d}$ of ABq, $J=13.0 \mathrm{~Hz}, 1 \mathrm{H}), 1.55(\mathrm{~s}, 9 \mathrm{H}), 1.13$ (s, 3H); ${ }^{13} \mathrm{C}$ NMR (100 MHz, $\left.\mathrm{CDCl}_{3}\right): \delta 169.0,144.4,141.1,139.9,138.0,131.1,129.5,128.6$, 128.4, 127.4, 126.1, 126.0, 113.1, 81.6, 44.9, 44.8, 35.9, 28.4, 23.2; IR (ATR): $\tilde{\mathrm{v}}=3056,3025$, 2977, 2924, 1713, 1457, 1366, 1229, 1153, $699 \mathrm{~cm}^{-1}$; HRMS (ESI) Calcd for $\mathrm{C}_{25} \mathrm{H}_{30} \mathrm{NaO}_{2}{ }^{+}$ $[\mathrm{M}+\mathrm{Na}]^{+}$385.2138, found 385.2141.

The product was derivatized into the corresponding lactone according to $\mathbf{M e t h o d} \mathbf{B}$, and chiral assay of the lactone was conducted on Chiralpak ${ }^{\circledR}$ IA column using IPA: $n$ Hex (5:95) as an eluent $(1.0 \mathrm{~mL} / \mathrm{min})$.
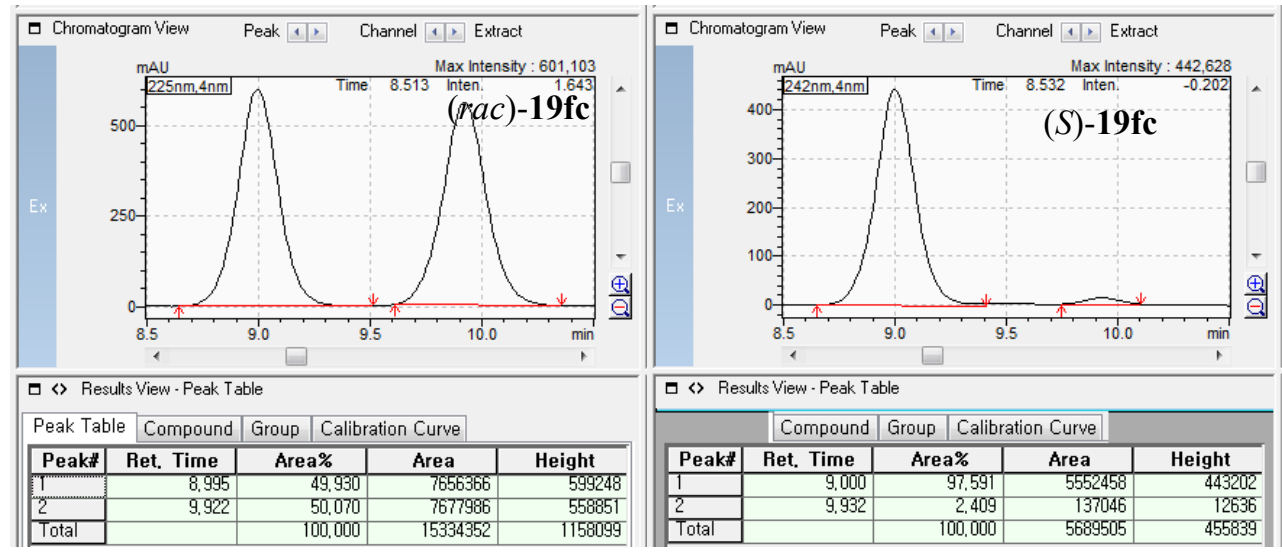


\subsubsection{Conversion of $\mathbf{1 4 f}$ into $\mathbf{2 0 f} .^{16}$}

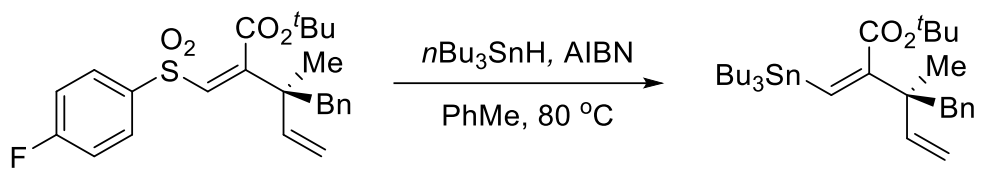

(S)-14f $(98 \%$ ee $)$

20f, $84 \%$ ( $Z$ only, $97 \%$ ee)

To a solution of $(S)-\mathbf{1 4 f}(21.5 \mathrm{mg}, 0.050 \mathrm{mmol})$ in toluene $(0.5 \mathrm{~mL})$ in a flame-dried Schlenk flask, was added tributyltin hydride $(29.1 \mathrm{mg} 0.10 \mathrm{mmol})$ and 2,2'-Azobis(2-methylpropionitrile) $(0.2 \mathrm{M}$ in toluene, $25.0 \mu \mathrm{L}, 0.0050 \mathrm{mmol})$ and the mixture was stirred $12 \mathrm{~h}$ at $80{ }^{\circ} \mathrm{C}$. The reaction mixture was concentrated in vacuo and the residue was purified by flash column chromatography $\left(\mathrm{SiO}_{2}\right)$ to provide tert-butyl (S,Z)-3-benzyl-3-methyl-2-((tributylstannyl)methylene)pent-4-enoate (23.5 mg, 84\%). 
<smiles>C=CC(=CC=[18O])C(=O)OCC(C)(Br)Br</smiles>

Colorless oil (23.5 mg, 84\%, EtOAc:Hex $=0: 1) ;[\alpha]^{20}{ }_{\mathrm{D}}=-32.8^{\circ}\left(\mathrm{c} 1.75, \mathrm{CHCl}_{3}, 97 \% \mathrm{oe}\right) ;{ }^{1} \mathrm{H}$ NMR (400 MHz, $\left.\mathrm{CDCl}_{3}\right): \delta$ 7.26-7.14 (m, 3H), 7.12-7.05 (m, 2H), $6.26(\mathrm{~s}, 1 \mathrm{H}), 6.08(\mathrm{dd}, J=$ 17.5, $10.8 \mathrm{~Hz}, 1 \mathrm{H}), 5.02$ (d, $J=10.7 \mathrm{~Hz}, 1 \mathrm{H}), 4.97$ (d, $J=17.5 \mathrm{~Hz}, 1 \mathrm{H}), 3.32$ (d of ABq, $J$ $=13.0 \mathrm{~Hz}, 1 \mathrm{H}), 2.87(\mathrm{~d}$ of ABq, $J=13.0 \mathrm{~Hz}, 1 \mathrm{H}), 1.57(\mathrm{~s}, 9 \mathrm{H}), 1.52-1.40(\mathrm{~m}, 6 \mathrm{H}), 1.34-1.21$ $(\mathrm{m}, 6 \mathrm{H}), 1.19$ (s, 3H), 0.89 (t, $J=6.3 \mathrm{~Hz}, 9 \mathrm{H}), 0.94-0.81(\mathrm{~m}, 6 \mathrm{H}) ;{ }^{13} \mathrm{C} \mathrm{NMR}\left(100 \mathrm{MHz}, \mathrm{CDCl}_{3}\right)$ : $\delta 168.6,153.0,146.7,146.0,138.7,130.8,127.4,125.9,111.7,81.2,47.1,45.3,29.2,28.3$, 27.4, 25.5, 13.8, 11.3; IR (ATR): $\tilde{\mathrm{v}}=2955,2921,2871,1689,1453,1367,1304,1237,1155$, 856, 744, $700 \mathrm{~cm}^{-1}$; HRMS (ESI) Calcd for $\mathrm{C}_{30} \mathrm{H}_{50} \mathrm{NaO}_{2} \mathrm{Sn}^{+}[\mathrm{M}+\mathrm{Na}]^{+}$585.2725, found 585.2731 .

The product was destannylated according to treated with $12 \mathrm{~N} \mathrm{HCl}$, and chiral assay of the $(S)$ 15f was conducted on Chiralpak $^{\circledR}$ OD-H column using IPA: $n$ Hex $(0: 100)$ as an eluent $(0.5$ $\mathrm{mL} / \mathrm{min})$.
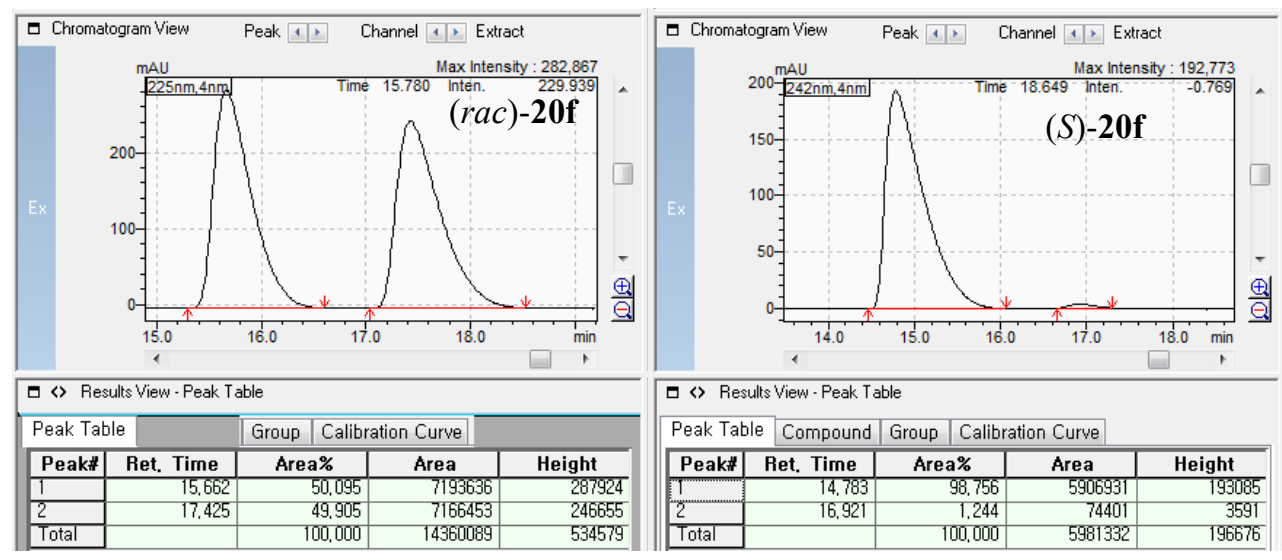


\subsubsection{Conversion of $\mathbf{1 4 f}$ into $\mathbf{2 1 f}$.}

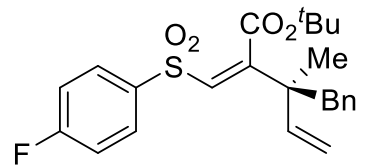

$(S)-14 f(98 \%$ ee $)$

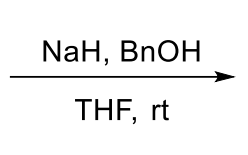

21f $90 \%$ (Z only, 98\%ee)

To a suspension of sodium hydride (60\% in mineral oil, $2.2 \mathrm{mg}, 0.055 \mathrm{mmol})$ in THF $(0.5 \mathrm{~mL})$ in a flame-dried Schlenk flask at $0{ }^{\circ} \mathrm{C}$, was added benzyl alcohol $(5.9 \mathrm{mg}, 0.055 \mathrm{mmol})$ and the mixture was stirred $30 \mathrm{~min}$ at $0{ }^{\circ} \mathrm{C}$. To this was added $(S)-\mathbf{1 4 f}(21.5 \mathrm{mg}, 0.050 \mathrm{mmol})$ and the mixture was allowed to warm to RT over $2 \mathrm{~h}$. The mixture was quenched with water $(1 \mathrm{~mL})$, extracted with $\mathrm{Et}_{2} \mathrm{O}(2 \mathrm{~mL} \times 3)$ and the organic phase was washed with brine, dried $\left(\mathrm{MgSO}_{4}\right)$, filtered and concentrated in vacuo. The residue was purified by flash column chromatography $\left(\mathrm{SiO}_{2}\right)$ to provide tert-butyl (S,Z)-3-benzyl-2-((benzyloxy)methylene)-3-methylpent-4-enoate as a colorless oil (17.0 $\mathrm{mg}, 90 \%)$. 
$\underbrace{\mathrm{Bn}}_{\mathrm{Bn}}(S)-\mathbf{2 1 f}$

Colorless oil (17.0 mg, 90\%, EtOAc:Hex = 1:50); $[\alpha]^{20}{ }_{\mathrm{D}}=-25.1^{\circ}\left(\mathrm{c} 1.02, \mathrm{CHCl}_{3}, 98 \% \mathrm{oe}\right) ;{ }^{1} \mathrm{H}$ NMR (400 MHz, $\left.\mathrm{CDCl}_{3}\right): \delta$ 7.40-7.27 (m, 5H), 7.26-7.13 (m, 5H), 5.94 (dd, J=17.5, $10.8 \mathrm{~Hz}$, 1H), $5.92(\mathrm{~s}, 1 \mathrm{H}), 5.05(\mathrm{~d}, J=10.7 \mathrm{~Hz}, 1 \mathrm{H}), 5.01(\mathrm{~d}, J=17.4 \mathrm{~Hz}, 1 \mathrm{H}), 4.85-4.74(\mathrm{~m}, 2 \mathrm{H}), 3.09$ (d of ABq, $J=13.0 \mathrm{~Hz}, 1 \mathrm{H}), 2.83(\mathrm{~d}$ of ABq, $J=13.0 \mathrm{~Hz}, 1 \mathrm{H}), 1.55(\mathrm{~s}, 9 \mathrm{H}), 1.12(\mathrm{~s}, 3 \mathrm{H}) ;{ }^{13} \mathrm{C}$ NMR (100 MHz, $\left.\mathrm{CDCl}_{3}\right): \delta 167.4,148.9,144.7,138.2,137.1,131.1,128.4,127.8,127.4,127.0$, 125.9, 119.2, 112.7, 80.9, 74.5, 45.0, 42.6, 28.4, 23.6; IR (ATR): $\tilde{\mathrm{v}}=3025,2977,2933,2871$, $1712,1449,1365,1247,1115,909,696 \mathrm{~cm}^{-1}$; HRMS (ESI) Calcd for $\mathrm{C}_{25} \mathrm{H}_{30} \mathrm{NaO}_{3}{ }^{+}[\mathrm{M}+\mathrm{Na}]^{+}$ 401.2087, found 401.2090.

Chiral assay was conducted on Chiralpak ${ }^{\circledR}$ IG column using IPA: $n$ Hex $(0.5: 99.5)$ as an eluent $(1.0 \mathrm{~mL} / \mathrm{min})$.
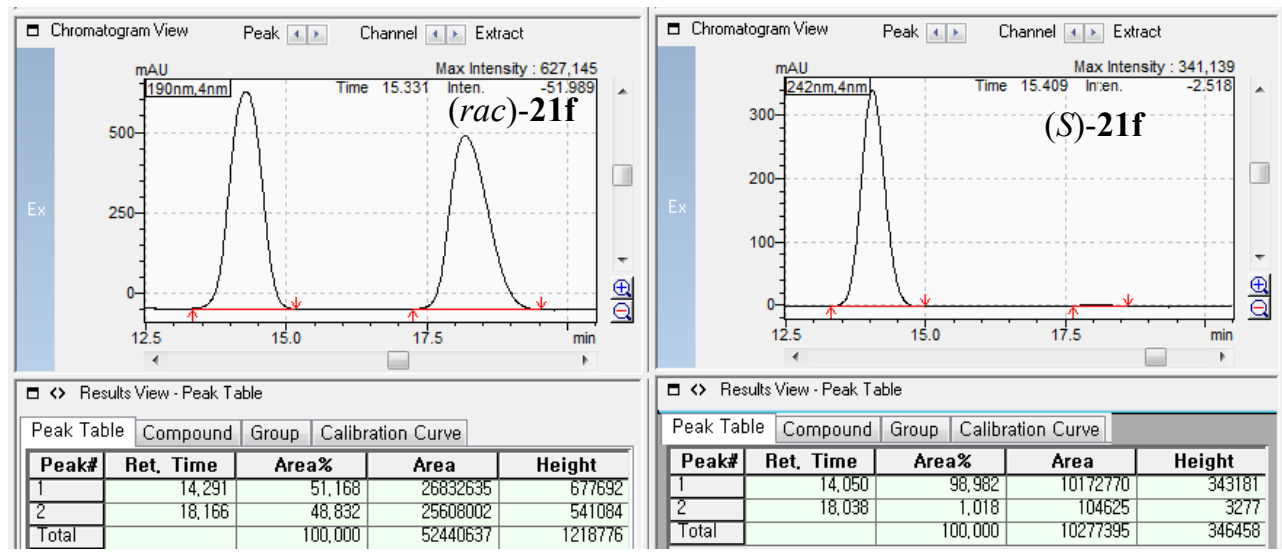
8.4. Conversion of $\mathbf{1 4 f}$ into $22 \mathrm{f}$.

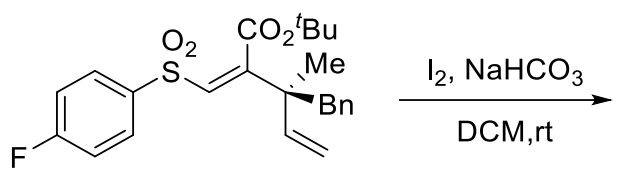

(S)-14f (98\% ee)

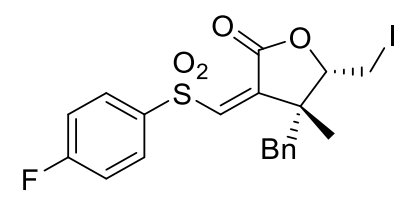

22f $86 \%$ (single dr, $99 \%$ ee)

To a solution of $(S)-\mathbf{1 4 f}(21.5 \mathrm{mg}, 0.050 \mathrm{mmol})$ in $\mathrm{CH}_{2} \mathrm{Cl}_{2}(0.25 \mathrm{~mL})$, was added iodine (15.2 $\mathrm{mg}, 0.060 \mathrm{mmol})$ and $\mathrm{NaHCO}_{3}(6.3 \mathrm{mg}, 0.075 \mathrm{mmol})$ and the mixture was stirred 2 days at RT. The mixture was quenched with saturated aq. $\mathrm{Na}_{2} \mathrm{~S}_{2} \mathrm{O}_{3}(0.5 \mathrm{~mL})$, extracted with $\mathrm{CH}_{2} \mathrm{Cl}_{2}(1 \mathrm{~mL}$ $\mathrm{x} 3$ ) and the organic phases were washed with brine, dried $\left(\mathrm{MgSO}_{4}\right)$, filtered and concentrated in vacuo. The residue was purified by flash column chromatography $\left(\mathrm{SiO}_{2}\right)$ to provide (4R,5S,Z)-4-benzyl-3-(((4-fluorophenyl)sulfonyl)methylene)-5-(iodomethyl)-4-methyldihydrofuran-2(3H)-one as a white solid $(21.6 \mathrm{mg}, 86 \%)$. 
<smiles>C[C@H]1C(=CS(=O)c2ccc(F)cc2)C(=O)O[C@@H]1CI</smiles>

$(S)-22 f$

White solid (21.6 mg, 86\%, EtOAc:Hex $=1: 5), \mathrm{mp}=139 \sim 140{ }^{\circ} \mathrm{C} ;[\alpha]^{20}{ }_{\mathrm{D}}=18.4^{\circ}(\mathrm{c} 0.48$, $\left.\mathrm{CHCl}_{3}, 99 \% \mathrm{ee}\right) ;{ }^{1} \mathrm{H} \mathrm{NMR}\left(400 \mathrm{MHz}, \mathrm{CDCl}_{3}\right): \delta 8.11$ (dd, $\left.J=9.0,5.1 \mathrm{~Hz}, 2 \mathrm{H}\right), 7.29$ (t, $J=8.6$ $\mathrm{Hz}, 2 \mathrm{H}), 7.19$ (t, $J=7.5 \mathrm{~Hz}, 1 \mathrm{H}), 7.04$ (t, $J=7.8 \mathrm{~Hz}, 2 \mathrm{H}), 6.64(\mathrm{~d}, J=7.1 \mathrm{~Hz}, 2 \mathrm{H}), 5.72(\mathrm{~s}$, 1H), 4.60 (t, $J=7.0 \mathrm{~Hz}, 1 \mathrm{H}), 3.41$ (d, $J=7.0 \mathrm{~Hz}, 2 \mathrm{H}), 2.73$ (d of ABq, $J=13.0 \mathrm{~Hz}, 1 \mathrm{H}), 2.58$ (d of ABq, $J=13.0 \mathrm{~Hz}, 1 \mathrm{H}), 1.29(\mathrm{~s}, 3 \mathrm{H}) ;{ }^{13} \mathrm{C} \mathrm{NMR}\left(100 \mathrm{MHz}, \mathrm{CDCl}_{3}\right): \delta 166.2(\mathrm{~d}, J=255.6$ $\mathrm{Hz}), 162.4,145.3,138.9,136.1$ (d, $J=2.9 \mathrm{~Hz}), 133.0,132.2$ (d, $J=9.6 \mathrm{~Hz}), 131.1,128.1,127.5$, $116.2(\mathrm{~d}, J=22.5 \mathrm{~Hz}), 86.0,50.2,38.1,20.4,-4.2$; IR (ATR): $\tilde{\mathrm{v}}=2924,2854,1775,1710,1589$, 1492, 1329, 1223, 1143, 1082, 982, 836, 746, $703 \mathrm{~cm}^{-1}$; HRMS (ESI) Calcd for $\mathrm{C}_{20} \mathrm{H}_{18} \mathrm{FINaO}_{4} \mathrm{~S}^{+}[\mathrm{M}+\mathrm{Na}]^{+}$522.9847, found 522.9850.

Chiral assay was conducted on Chiralpak ${ }^{\circledR}$ IG column using IPA: $n$ Hex (30:70) as an eluent (1.0 $\mathrm{mL} / \mathrm{min})$.
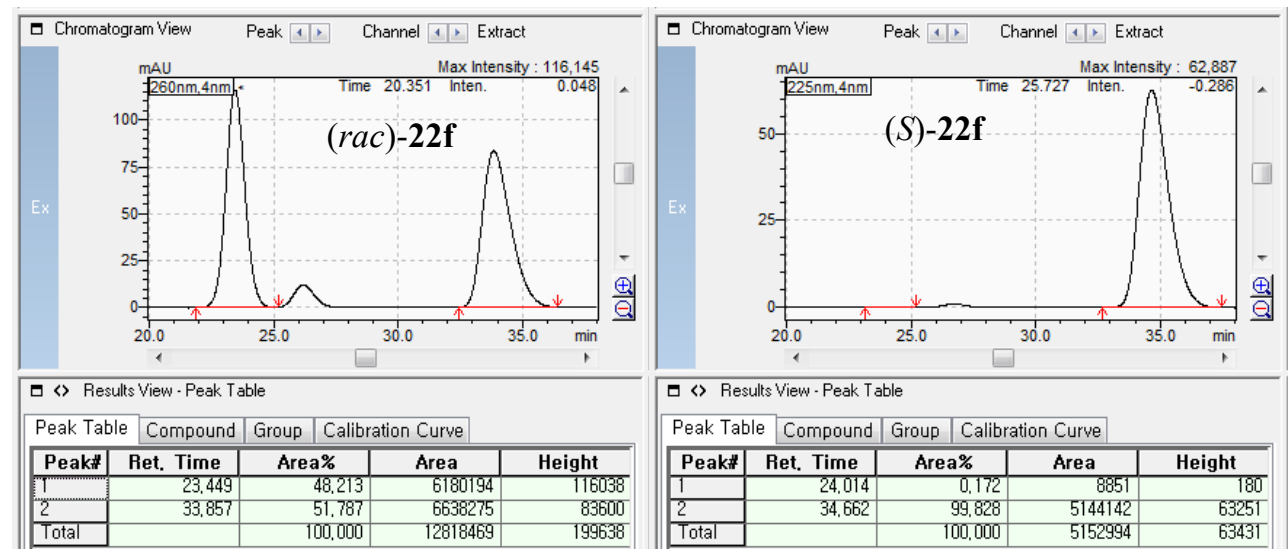
<smiles>C=CC([18O])([18OH])C(=C[S+]([O-])c1ccc(F)cc1)C(=O)OC</smiles>

$(S)-14 f(98 \%$ ee $)$

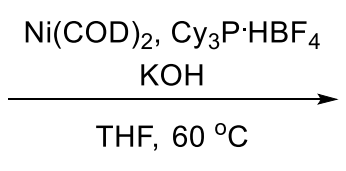

Step 1<smiles>C=CC(Br)(Br)C(=Cc1ccccc1OC)C(=O)OC</smiles>

$88 \%$

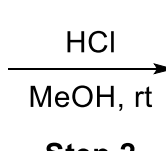

Step 2

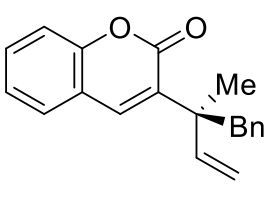

23f $96 \%(96 \%$ ee $)$

Step 1. ${ }^{14}(S)$-14f (21.5 mg, $\left.0.050 \mathrm{mmol}\right)$, 2-(methoxy-methoxy)phenylboronic acid (15.2 mg, $0.10 \mathrm{mmol})$, and tricyclohexylphosphine tetrafluoroborate $(3.7 \mathrm{mg}, 0.010 \mathrm{mmol})$ was was placed in a flame-dried vial. The vial was transferred to an argon-filled glovebox. To this was added bis(1,5-cyclooctadiene)nickel(0) (1.4 mg, $0.0050 \mathrm{mmol})$, potassium hydroxide (5.6 $\mathrm{mg}$, $0.10 \mathrm{mmol})$ and THF $(0.5 \mathrm{~mL})$ and the mixture was stirred $12 \mathrm{~h}$ at $60{ }^{\circ} \mathrm{C}$. The mixture was quenched with saturated aq. $\mathrm{NH}_{4} \mathrm{Cl}(0.5 \mathrm{~mL})$, extracted $\mathrm{Et}_{2} \mathrm{O}(5 \mathrm{~mL}$ x 3$)$ and the combined organic phases were washed with brine, dried $\left(\mathrm{MgSO}_{4}\right)$, filtered and concentrated in vacuo. The residue was purified by flash column chromatography $\left(\mathrm{SiO}_{2}, \mathrm{EtOAc}: \mathrm{Hex}=1: 10\right)$ to provide tert-butyl (S,Z)-3-benzyl-2-(2-(methoxymethoxy)-benzylidene)-3-methyl-pent-4-enoate as a colorless oil (18.0 mg, 88\%).

Step 2. To a solution of tert-butyl (S,Z)-3-benzyl-2-(2-(methoxymethoxy)benzylidene)-3methylpent-4-enoate $(12.2 \mathrm{mg}, 0.030 \mathrm{mmol})$ in $\mathrm{MeOH}(0.30 \mathrm{~mL})$ was added hydrochloric acid (11.3 $\mathrm{M}$ in $\mathrm{H}_{2} \mathrm{O}, 26.5 \mu \mathrm{L}, 0.3 \mathrm{mmol}$ ) and the mixture was stirred $4 \mathrm{~h}$ at RT. The mixture was diluted with water $(2 \mathrm{~mL})$, extracted with ethyl acetate $(2 \mathrm{~mL}$ x 3$)$ and the combined organic phases were washed with brine, dried $\left(\mathrm{MgSO}_{4}\right)$, filtered and concentrated in vacuo. The residue was purified by flash column chromatography $\left(\mathrm{SiO}_{2}, \mathrm{EtOAc:Hex}=1: 8\right)$ to provide $(S)$-23f as a white solid (8.3 mg, 95\%). 


\section{$(S)-23 f$}

White solid (EtOAc:Hex = 1:5), $\mathrm{mp}=103 \sim 104{ }^{\circ} \mathrm{C} ;[\alpha]^{20} \mathrm{D}=-59.7^{\circ}\left(\mathrm{c} 0.82, \mathrm{CHCl}_{3}, 96 \%\right.$ ee); ${ }^{1} \mathrm{H}$ NMR (400 MHz, $\mathrm{CDCl}_{3}$ ): $\delta$ 7.50-7.42 (m, 1H), 7.40-7.28 (m, 3H), 7.25-7.09 (m, 4H), 7.08$7.01(\mathrm{~m}, 2 \mathrm{H}), 6.35$ (dd, $J=17.5,10.8 \mathrm{~Hz}, 1 \mathrm{H}), 5.17$ (d, $J=10.8 \mathrm{~Hz}, 1 \mathrm{H}), 5.08(\mathrm{~d}, J=17.5 \mathrm{~Hz}$, $1 \mathrm{H}), 3.48(\mathrm{~d}$ of ABq, $J=13.1 \mathrm{~Hz}, 1 \mathrm{H}), 3.19$ (d of ABq, $J=13.2 \mathrm{~Hz}, 1 \mathrm{H}), 1.44(\mathrm{~s}, 3 \mathrm{H}) ;{ }^{13} \mathrm{C}$ $\operatorname{NMR}\left(100 \mathrm{MHz}, \mathrm{CDCl}_{3}\right): \delta 160.1,153.3,144.1,139.3,138.1,133.6,130.8,130.5,127.8,126.2$, 124.1, 119.2, 116.1, 113.4, 45.0, 44.1, 23.2; IR (ATR): $\tilde{\mathrm{v}}=2958,2928,2867,1723,1609,1457$, 1173, 1035, 923, $755 \mathrm{~cm}^{-1}$; HRMS (ESI) calcd for $\mathrm{C}_{20} \mathrm{H}_{18} \mathrm{NaO}_{2}{ }^{+}[\mathrm{M}+\mathrm{Na}]^{+} 313.1199$, found 313.1200 .

Chiral assay was conducted on Chiralpak ${ }^{\circledR}$ OJ-H column using IPA: $n$ Hex (5:95) as an eluent (1.0 $\mathrm{mL} / \mathrm{min})$.
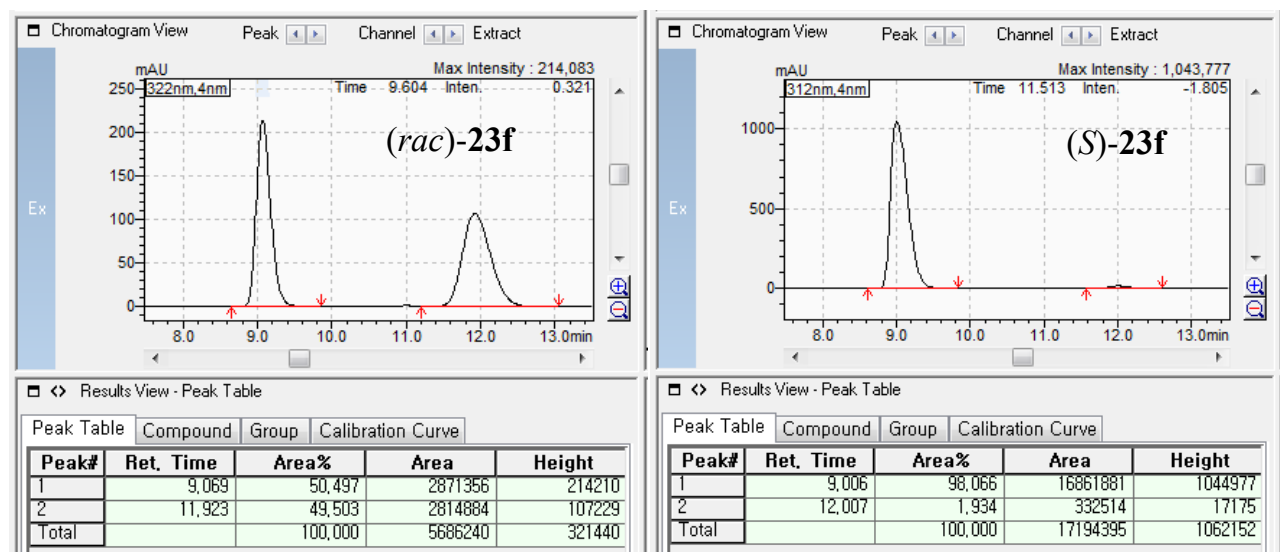


\section{Mechanistic Study}

\subsection{Cross-over experiment.}

9.1.1. Reactions of substrates used in this study (Scheme 3A)
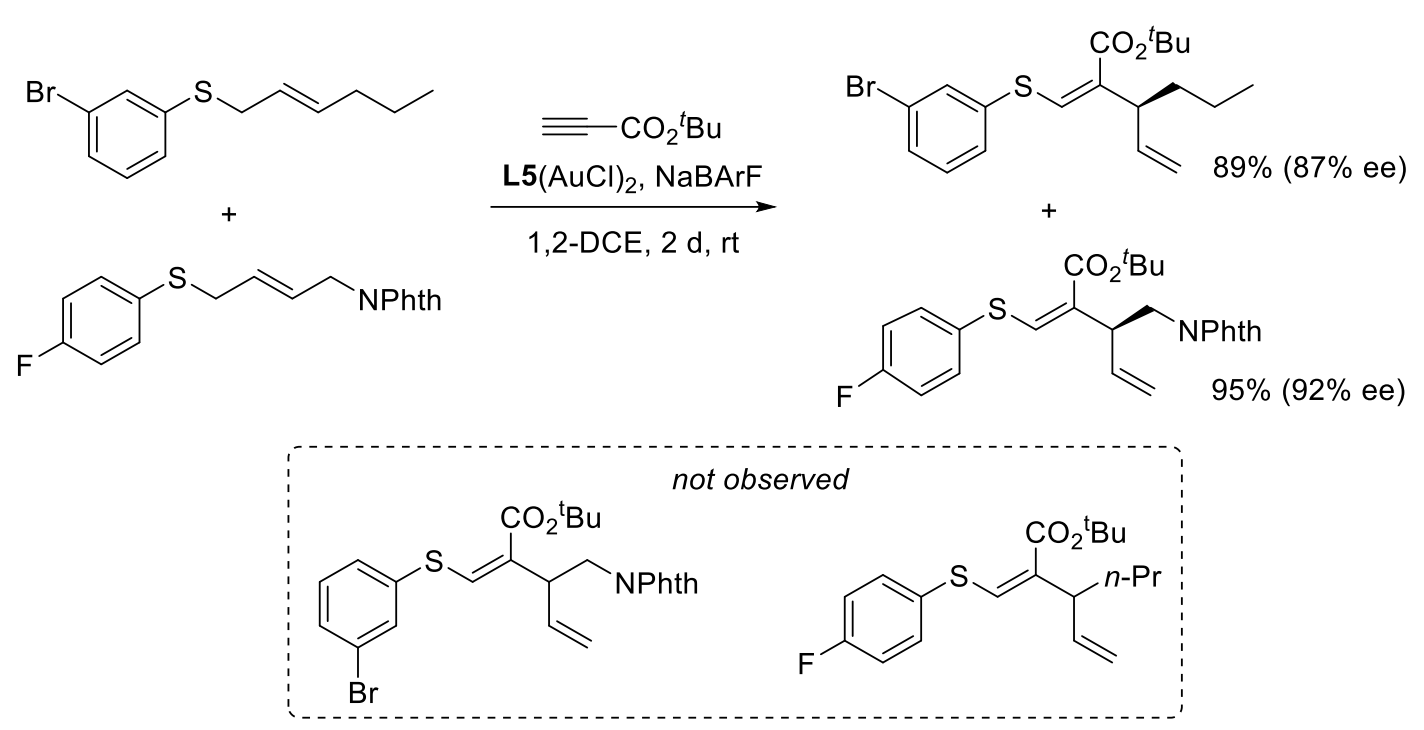

$\left(R, S_{p}\right)$-1-naphthyl/DM-Josiphos $(\mathrm{AuCl})_{2} \mathbf{L 5}(12.0 \mathrm{mg}, 0.010 \mathrm{mmol})$ and sodium tetrakis[3,5bis(trifluoromethyl)phenyl]borate $(8.8 \mathrm{mg}, 0.010 \mathrm{~mol})$ was placed in a flame-dried vial and was dissolved in 1,2-DCE $(0.8 \mathrm{~mL})$. The resulting mixture was stirred $20 \mathrm{~min}$ at RT. To this mixture was added a mixture of two allylsulfides (each $0.10 \mathrm{mmol})$ in 1,2-DCE $(0.2 \mathrm{~mL})$, followed by tert-butyl propiolate $1(86.7 \mathrm{mg}, 0.60 \mathrm{mmol})$ and the resulting mixture was stirred at $\mathrm{rt}$ for $2 \mathrm{~d}$. When the reaction was judged to be complete by TLC, the reaction mixture was concentrated in vacuo and the residue was purified by flash column chromatography $\left(\mathrm{SiO}_{2}\right)$.<smiles>CCC/C=C/CSc1cccc(Br)c1</smiles>

Pale yellow oil (EtOAc:Hex = 1:10); ${ }^{1} \mathrm{H}$ NMR (400 MHz, $\left.\mathrm{CDCl}_{3}\right): \delta 7.45$ (t, $\left.J=1.8 \mathrm{~Hz}, 1 \mathrm{H}\right)$, 7.32-7.26 (m, 1H), 7.25-7.20 (m, 1H), $7.12(\mathrm{t}, J=7.9 \mathrm{~Hz}, 1 \mathrm{H}), 5.63-5.40(\mathrm{~m}, 2 \mathrm{H}), 3.51(\mathrm{dd}, J$ $=6.8,0.9 \mathrm{~Hz}, 2 \mathrm{H}), 2.02-1.92(\mathrm{~m}, 2 \mathrm{H}), 1.33$ (sextet, $J=7.4 \mathrm{~Hz}, 2 \mathrm{H}), 0.84(\mathrm{t}, J=7.4 \mathrm{~Hz}, 3 \mathrm{H})$; ${ }^{13} \mathrm{C} \mathrm{NMR}\left(100 \mathrm{MHz}, \mathrm{CDCl}_{3}\right): \delta 138.9,135.0,131.9,130.0,128.9,128.0,124.5,122.6,36.3$, 34.3, 22.4, 13.6; IR (ATR): $\tilde{\mathrm{v}}=2958,2929,2872,2841,1739,1576,1556,1459,1392,1217$, 1068, 964, 913, 771, $754 \mathrm{~cm}^{-1}$; HRMS (ESI) Calcd for $\mathrm{C}_{12} \mathrm{H}_{15} \mathrm{BrNaS}^{+}[\mathrm{M}+\mathrm{Na}]^{+} 292.9970$, found 292.9972 . 
<smiles>C=CC(CCC)C(=CSc1cccc(Br)c1)C(=O)OCC</smiles>

Pale yellow oil (35.2 mg, 89\%, EtOAc:Hex =1:10); $[\alpha]^{20}{ }_{\mathrm{D}}=31.8^{\circ}$ (c 2.51, $\mathrm{CHCl}_{3}, 87$ \%ee); ${ }^{1} \mathrm{H}$ NMR (400 MHz, $\left.\mathrm{CDCl}_{3}\right): \delta 7.59$ (t, $\left.J=1.8 \mathrm{~Hz}, 1 \mathrm{H}\right), 7.46-7.40(\mathrm{~m}, 1 \mathrm{H}), 7.39-7.34(\mathrm{~m}, 1 \mathrm{H})$, $7.22(\mathrm{t}, J=7.9 \mathrm{~Hz}, 1 \mathrm{H}), 6.79$ (d, $J=0.3 \mathrm{~Hz}, 1 \mathrm{H}), 5.78$ (ddd, $J=17.6,10.0,7.6 \mathrm{~Hz}, 1 \mathrm{H}), 5.04$ $(\mathrm{d}, J=17.4 \mathrm{~Hz}, 1 \mathrm{H}), 5.04(\mathrm{~d}, J=10.2 \mathrm{~Hz}, 1 \mathrm{H}), 3.22$ (dt, $J=7.4,7.3 \mathrm{~Hz}, 1 \mathrm{H}), 1.63-1.20$ (m, 4H), 1.55 (s, 9H) 0.91 (t, $\left.J=7.3 \mathrm{~Hz}, 3 \mathrm{H}) ;{ }^{13} \mathrm{C} \mathrm{NMR} \mathrm{(100} \mathrm{MHz,} \mathrm{CDCl}_{3}\right): \delta 165.9,140.4,140.2$, $139.9,133.2$, 131.2, 130.7, 130.6, 129.1, 123.0, 115.0, 81.6, 45.9, 36.1, 28.3, 20.6, 14.0; IR (ATR): $\tilde{\mathrm{v}}=3078,2957,2929,2872,1696,1561,1460,1366,1232,1156,914,777,752 \mathrm{~cm}^{-1}$; HRMS (ESI) Calcd for $\mathrm{C}_{19} \mathrm{H}_{25} \mathrm{BrNaO}_{2} \mathrm{~S}^{+}[\mathrm{M}+\mathrm{Na}]^{+} 419.0651$, found 419.0653.

The product was derivatized into the corresponding sulfone according to Method A, and chiral assay of the sulfone Chiral assay was conducted on Chiralpak ${ }^{\circledR}$ IC column using IPA: $n$ Hex (2:98) as an eluent (1.0 $\mathrm{mL} / \mathrm{min})$.
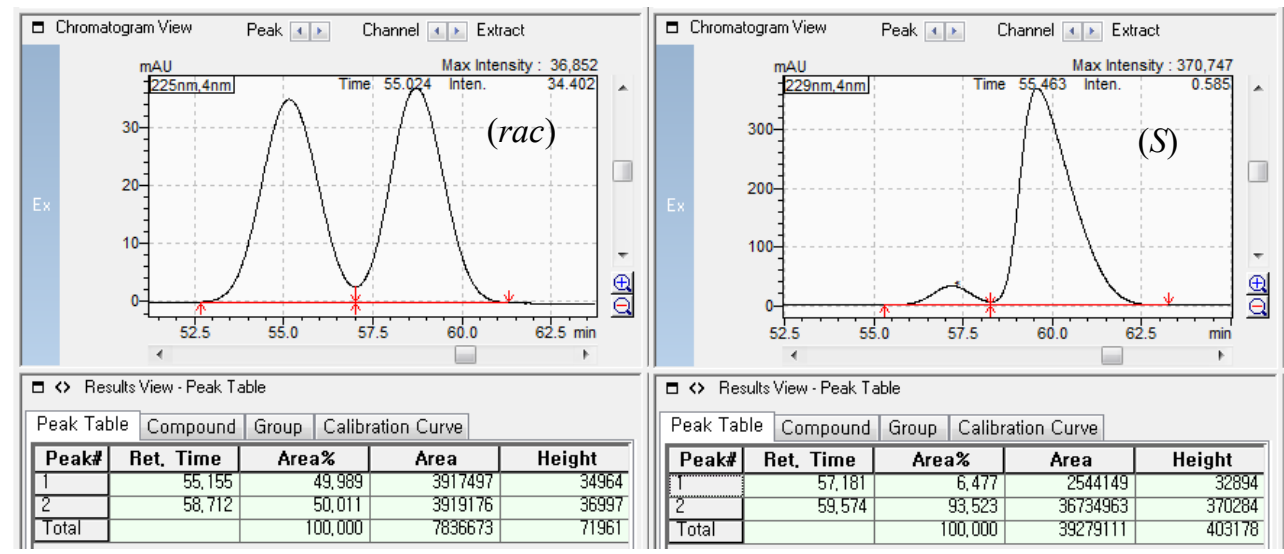
9.1.2. Reactions of substrates used Shi's study (Scheme 3B).
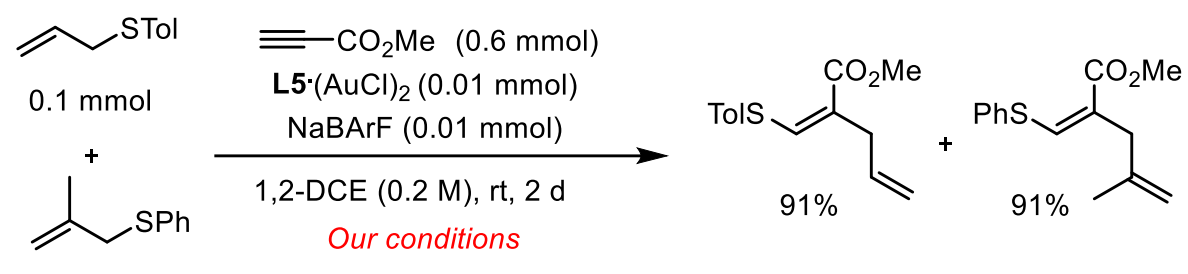

$0.1 \mathrm{mmol}$
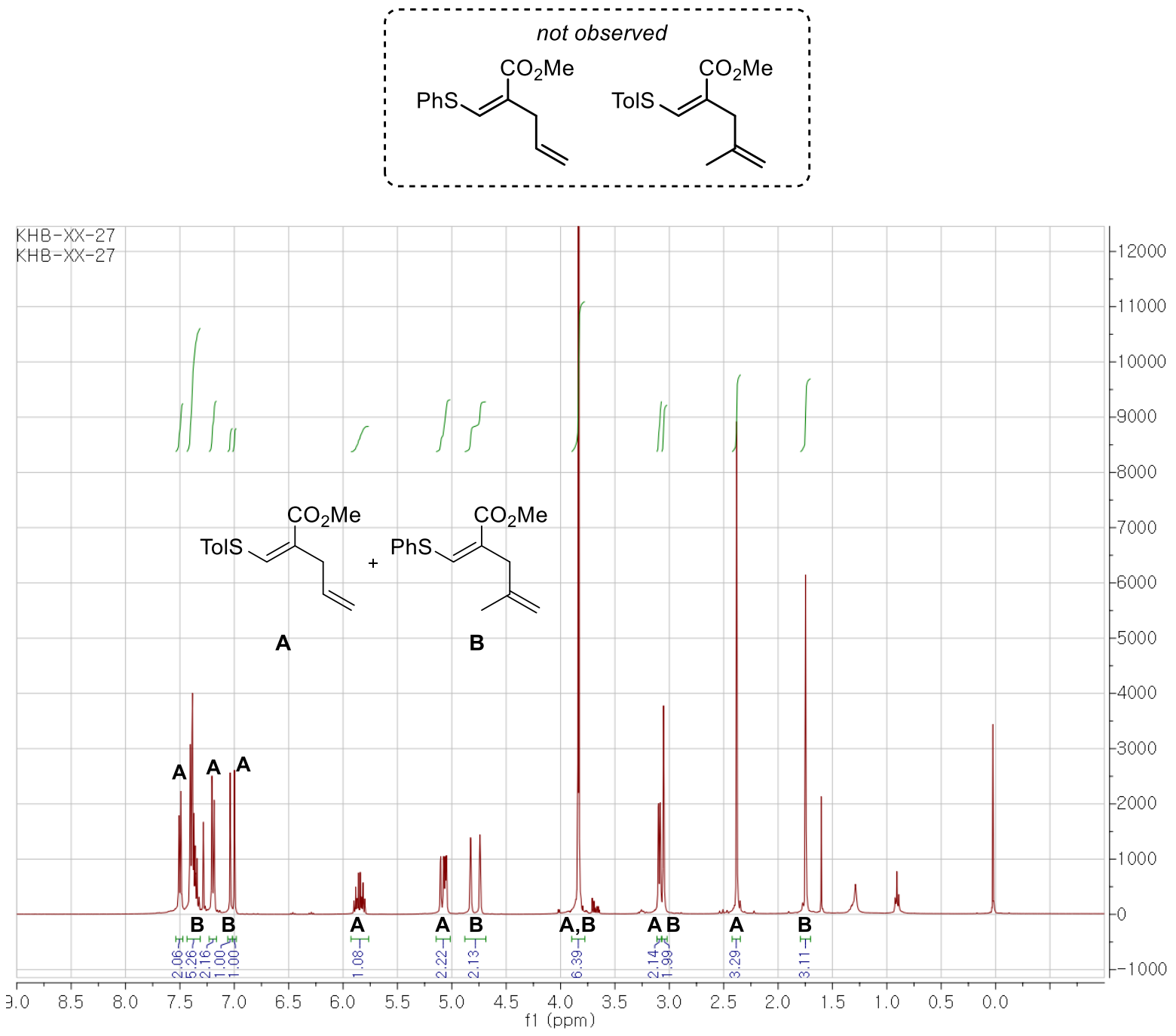


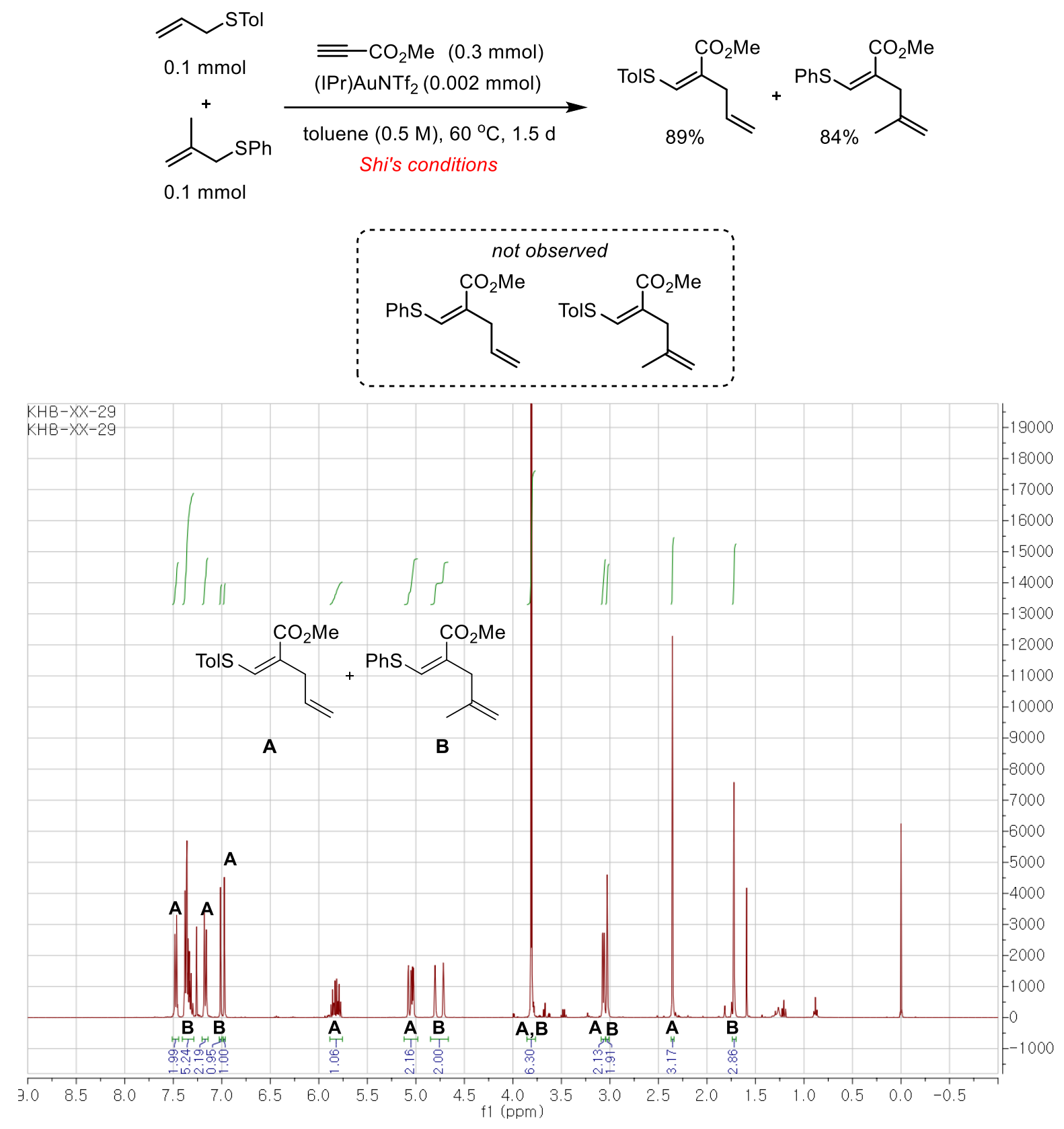




\subsection{Kinetic analysis.}

A set of allyl sulfides derivatives of 6a-S1 6a-S6 below having different $p$-aryl substituents were prepared and their rates of reaction at $301 \mathrm{~K}$ were followed by GLC using $n$-dodecane as internal standard. All allyl sulfide derivatives displayed $0^{\text {th }}$-order dependence on the concentration of the allyl sulfides.<smiles>[R]c1ccc(SCC=CC(C)C)cc1</smiles>
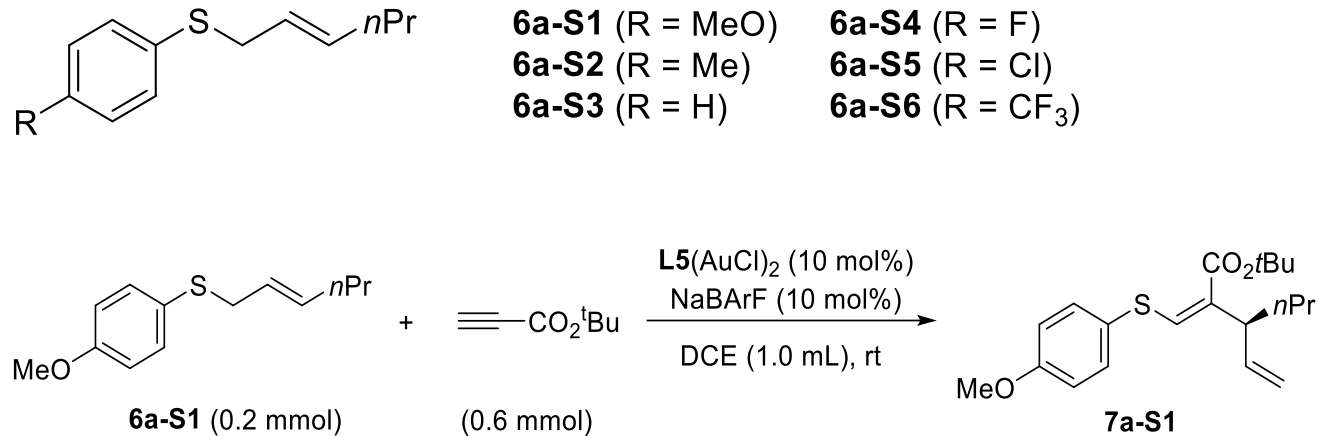

$([\mathrm{S}]=[\mathbf{6 a}-\mathrm{S} 1])$

\begin{tabular}{cccc}
\hline time $(\mathrm{min})$ & {$[\mathrm{S}]$} & $\ln [\mathrm{S}]$ & $1 /[\mathrm{S}]$ \\
\hline 0 & 0.20473 & -1.58608 & 4.88455 \\
63 & 0.19377 & -1.64108 & 5.16075 \\
126 & 0.18196 & -1.70394 & 5.49557 \\
189 & 0.16806 & -1.78342 & 5.95016 \\
252 & 0.15566 & -1.86007 & 6.42421 \\
315 & 0.14431 & -1.93579 & 6.92950 \\
378 & 0.13159 & -2.02809 & 7.59954 \\
441 & 0.11942 & -2.12512 & 8.37389 \\
504 & 0.10669 & -2.23783 & 9.37299 \\
567 & 0.09504 & -2.35348 & 10.52215 \\
630 & 0.08283 & -2.49099 & 12.07324 \\
693 & 0.07081 & -2.64780 & 14.12290 \\
756 & 0.05939 & -2.82367 & 16.83856 \\
819 & 0.04833 & -3.02964 & 20.68972 \\
882 & 0.03816 & -3.26593 & 26.20459 \\
945 & 0.02954 & -3.52185 & 33.84708 \\
1008 & 0.02167 & -3.83192 & 46.15106 \\
1071 & 0.01427 & -4.24932 & 70.05807 \\
1134 & 0.00914 & -4.69515 & 109.41523 \\
1197 & 0.00622 & -5.07972 & 160.72886 \\
\hline & & & \\
\hline
\end{tabular}
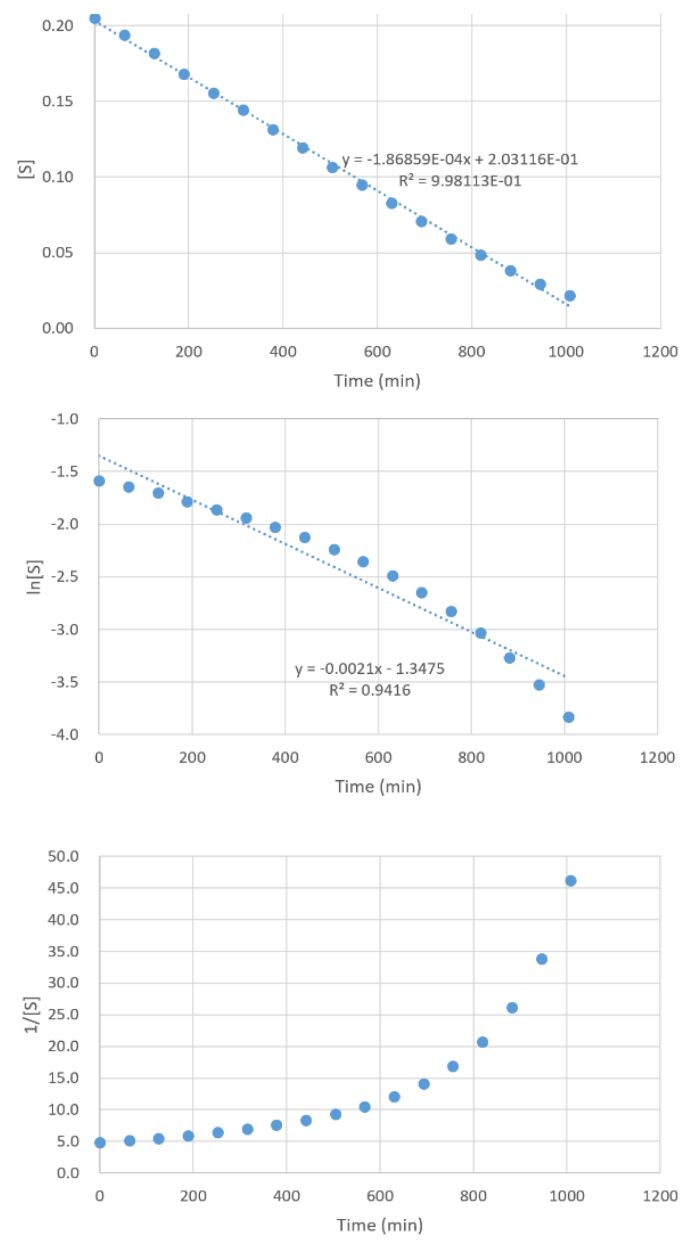


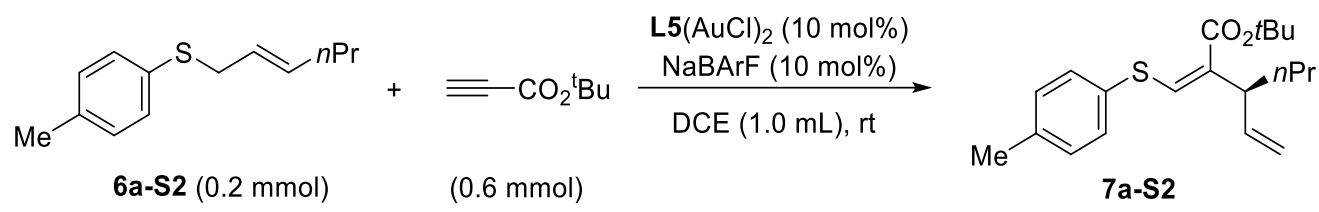

$([\mathrm{S}]=[\mathbf{6 a}-\mathbf{S 2}])$

\begin{tabular}{|c|c|c|c|}
\hline time (min) & {$[\mathrm{S}]$} & $\ln [S]$ & $1 /[S]$ \\
\hline 0 & 0.20023 & 0.00117 & 4.99415 \\
\hline 63 & 0.18708 & -0.06679 & 5.34533 \\
\hline 126 & 0.16772 & -0.17603 & 5.96237 \\
\hline 189 & 0.14990 & -0.28837 & 6.67128 \\
\hline 252 & 0.13254 & -0.41144 & 7.54496 \\
\hline 315 & 0.11590 & -0.54559 & 8.62811 \\
\hline 378 & 0.09994 & -0.69374 & 10.00592 \\
\hline 441 & 0.08442 & -0.86253 & 11.84569 \\
\hline 504 & 0.07033 & -1.04506 & 14.21786 \\
\hline 567 & 0.05572 & -1.27801 & 17.94740 \\
\hline 630 & 0.04264 & -1.54564 & 23.45483 \\
\hline 693 & 0.03050 & -1.88063 & 32.78811 \\
\hline 756 & 0.01866 & -2.37170 & 53.57773 \\
\hline 819 & 0.00990 & -3.00564 & 100.995949 \\
\hline 882 & 0.00607 & -3.4946 & 164.685711 \\
\hline 945 & 0.00428 & -3.84359 & 233.46287 \\
\hline 1008 & 0.00327 & -4.11229 & 305.43126 \\
\hline 1071 & 0.00262 & -4.33506 & 381.64858 \\
\hline
\end{tabular}
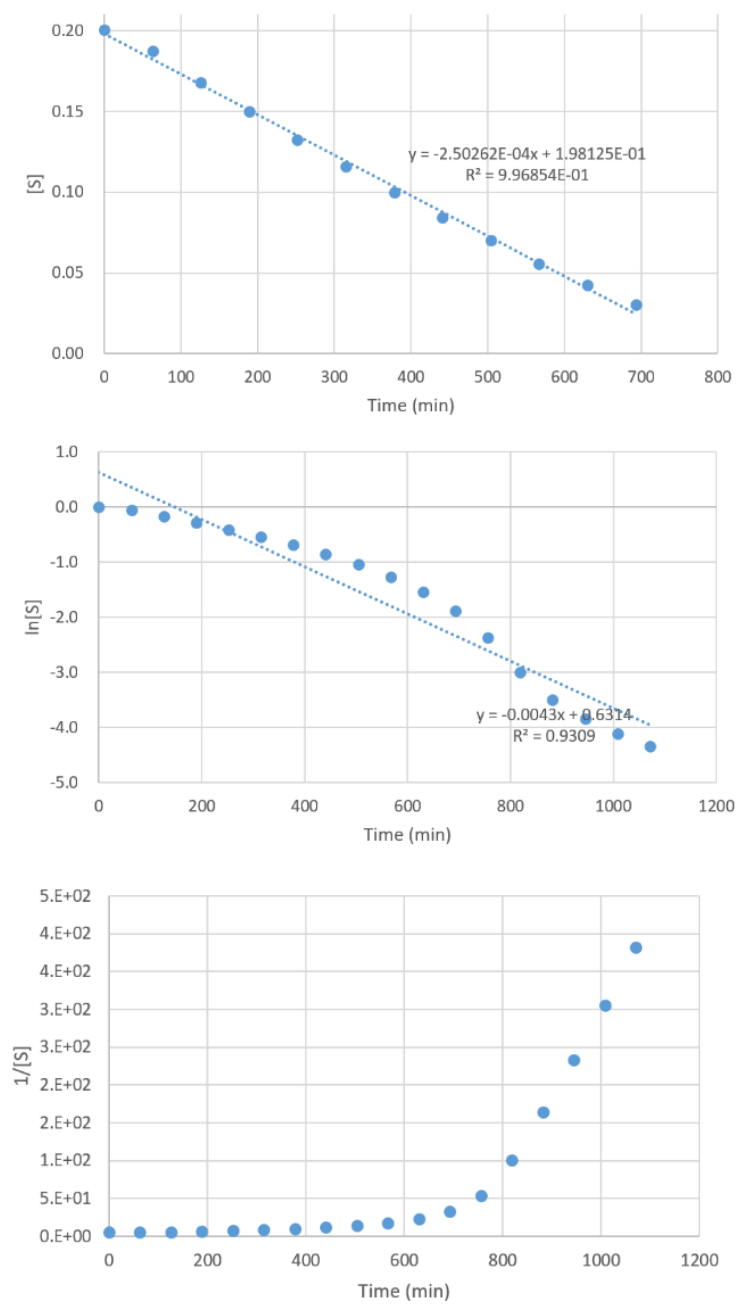


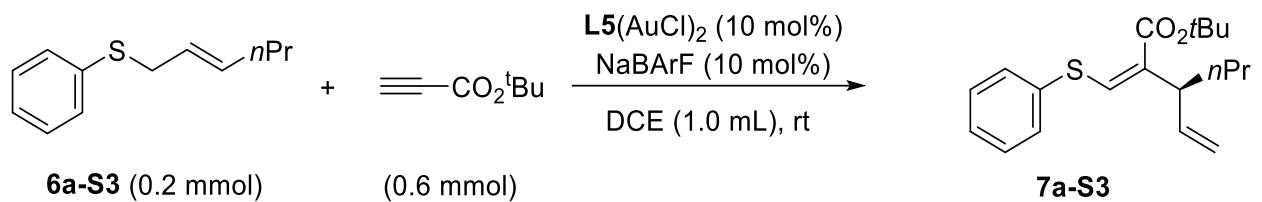

$([\mathrm{S}]=[\mathbf{6 a - S 3}])$

\begin{tabular}{cccc}
\hline time $(\mathrm{min})$ & {$[\mathrm{S}]$} & $\ln [\mathrm{S}]$ & $1 /[\mathrm{S}]$ \\
\hline 0 & 0.20023 & -1.60827 & 4.99416 \\
63 & 0.17910 & -1.71979 & 5.58338 \\
126 & 0.15489 & -1.86504 & 6.45620 \\
189 & 0.13154 & -2.02842 & 7.60204 \\
252 & 0.10948 & -2.21200 & 9.13399 \\
315 & 0.08740 & -2.43730 & 11.44206 \\
378 & 0.07133 & -2.64050 & 14.02021 \\
441 & 0.05437 & -2.91195 & 18.39255 \\
504 & 0.03752 & -3.28288 & 26.65244 \\
567 & 0.02177 & -3.82704 & 45.92653 \\
\hline
\end{tabular}
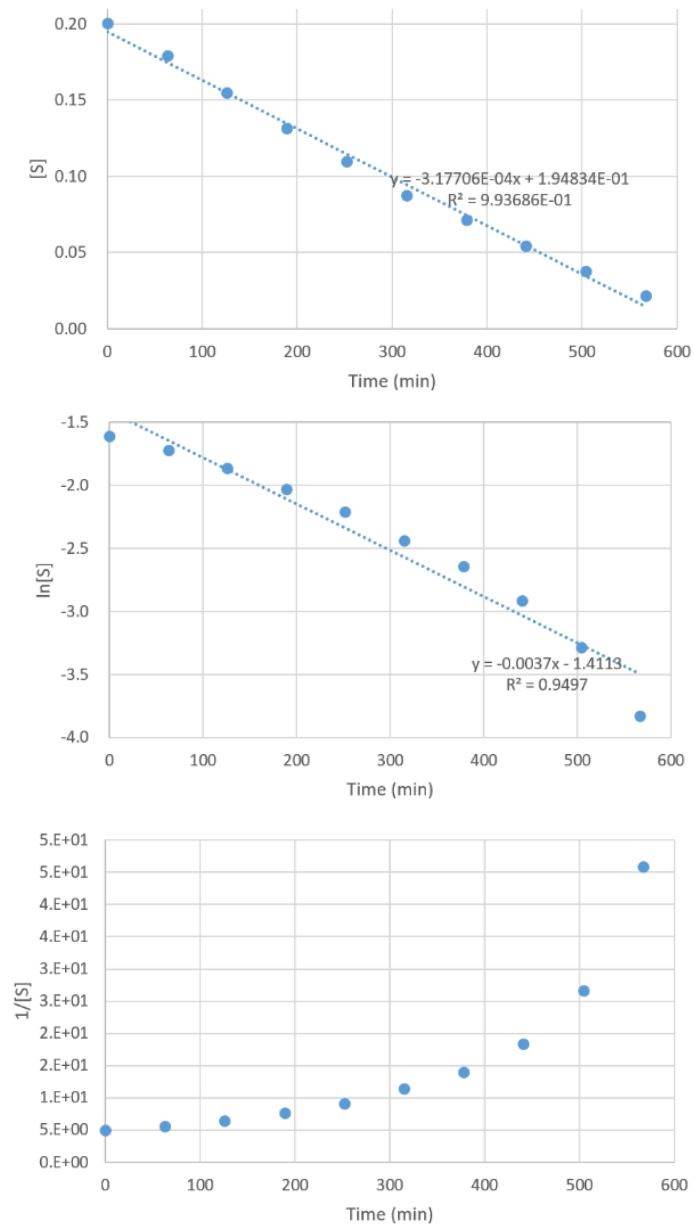


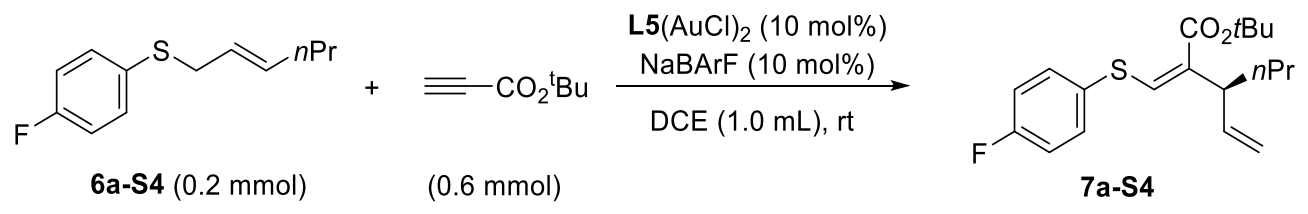

$([S]=[\mathbf{6 a}-\mathrm{S4}])$

\begin{tabular}{cccc}
\hline time $(\mathrm{min})$ & {$[\mathrm{S}]$} & $\ln [\mathrm{S}]$ & $1 /[\mathrm{S}]$ \\
\hline 0 & 0.200 & -1.609 & 5.000 \\
13 & 0.190 & -1.660 & 5.259 \\
76 & 0.164 & -1.809 & 6.106 \\
139 & 0.138 & -1.982 & 7.261 \\
202 & 0.113 & -2.180 & 8.844 \\
265 & 0.089 & -2.421 & 11.259 \\
328 & 0.066 & -2.723 & 15.231 \\
391 & 0.044 & -3.130 & 22.871 \\
454 & 0.022 & -3.834 & 46.229 \\
517 & 0.007 & -4.979 & 145.370 \\
\hline
\end{tabular}
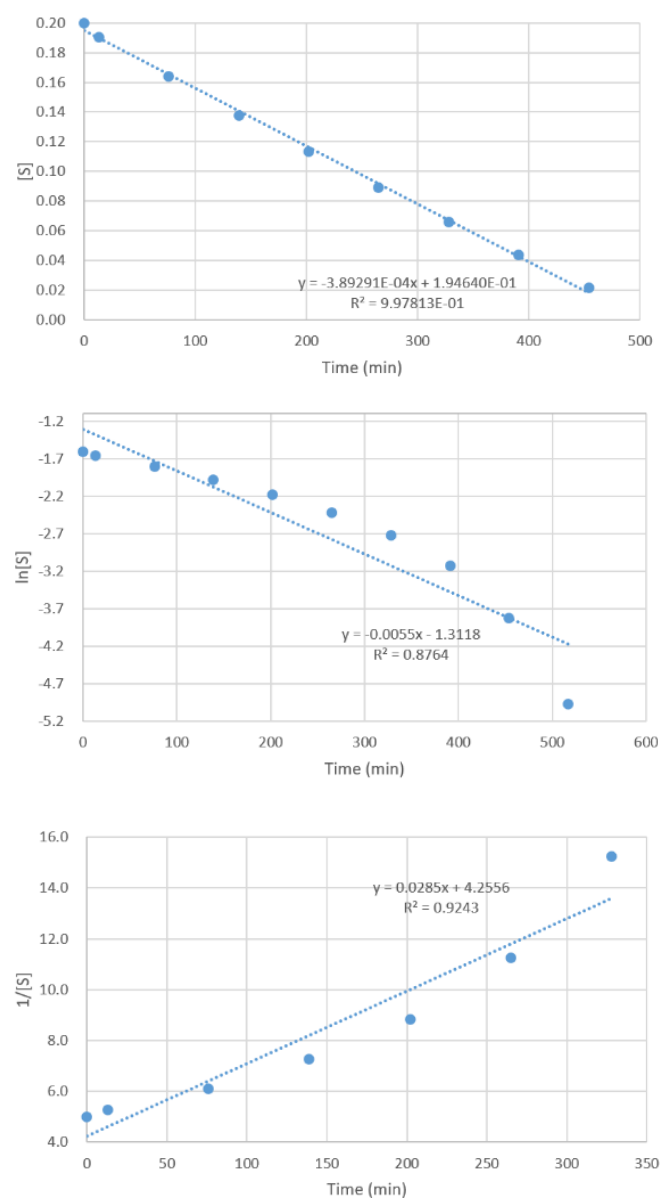


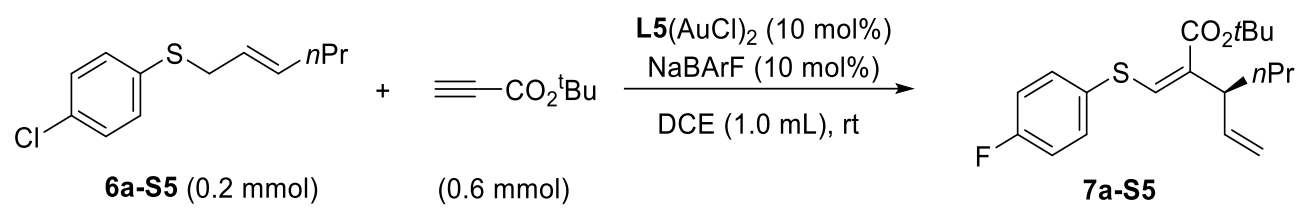

$([\mathrm{S}]=[\mathbf{6 a}-\mathrm{S} 5])$

\begin{tabular}{cccc}
\hline Time $(\mathrm{min})$ & {$[\mathrm{S}]$} & $\ln [\mathrm{S}]$ & $1 /[\mathrm{S}]$ \\
\hline 0 & 0.20000 & -1.60944 & 5.00000 \\
2 & 0.19390 & -1.64040 & 5.15723 \\
65 & 0.14642 & -1.92126 & 6.82955 \\
128 & 0.10234 & -2.27943 & 9.77115 \\
191 & 0.06087 & -2.79903 & 16.42876 \\
254 & 0.02386 & -3.73547 & 41.90764 \\
317 & 0.00426 & -5.45828 & 234.69327 \\
\hline
\end{tabular}
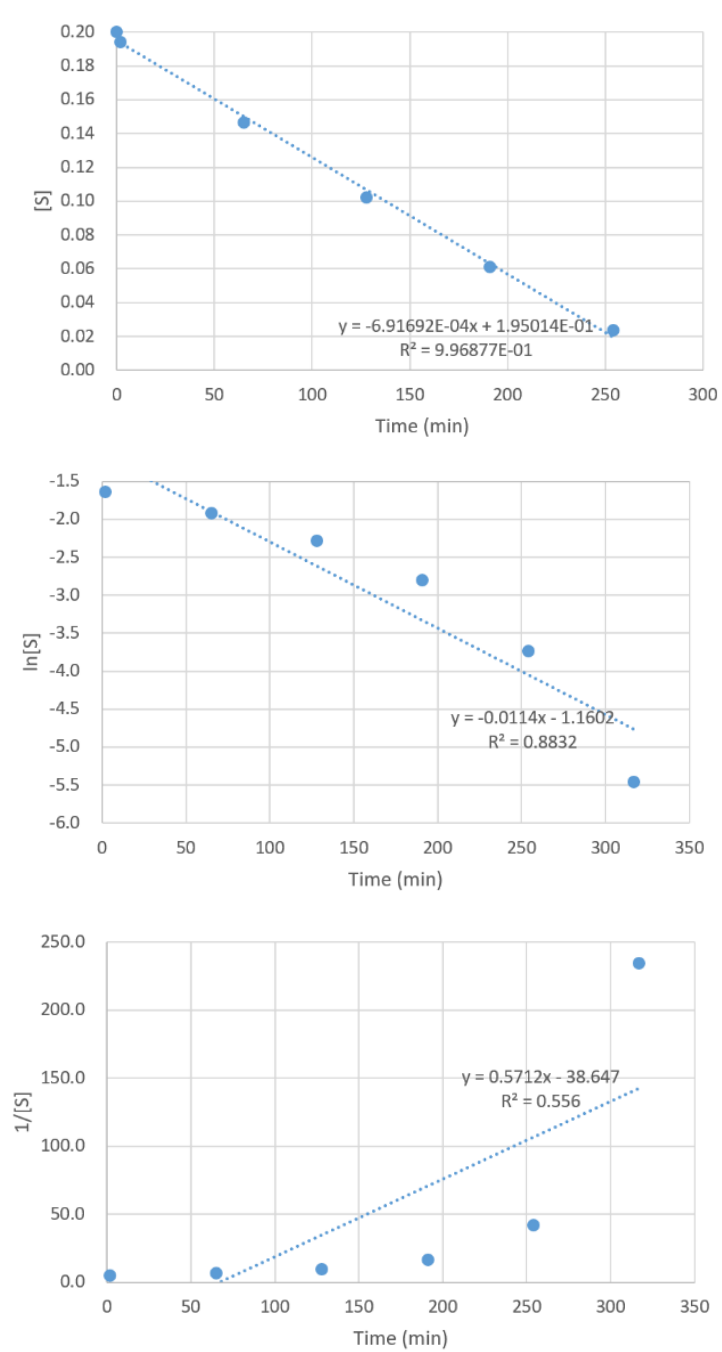


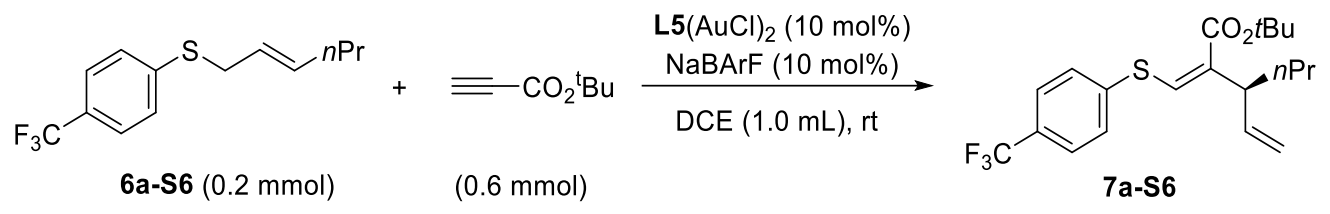

$([S]=[6 \mathbf{a}-\mathrm{S6}])$

\begin{tabular}{cccc}
\hline Time $(\min )$ & {$[\mathrm{S}]$} & $\ln [\mathrm{S}]$ & $1 /[\mathrm{S}]$ \\
\hline 0 & 0.19990 & -1.60995 & 5.00258 \\
63 & 0.12433 & -2.08481 & 8.04309 \\
126 & 0.04899 & -3.01612 & 20.41195 \\
189 & 0.00392 & -5.54046 & 254.79463 \\
\hline
\end{tabular}
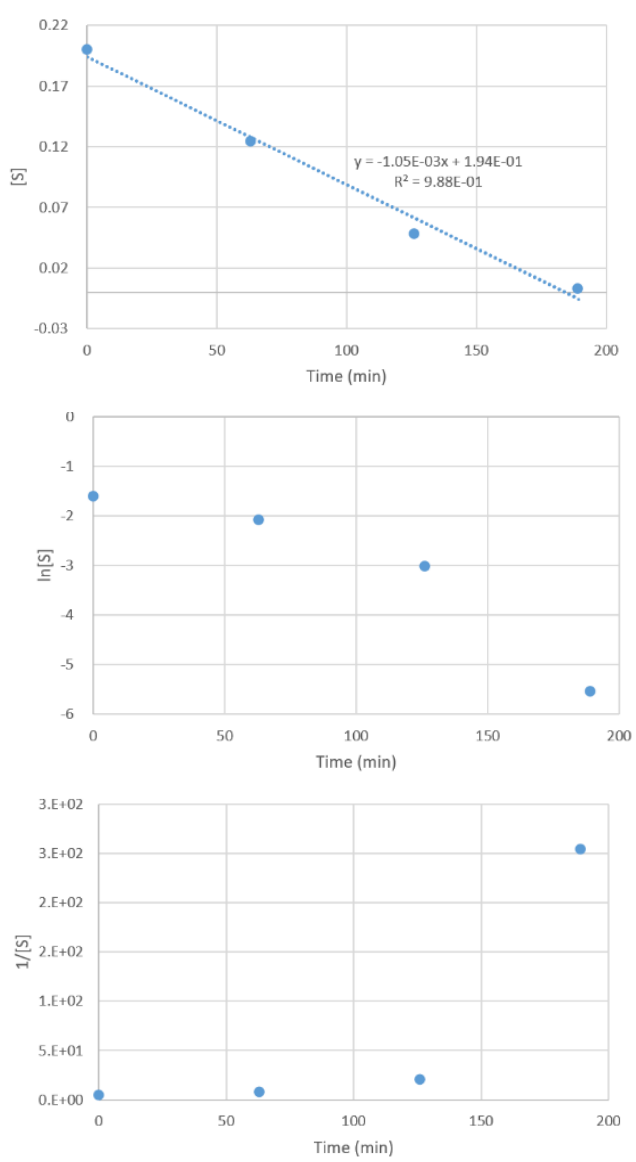


\subsection{Hammett analysis.}

From the above $0^{\text {th }}$ order rate constants, $k(\mathbf{M} / \mathrm{min})$ for $\mathbf{6 a - S 1 - 6 a - S 6 , ~ w e ~ o b s e r v e d ~ t h a t ~ t h e r e ~ i s ~}$ a strong linear correlation between $\log \left(k_{\mathrm{R}} / k_{\mathrm{H}}\right)$ and $\sigma_{\mathrm{p}}$-constant (Hammett plot below).

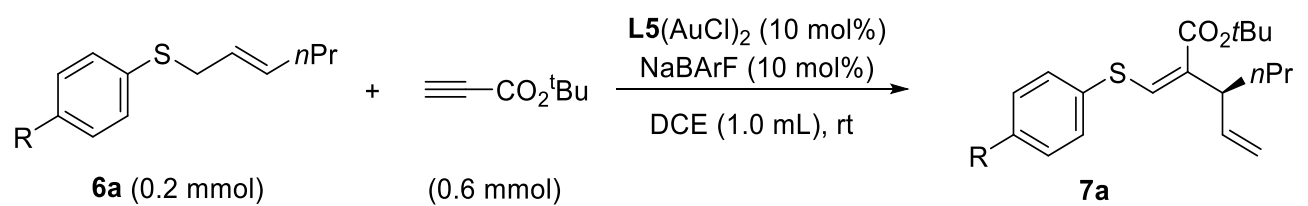

\begin{tabular}{ccccccc}
\hline substrate & $\mathrm{R}$ & $\sigma_{\mathrm{p}}$ & $\sigma+$ & $\sigma-$ & $k(\mathrm{M} / \mathrm{min})$ & $\log \left(k_{\mathrm{R}} / k_{\mathrm{H}}\right)$ \\
\hline 6a-S1 & $\mathrm{p}-\mathrm{OMe}$ & -0.27 & -0.78 & -0.26 & $-1.87 \mathrm{E}-04$ & -0.230511 \\
6a-S2 & $\mathrm{p}-\mathrm{Me}$ & -0.17 & -0.31 & -0.17 & $-2.50 \mathrm{E}-04$ & -0.103631 \\
6a-S3 & $\mathrm{p}-\mathrm{H}$ & 0 & 0 & 0 & $-3.18 \mathrm{E}-04$ & 0.000000 \\
6a-S4 & $\mathrm{p}-\mathrm{F}$ & 0.06 & -0.07 & -0.03 & $-3.89 \mathrm{E}-04$ & 0.088249 \\
6a-S5 & $\mathrm{p}-\mathrm{Cl}$ & 0.23 & 0.11 & 0.19 & $-6.92 \mathrm{E}-04$ & 0.337887 \\
6a-S6 & $\mathrm{p}-\mathrm{CF} 3$ & 0.54 & 0.61 & 0.65 & $-1.20 \mathrm{E}-03$ & 0.576312 \\
\hline
\end{tabular}

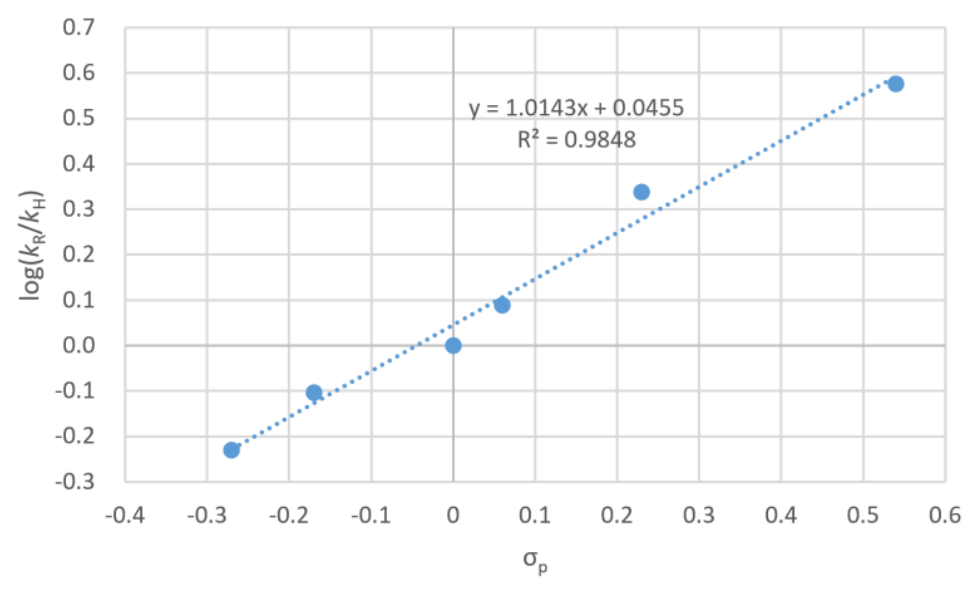




\subsection{Reaction order.}

9.4.1. The dependence of $k(\mathrm{M} / \mathrm{min})$ on the amount of tert-butyl propiolate (1):

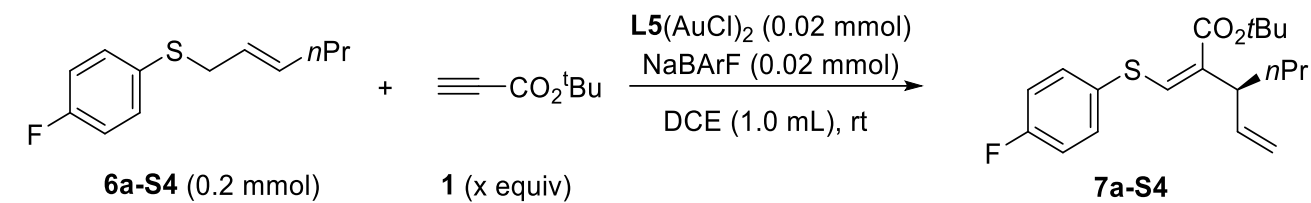

\begin{tabular}{cc}
\hline$[1](\mathrm{M})$ & $k_{\mathrm{obs}}(\mathrm{M} / \mathrm{min})$ \\
\hline 0 & 0 \\
0.3 & $1.55 \times 10^{-4}$ \\
0.6 & $3.89 \times 10^{-4}$ \\
1.2 & $8.58 \times 10^{-4}$ \\
\hline
\end{tabular}

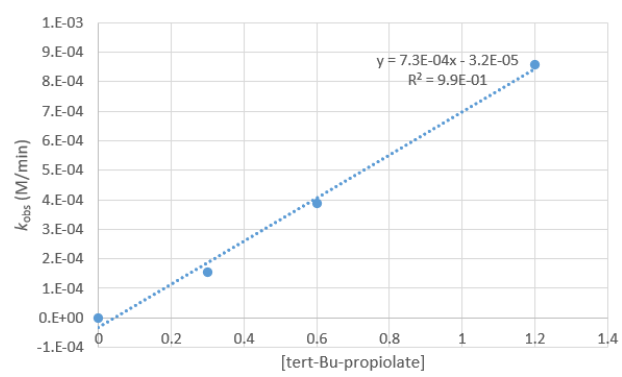

9.4.2. The dependence of $k(\mathrm{M} / \mathrm{min})$ on the amount of catalyst $\left(\mathbf{L 5}(\mathrm{AuCl})_{2} / \mathrm{NaBArF}\right)$ :

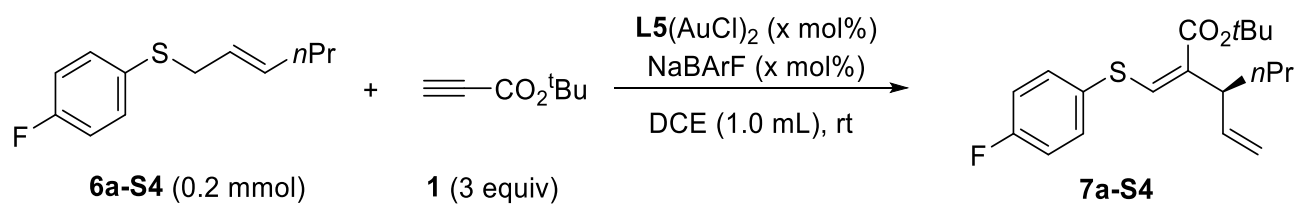

\begin{tabular}{cc}
\hline [catalyst] $(\mathrm{M})$ & $k_{\text {obs }}(\mathrm{M} / \mathrm{min})$ \\
\hline 0 & 0 \\
0.010 & $2.26 \times 10^{-4}$ \\
0.020 & $3.89 \times 10^{-4}$ \\
0.040 & $9.36 \times 10^{-4}$ \\
\hline
\end{tabular}

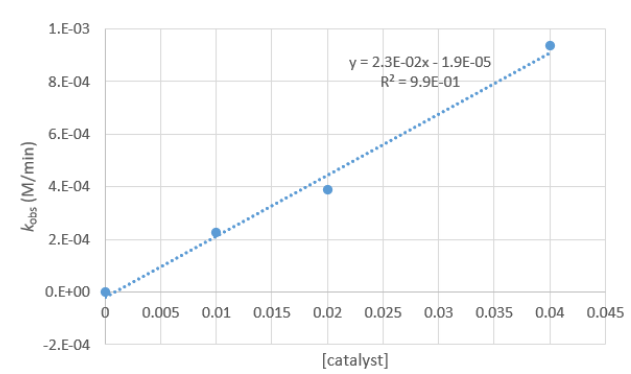


9.4.3. The dependence of $k(\mathrm{M} / \mathrm{min})$ on the amount of allyl sulfide $\mathbf{6 a}$ :

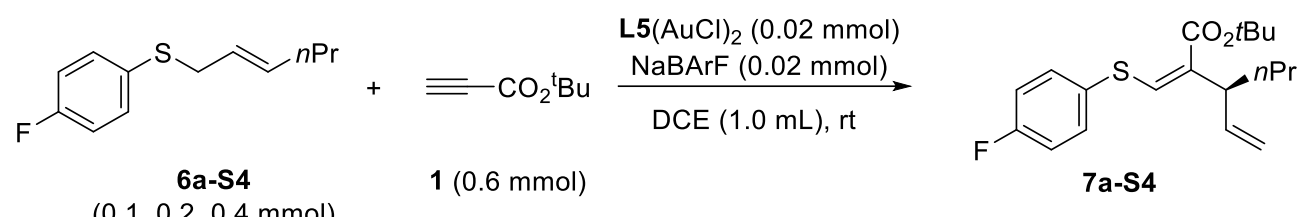

$(0.1,0.2,0.4 \mathrm{mmol})$

\begin{tabular}{cc}
\hline$[6 \mathrm{a}](\mathrm{M})$ & $k_{\text {obs }}(\mathrm{M} / \mathrm{min})$ \\
\hline 0.1 & $3.81 \times 10^{-4}$ \\
0.2 & $3.89 \times 10^{-4}$ \\
0.4 & $3.74 \times 10^{-4}$ \\
\hline
\end{tabular}

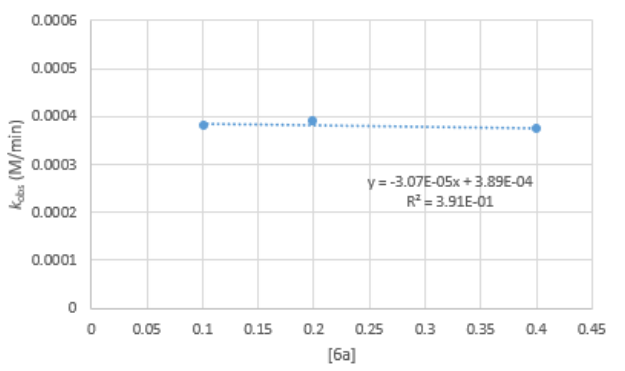

\section{5. ${ }^{31} \mathrm{P}$ NMR study.}

Cationic gold complex was formed according to GP14 from $\left(R, S_{p}\right)$-1-naphthyl/DMJosiphos $(\mathrm{AuCl})_{2} \quad \mathbf{L 5} \quad(6.0 \mathrm{mg}, \quad 0.0050 \mathrm{mmol})$ and sodium tetrakis[3,5-bis(trifluoromethyl)phenyl]borate $(4.4 \mathrm{mg}, 0.0050 \mathrm{mmol})$. To this was added a solution of allyl sulfide, and the mixture was stirred for $5 \mathrm{~min}$ before ${ }^{31} \mathrm{P}$ NMR measurement. Subsequently, tertbutyl propiolate was added to the mixture and after $5 \mathrm{~min}{ }^{31} \mathrm{P}$ NMR was taken. This experiment was repeated with reversed addition sequence. 
(L)Au ${ }^{+}$

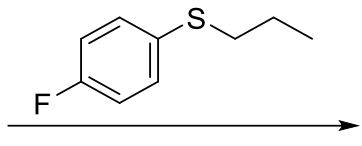

${ }^{31} \mathrm{P}$ NMR $\quad 38.0,34.2$,

(ppm)

19.2, $-8.4 \mathrm{ppm}$

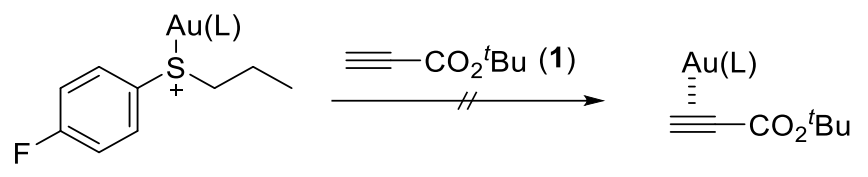

41.0, 40.5,

$19.9,-7.6 \mathrm{ppm}$ no change

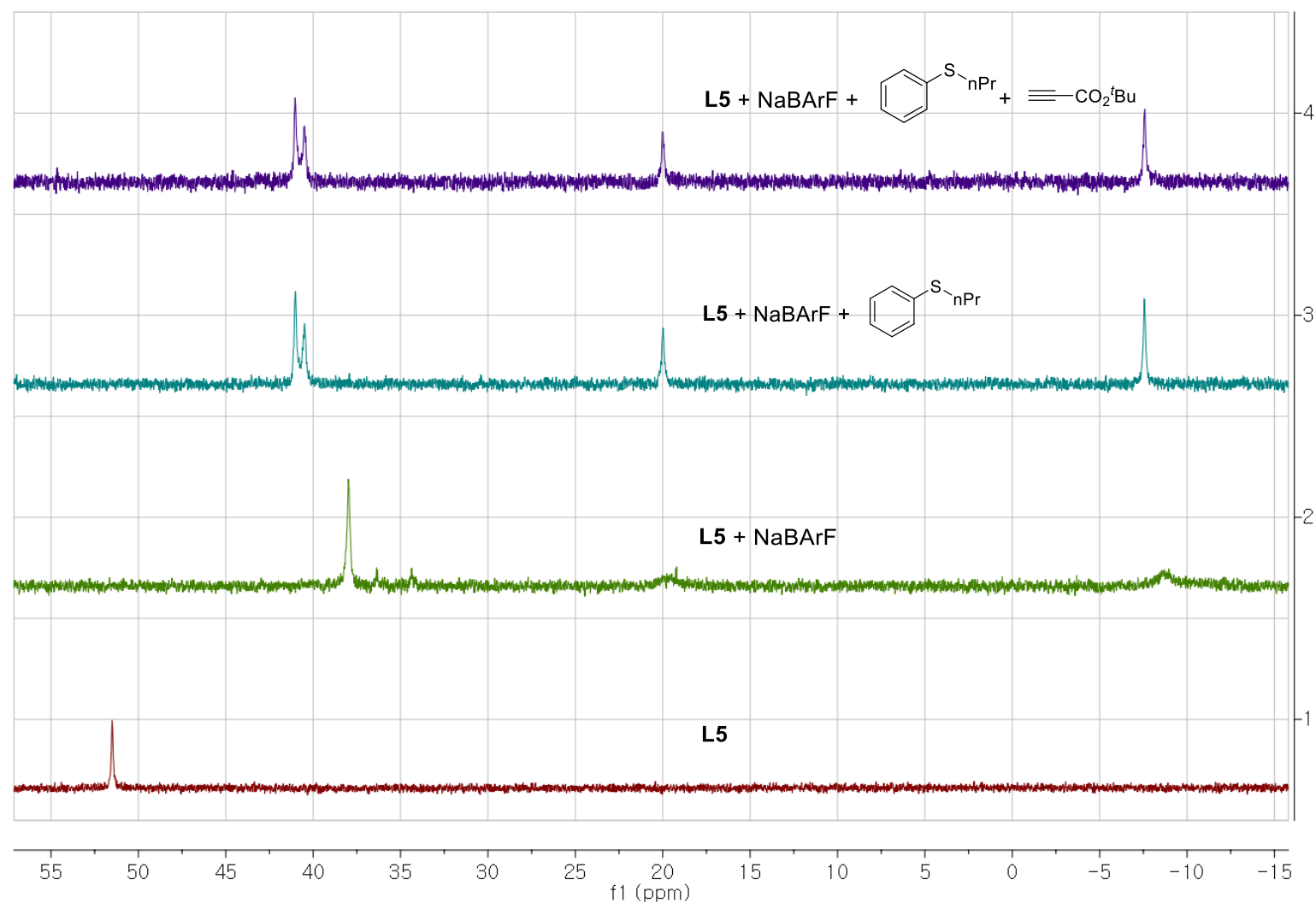



(L)Au+

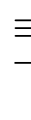

19.2, -8.4 ppm

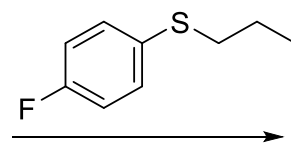<smiles>CCC[SH](C)c1ccc(F)cc1</smiles>

41.0, 40.5,

$19.9,-7.6 \mathrm{ppm}$

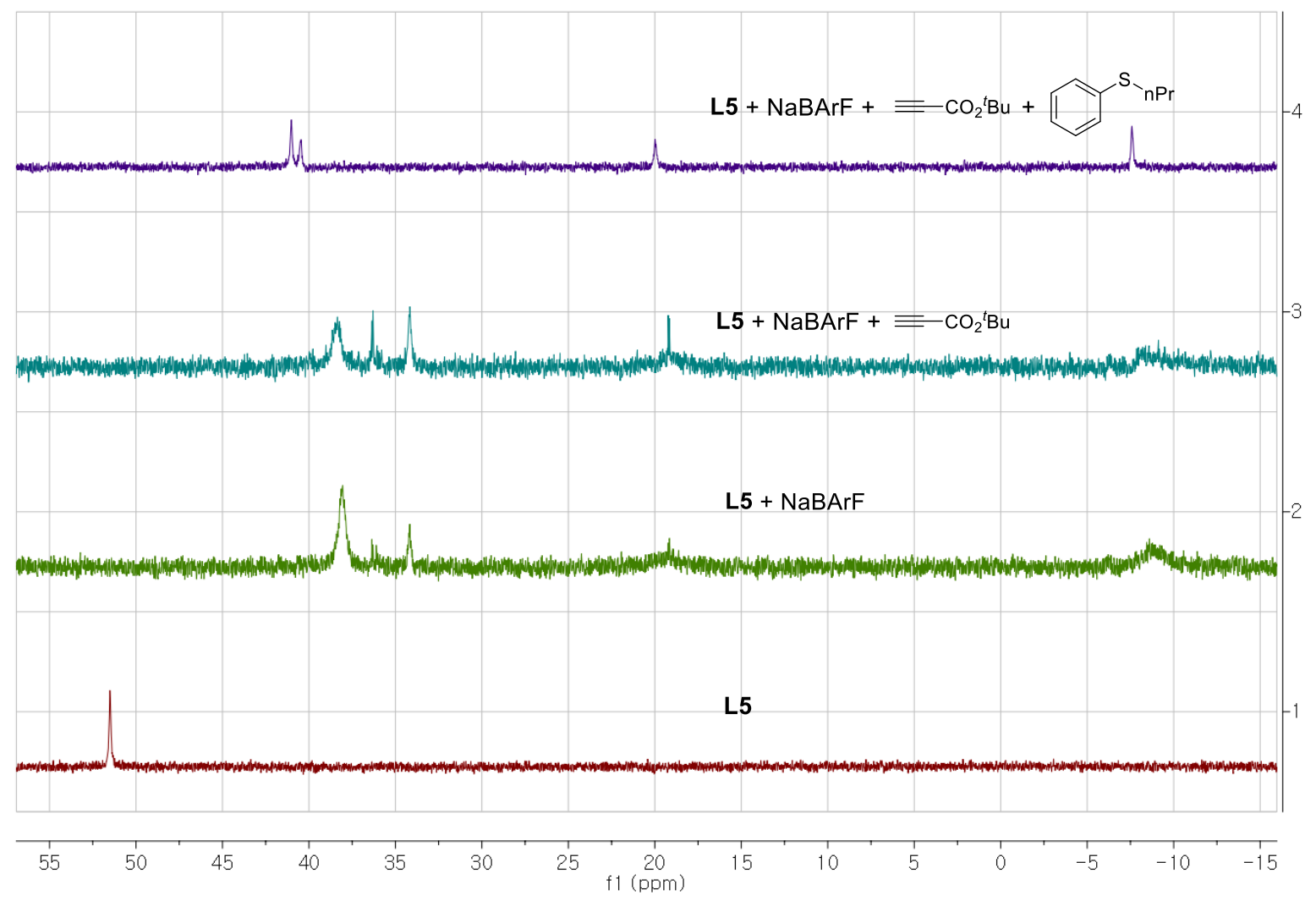




\section{References}

1. Armarego, W. L. F.; Chai, C. L. L. Purification of Laboratory Chemicals; Elsevier: Oxford, 2009.

2. Mézailles, N.; Ricard, L.; Gagosz, F. Org. Lett. 2005, 7, 4133.

3. Kraus, H.; Franc-ais, A.; O’Brien, M.; Frost, J.; Dieguez-Vazquez, A.; Polara, A.; Baricordi, N.; Horan, R.; Hsu, D.-S.; Tsunoda, T.; Ley, S. V. Chem. Sci. 2013, 4, 1989.

4. Nicolaou, K. C.; Rhoades, D.; Lamani, M.; Pattanayak, M. R.; Kumar, S. M. J. Am. Chem. Soc. 2016, 138, 7532 .

5. Tian, Y.; Jürgens, E.; Kunz, D. Chem. Commun. 2018, 54, 11340.

6. Cases, M.; Gonzalez-Lopez de Turiso, F.; Hadjisoteriou, M. S.; Pattenden, G. Org. Biomol. Chem., 2005, 3, 2786.

7. Ghosh, A. K.; Li, J. Org. Lett. 2009, 11, 4164.

8. Roy, S.; Spilling, C. D. Org. Lett. 2010, 12, 5326.

9. Gropp, C.; Fischer, S.; Husch, T.; Trapp, N.; Carreira, E. M.; Diederich, F. J. Am. Chem. Soc. 2020, 142, 4749

10. Martin, D. B. C.; Nguyen, L. Q.; Vanderwal, C. D. J. Org. Chem. 2012, 77, 17.

11. Werle, S.; Fey, T.; Neudörfl, J.-M.; Schmalz, H.-G. Org. Lett. 2007, 9, 3555.

12. Satyanarayana, G.; Pflasterer, D.; Helmchen, G. Eur. J. Org. Chem. 2011, 34, 6877.

13. Keck, G. E.; Savin, K. A.; Weglarz, M. A. J. Org. Chem. 1995, 60, 3194-3204.

14. Gong, L.; Sun, H.-B.; Deng, L.-F.; Zhang, X.; Liu, J.; Yang, S.; Niu, D. J. Am. Chem. Soc. 2019, 141, $7680-7686$.

15. Baba, T.; Huang, G.; Isobe. M. Tetrahedron, 2003, 59, 6851-6872.

16. Berkowitz, D. B.; de la Salud-Bea, R.; Jahng, W.-J. Org. Lett. 2004, 6, 1821-1824. 